\title{
The effect of lactate on the normoxic, ischemic and reperfused heart
}

Citation for published version (APA):

de Groot, M. J. M. (1992). The effect of lactate on the normoxic, ischemic and reperfused heart. [Doctoral Thesis, Maastricht University]. Rijksuniversiteit Limburg. https://doi.org/10.26481/dis.19920326mg

Document status and date:

Published: 01/01/1992

DOI:

10.26481/dis.19920326mg

Document Version:

Publisher's PDF, also known as Version of record

\section{Please check the document version of this publication:}

- A submitted manuscript is the version of the article upon submission and before peer-review. There can be important differences between the submitted version and the official published version of record.

People interested in the research are advised to contact the author for the final version of the publication, or visit the DOI to the publisher's website.

- The final author version and the galley proof are versions of the publication after peer review.

- The final published version features the final layout of the paper including the volume, issue and page numbers.

Link to publication

\footnotetext{
General rights rights.

- You may freely distribute the URL identifying the publication in the public portal. please follow below link for the End User Agreement:

www.umlib.nl/taverne-license

Take down policy

If you believe that this document breaches copyright please contact us at:

repository@maastrichtuniversity.nl

providing details and we will investigate your claim.
}

Copyright and moral rights for the publications made accessible in the public portal are retained by the authors and/or other copyright owners and it is a condition of accessing publications that users recognise and abide by the legal requirements associated with these

- Users may download and print one copy of any publication from the public portal for the purpose of private study or research.

- You may not further distribute the material or use it for any profit-making activity or commercial gain

If the publication is distributed under the terms of Article $25 \mathrm{fa}$ of the Dutch Copyright Act, indicated by the "Taverne" license above, 
The Effect of Lactate on the Normoxic,

Ischemic and Reperfused Heart 


\title{
The Effect of Lactate on the Normoxic, Ischemic and Reperfused Heart
}

\author{
Proefschrift
}

ter verkrijging van de graad van doctor aan de Rijksuniversiteit Limburg te Maastricht, op gezag van de Rector Magnificus, Prof. Mr. M.J Cohen, volgens het besluit van het College van Dekanen.

in het openbaar te verdedigen op donderdag 26 maart 1992 om 14.00 uur

door

Monica Johanna Maria de Groot

geboren te Riel 
Promotor:

Prof. Dr. G.J. van der Vusse

Beoordelingscommissie:

Prot. Dr. J.W. Arends, voorzitter

Prof. Dr. M. Borgers

Proff. Dr. W.C. Hülsmann

Prof. Dr. M.l.M. Noble, University of Landon, Londan, UK

Prof. Dr. O.C.K.M. Penn

CIP-GEGEVENS KONINKLIJKE BIBLIOTHEEK, DEN HAAG

Groot, Monica Johanna Maria de

The effect of lactate on the normoxic, ischemic and reperfused heart / Monica Johanna Maria de Groot; [III.

by the author]. - Maastricht: Datawyse. -Ill.

Proefschrift Maastricht. - Met lit. opg. - Met

samenvatting in het Nederlands.

ISBN 90-5291-075-8

Trefw.: lactaat/ hart/ ischemie

Druk: Datawyse, Maastricht/ Krips Repro, Meppel

De uitgave van dit proefschrift werd mede mogelijk gemaakt door financiële steun van: -Stichting Wetenschappelijk Durrer-Fonds

- Nederlandse Hartstichting 
Aan mijn ouders 


\section{CONTENTS}

1. General introduction 11

1.1 Substrates in the heart 12

1.2 Effect of substrates on cardiac susceptibility to ischemic and reperfusion damage $\quad 15$

$\begin{array}{lll}1.3 & \text { Aim of the thesis } & 15\end{array}$

1.4 Experimental approach 15

1.5 Outline of the thesis 16

$\begin{array}{lll}1.6 & \text { References } & 17\end{array}$

2. The effect of lactate on cardlac function during prolonged normoxic perfusion

2.1 Introduction 21

2.2 Methods 21

2.3 Results 24

2.4 Discussion 27

2.5 References 30

3. The effect of lactate on the reperfused ischemic rat heart 33

3.1 Introduction 35

3.2 Methods $\quad 36$

3.3 Results 38

$\begin{array}{ll}3.4 & \text { Discussion }\end{array}$

3.5 References 51

4. Lactate-induced changes in the lipid content of the ischemic and reperfused myocardium 55

$\begin{array}{lll}4.1 & \text { Introduction } & 57\end{array}$

4.2 Methods $\quad 59$

4.3 Results 61

4.4 Discussion 68

4.5 References $\quad 74$

5. Lactate-induced changes in the nucleotide metabolism of $\begin{array}{ll}\text { the postischemic heart } & 77\end{array}$

5.1 Intraduction 79

5.2 Methods $\quad 80$

5.3 Results 81

5.4 Discussion 89

5.5 References 94

6. Lactate-induced underperfusion of the left ventricular inner layers of the postischemic heart $\quad 97$

6.1 Introduction 99

6.2 Methods 99

$\begin{array}{llr}6.3 \text { Results } & 102\end{array}$

6.4 Discussion 109

6.5 References 114 
7. Glycerol-3-phosphate hydrolysing activity and its subcellular locallzation in rat cardiac muscle

7.1 Introduction

7.2 Methods

7.3 Results

7.4 Discussion

7.5 References

8. General Discussion 131

8.1 Function 131

8.2 Function in relation to metabolic factors 132

8.3 Function in relation to coronary flow through the inner and outer layers of the left ventricle

8.4 Coronary flow and metabolic factors

8.5 Conclusion and hypothesis

8.6 References

Summary

Samenvatting

Publications

Curriculum Vitae

Nawoord 


\section{Chapter 1}

\section{GENERAL INTRODUCTION}

\subsection{SUBSTRATES IN THE HEART}

The heart is able to utilize a variety of oxidizable substrates to produce energy for electrical and mechanical processes. Fatty acids, glucose and lactate have been recognized as major sources of energy, while pyruvate, ketone bodies and amino acids do not markedly contribute in vivo.

The actual amount and type of substrate used strongly depend on the extracellular concentration of these substrates, the presence of competing substrates, workload of the heart, and circulating and locally released hormones (Neely et al, 1972).

\section{Substrates under normoxic conditions}

Under normal normoxic circumstances, fatty acids are most important as fuels for myocardial energy. Up to $70 \%$ of the cardiac energy need can be fulfilled by fatty acid oxidation. Fatty acids can be delivered by endogenous lipid pools or extracted from the circulation. However, endogenous pools do not markedly contribute to energy delivery when extracellular substrates are available in sufficient amounts. The uptake and intracellular conversion of fatty acids is depicted in fig 1.1.

The consumption of glucose in the normoxic heart is usually limited due to inhibition of glycolysis by fatty acids although the blood concentration of glucose is higher $(5 \mathrm{mM})$ than the average concentration of fatty acids $(0.4 \mathrm{mM})$. Under normal circumstances, only 15 to $30 \%$ of myocardial energy production is provided by glucose. Glucose may be derived from the endogenous glycogen pool (only in emergency situations) or extracted from the circulation. The uptake of glucose and metabolism of glucose in the cell is illustrated in fig 1.2.

(For detailed reviews see Opie, 1969; Neely et al, 1972; Neely and Morgan, 1974). 


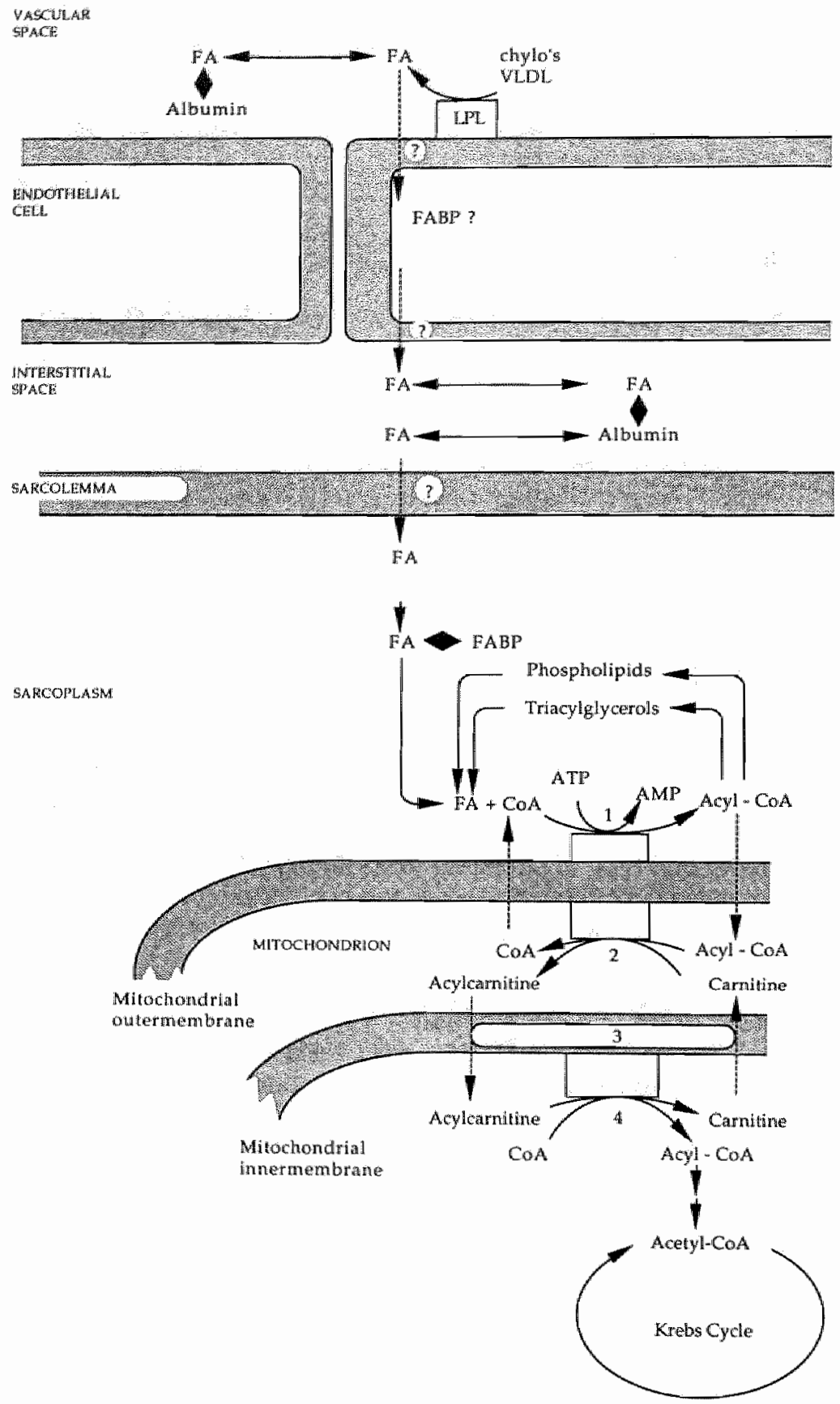

Fig. 1.1 Schematic representation of uptake and intraceltular conversion of fatty acids in myocardial lissue. FA, fatty acid; FABP, fatty acid-binding protein; CoA, Coenzyme A; LPL, lipoprotein lipase; 1 . fatty acyl COA synthatase; 2, carnitine acyl transferase 1; 3, acylcarnitine-carnitine translocase; 4, carnitine acyl transterase 1 . 
The concentration of circulating lactate is low at rest about $1 \mathrm{mM}$. At this low resting level, lactate will not be sufficient to meet energy needs and thus other substrates will be utillzed. Bing and coworkers (1953) have shown that by raising arterial lactate concentration myocardial utilization of lactate will be increased. In this regard, Lochner and Masseri (1959) demonstrated that in dogs the participation of lactate in oxidative metabolism may increase from $25 \%$ at rest to $58 \%$ during treadmill exercise. Similarly, Keul and associates (1965) observed that in man the contribution of lactate to myocardial substrate metabolism is raised during work. With moderate exercise, the arterial lactate concentration rises to $5 \mathrm{mM}$ due to lactate discharge from the working skeletal muscle. More severe exercise even raises lactate concentration up to 10 to $15 \mathrm{mM}$ (Hollman et al, 1981; Wasserman, 1986). Drake and coworkers (1980) demonstrated that when the normal dog heart was given the choice of lactate, glucose or fatty acids as fuel "lactate was the preferred substrate. In this respect, over $85 \%$ of total substrates oxidized was lactate, when the plasma lactate concentration was artificially elevated above $4.5 \mathrm{mM}$. The uptake of lactate and oxidation of lactate is also shown in fig 1.2 .

\section{Substrates under ischemic conditions}

Ischemia implies a reduction in coronary flow and, hence, a restriction of substrate and oxygen supply. While endagenous pools may provide fuel for some time, lack of oxygen may be a more crucial factor.

In ischemic tissue fatty acids might become available by hydrolysis of endogenous triacylglycerols and/or phospholipids (fig 1.1). Restricted availability of oxygen suppresses fatty acid oxidation leading to accumulation of fatty acids (Van der Vusse et al, 1982; Chien et al, 1984; Van Bilsen et al, 1989; Otanl et al, 1989) and a change in the fatty acid composition of triacylglycerols and phospholipids (Chien et al, 1984; Burton et al, 1986).

The contribution of glucose as fuel becomes more significant in ischemic hearts. Glucose may be derived from endogenous glyoogen (fig 1.2). ATP formation takes place through anaerobic glycolysis although ATP delivery is much less than by complete oxidation of glucose. Initially, the rate of glycolysis will be stimulated. When products of glycolysis (lactate, hydrogen ions and NADH) have accumulated in significant amounts in the cytoplasmic compartment, the rate of glycolysis will slow down due to inhibition of regulatory enzymes (Rovetto et al, 1975; Mochizuki and Neely, 1979). Consequently, delivery of energy will be reduced while ATP-dependent processes (mechanical work, maintenance of transmembrane ionic gradients) might become impaired.

Like fatty acids, the use of lactate as substrate is blocked during ischemia since degradation of lactate is aerobic. Instead, the heart produces lactate by breakdown of glucose, derived from endogenous glycogen, via glycolysis and converting pyruvate into lactate due to the elevated redox state of the heart under ischemic conditions (fig 1.2). 
chapter 1

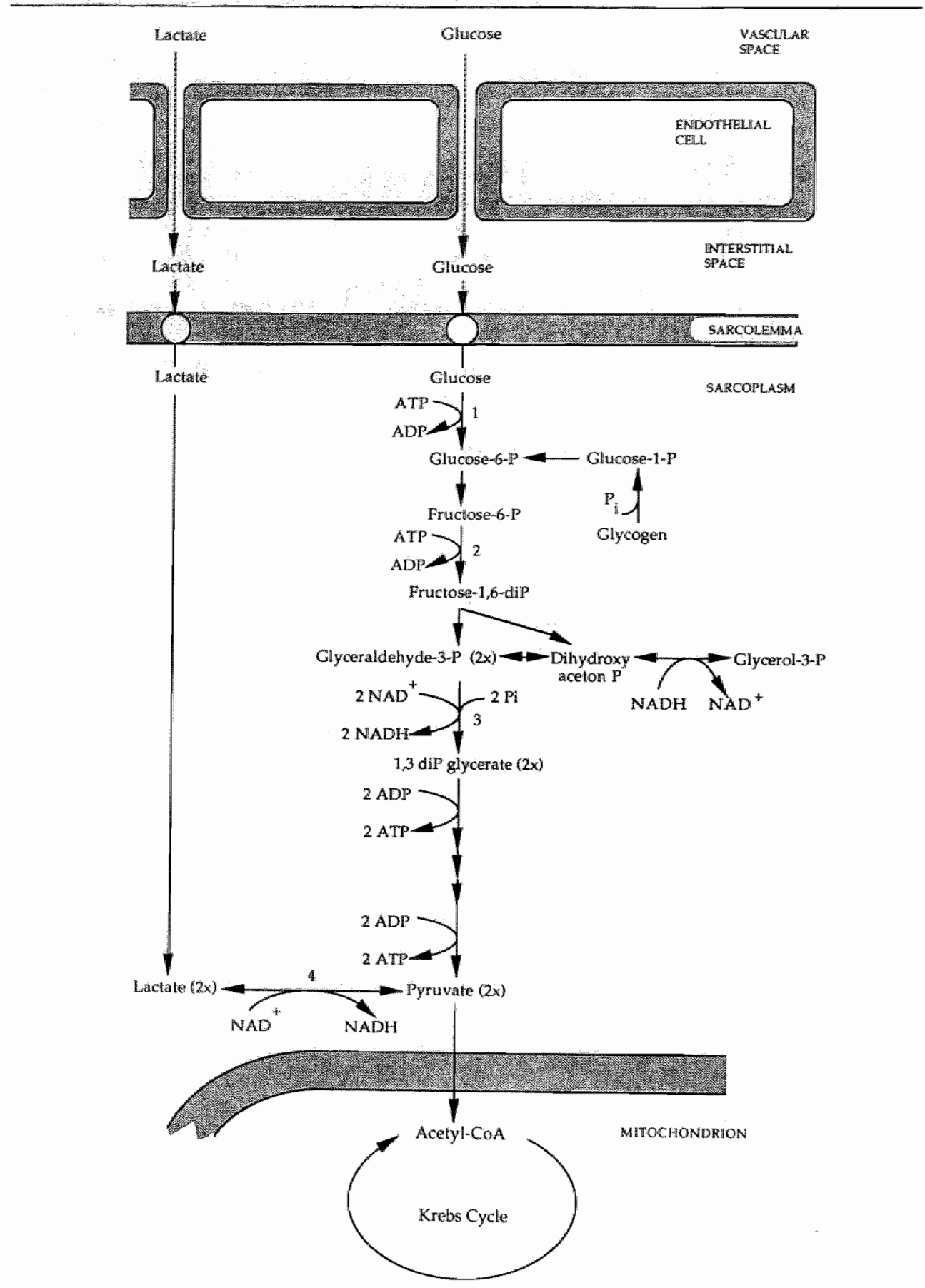

Fig. 1.2 Schematic representation of uptake and intracellular conversion of glucose in myocardial tissue. $P_{\text {i }}$ refers to inorganic phosphate; 1 , hexokinase; 2 , phasphofructokinase; 3 , glyceraldehyde-3phosphate dehydrogenase; 4 , lactate dehydrogenase. The numbers 1 to 3 refer to key enzymes in the glycolytic pathway. 


\subsection{EFFECT OF SUBSTRATES ON CARDIAC SUSCEPTIBILITY TO ISCHEMIC AND REPERFUSION DAMAGE}

Circulating substrates can have an important influence on the outcome of myocardial ischemia. Direct support for the influence of substrates on postischemic recovery has been obtained from isolated hearts subjected to no-flow or low-flow ischemia. In this regard, fatty acids have been found detrimental for the postischemic heart, whereas glucose has protective properties against ischemic damage (De Leiris and Opie, 1978; Bricknell and Opie, 1978; Lopaschuk et al, 1990). Pyruvate present as sole substrate impairs cardiac function after ischemia (Mallet ef al, 1990). In contrast, when added as a cosubstrate of glucose or glucose plus lactate it was found to enhance cardiac tolerance towards ischemia (Bünger et al, 1989; Van Bilsen et al, 1989). The susceptibility of the ischemic and reperfused heart to exogenous lactate has not been clearly investigated. Limited information is available from a study of Bünger and coworkers (1989) that demonstrated a detrimental effect of a raised exogenous lactate concentration ( $5 \mathrm{mM}$ versus $15 \mathrm{mM}$ ) on hemodynamic function after 45 min of low flow ischemia, intensified by infusion of a high dose of L-norepinephrine. Some authors (Bricknell and Opie, 1978; Carlson et al, 1987) reported increased leakage of cytoplasmic enzymes (indicating cell damage) after ischemia when lactate was present either as sole substrate or in combination with glucose compared to glucose alone. Interestingly, a recent study (Geisbuhler and Rovetto, 1990) showed that lactate does not enhance anoxia/reoxygenation damage in isolated adult rat cardiac myocytes.

\subsection{AIM OF THE THESIS}

It was the objective of this study to investigate the effect of exogenous lactate (sodium salt, $\mathrm{pH}$ 7.4) on hemodynamic and metabolic properties of the heart under normoxic, ischemic and reperfused conditions. Since the influence of lactate on cardiac function during prolonged normoxic perfusion has not been identified, special attention was paid to the long-term effect of a high extracellular lactate concentration on hemodynamic performance, the tissue content of high-energy phosphates and glycogen, and lipid homeostasis (Chapter 2). The influence of extracellular lactate on postischemic heart was investigated by hemodynamic recovery after ischemia and changes in glycolysis (Chapter 3 ). In addition, changes in lipid homeostasis (Chapter 4), high-energy phosphate metabolism (chapter 5) and regional flow patterns (Chapter 6) were subject of study. Finally, the significance of glycerol release as index of triacylglycerol hydrolysis has been explored in chapter 7 .

\subsection{EXPERIMENTAL APPROACH}

The isolated working rat heart, perfused with a modified Krebs-Henseleit bicarbonate buffer was used as model (For more details see Van Bilsen et al, 1991). Although this ex vivo model differs from the heart in situ (such as limited oxygen 
carrying capacity of the buffer, no colloid asmolic pressure in the vascular comparment, no hormonal imfluence, no sympathetic innervation), experimental conditions are controllable (such as perfusion pressure, composition of fluid) and, hence, faclitate interpretation of the results:

To establish the hemodynamic and metabolic effect of lactate and to elucidate mechanisms involved, hearts were pertused with either glucose $(11 \mathrm{mM})$, glucose $(11$ $\mathrm{mM}$ ) plus lactate $(5 \mathrm{mM}$, a level which may be found in man) or glucose (11 mM) plus pyruvate $(5 \mathrm{mM})$. Glucose was taken as control. However, glucose only is insufficient as substrate as it depletes endogenous substrate pools (Crass, 1972; Neely and Morgan, 1974; Van Bilsen et al, 1988). Therefore, lactate addition was also compared to pyruvate addition. Lactate and pyruvate are very close to each other in the metabolic route, i.e. lactate is the reduced form of pyruvate. Fatty acids were omitted from the perfusion medium. Although fatty acids are common blood substrates, supply of exogenous fatty acids would complicate understanding of endogenous metabolic processes in the present experimental set up.

\subsection{OUTLINE OF THE THESIS}

Chapter 2 considers whether exogenous lactate in combination with glucose influences cardiac stability during prolonged normoxic perfusion. Hemodynamic performance was monitored by heart rate, cardiac output and left ventricular developed pressure. Metabolic processes were evaluated by utilization of endogenous substrate pools (glycogen and triacylglycerols) and the content of high-energy phosphates (creatine phosphate and ATP). Special attention was paid to the turnover of triacylglycerols.

The susceptibility of the reperfused ischemic myocardium to exogenous lactate is outlined in chapter 3 . The severity of ischemic insult was varied by three time intervals, i.e. 15,30 or $45 \mathrm{~min}$ of ischemia. During preischemic and postischemic periods, hemodynamic function (heart rate, cardiac output, left ventricular developed pressure) was assessed. Lactate dehydrogenase release was determined as a marker of loss of cell membrane integrity. Lactate concentrations in effiuents were measured to monitor net myocardial lactate extraction during (re)perfusion. Glycolysis, assessed by changes in tissue content of glycogen, lactate, NADH and glycerol-3-phosphate, was evaluated as a possible determinant of hemodynamic recovery.

The effect of exogenous lactate on changes of the cardiac lipid pool under ischemic and reperfused conditions is presented in chapter 4 . Accumulation of fatty acids, involvement of the phospholipid pool (total phospholipid content, arachidonic acid accumulation) and triacylglycerol homeostasis (total triacylglycerol content, glycerol-3-phosphate and glycerol) were considered. Fatty acid accumulation was related to hemodynamic recovery.

Chapter 5 describes whether exogenous lactate induces changes in cardiac highenergy phosphate metabolism after various intervals of ischemia and reperfusion. Tissue contents of creatine phosphate, ATP and GTP as well as breakdown of the high-energy phosphates in nucleosides and oxypurines were assessed.

Chapter 6 pays attention to regional flow patterns in the lactate hearts subjected to 15,30 or $45 \mathrm{~min}$ of ischemia. Flow through inner and outer layers of left ventricle 
and through right ventricle was determined.

Chapter 7 considers whether glycerol-3-phosphate can be directly hydrolysed into glycerol. So far, it has been assumed that the glycerol part of glycerol-3-P is incorporated into the triacylglycerol pool and subsequently released as free glycerol. In this study the glycerol-3-P hydrolysing activity was measured in cardiac homogenates with special attention to subcellular localization and substrate and $\mathrm{pH}$ dependency.

A general discussion is presented in Chapter 8 .

\subsection{REFERENCES}

1. Bing PJ, Siegel A, Vitale A, Balboni $F$, Sparks E, Taeschler M, Klapper M, Ecwards S (1953) Metabolic studies on the human heart in vivo. I studies on carbohydrate metabolism of the human heart. Am J Med 15: 284-296

2. Bricknell OL, Opie LH (1978) Effects of substrates on tissue metabolic changes in the isolated rat heart during underperfusion and on release of lactate dehydrogenase and arthythmias during repertusion. Circ Res 43: 102-115

3. Bünger R, Mallet, RT, Hartman DA (1989) Pyruvate-enhanced phosphoryllation potential and inotropism in normoxic and postischemic isolated working heart. Eur J Biochem 180: 221-233

4. Burton KP, Buja LM, Sen A. Willerson JT, Chien KR (1986) Accumulation of arachidonate in Iriacylglycerols and unesterified fatty acids during ischemia and reflow in the isolated rat heart. Am J Pathol 124: 238-245

5. Carlson L, Abrahamsson $T$, Almgren $O$, Svensson $L$ (1987) ischaemia-induced release of noradrenaline and creatine kinase in the isolated, working rat heart. Acta Physiol Scand 130: 83-93

6. Chien $K R_{\text {. Han }} \mathrm{A}$, Sen $\mathrm{A}$, Buja LM, Willerson $J T$ (1984) Accumulation of unesterified arachidonic acid in ischemic canine myocardium. Relationship to a phosphadilylcholine deacylation-reacylation cycle and the depletion of membrane phospholipids. Circ Res 54: 313-322

7. Crass, MF III (1972) Exogenous substrale effects on endogenous lipid melabolism in the working rat heart. Biochim Biophys Acta 280: 71-81

8. De Leiris J, Opie LH (1978) Effects of substrates and of coronary artery ligation on mechanical performance and on release of lactate dehydrogenase and creatine phospho-kinase in isolated working rat hearts. Cardjovasc Res 12: 585-596

9. Drake AJ, Haines JR, Noble MIM (1980) Preterential uptake of lactale by the normal myocardium in dogs. Cardiovasc Res 14:65-72

10. Geisbuhler TP, Rovetto MJ (1990) Lactate does nol enhance anoxia reoxygenation damage in adutt rat cardiac myacytes. $\mathrm{J}$ Mol Cell Cardiol 22: 1325-1335

11. Hollmann W, Rost R, Liesen H. Dulaux B. Heck H, Mader A (1981) Assessment of different forms of physical activity with respect to preventive and rehabilitative cardiology. Int $J$ Sports Med 2: 67 80

12. Keul J, Dolf $E$, Stein $H_{4}$ Fleer U, Reindell $H$ (1965) Uber den Stolfwechsel des menschlichem Herzens III Der axydalive Stolfwechsel des menschilichen Herzens unter verschiedenen Arbeitsbedingungen. Pllügers Archiv 282: 43-53

13. Lochner $W$, Nasseri $M$ (1959) Uber den venösen Sauerstofidruck, die einstellung der Coronardurchblutung und den Kohlenhydratstoffwechsel des Herzens bei Muskelarbeil. Pilügers Archiv 269: 407-4116

14. Lopaschuk GD, Spafford MA, Davies NJ, Wall SR (1990) Glucose and palmitate oxidation in isolated working ral hearts repertused after a period of transient global ischemia. Circ Res 66: 546 553

15. Mallet RT, Hartman DA, Bünger $R(1990)$ Glucose requirement for postischemic recovery of perfused working heart. Eur J Biochem 188: $481-493$

16. Mochizuki S, Neely JR (1979) Control of glyceraldehyde-3-phosphate dehydrogenase in cardiac muscle. J Mol Cell Cardiol 11:221-236 
17. Neely JP. Rovelto MJ, Oram JF (1972) Myocardial utilization of carbohydrate and fipids. Progr Cardiovase Dis 15: 289.329

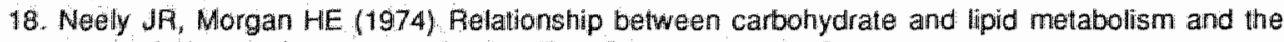
energy balance of heart muscle. Ann Rev Physiol 36: $413-459$

19. Opie LH (1969) Metabolism of the heart in health and disease. Am Heart J 77: 100-122

20. Otani H, Prasad MA, Jones RM, Das DK (1989) Mechanism of membrane phospholipid degradation in ischemic-reperlused rat hearts Am J Physiol 257: H252 H258

21. Rovetto $\mathrm{MJ}_{i}$ Lambenton WF, Neely JP (1975) Mechanisms of glycolytic inthibition in ischemic rat hearts. Circ Res $37: 742-751$

22. Van Bilsen $M$, Van der Vusse GJ, Snoeckx LHEH, Arts $T$, Coumans WA, Willemsen PHM, Reneman RS (1988) Effects of pyruvate on postischemic myocardial recovery at various workloads. Pflügers Archiv-Eur J Physiol 413: 167-173

23. Van Bilsen $M$, Van der Vusse $G J$, Willemsen PHM, Coumans WA, Roemen THM, Reneman RS (1989) Lipid alterations in isolated, working rat hearts during ischemia and reperlusion: its relation to myocardial damage. Circ Res 64: $304-314$

24. Van Bilsen M, Snoeckx LHEH, Arts. T, Van der Vusse GJ, Reneman RS (1991) Performance of the isolated, ejecting heart: effects of aortic impedance and exogenous substrates. Pflügers Archiv-Eur J Physiol 419: 7-12

25. Van der Vusse GJ, Roemen THM, Prinzen FW, Coumans WA, Reneman RS (1982) Uptake and tissue content of latty acids in dog myocardium under normoxic and ischemic conditions. Circ Res 50: $538-546$

26. Wasserman K (1986) Anaerobiosis, lactate and gas exchange during exercise: the issues. Fed Proc 45: 2904-2909 
CHAPTER 2

THE EFFECT OF LACTATE ON CARDIAC FUNCTION DURING PROLONGED NORMOXIC PERFUSION

\# This chapter is derived from:

-De Groot MJM, Willemsen PHM, Coumans WA, Van Bilsen M, Van der Vusse GJ (1989) Lactateinduced stimulation of myocardial triacylglycerol turnover. Blochim Biophys Acta 1006:111-115

- Van der Vusse GJ, De Groot M.MM (1991) The effect of exogenous lactate and pyruvate on triacylglycerol turnover in the normoxic heart. In: Sideman $S$, Beyar $R$, Kléber $A G$ (ed) Cardiac electrophysiology, circulation, and transport. Kluwer Acad Publish "Dordrecht pp 351-358 


\begin{abstract}
Under normoxic circumstances, exogenous lactate and pyruvate $(5 \mathrm{mM})$ prevent the decline in functional stability of isolated rat hearts, prolonged perfused with a glucose containing Krebs-Henseleit buffer. Endogenous glycogen and triacylglycerol stores were preserved in contrast to depletion in glucose hearts. Unlike pyruvate, lactate stimulated the turnover of the cardiac triacylglycerol pool throughout the perfusion period which is indicated by increased glycerol release in association with maintained levels of triacylglycerols. Attenuation of feedback inhibition of triacy/glycerol lipase by fatty acids as a possible cause of the elevated triacylglycerol turnover rate can be ruled out since tissue fatty acid levels were elevated in lactate perfused hearts. The present findings are in favour of the notion that lactate enhances triacylglycerol turnover through increased glycerol-3-phosphate llevels.
\end{abstract}




\subsection{INTRODUCTION}

Most of the energy needs of the in wivo myocardium are met through oxidation of circulating fatty acids, lactate and glucose (Neely et al, 1972). In addition, endogenous stores of glycogen and triacylglycerols may serve as fuel when needed. In isolated hearts, glucose is the most common substrate used in the perfusion fluid. However, when glucose is the sole exogenous substrate available, its utilization can not fulfil the energy requirements of the heart (Crass, 1972; Takenaka and Takeo, 1976; Morgan et al, 1984; Van Bilsen et al ${ }_{1988}$; . This may be caused by restricted membrane transport of glucose. The glucose-perfused organ starts to deplete its endogenous substrate stores. Both glycogen and triacylglycerols are used to maintain an adequate supply of oxidizable substrates. Van Bilsen and coworkers (1988) demonstrated that addition of exogenous pyruvate to the buffer can prevent depletion of endogenous substrate pools indicating that pyruvate can be used as an alternative substrate. In vivo, the normal circulating level of pyruvate is too low to serve as major source of energy for the heart. In contrast, the reduced form of pyruvate, i.e. lactate, is present in blood in higher quantities and may contribute to cardiac energy metabolism. This contribution will become even more significant when the supply of lactate to the heart is increased. For example, increased concentrations of lactate in blood are easily observed after severe exercise (up to $15 \mathrm{mM}$, Wasserman, 1986).

It was the aim of the present study to investigate whether lactate, like pyruvate. added to a glucose-containing perfusion buffer can meet the energy needs of the heart during prolonged normoxic perfusion. To this end ${ }_{n}$ isolated working rat hearts were perfused with a modified Krebs-Henseleit bicarbonate buffer containing either glucose $(11 \mathrm{mM})$, glucose $(11 \mathrm{mM})$ plus pyruvate $(5 \mathrm{mM})$ or glucose $(11 \mathrm{mM})$ plus lactate (5 $\mathrm{mM}$ ). The concentration of exogenous lactate was chosen at $5 \mathrm{mM}$ since lactate is the major substrate for oxidation when present at arterial concentrations exceeding 4.5 $\mathrm{mM}$ (Drake et al, 1980 ). Cardiac stability during prolonged normoxic perfusion was monitored by evaluating heart rate, cardiac output and left ventricular developed pressure of the isolated, working rat heart. Metabolic responses were assessed by endogenous levels of glycogen and triacylglycerols and by the content of high-energy phosphates (creatine phosphate and ATP). Moreover, this study focused on stimulation of the triacylglycerol-fatty cycle (i.e. hydrolysis and resynthesis of triacylglycerols), if any, by lactate. To elucidate a possible mechanism of action, the influence of lactate on parameters most likely involved in triacylglyceral turnover, such as intracellular levels of fatty acids (products of hydrolysis) and glycerol-3-phosphate (precursor of reesterification) was assessed. Release of glycerol in coronary effluent was monitored as a measure of triacylglycerol hydrolysis.

\subsection{METHODS}

\section{Animals}

Hearts were obtained from male Lewis rats (10 weeks old, average body weight $280 \mathrm{~g}$ ). The animals were fed ad libitum (SRM-A, Hope Farms). 


\section{Preparation}

Under light ether anaesthesia, hearts were rapidly excised and immediately immersed in an ice-chilled perfusion medium (see below). After removal of lung and fat tissue, hearts were ligated to the aortic cannula of the perfusion system and retrograde perfusion was started at a perfusion pressure of $8 \mathrm{kPa}$. A second cannula was connected to the left atrium to allow antegrade perfusion of the hearts. The perfusion system has been described previously (Snoeckx et al, 1986, Van Bilsen et al, 1991), The perfusion medium, a modified Krebs Henseleit buffer, contained (in $\mathrm{mM}) \mathrm{NaCl}(130.0), \mathrm{KCl}(5.6), \mathrm{CaCl}_{2}(2.2), \mathrm{MgCl}_{2}$ (1.0), $\mathrm{NaH}_{2} \mathrm{PO}_{4}$ (1.2), $\mathrm{NaHCO}_{3}$ (28.6). $\mathrm{D}(+)$ Glucose $(11 \mathrm{mM})$, glucose $(11 \mathrm{mM})$ in combination with $L(+)$ lactate $(5 \mathrm{mM})$ or glucose (11 $\mathrm{mM})$ in combination with pyruvate $(5 \mathrm{mM}$; sodium salt) were added as substrates. The $\mathrm{pH}$ of the lactate buffer was adjusted by $\mathrm{NaOH}$. The buffer was equilibrated with a mixture of $95 \% \mathrm{O}_{2} / 5 \% \mathrm{CO}_{2}\left(\mathrm{pO}_{2}>75 \mathrm{kPa}\right)$ and continuously filtered (Millipore filter; $1.2 \mu \mathrm{m}$ pore size) during the perfusion period. The final $\mathrm{pH}$ range varied from 7.35 to 7.45 . Temperature was kept at $37^{\circ} \mathrm{C}$.

\section{Experimental protocol}

The hearts were preperfused at a pressure of $8 \mathrm{kPa}$ according to the Langendorff technique. Subsequently, hearts were subjected to antegrade perfusion for either 30 or $120 \mathrm{~min}$. Left atrial filling pressure was $1 \mathrm{kPa}$ and diastolic aortic pressure was 8 $\mathrm{kPa}$. Hearts were freeze-clamped at the end of Langendorff phase ( $t=0 \mathrm{~min}$ ), after 30 $(t=30 \mathrm{~min})$ or $120 \mathrm{~min}(\mathrm{t}=120 \mathrm{~min})$ of antegrade perfusion.

\section{Hemodynamics}

Hemodynamic variables were registered on a 6 channel recorder (Schwarzer). Aortic pressure was measured at the entrance of the aortic cannula via a catheter connected to a CTC pressure transducer. Left ventricular pressure was measured via a catheter inserted into the left ventricle through the apex. Left ventricular developed pressure (LVDP) was calculated as the difference between left ventricular systolic and end-diastolic pressure. Aortic flow (AF) was measured by an electromagnetic flow probe in the aortic outflow tract (Skalar) connected to a sine wave electromagnetic flowmeter (Transflow 601). Coronary flow (CF) was determined by timed collection of the coronary effluent. Cardiac output (CO) was assessed by adding AF and CF. Heart rate $(\mathrm{HR})$ was calculated by using pressure registrations.

\section{Biochemical analysis}

At $t=0,30$ or $120 \mathrm{~min}$, ventricular tissue was rapidly dissected from atrial tissue with a surgical blade and immediately freeze clamped with the use of aluminum tongues, cooled in liquid nitrogen. Coronary effluents were sampled throughout the experiment. Samples were stored at $-80^{\circ} \mathrm{C}$ until analysis.

\section{Tissue}

Creatine phosphate, ATP, glycerol-3-phosphate and glucose : Small parts of the frozen ventricles were freeze dried at $-30^{\circ} \mathrm{C}$. Subsequently, metabolites were extracted by use of a mixture of perchloric acid $(3 \mathrm{M})$ and dithiotreithol $(5 \mathrm{mM})$ as described 
previously (Snoeckx et al, 1986). Creatine phosphate (CP) was determined fluorometrically (Van der Vusse et al, 1984). Tissue contents of ATP were assayed by high performance liquid chromatography (Varian 5500) according to the method of Wijnants and Van Belle (1985). Glycerol-3-phosphate (Glycerol-3-P) was determined fluorometrically according to Laurell and Tibbling (1966). Glucose was measured fluorometrically as described by Van der Vusse and coworkers (1984).

Glycogen: Aliquots of ventricular tissue were freeze dried. After adding $1 \mathrm{~N} \mathrm{HCl}$ to the freeze dried material, glycogen was hydrolysed at $100^{\circ} \mathrm{C}$ during 3 hours. The samples were neutralized with Tris $(0.12 \mathrm{M}) / \mathrm{KOH}(2.1 \mathrm{M})$, saturated with $\mathrm{KCl}$, and subsequently glucose residues were measured fluorometrically as described by Van der Vusse and coworkers (1984). The values obtained were corrected for the content of tree glucose in the tissue.

Fatty acids and triacylglycerols: Part of the frozen tissue was powdered at the temperature of liquid nitrogen and subsequently extracted with chloroform/methanol (2:1, by vol.; Van der Vusse et all, 1982; Roemen and Van der Vusse, 1985). Neutral and polar lipids were separated by silicagel column chromatography (Roemen and Van der Vusse, 1985). The neutral lipid fraction was further separated using thin layer chromatography. The lipid spots, corresponding to fatty acids and triacylglycerols, were scraped from the plates. After elution from the silicagel powder and methylation, the fatty acid methylesters were quantified by gas liquid chromatography (Van der Vusse et al, 1982; Roemen and Van der Vusse, 1985).

\section{Coronary effluent}

Glycerol and lactate: Glycerol was determined fluarometrically in deproteinized (perchloric acid) and neutralized $\left(\mathrm{KHCO}_{3}\right)$ effluent samples according to the method of Laurell and Tibbling (1966). Lactate was assessed spectrophotometrically by use of a Cobas Bio autoanalyzer (Apstein et al, 1970).

\section{Normalization of data}

Measurements in tissue samples are expressed in moles per gram dry weight. The dry weight of cardiac tissue was determined by freeze drying overnight. Datta concerning release of substances in the coronary effluent are expressed as moles per gram wet weight. Therefore it is accepted that release per heart is equivalent to release per gram wet weight as earlier findings demonstrated that hearts of rats of this age weigh approximately $1 \mathrm{gram}(0.97 \pm 0.07$; mean $\pm \mathrm{sd})$. For conversion of moles per gram wet weight to moles per gram dry weight a factor 6.25 is used as empirically determined.

\section{Statistical analysis}

Data are presented as median values and $95 \%$ confidence limits throughout. Differences within groups were evaluated for significance using Wilcoxon's matchedpairs signed ranks test. Differences between groups were tested for significance using Mann Whitney $U$ test. $P$ values less than 0.05 were considered to be statistically significant. 


\section{RESULTS}

\section{Hemodynamics}

Addition of lactate or pyruvate to the perfusion medium did not alter the initial baseline hemodynamic function of isolated working hearts (measured at $t=15 \mathrm{~min}$ of antegrade perfusion; table 2.1). After prolonged pertusion ( $t=120 \mathrm{~min}$ ) heart rate was maintained in the three groups of hearts. In glucose perfused hearts, cardiac output and left ventricular developed pressure were declined by 11.1 and $10.2 \%$, respectively. When lactate or pyruvate was added, decline of hemodynamic performance during prolonged perfusion was reduced (table 2.1 ).

\section{Metabolic responses in tissue}

Compared to the tissue content measured at $t=0 \mathrm{~min}, \mathrm{CP}$ and ATP levels were slightly decreased after $120 \mathrm{~min}$ of normoxic perfusion in glucose and lactate hearts (table 2.2). No significant change was found between 30 and $120 \mathrm{~min}$ of perfusion in all groups of hearts. At 120 min of normoxic perfusion, the CP content was markedly higher in pyruvate than in glucose or lactate hearts.

Glucose as sole substrate was found to be insufficient to preserve endogenous substrate stores. During $120 \mathrm{~min}$ of antegrade perfusion glycogen and triacylglycerol

Table 2.1 Hemodynamic performance of isolated, ejecting hearts during prolonged normoxic perfusion. The effect of lactate or pyruvate added to a glucose containing perfusion medium.

time HR CO LVDP

G

$\begin{array}{rlll}15 & 278(266-323) & 64.5(60.6-67.2) & 12.8(12.1-13.3) \\ 120 & 280(250-306) & 57.4(54.9-63.1)^{\mathrm{a}} & 11.5(11.1-12.1)^{\mathrm{a}}\end{array}$

L

$\begin{array}{rlll}15 & 278(248-294) & 63.7(58.8-67.4) & 12.3(11.6-12.9) \\ 120 & 286(252-900) & 62.1(55.5-67.4) & 12.5(11.3-12.8)^{\mathrm{b}} \\ & & & \\ 15 & 272(256-294) & 60.4(53.6-68.0) & 12.4(11.2-13.5) \\ 120 & 270(248-316) & 56.8(50.0-65.0)^{\mathrm{a}} & 12.1(10.4-12.8)^{\mathrm{a}}\end{array}$

Data are presented as median values and $95 \%$ confidence limits. Heart rate (HA), cardiac output (CO) and lett ventricular developed pressure (LVDP) are expressed in beats/min. mümin and $\mathrm{kPa}$, respectively. Hemodynamic parameters are measured at $15 \mathrm{~min}$ and at $120 \mathrm{~min}$ of antegrade periusion. $G$ refers to glucose $(11 \mathrm{mM})$ perfused hearts, $n$ (number of experiments) $=15 ; L$ refers to glucose ( 11 mM) plus lactate (5 mM) pertused hearts. $n=13: P$ refers to glucose (11 $\mathrm{mM}$ ) plus pyruvate $(5 \mathrm{mM})$ pertused hearts, $n=6$.

$b$ indicates significantly different from values measured at $t=15 \mathrm{~min}$ in corresponding hearts; $b$ indicates significantly different from values measured in glucose perfused hearts at corresponding
times; $(p<0.05)$. 
contents decreased by $75 \%$ and $78 \%$ respectively $(t=120$ versus $t=0$; table 2.3 . When either lactate or pyruvate was added as cosubstrate to the perfusion medium, both glycogen and triacylglycerol stores were presenved (table 2.3).

The level of fatty acids was not allered in hearts perfused with glucose as sole substrate but was markedly increased in hearts perfused with glucose plus lactate during $120 \mathrm{~min}$ of normoxic perfusion (versus $\mathrm{t}=0 \mathrm{~min}$, table 2.3). The fatty acid levels in pyruvate perfused hearts were comparable to those in lactate perfused hearts after 30 and $120 \mathrm{~min}$ (table 2.3 ).

The tissue content of glycerol-3-P increased in glucose and lactate hearts during 120 min of normoxic perfusion. In pyruvate hearts, the raise of glycerol-3-P (during 90 min) did not reach the level of significance. After $120 \mathrm{~min}$, the content of glycerol-3-P was profoundly higher in lactate hearts than in glucose or pyruvate hearts (table 2.3).

Table 2.2 Myocardial tissue content of creatine phosphate and ATP after 0,30 min and 120 min of normoxic antegrade perfusion. The effect of lactate or pynuate added to a glucose containing perfusion medium.

\begin{tabular}{|c|c|c|c|}
\hline Time & $\mathrm{n}$ & $C P$ & ATP \\
\hline \multicolumn{4}{|l|}{$G$} \\
\hline 0 & 10 & $35.8(31.4-44.3)$ & $22.9(21.6 \cdot 25.1)$ \\
\hline 30 & 7 & $20.2(9.7-25.4)$ & $16.6(14.7-18.2)$ \\
\hline 120 & 13 & $18.2(12.6-25.7)^{\mathrm{a}}$ & $18.0(15.2-20.8)^{2}$ \\
\hline \multicolumn{4}{|l|}{ L } \\
\hline 0 & 10 & $40.4(27.1-43.7)$ & $23.1(22.2-24.6)$ \\
\hline 30 & 7 & $22.2(9.6-32.4)$ & $16.9(14.2-20.7)$ \\
\hline 120 & 13 & $20.3(13.6-32.2)^{\mathrm{a}}$ & $17.3(16.3-20.3)^{a}$ \\
\hline \multicolumn{4}{|l|}{$P$} \\
\hline 0 & 0 & $\mathrm{~nm}$ & $\mathrm{~nm}$ \\
\hline 3.0 & 8 & $29.2(11.4-56.7)^{c}$ & $20.1(13.6-22.8)^{\circ}$ \\
\hline 120 & 6 & $33.5(28.3-38.4)^{c, d}$ & $17.0(15.2-20.3)$ \\
\hline
\end{tabular}

Data are presented as median values and $95 \%$ confidence limits. $n$ refers to number of experiments. Creatine phosphate (CP) and ATP are expressed as $\mu$ mol/g dry weight; Tissue contents are measured at $O, 30 \mathrm{~min}$ and $120 \mathrm{~min}$ of normoxic, antegrade perfusion (Time). $G, L$ and $P$ refer to glucose (11 $\mathrm{mM})$, glucose (11 $\mathrm{mM}$ ) phus lactate $(5 \mathrm{mM})$ or glucose (11 $\mathrm{mM}$ ) plus pyruwate (5 mM) perlused hearts, respectively. $n m$ means not measured.

andicates significantly different from walues measured at $t=0 \mathrm{~min}$ in hearts supplied with the same substrate:

${ }^{b}$ indicates significantly different from values measured at $t=30 \mathrm{~min}$ in hearts supplied with the same substrate:

${ }^{c}$ indicates significantly different from values measured in glucose perfused hearts at corresponding times;

${ }^{\prime}$ indicates significantly different from values measured in lactate perfused hearts at corresponding times; $(p<0.05)$ 


\section{Lactate uptake/rellease}

Measurements in coronary effluents, collected after the stabilization period, demonstrated that glucose and pyruvate perfused hearts released lactate $[0.6(0.4-0.8)$ and $0.9(0.7-0.9) \mu \mathrm{mol} / \mathrm{g}$ wet weight.min, respectively], whereas glucose plus lactate perfused hearts extracted lactate. The median value for lactate uptake, as calculated by arterial-venous differences and coronary flow, was $2.1 \mu \mathrm{mol} / \mathrm{g}$ wet weight.min ( $95 \%$ confidence limits: $1.5-2.8 \mu \mathrm{mol} / \mathrm{g}$ wet weight.min) corresponding to a total uptake of 0.25 mmol lactate per gram wet weight during $120 \mathrm{~min}$ of antegrade perfusion.

\section{Glycerol release}

Throughout antegrade perfusion, the production rate of glycerol was constant and amounted to $6.3 \mathrm{nmol} / \mathrm{g}$ wet weight.min in glucose perfused hearts. Cumulative glycerol release over 120 min was $0.8 \mu$ mol/g wet weight (fig 2.1). In pyruvate hearts, glycerol release was in the same range, i.e. $2.5 \mathrm{nmol} / \mathrm{g}$ wet weight. min corresponding to a total release of $0.3 \mu \mathrm{mol} / \mathrm{g}$ wet weight over $120 \mathrm{~min}$ (fig 2.1 ). In hearts perfused with glucose plus lactate, coronary glycerol release was $17.2 \mathrm{nmol} / \mathrm{g}$ wet weight.min corresponding to $2.1 \mu \mathrm{mol} / \mathrm{g}$ dry weight. $120 \mathrm{~min}$ which is about 7 and 2.6 times higher than in pyruvate or glucose perfused hearts.

Less than $3.5 \%$ of the total amount of glycerol produced was retained in the tissue (data not shown) and this proportion did not significantly change during perfusion.

Table 2.3 Myocardial tissue content of glycogen, triacylglycerols, fatty acids and glycerol-3-P after 0 , $30 \mathrm{~min}$ and $120 \mathrm{~min}$ of normoxic antegrade perfusion. The effect of lactate or pyruvate added to a glucose containing perfusion medium.

\begin{tabular}{|c|c|c|c|c|c|}
\hline Time & $n$ & Glyc & $\mathrm{TG}$ & FA & G3P \\
\hline \multicolumn{6}{|l|}{ G } \\
\hline 0 & 10 & $139(114-169)$ & $15.2(13.7-25.7)$ & $72(40-241)$ & $0.12(0.06-0.30)$ \\
\hline 30 & 7 & $109(76-151)$ & $11.1(5.7-20.5)$ & $77(46-153)$ & $0.00(0.00-0.47)$ \\
\hline 120 & 13 & $35(25-71)^{a b}$ & $3.3(2.6-6.6)^{\mathrm{a}, \mathrm{b}}$ & $70(61-114)$ & $0.35(0.20-0.79)^{a . b}$ \\
\hline \multicolumn{6}{|l|}{ L } \\
\hline 0 & 12 & $145(108-1.49)$ & $21.6(15.131 .9)$ & $115(64-174)$ & $0.61(0.40-0.90)^{c}$ \\
\hline 30 & 7 & $182(14+1-232)^{e}$ & $18.7(12.6-26.4)$ & $272(146-642)^{c}$ & $0.41(0.00-0.97)^{\mathrm{c}}$ \\
\hline 120 & 13 & $184(144-197)^{\mathrm{a}, \mathrm{c}}$ & $19.0(11.5-34.4)^{c}$ & $217(168-267)^{a_{c} c}$ & $0.94(0.67-1.411)^{\mathrm{a}, \mathrm{b}, \mathrm{c}}$ \\
\hline \multicolumn{6}{|l|}{$P$} \\
\hline 0 & 0 & $\mathrm{~nm}$ & $\mathrm{~nm}$ & $\mathrm{~mm}$ & $\mathrm{~nm}$ \\
\hline 30 & 8 & $181(121-255)^{\mathrm{C}}$ & $20.6(113.6-34.2)^{\mathrm{C}}$ & $237(182-408)^{\mathrm{C}}$ & $0.00(0.00-0.95)$ \\
\hline 120 & 6 & $232(183-307)^{\mathrm{C}}$ & $23.2(21.1-25.3)^{\mathrm{o}}$ & $254(241-266)^{c}$ & $0.24(0.00-1.23)^{d}$ \\
\hline
\end{tabular}

Data are presented as median values and $95 \%$ confidence limits. Glycogen (Glyc) is expressed as umol glucose equivalents/g dry weight: Triacylglycerols (TG) as $\mu$ mol fatty acid equivalents/g dry weight; Fatty acids (FA) as nmollg dry weight: Glycerol-3-phosphate (G3P) as $\mu$ mol'g dry weight. Tissue contents are measured at $0,30 \mathrm{~min}$ and $120 \mathrm{~min}$ of normoxic, antegrade pertusion (Timel. nm means not measured. For other abbreviations and legends see Table 2.2. 
umol glycerol releasedit

$g$ wet weight. 120 min

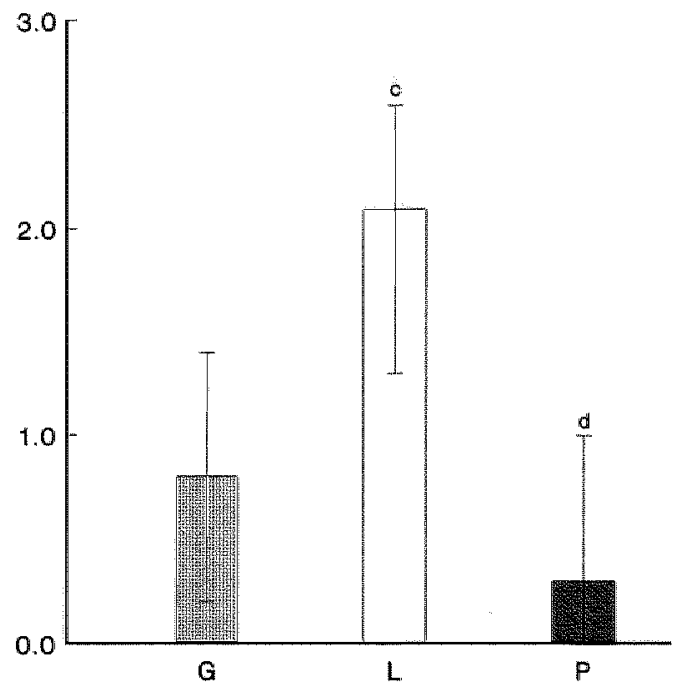

Fig 2.1. Cumulative release of glycerol during 120 min of normoxic perfusion. Data are presented as median values and $95 \%$ confidence limits. Glycerol release is expressed as umol per $g$ wet weight per $120 \mathrm{~min}$. G refers to hearts perfused with givcase $(11 \mathrm{mM})$ : $L$ refers to hearts perfused with glucase (11 $\mathrm{mM}$ ) plus lactate $(5 \mathrm{mM})$; $P$ refers to hearts pertused with glucose $(11 \mathrm{mM})$ plus pyruvate $(5 \mathrm{mM})$ "indicates significantly different from values measured in glucose perfused hearts;

indicates significantly different from walues measured in lactate perfused hearts; $(p<0.05)$.

\subsection{DISCUSSION}

\section{Cardiac stability}

The present study shows that glucose as sole substrate (in the absence of insulin) is unable to meet energy requirements of the isolated, ejecting rat heart during prolonged normoxic perfusion. This observation supports earlier findings (Crass, 1972; Takenaka and Takeo, 1976; Morgan et al, 1984; Van Bilsen et al, 1988). Endogenous substrate stores were depleted to maintain the supply of oxidizable compounds and, hence "the content of CP and ATP at the desired level. Both glycogen and triacylglycerols, providing glucose and fatty acid moieties, respectively, served this purpose.

When either lactate or pyruvate, at the concentration of $5 \mathrm{mM}$, was added to the pertusion medium decline in function was less during prolonged normoxic perfusion. With respect to lactate, our data showed that the uptake of lactate was $2.1 \mu \mathrm{mol} / \mathrm{g}$ wet 
weightmin. Complete oxidation of this amount of lactate requires $6.3 \mu$ mol $\mathrm{O}_{2} / \mathrm{g}$ wet weight.min. Using the formula of Hüter and coworkers (1985), the oxygen consumption by the isolated, working rat heart in the present study was calculated to be $7.1 \mu \mathrm{mol} \mathrm{O} / \mathrm{g}$ wet weight.min. Thus about $90 \%$ of myocardial oxygen is used for oxidation of lactate. Both lactate and pyruvate blocked the consumption of substrates, released from endogenous stores. The exact site and mechanism of inhibition are incompletely elucidated. Pyruvate is known to stimulate its own intracellular conversion by keeping pyruwate dehydrogenase in an active state (Bünger et al, 1989). Since CoA is an important cofactor for conversion of pyruvate into acelyl $\operatorname{CoA}$, competition with fatty acid activation, a reaction step that also requires $C O A$, might take place at the level of CoA utilization. The same may hold for lactate, once converted into pyruvate by action of lactate dehydrogenase. Moreover, conversion of lactate into pyruvate raises the cytoplasmic NADH/NAD* ratio. This, in turn, will be translated into an enhanced mitochondrial redox state (by the malate/aspartate shuttle). Elevated

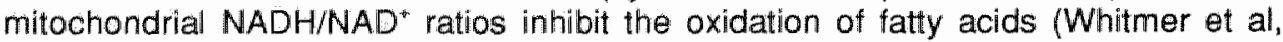
1978; Moore, 1985). Bielefeld and coworkers (1985) have suggested that lactate inhibits the enzyme carnitine acyl transferase I (CAT-1), located at the inner side of the mitochondrial outer membrane (Murthy and Pande, 1987). Their conclusion is based on the finding that the cytoplasmic concentration of acylcarnitine drops while the incorporation of fatty acyl moieties into the endogenous triacylglycerol pool is enhanced in the lactate perfused hearts. The same authors speculated that lactate may stimulate acetyl CoA carboxylase activity and, hence, elevate the concentration of malonyl COA, which is a strong inhibitor of CAT-1 (McGarry et al, 1983). The present findings might indicate that lactate-induced inhibition of CAT-1 activity is not the sole factor leading to enhanced triacylglycerol formation with a concomitant decrease in fatty acid oxidation. It is quite feasible, that increased glycerol-3-P levels in the cardiac cell will compete for acyl COA to form triacylglycerols (see below). Reduced supply of acyl COA to CAT-I will subsequently result in a diminished delivery of acyl moieties to the mitochondrial matrix.

\section{Turnover of triacylglycerols}

The present study indicates that the isolated, ejecting rat heart continuously produced glycerol. Denton and Randle (1967) have shown that release of glycerol from the isolated normoxic rat heart represents a reliable parameter to estimate degradation of endogenous triacylglycerols. The total amount of glycerol released from hearts, perfused with glucose as sole substrate during $120 \mathrm{~min}$, was about $0.8 \mu \mathrm{mol} / \mathrm{g}$ wet weight or $4.7 \mathrm{\mu mol} / \mathrm{g}$ dry weight. This value corresponds well with the net amount lost from the endogenous triacylglycerol pool during $120 \mathrm{~min}$ of perfusion $(4.0 \mu \mathrm{mol}$ glycerol, forming the backbone of triacylglycerols, per g dry weight of tissue). Since the myocardial triacylglycerol content did not undergo a measurable change in lactate or pyruvate hearts, release of glyceroi in these hearts indicates that degradation of triacylglycerols must be in equilibrium with resynthesis of triacylglycerols. This situation will create an operative triacylglycerol/fatty acid cycle. Compared to pyruvate perfused hearts the turnover rate of the triacylglycerol/fatty acid cycle was about 7 times higher in the lactate group.

The enhanced rate of triacylglycerol turnover in lactate perfused hearts might be controlled by either the hydrolytic or synthetic pathway. Endogenous lipolysis is mainly 
determined by the activity of lysosomal lipases in addition to neutral lipases (Wang et al, 1977; Hülsmann et al, 1981; Stam et al, 1986). The lipolytic activity is regulated by a variety of hormonal and metabolic factors (Severson and Hurley, 1982; Goldberg and Khoo, 1985; Stam and Hülsmann, 1985; Schoonderwoerd et al, 1987). Earlier studies have reported a regulation of lipase activity by lipolytic products, i.e. fatty acids. via feedback control (Severson and Hurley, 1982; Stam and Hülsmann, 1985). The present study questions the importance of falty acids as inhibitory products under physiological conditions since increased lipolysis was found to be associated with enhanced tissue levels of fatty acids im lactate perfused hearts. Stam and Hülsmann (1985) observed inhibitory effects of palmitate on triacylglycerol lipases at concentrations between 250 and $2000 \mu \mathrm{M}$ in witro. Severson and Hurtey (1982) demonstrated that a concentration of $100 \mu \mathrm{M}$ of oleic acid caused no inhibition of acid lipase activity, whereas it produced half maximal inhibition of neutral triacylglycerol lipase activity (in presence of $0.05 \%$ albumin). It is uncertain whether these concentrations will be reached in the normoxic cardiac cell. In the present study the measured fatty acid content, i.e. $217 \mathrm{nmol} / \mathrm{g} \mathrm{dry}$ weight may correspond to about 60 $\mu \mathrm{mol} / \mathrm{intracellular}$ fluid (in case all fatty acids are solubilized in cytoplasm), which is below the concentrations used to establish inhibition of triacylglycerol hydrolysis in in vitro experiments.

Alternatively, the rate of triacylglycerol turnover may be regulated at the levell of synthesis. In lactate perfused hearts, the rate of synthesis was elevated as indicated by increased rates of glycerol release with virtually unchanged levels of triacylglycerols. Fatty acid esterification is strongly dependent on availability of the precursor glycerol-3-P (Schoonderwoerd et al, 1987). In this respect it is noteworthy that higher levels of glycerol-3-P were measured in glucose plus lactate perfused hearts than in hearts perfused with glucose plus pyruvate or glucose only. Mass action of glycerol-3-P may control the rate of triacylglycerol turnover by stimulating the rate of esterification. Since no increase in total triacylglycerol content could be measured, we suggest that part of the triacylglycerol pool is converted into an active pool which is more readily accessible to hydrolytic enzymes.

Cycling of triacylglycerols/ fatty acids is associated with the consumption of ATP, required for formation of glycerol-3-P and activation of fatty acids to acyl CoA. Hence the question can be raised whether activation of this cycle poses a burden on the energetic state of the heart. The release of glycerol in lactate perfused hearts amounted to $17.2 \mathrm{nmol} / \mathrm{g}$ wet weight.min (fig 2.1). This value corresponds to a fatty acid release of $0.3 \mu \mathrm{mol} / \mathrm{g}$ dry weight. $\mathrm{min}$. Since the fatty acid content of the total triacylglycerol pool is about $20 \mu \mathrm{mol} / \mathrm{g}$ dry weight, it can be calculated that each minute approximately $1.5 \%$ of the triacylglycerol pool is cycled. For conversion of 3 fatty acyl moieties into 3 acyl CoA, 6 mol ATP is used. The production of 1 mol glycerol-3-P requires the hydrolysis of 1 mol ATP. Hence, it can be inferred that 7 mol ATP is charged for each mol of glycerol hydrolysed. The production of $17.2 \mathrm{nmol}$ glycerol/g wet weight.min of tissue corresponds with the consumption of $120 \mathrm{nmol}$ ATP/g wet weight.min. Using the formula of Hütter and coworkers (1985), the oxygen consumption by the isolated, working rat heart in the present study will be about 7 $\mu \mathrm{mol} \mathrm{O}_{2} / \mathrm{g}$ wet weight.min. Assuming an ATP over $\mathrm{O}_{2}$ ratio of 6 , the total amount of ATP produced by rephosphorylation of ADP is in the order of $42 \mu \mathrm{mol} / \mathrm{g}$ wet weight.min. This value indicates that about $0.3 \%$ of ATP generated is used for the lactate-stimulated "futile" triacylglycerol/fatty acid cycle. Hence, increased production 
of glycerol in lactate perfused hearts is most likely inconsequential from an energetic point of view. It cannot be excluded that triacylglycerol/fatty acid cycling might add to impaired functional recovery of the heart after a transient ischemic insult, when energy supply is disturbed.

\subsection{REFERENCES}

1. Apstein CS, Puchner SE, Brachfeld N (1970) Improved automated lactate determination. Anal Blochem 38: 20-34

2. Bielefeld DR, Vary TC, Neely JR (1985) Inhibition of carnitine palmitoyl-CoA transferase activity and fatty acid oxidation by lactate and oxfenicine in cardiac muscle. J Mol Cell Cardiol 17: 619-625

3. Bünger R. Mallet RT, Hartman DA (1989) Pyruvate-enhanced phosphorylation potential and inotropism in normoxic and postischemic isolated working heart. Eur J Biochem 180: 221-233

4. Crass MF (1972) Exogenous substrate effects on endogenous lipid metabolism in the working rat heart. Biochim Biophys Acta 280: 71-81

5. Denlon RM, Randle PJ (1967) Measurements of flow of carbonatoms from glucose and glycogen glucose to glyceride glycerol and glycerol in rat heart and epididymal adipose tissue. Biochem $\mathrm{J}$ 104: $423-434$

6. Drake AJ, Haines $\mathrm{JR}_{\text {n }}$ Noble MIM (1980) Preferential uptake of lactate by the normal myocardium in dogs. Cardiovasc Res 2: 65-72

7. Goldberg $\mathrm{DI}, \mathrm{Khoo} \mathrm{JC}$ (1985) Activation of myocardial neutral triglyceride lipase and neutral cholesterol esterase by CAMP-dependent protein kinase. J Biol Chem 260: 5879-5882

8. Hülsmann WC, Stam H, Breeman WAP (1981) Acid-and neutral lipases involved in endogenous lipolysis in small intestine and heart. Biochem Biophys Res Commun 102: 440-448

9. Hütter JF, Piper HM, Spieckerman PG (1985) An index for estimation of oxygen consumption in rat heart by hemodynamic parameters. Am J Physiol 249: H729-H734.

10. Laurell $S$, Tibbling $G(1966)$ An enzymatic fluorometric micromethod for the determination of glycerol. Clin Chim Acta 13: 317-322

11. MCGarry JD, Mills SE, Long CS, Foster DW (1983) Observations on the affinity for carnitine, and malonyl-CoA sensitivity, of carnitine palmiloyltranslerase $I$ in animal and human tissues. Biochem
$J 214: 21-28$

12. Moore KH (1985) Fatty acid oxidation in ischemic heart. Mol Physiol 8: 549-563

13. Morgan HE, Neely JR, Kira $Y$ (1984) Factors determining the utilization of glucose in isolated rat hearts. Basic Res Cardiol 79: 292-299

14. Murthy MSA, Pande SV (1987) MalonylCoA binding site and the overt carnitine palmitoyltransferase activity reside on the opposite sides of the outer mitochondrial membrane. Proc Natl Acad Sci USA 84: $378-382$

15. Neely JR, Rovetto JJ, Oram JF (1972) Myocardial utilization of carbohydrate and lipids. Progr
Cardiovasc Dis 15.

16. Hoemen THM, Van der Vusse GJ (1985) Application of silicagel column chromatography in the assessment of non-esterified fatty acids and phosphoglycerides in myocardial tissue. J Chromatogr
34.4: $304-308$

17. Schoonderwoerd $K$, Broekhoven-Schokker $S$, Hülsmann $W C_{n}$ Stam H (1987) Stimulation of myocardial neutral triglyceride lipase activity by adenosine-3':5"-monophosphate: involvement of
glycogenolysis. Basic Res Cardiol 82 (suppl 1): $29-36$

18. Severson DL, Hurley $B$ (1982) Regulation of rat heart triacylglycerol ester hydrolases by free fatty acids, fally acyl COA and fatty acyl carnitine. J Mol Cell Cardiol 1.4:467.474

19. Snoeckx LHEH, Van der Vusse GJ, Coumans WA, Willemsen PHM, Van der Nagel T, Reneman RS (1986) Myocardial function in normal and spontaneously hypertensive rats during reperfusion after a period of global ischemia. Cardiovasc Res 20:67-75 20. Stam H, Hülsmann WC (1985) Regulation of tipases involved in the supply of substrate fatty acids
for the heart. Eur Heart $J 6: 158-167$

21. Stam H. Broekhoven-Schokker S, Hülsmann WC (1986) Sludies on the involvement of lipolytic 
enzymes in endogenous lipolysis of the isolated rat heart. Biochim Biophys Acta 875: 87-96

22. Takenaka $F$, Takeo S (1976) Eflects of isoproterenol on myociardial lipid metabolism in rat hearts perfused with and without exogenous substrates. J Mol Cell Cardiol 78: 326-337

23. Van Bilsen $M$, Van der Vusse GJ, Snoeckx LHEH, Arts $T$, Coumans WA, Willemsen PHM, Reneman RS (1988) Effects of pyruvate on postischemic myocardial recovery at various workloads. Pflügers Archiv-Eur J Physiol 413: 167-173

24. Van Bilsen M, Snoeckx LHEH, Art's T, Van der Vusse GJ, Reneman RS (1991) Performance of the isolated, ejecting heart: effects of aortic impedance and exogenous substrates. Pflugers Archiv-Eur J Physiol 419:7-12

25. Van der Vusse GJ, Roemen THM Prinzen FW, Coumans WA, Reneman RS (1982) Uptake and tissue content of falty acids in dog myocardium under normoxic and ischemic conditions. Circ Res $50: 538-546$

26. Van der Vusse GJ, Coumans: WA, Van der Veen FH, Drake A, Flameng W, Suy R (1984) ATP, creatine phosphate, and glycogen content in human myocardial biopsies: markers for the efficacy of cardioprotection during aorta-coronary bypass surgery. Vase Surg 18, 127-134

27. Wang TW, Menahan LA, Lech $J J(1977)$ Subcellular localization of marker enzymes, lipase and triglyceride in rat heart. $J$ Mol Cell Cardiol 9:25.38

28. Wasserman K (1986) Anaerobiosis, lactate and gas exchange during exercise: the issues. Fed Proc 45: $2904-2909$

29. Wijnants J, Van Belle H (1985) Single-nun high periormance liquid chromatography af mucleotides, nucleosides and major purine bases and its application to different tissue extracts. Anal Biochem 144: $258-266$

30. Whitmer JT, Idell-Wenger JA, Rovetto MJ, Neely JR (1978) Control of falty acid metabolism in ischemic and hypoxic hearts. J Biol Chem 253: 4305-4309 
CHAPTER 3

THE EFFECT OF LACTATE ON THE

REPERFUSED ISCHEMIC RAT HEART

\#The results of this chapter are in preparation for publication by De Groot MUM, Coumans WA, Willemsen PHM, Van der Vusse GJ 


\begin{abstract}
Hemodynamic and metabolic responsiveness of the reperfused ischemic heart to exogenous lactate was evaluated after various grades of ischemic insult $(15,30$ or 45 min interval). Glycolysis was considered as a possible determinant of cardiac recovery. Isolated, working rat hearts were perfused with a Krebs Henseleit bicarbonate buffer containing glucose ( $11 \mathrm{mM}$ ) as basal substrate and lactate $(5 \mathrm{mM})$ or pyruvate $(5 \mathrm{mM})$ as cosubstrates. In lactate reperfused hearts cardiac output and left ventricular developed pressure were impaired after 30 and $45 \mathrm{~min}$ of ischemia compared to glucose hearts. Pyruvate perfused hearts demonstrated improved functional recovery after 30 min of ischemia, but interior function after 45 min of ischemia as compared to glucose hearts. No protective role of high or low glycogen stores prior to ischemia could be observed. Accumulation of glycolytic intermediates including lactate, glycerol3-phosphate and reduced nicotinamide adenine dinucleotide (total) during ischemia neither seemed responsible for the diversity of cardiac function. Several parameters suggest underperfusion of certain areas of the reperfused lactate hearts which may influence restoration of hemodynamic function during the postischemic phase.
\end{abstract}




\section{1 INTRODUCTION}

The heart can oxidize various substrates to meet its energy needs. Although under normal physiological conditions fatty acids are the major fuel for normoxic hearts, other substrates (pyruvate, lactate, ketone bodies, amino acids) might compete with fatty acids depending on their extracellular concentration, hormonal balance and workload of the heart (Neely and Morgan, 1974). Of the blood-borne metabolites, the concentration of lactate is probably the most varying since it increases very readily e.g. during physical activities, hypoxemia or cardiovascular insufficiency (Moret, 1980). Normal blood concentrations are below $1 \mathrm{mM}$ while concentrations up to $15 \mathrm{mM}$ have been reported during severe exercise (Wasserman, 1986). Drake et all (1980) demonstrated that the normoxic heart predominantly oxidizes lactate instead of fatty acids when the lactate concentration increases above $4.5 \mathrm{mM}$. It has also been found in our own laboratory that the consumption of exogenous lactate is considerable in the normoxic rat heart (Chapter 2; De Groot et al, 1989). However, the heart does not seem to be able to cope with increased exogenous lactate concentrations under less ideal circumstances, i.e. ischemia and reperfusion (Bünger et al, 1989). Interestingly, pyruvate, the oxidized form of lactate, has been shown to exert beneficial effects on postischemic hemodynamic recovery (Liedtke and Nellis, 1978; Mochizuki and Neely, 1980; Van Billsen et al, 1988; Bünger et al 1989).

The responsible mechanism for impaired functional recovery is still not clear. Neely and Grotyohann (1984) suggested a detrimental role of anaerobic glycolysis including production of endogenous lactate, hydrogen ion and reduced nicotinamide adenine dinucleotide (NADH) in ischemic damage. Disparate results were obtained by Lagerstrom and coworkers (1988) who demonstrated that preservation of glycogen stores prior to ischemia is beneficial to the affected heart rather than prevention of endogenous lactate accumulation during ischemia. Moreover, Mallet and associates (1990) have recently supported the importance of a stimulated glycolytic flux in contractile recovery of the low-flow ischemic and reperfused heart.

The purpose of the present study was firstly to evaluate hemodynamic responsiveness of the postischemic heart to exogenous lactate $(5 \mathrm{mM})$ as a function of the severity of ischemic insult. To this end the ischemic period varied from 15 to 45 min. Secondly, the glycogenolysis/ glycolysis process was investigated in relation to cardiac recovery during reperfusion. Hearts were perfused with either glucose (11 $\mathrm{mM})$, glucose $(11 \mathrm{mM})$ plus lactate $(5 \mathrm{mM})$ or glucose $(11 \mathrm{mM})$ plus pyruvate $(5 \mathrm{mM})$. Glucose perfused hearts were taken as controls. Lactate and pyruvate hearts were compared as lactate and pyruvate are very close to each other in the metabolic route whille their effect on functional recovery is reported to be diverse (Mochizuki and Neely, 1980; Van Bilsen et al, 1988; Bünger et al, 1989). During preischemic and postischemic periods hemodynamic function was assessed from parameters as heart rate, cardiac output, left ventricular developed pressure, coronary flow and the incidence of arrhythmias. Lactate dehydrogenase release was determined as a marker of loss of cell membrane integrity during reperfusion. Lactate concentrations in coronary effluents were measured to monitor myocardial lactate extraction during (re)perfusion. Whole tissue contents of glycogen, lactate, glycerol-3-P and $N A D(H)$ were measured as indices of glycogenolysis and subsequent glycolysis. 


\subsection{METHODS}

\section{Animails}

Hearts were obtained from male Lewis rats (10 weeks old, range body weight 250-350 g). The animals were kept under an artificial light cycle of 12 hours and had free access to laboratory chow (SRM-A; Hope farms) and water.

\section{Preparation}

Under light ether anaesthesia, hearts were rapidly excised and cannulated as detailed previously (Snoeckx et al 1986; Van Bilsen et al, 1991). The perfusion medium, a modified Krebs Henseleit bicarbonate buffer, contained (in mM): $\mathrm{NaCl}$ (130.0), $\mathrm{KCl}(5.6), \mathrm{CaCl}_{2}(2.2), \mathrm{MgCl}_{2}(1.2), \mathrm{NaH}_{2} \mathrm{PO}_{4}$ (1.2), $\mathrm{NaHCO}_{3}(25.0) . \mathrm{D}(+)$ glucose $(11 \mathrm{mM})$ was added as basal substrate. Where indicated, pyruvate $(5 \mathrm{mM}$, sodium salt) or L(+)-lactic acid ( $5 \mathrm{~mm}$ ) was added as cosubstrate. Lactic acid was neutralized with $\mathrm{NaOH}$. The buffer was equilibrated with a mixture of $95 \% \mathrm{O}_{2} / 5 \%$ $\mathrm{CO}_{2}\left(\mathrm{pO}_{2}>75 \mathrm{kPa}\right)$ and continuously filtered (Millipore filter; $1.2 \mu \mathrm{m}$ pore size) during the perfusion period. The final $\mathrm{pH}$ varied from 7.35 to 7.45 . The temperature of the heart was kept at $37^{\circ} \mathrm{C}$ throughout the experiment.

\section{Experimental protocol}

The hearts were retrogradely perfused during $10 \mathrm{~min}$ according to the Langendorff technique. Following the stabilization period, the hearts were subjected to antegrade perfusion for $30 \mathrm{~min}$. Left atrial filling pressure was set at $1 \mathrm{kPa}$ and diastolic aortic pressure at $8 \mathrm{kPa}$. Subsequently, hearts were submitted to $15,30 \mathrm{or}$ $45 \mathrm{~min}$ of normothermic no-flow ischemia followed by $35 \mathrm{~min}$ of reperfusion (retrogradely during the first $5 \mathrm{~min}$ and antegradely, thereafter). Since the hearts were perfused in the assisted mode (Van Bilsen et al, 1991), coronary perfusion pressure (8. kPa) was maintained even when reperfused hearts were unable to eject and, hence, provide their own coronary flow.

\section{Hemodynamics}

Hemodynamic variables (aortic pressure, left ventricular pressure, aortic flow) were measured as described by Snoeckx ot al (1986). Platinum electrodes were attached to the surface of right atrium and ventricle to record the electrogram. Coronary flow was determined by timed collection of the coronary effluent. Cardiac output (CO) was assessed by adding aortic flow and coronary flow. Left ventricular develloped pressure (LVDP) was calculated as the difference between left ventricular systolic and end-diastolic pressure. Heart rate (HR) was calculated by using the electrogram registrations.

\section{Biochemical analysis}

Ventricular tissue was rapidly dissected from atrial tissue with a surgical blade and immediately freeze clamped at the end of preischemic, ischemic or postischemic 
periods. Coronary effluents were sampled during the preischemic $(t=15-25 \mathrm{~min})$ and pastischemic phase $(t=0-5,5-10,10-15,15-20,20-35 \mathrm{~min}$ of repertusion). Samples were stored at $-80^{\circ} \mathrm{C}$. until analysis.

\section{Tissue}

Lactate, glycerol 3-phosphate and glucose. Small parts of the frozen ventricles were freeze dried. Subsequently, extraction of freeze dried samples was performed by use of an ice-cold extraction fluid containing perchloric acid ( $3 \mathrm{M}$ ) and dithiothreitol $(5 \mathrm{mM}$ ) as described previously (Snoeckx et al, 1986). Lactate, glycerol-3-P and glucose were determined fluorometrically in neutralized extracts (Laurell and Tibbling, 1966; Passonneau 1974; Van der Vusse et al, 1984).

$\mathrm{NAD}^{+}$. The neutralized perchloric acid extract was also used for determination of $\mathrm{NAD}^{+}$. NAD $\mathrm{D}^{+}$was determined by HPLC according to the procedure of Wijnants and Van Belle (1985).

NADH. Part of the frozen tissue was powdered at the temperature of liquid nitrogen. Subsequently, NADH was extracted with $0.5 \mathrm{M} \mathrm{KOH}$ in $50 \%$ ethanol for 5 min at $90^{\circ} \mathrm{C}$. Samples were neutralized by $0.5 \mathrm{M}$ triethanolamine in phosphate buffer and centrifuged at $4{ }^{\circ} \mathrm{C}$ at $1800 \mathrm{~g}$ for $20 \mathrm{~min}$. The supernatant was freeze dried, subsequently solved in a Tris/ $\mathrm{HCl}$ buffer $(\mathrm{pH} 8.1)$ and $\mathrm{NADH}$ was determined by HPLC according to the method of Cighetti et al (1989).

Glycogen. Aliquots of ventricular tissue were freeze dried. After adding $1 \mathrm{~N} \mathrm{HCl}$ to the freeze dried material, glycogen was hydrolysed at $100{ }^{\circ} \mathrm{C}$ for 3 hours. The samples were neutralized with Tris $(0.12 \mathrm{M}) / \mathrm{KOH}(2.1 \mathrm{M})$, saturated with $\mathrm{KCl}$. Subsequently, glucose residues were measured fluorometrically as described by Van der Vusse and coworkers (1984). The values obtained were corrected for the content of free glucose in the tissue.

\section{Coronary effluent}

Lactate and lactate dehydrogenase (LDH) were assessed spectrophotometrically by use of a Cobas Bio autoanalyser (Apstein et al, 1970; Bergmeyer and Bernt, 1974).

\section{Normalization of data}

Measurements in tissue samples are expressed in moles per gram dry weight. The dry weight of cardiac tissue was determined by freeze drying small aliquots of tissue overnight. Data concerning release of substances in the coronary effluent are expressed as units or moles per gram wet weight (release per heart corresponds to rellease per gram wet tissue).

\section{Statistical analysis}

Data are presented as median values and $95 \%$ confidence limits throughout. Differences within groups were evaluated for significance using Wilcoxon's matchedpairs signed ranks test. Differences between groups were analyzed by the Mann Whitney $U$ test. $P$ values less than 0.05 were considered to be statistically significant. 


\subsection{RESULTS}

\section{Hemodynamic recovery}

Table 3.1 gives a qualitative picture of the different modes of action of glucose, lactate and pyruwate perfused hearts after 15,30 or 45 min of ischemia and 35 min of reperfusion. Following 15 min of ischemia, hearts were mainly in ejecting mode. Just 1 heart out of the pyruvate group started to fibrillate. After $30 \mathrm{~min}$ of ischemia markedly different results were found between the three substrate groups. Glucose and pyruvate perfused hearts were predominantly ejecting but lactate perfused hearts were not able to maintain cardiac output (except one heart). In addition, the incidence of irregular electrical activity was increased in the lactate perfused hearts. After $45 \mathrm{~min}$ of ischemia, only some glucose perfused hearts recovered cardiac output. In the lactate group 4 of 7 hearts were electro-mechanically uncoupled (no mechanical activity despite regular sinus rhythm) whereas in the pyruvate group the majority of hearts were out of rhythm.

A quantitative picture of hemodynamic performance in control and reperfused hearts is presented in table 3.2. Compared to glucose perfused hearts, addition of lactate $(5 \mathrm{mM})$ did not affect cardiac function during the preischemic phase. By supply of exogenous pyruvate, the cardiac output was slightly lower than in normoxic glucose hearts. The exogenous substrates markedly determined the extent of hemodynamic recovery during reperfusion following different time intervals of ischemia. After $15 \mathrm{~min}$ of ischemia and $35 \mathrm{~min}$ of reperfusion, cardiac output was reduced in lactate and glucose hearts ( $85 \%$ and $91 \%$ of preischemic value, respectively; $p<0.05$ ), whereas in pyruvate hearts cardiac output returned almost completely to preischemic values

Table 3.1 Modes of cardiac action at the end of 35 min of reperfusion following 15,30 or $45 \mathrm{~min}$ of ischemia. The effect of lactate or pyruvate added to a glucose containing pentusion medium.

\begin{tabular}{|c|c|c|c|c|c|}
\hline Prolocol & Substrate & $E$ & NE & $\mathrm{F}$ & EMU \\
\hline \multirow[t]{3}{*}{$15^{n} \mid / / \pi$} & $\mathrm{G}$ & 6 & 0 & 0 & 0 \\
\hline & L & 6 & 0 & 0 & 0 \\
\hline & P & 6 & 0 & 1 & 0 \\
\hline \multirow[t]{3}{*}{$30^{\circ} \mathrm{V} / \mathrm{A}$} & $\mathrm{G}$ & 6 & 0 & 1 & 0 \\
\hline & L & 1 & 4 & 3 & 0 \\
\hline & $P$ & 6 & 0 & 0 & 0 \\
\hline \multirow[t]{3}{*}{$45^{\prime \prime} 1 / A$} & $G$ & 4 & 4 & 1 & 0 \\
\hline & L & 0 & 3 & 0 & 4 \\
\hline & $P$ & 0 & 1 & 5 & 1 \\
\hline
\end{tabular}

Date represent the number of hearts. $15 \mathrm{~W} R, 30 \mathrm{~W} / \mathrm{R}$ and $45 \mathrm{~W} / \mathrm{A}$ refer to measurements at the end of repertusion preceded by 15,30 and 45 min of ischemia. E=jecting heart. $N E=$ non-ejecting heart but regular mechanical activity. F=failing heart (thythm disturbance), EMU=electromechanically uncoupled heart, $n=$ lotal number of hearts. $G=$ glucose $(11 \mathrm{mM}), L=$ glucose $(11 \mathrm{mM})$ plus lactate $(5 \mathrm{mM}), P=$ givcose (11 $\mathrm{mM})$ plus pyruwate $(5 \mathrm{mM})$. 
(except one case; recovery calculations are based on individual data-in other words; each heart serves as its own control). In all groups, no marked changes were observed for the left ventricular developed pressure (about $98 \%$ of preischemic value). After 30 min of ischemia, differences between the substrate groups were more obvious as recovery of cardiac output in glucose, lactate and pyruvate hearts was 32 , 0 and $77 \%$ of preischemic value, respectively. Recovery of left ventricular developed pressure was also distinct, i.e. 91 " 16 and $99 \%$ of preischemic value in the glucose, lactate and pyruvate group respectively. After $45 \mathrm{~min}$ of ischemia, cardiac performance was inferior in lactate and pyruvate hearts, whereas in glucose hearts resumption of cardliac output and left ventricular developed pressure were $17 \%$ and $63 \%$ of preischemic value, respectively.

Total coronary flow was higher in pyruvate than in lactate hearts during preischemic perfusion. Following $15 \mathrm{~min}$ of ischemia and subsequent reperfusion, no marked changes were observed in the three substrate groups. After 30 min of ischemia and

Table 3.2 Functional performance of isolated working rat hearts subjected to 15,30 or 45 min of ischemia followed by $35 \mathrm{~min}$ of reperfusion, in the absence or presence of lactate ar pyruvate.

$\begin{array}{llll}\text { HR } & \mathrm{CO} & \mathrm{CF} & \text { LVDP }\end{array}$

\section{Pre-1}

G $289(273-306)$

L $\quad 282(272-297)$

P $283(268-300)$

$64.3(60.5-66.0)$ $62.0(59.5-64.0)$

$59.8(57.3-64.0)^{\mathrm{d}}$

\section{$15^{\prime \prime} \mathrm{l} / \mathrm{R}$}

G $268(254-291)$

L $\quad 263(246-300)$

P $\quad 283(268-300)$

30'/R

$\begin{array}{ll}G & 267(254-297) \\ L & 256(227-294) \\ P & 273(246-306)\end{array}$

$45^{\prime \prime} / \mathrm{R}$

$\begin{array}{ll}G & 263(222-349) \\ L & 268(263-326) \\ P & 287(268-306)^{d}\end{array}$

\author{
$57.5(51.6 .62 .0)^{\mathrm{a}}$ \\ $56.0(44.7-60.0)^{\mathrm{a}}$ \\ $57.7(0.0-74.7)$
}

$19.3(0.0-43.7)^{\mathrm{a}}$
$0.0(0.0-0.7)^{\mathrm{a} d}$
$45.0(42.3-57.2)^{\mathrm{a} . \mathrm{de}}$

$11.4(0.0-15.0)^{\mathrm{a}}$
$0.0(0.0-0.0)^{\mathrm{a}, \mathrm{d}}$
$0.0(0.0-0.0)^{\mathrm{a}, \mathrm{d}}$
$12.5(11.3-13.2)$
$11.8(10.9-13.5)$
$13.5(12.5-14.0)^{\mathrm{e}}$

$12.1(11.9-12.8)$

$12.5(11.9-12.9)$

$12.3(12.0-12.8)$

$10.2(9.6-15.0)$
$11.4(7.7-15.0)$
$13.0(10.9-17.7)^{d}$

$11.9(10.8-12.5)$

$12.5(12.1-13.6)^{\mathrm{d}}$

$12.3(0.0-13.6)$

$11.6(9.7-16.3)$
$10.7(7.7-13.7)$
$14.5(12.0-16.3)^{\text {a.d.e. }}$

$10.9(0.0-12.0)^{\text {at }}$

$1.9(0.0-7.2)^{\mathrm{a}, \mathrm{dd}}$

$12.7(11.6-13.1)^{d \cdot \theta}$

$10.3(9.7-11.8)^{\mathrm{a}}$
$8.0(4.8-12.8)^{\mathrm{a}}$
$10.5(5.7-14.4)^{\mathrm{a}}$

$8.1(0.0-9.6)^{\mathrm{at}}$

$0.0(0.0-4.0)^{\mathrm{a}, \mathrm{d}}$

$0.0(0.0-7.5)^{a, d}$

Heart rate (HR), cardiac output (CO), coronary llow (CF) and left ventricular developed pressure (LVDP) are expressed in beats/min, ml'min. ml/min and $\mathrm{kPa}$, respectively. For heart rate, only hearts with regular sinus rhythm are considered (see table 3.1 for the number of experiments). Data are presented as median values and $95 \%$ confidence limits. Pre 1 refers to preischemic value: $15 \mathrm{t} / \mathrm{R}, 30^{\prime} \mathrm{l} / \mathrm{A}$ and $45 \mathrm{~W} / \mathrm{R}$ refer to measurements at the end of repertusion preceded by 15,30 and $45 \mathrm{~min}$ of ischemia. $G=$ glucose $(11 \mathrm{mM}), L=$ glucose $(11 \mathrm{mM})$ plus lactate $(5 \mathrm{mM}), P_{=}$glucose $(11 \mathrm{mM})$ plus pyrumate $(5$ mM). ${ }^{a}$ indicates significantly different from preischemic values;

${ }^{d}$ indicates significantly different from glucose perfused hearts at corresponding times;

e indicates significantly different from lactate hearts at corresponding times; $(p<0.05)$ 
reperfusion, flow was slightly increased in pyruvate hearts. After $45 \mathrm{~min}$ of ischemia all substrate groups showed moderate decreases of coronary flow at the end of reperfusion compared to their preischemic values. Heart rate did not significantly change when hearts in regular sinus thythm were considered. Irregular beating hearts demonstrated trains of electrical signals up to 5500 per min.

\section{Enzyme release}

Preischemic $L D H$ release was very low (about $25 \mathrm{mU} / \mathrm{min}$ ) and did not differ between the glucose, lactate and pyruvate group (see fig 3.1 ).

After a period of ischemia, LDH release was (transiently) increased during reperfusion. Following 15 min of ischemia, glucose perfused hearts released a maximal amount of LDH during the first 5 min of reperfusion and demonstrated decreasing washout thereafter. Lactate perfused hearts showed a peak value between 5 and 10 min and diminished their release the next $25 \mathrm{~min}$. From a qualitative point of view, pyruvate perfused hearts showed a similar pattern of LDH release as glucose perfused hearts. Total LDH release after 15 min of ischemia (table 3.3; corrected for basal release) was low, i.e. $0.4,1.0$ and $0.1 \mathrm{U}$ per $g$ wet weight per $35 \mathrm{~min}$ of reperfusion in the glucose, lactate and pyruvate group, respectively (not significantly different). Glucose and lactate hearts subjected to 30 min of ischemia demonstrated maximal rellease of LDH in a later phase of repertusion. In glucose perfused hearts a peak release value during 10 to 15 min of reperfusion was found and LDH washout gradually declined thereafter. Lactate perfused hearts also showed maximal release during time interval 10 to 15 min, but LDH kept leaking at a high level throughout the postischemic period. In pyruvate perfused hearts, LDH release was maximal during the first 5 min of reperfusion and rapidly declined continuing reperfusion. Cumulative release of LDH after 30 min of ischemia and subsequent reperfusion was significantly higher in lactate hearts than in pyruvate and glucose hearts. In pyruvate hearts cumulative release was markedly lower than in glucose hearts at this time point (table 3.3). Following 45 min of ischemia, $\mathrm{LDH}$ release started slowly and continued at a high level throughout reperfusion in all hearts. Cumulative $\mathrm{LDH}$ release was comparable in the glucose, lactate and pyruvate perfused hearts, l.e. 10 to $12 \mathrm{U}$ per g wet weight per $35 \mathrm{~min}$ of reperfusion.

Table 3.3 Cumulative release of lactate dehydrogenase (LDH) during 35 min of reperfusion following 15,30 or 45 min of ischemia, in absence or presence of lactate $(L)$ or pyruvate $(P)$.

$+5 ! / P$

$\begin{array}{ll}G & 0.4(0.1-1.2) \\ L & 1.0(0.2-2.0) \\ P & 0.1(0.0-1.1)\end{array}$

$30^{\prime} \mathrm{I} / \mathrm{PI}$

$$
\begin{gathered}
6.0(2.2-18.5) \\
15.1(11.9-21.2)^{d} \\
2.5(0.2 \times 3.0)^{d}
\end{gathered}
$$

$45 \mathrm{~V} / \mathrm{A}$

$9.8(0.6-25.0)$

$11.7(4.3-18.4)$

$11.8(8.1-15.8)$

LDH is expressed as U/g wet weight. $35 \mathrm{~min}$, corrected for basal release as measured during the preischemic phase. Data are presented as median values and $95 \%$ confidence limits. For abbreviations and legends see table 3.2. 
FaU L DHY

6 we weightorim
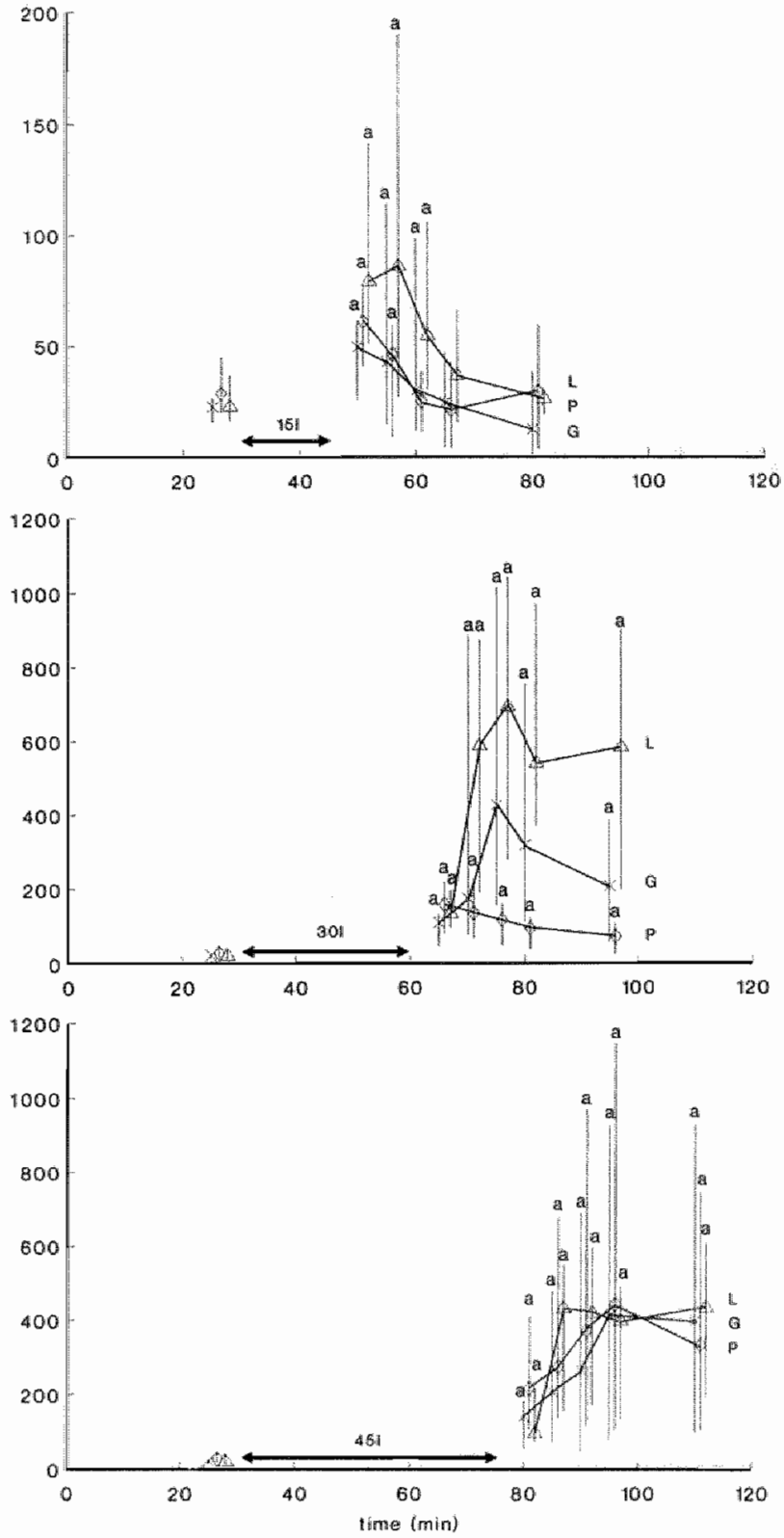

Fig 3.1 Coronary release of lactate dehydrogenase (LDH) prior to and after 15, 30 or 45 min of ischemia, from glucose, lactate and pyruvate perfused hearts. Data are presented as median values and $95 \%$ confidence limits. Release values are expressed as $\mathrm{mu} / \mathrm{g}$ wet weight min. $\mathrm{x}=$ glucose $(11$ $m M), G ; \Delta=$ glucose $(11 \mathrm{mM})$ plus lactate $(5 \mathrm{mM}), \mathrm{L} ; 0=$ glucose $(11 \mathrm{mM})$ plus pyruvate $(5 \mathrm{mM}), P$. Ischemia started after $30 \mathrm{~min}$ of antegrade perfusion, as indicated by double headed arrow.

andicates significantly different from corresponding preischemic value; $(p<0.05)$. 
whol lactate

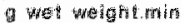
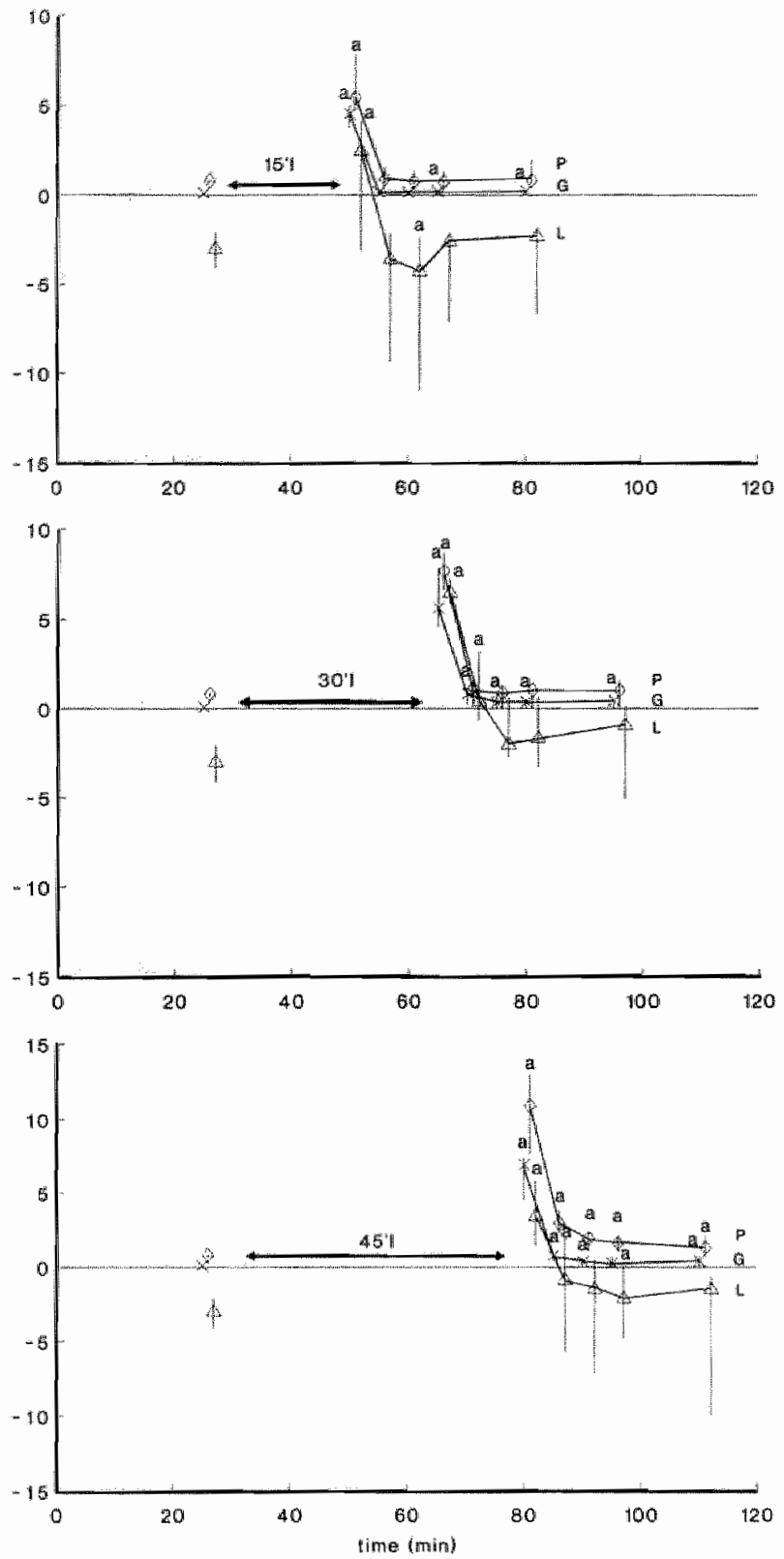

Fig 3.2 Coronary uptake/ release of lactate prior to and after 15,30 or 45 min of ischemia, by hearts perfused with glucose, lactate or pyruwate. Median values and $95 \%$ confidence limits are presented. Data are expressed as $\mu$ molig wet weight.min. Positive values refer to release, negative values to uptake. $x=$ ghucose $(11 \mathrm{mM}), G ; \Delta=$ glucose $(11 \mathrm{mM})$ pius lactate $(5 \mathrm{mM}), L ; \diamond=$ ghucose $(11 \mathrm{mM})$ plus pyruvate (5 mM). P. Ischemia started atter 30 min of antegrade pertusion, as indicated by double headed arrow. ${ }^{a}$ means significantly different from corresponding preischemic value; $(p<0.05)$. 


\section{Lactate extraction/release}

Hearts perfused by extracellular lactate extracted this substrate during control perfusion ( $3.0 \mu \mathrm{mol} / \mathrm{g}$ wet weight.min) as calculated by arterial-venous differences and coronary flow (see fig 3.2). Glucose and pyruvate hearts, though, released lactate $(0.1$ and $0.8 \mu \mathrm{mol} / \mathrm{g}$ wet weight. min, respectively).

Following ischemia, all reperfused hearts initially released lactate in pronounced amounts, but release values decreased towards preischemic values during reperfusion, i.e. lactate extraction in lactate hearts and low lactate release in glucose and pyruvate hearts. The time interval of return as well as the extent of return depended on duration of ischemia and kind of substrate. In this way, hearts subjected to 15 min of ischemia accomplished washout of accumulated lactate in a few minutes. At the end of reperfusion, preischemic venous concentrations were obtained in lactate and pyruvate hearts, whereas in glucose hearts these levels remained slightly but significantly elevated. After $30 \mathrm{~min}$ of ischemia, only pyruvate perfused hearts were able to return raised lactate levels to preischemic values within $10 \mathrm{~min}$. For glucose hearts a similar release pattern was observed but lactate levels were maintained significantly elevated above preischemic values during the reperfusion interval. In lactate hearts net extraction values were obtained in 10 to $15 \mathrm{~min}$. Following $45 \mathrm{~min}$ of ischemia the release of lactate was elevated at the end of reperfusion in both glucose and pyruvate hearts. Lactate hearts showed a tendency of reduced lactate extraction, but the difference with preischemic values did not reach the level of significance.

\section{Consumption of glycogen}

In preischemic hearts glycogen stores were higher in the lactate and pyruwate group (about $180 \mu \mathrm{mol}$ glucose equivalents per $\mathrm{g}$ dry weight) than in the glucose group (109 $\mu \mathrm{mol}$ glucose equivalents per g dry weight; table 3.4 ).

During ischemia glycogen was markedly utilized in all hearts. After $15 \mathrm{~min}$ of ischemia, tissue glycogen content was decreased by $83.9,91.9$ and $98.2 \mu \mathrm{mol}$ glucose equivalents/g dry weight in glucose, lactate and pyruvate hearts, respectively. From 15 to $30 \mathrm{~min}$ of ischemia, glycogen consumption was restricted in glucose and pyruvate hearts whereas in lactate hearts glycogen utilization was still considerable. After 45 min of ischemia, 96.1, 145.2 and $119.3 \mu \mathrm{mol}$ glucose equivalents/g dry weight were selt free from the cardiac glycogen pool in glucose, lactate and pyruvate hearts, respectively (table 3.4 , calculated by median values).

By reperfusion following $15 \mathrm{~min}$ of ischemia, tissue glycogen levels were restored in glucose, lactate and pyruvate hearts (end-reperfusion values not significantly different from preischemic values). After $30 \mathrm{~min}$ of ischemia, only pyruvate hearts replenished the glycogen pool, but the preischemic level was not achieved. Following 45 min of ischemia, there was a slight replenishment of the glycogen store in glucose and lactate hearts.

\section{Lactate and glycerol-3-P}

Table 3.4 summarizes lactate and glycerol-3-P contents in cardiac tissue after various time intervals of ischemia, followed by reperfusion. In lactate hearts preischemic lactate values were of the same order as in glucose and pyruvate hearts 
Table 3.4. The content of glycogen, vactate and glycerol 3-phosphate in isolated working rat hearts subjected to 15,30 or 45 min of ischemia, followed by 35 min of reperfusion, in the absence or presence of factate or pyruvate.

\begin{tabular}{|c|c|c|c|}
\hline & Giycogen & Lactate & G3P \\
\hline \multicolumn{4}{|l|}{ Pre-1 } \\
\hline $\mathrm{G}$ & $108.9(76.2-150.5)$ & $9.0(6.5-11.8)$ & $0.00(0.00-0.47)$ \\
\hline $\mathrm{L}$ & $182.1(140.6-232.4)^{d}$ & $25.5(16.0-32.5)^{d}$ & $0.41(0.00-0.97)^{\mathrm{d}}$ \\
\hline P & $180.7(120.1-255.3)^{d}$ & $5.7(2.4-16.5)^{e}$ & $0.00(0.00-0.95)$ \\
\hline \multicolumn{4}{|l|}{$15 !$} \\
\hline G & $25.0(6.8-77.8)^{a}$ & $87.0(66.3-135.2)^{21}$ & $4.58(2.75-5.62)^{\mathrm{a}}$ \\
\hline $\mathrm{L}$ & $90.2(48.2-129.6)^{\mathrm{add}}$ & $106.7(83.1-125.6)^{\mathrm{a}}$ & $6.23(3.98-7.04)^{\mathrm{a}}$ \\
\hline$\vec{p}$ & $32.5(53.7 \cdot 139.8)^{\mathrm{a}, d}$ & $85.0(46.6-143.5)^{a}$ & $3.62(2.28-6.85)^{\mathrm{a}, 8}$ \\
\hline \multicolumn{4}{|l|}{304} \\
\hline $\mathrm{G}$ & $24.8 \cdot(3.4-72.5)^{\mathrm{a}}$ & $90.2(478-111.3)^{a}$ & $6.29(3.60-8.22)^{a}$ \\
\hline $\mathrm{L}$ & $44.2(24.1-78.4)^{a} b$ & $195.5(83.7-235.4)^{\mathrm{a}, \mathrm{d}}$ & $9.77(6.8-13.30)^{ \pm, b, d}$ \\
\hline$P$ & $83.9(33.6 \cdot 115.44)^{\mathrm{a} . \mathrm{d}}$ & $136.0(94.2-198.4)^{a b d}$ & $6.82(4.69 \times 9.79)^{a b}$ \\
\hline \multicolumn{4}{|c|}{ 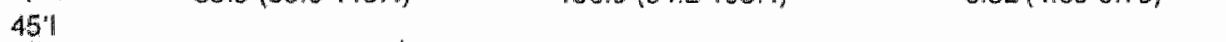 } \\
\hline$G$ & $12.8(6.2-14.5)^{a, b}$ & $95.8(68.1-145.6)^{a}$ & $5.34(3.13-6.35)^{\mathrm{a}}$ \\
\hline L & $36.9(8.3-57.7)^{\mathrm{a} . d}$ & $210.7(85.6 \cdot 242.1)^{\mathrm{a} d \mathrm{~d}}$ & $10.02(6.18-10.79)^{\mathrm{a}, \mathrm{d}}$ \\
\hline $\mathrm{P}$ & $61.4(30.9-77.7)^{a, d i a}$ & $152.4(125 . \| \cdot 190.4)^{a_{0} d, \theta}$ & $8.86(6.10-12.12)^{a, d}$ \\
\hline \multicolumn{4}{|c|}{$15^{1} \mathrm{l} / \mathrm{R}$} \\
\hline$G$ & $83.1(37.0-175.8)^{c}$ & $8.5(4.6-10.9)^{6}$ & $0.00(0.00-0.39)^{c}$ \\
\hline $\mathrm{L}$ & $135.6(97.4 .236 .2)^{d}$ & $22.0(18.3-42.1)^{c d d}$ & $0.03(0.00-0.52)^{0.6}$ \\
\hline $\mathrm{P}$ & $196.2(122.3-240.4)^{\mathrm{cd}}$ & $8.8(4.2-20.2)^{\mathrm{c}, e}$ & $0.00(0.00-10.32)^{c}$ \\
\hline \multicolumn{4}{|c|}{$30 " \mathrm{H} / \mathrm{R}$} \\
\hline $\mathrm{G}$ & $38.1(18.7-99.4)^{\mathrm{a}}$ & $6.7(3.2-34,0)^{c}$ & $0.00 \cdot(0.00-1.64)^{\mathrm{C}}$ \\
\hline$L$ & $50.9(8.9-233.5)^{3}$ & $19.7(7.8-38.8)^{\mathrm{C}}$ & $1.38(0.00-3.11)^{c}$ \\
\hline $\mathrm{P}$ & $1332(95.1-161.3)^{a, c, d}$ & $8.5(3.1-19.6)^{6,0}$ & $0.02(0.00-0.74)^{c, e}$ \\
\hline \multicolumn{4}{|c|}{$45: / 7$} \\
\hline $\mathrm{G}$ & $28.3(9.9-69.2)^{a, c}$ & $9.2(4.7-14.7)^{\mathrm{C}}$ & $0.00(0.00-0.86)^{\mathrm{C}}$ \\
\hline $\mathrm{L}$ & $66.3(11.1-189.3)^{a}, c$ & $82.5(22.0-203.9)^{a, c . d}$ & $7.00(1.00-9.18)^{\mathrm{a}, \mathrm{d}}$ \\
\hline $\mathrm{p}$ & $57.2(23.793 .0)^{a}$ & $23.0(11.4-78.0)^{\mathrm{a}, c, d_{1} \mathrm{e}}$ & $1.04(0.01-3.03)^{\mathrm{a}, \mathrm{c}, \mathrm{de}}$ \\
\hline
\end{tabular}

Data are presented as median values and $95 \%$ confidence lirvits. The tisswe content of glycogen is expressed as $\mu$ mol glucose equivalents per $g$ dry weight: lactate and glycerol-3-P (G3P) as $\mu$ mol per $g$ dry weight. Pre-l reters to preischemic value; $15 \%, 301$ an $45 \%$ to values measured after 15,30 or 45 min of ischemia, respectively. 15\%R. $30 \mathrm{WA}$ and $45 \mathrm{~W} / \mathrm{h}$ to vakes measured at the end of $35 \mathrm{~min}$ of reperfusion preceded by 15,30 and 45 min of ischemia. For abbreviations $G . L$ and P see table 3.2 indicates significantly different from preischemic values;

"indicates significantly different from the preceding ischemic value 130 vs 15 min of ischemia and 45 vs 30 min of ischemia:

"indicates significantly oifferent from its ischemic value:"

indicates significantly different from glucose perfused hearts at corresponding times.

- indicates significantly different from kactate hearts at corresponding times; $(0<0.05)$

when corrected for the lactate amount in extraceltular fluid (corrected value is 13.0 umol per g dry weight).

During ischemia the lactate content increased several fold in the three substrate groups. In glucose hearts lactate accumulation amounted to $87 \mu$ mol per $\mathrm{g}$ dry weight after $15 \mathrm{~min}$ of ischemia and this level was maintained till $45 \mathrm{~min}$ of ischemia. In lactate and pyruvate hearts a similar extent of lactate accumulation was reached after 
$15 \mathrm{~min}$ of ischemia, but formation of lactate continued till $30 \mathrm{~min}$ of ischemia. Thereafter, no substantial increase was found in these groups. Moreover, fotal lactate accumulation during 30 and $45 \mathrm{~min}$ of ischemia was significantly higher in lactate hearts than in glucose hearts. A marked difference between lactate and pyruvate hearts was found after $45 \mathrm{~min}$ of ischemia.

During reperfusion tissue lactate levels dramatically fell, most likely due to release of this substance into the vascular compartment (see fig 3.2). After 15 or $30 \mathrm{~min}$ of ischemia and subsequent reperfusion, the cardiac lactate content was identical to basal values measured after the preischemic phase. Howewer, tissue lactate levels were still increased in lactate and pyruvate hearts exposed to $45 \mathrm{~min}$ of ischemia. In this respect, the median amount of tissue lactate in hearts perfused by exogenous lactate was appreciably higher than in those perfused by pyruvate.

The preischemic value of cardiac glycerol-3-P was slightly higher in lactate hearts than in glucose hearts. Although in pyruvate hearts the median value of glycerol-3-P was as low as in glucose hearts, no significant difference with lactate hearts was observed.

Like lactate, glycerol-3-P markedly increased when hearts were ischemic. The content of glycerol-3-P amounted to $4.6 \mu \mathrm{mol}$ per $\mathrm{g}$ dry weight after $15 \mathrm{~min}$ of ischemia and remained constant thereafter in glucose perfused heants. In lactate hearts the content of glycerol-3-P amounted to $6.2 \mu \mathrm{mol}$ per $\mathrm{g}$ dry weight atter $15 \mathrm{~min}$ of ischemia and to $9.8 \mu \mathrm{mol}$ per $\mathrm{g}$ dry weight after $30 \mathrm{~min}$ of ischemia, but was not further raised (10.0 umol per $\mathrm{g}$ dry weight) after $45 \mathrm{~min}$ of ischemia. Similarly, pyruvate hearts demonstrated a significant increase of glycerol-3-P from 15 to $30 \mathrm{~min}$, but tended to further increase the content of glycerol-3-P till 45 min of ischemia. Ischemic glycerol-3$P$ levels were more elevated in lactate hearts than in glucose hearts after 30 and 45 min of ischemia. Differences between lactate and pyruvate hearts did not reach the level of significance.

Following reperfusion, glycerol-3-P contents were considerably reduced in all hearts exposed to 15 and $30 \mathrm{~min}$ of ischemia. After $45 \mathrm{~min}$ of ischemia and subsequent reperfusion, only glucose hearts restored glycerol-3-P levels to basal values. In contrast, lactate and pyruvate hearts demonstrated significantly increased glycerol-3-P contents at this time point compared to their preischemic values.

\section{NADH and NAD*}

Extracellular lactate supply did not change the total NADH and NAD* content in cardiac tissue under preischemic normoxic conditions (table 3.5).

Atter ischemia, NADH levels were increased and/or NAD* levels were decreased. In lactate perfused hearts ischemic NADH formation quickly reached a maximum level after $15 \mathrm{~min}$ of flow deprivation and this value was maintained during longer intervals of ischemia. NAD* was markedly reduced after 45 min of ischemia. In pyruvate hearts, NADH tended to increase but did not reach the level of significance. NAD" was also significantly decreased after $45 \mathrm{~min}$ of ischemia leading to comparable NADH/NAD* ratios as in lactate hearts. In glucose perfused hearts the extent of NADH accumulation was related to the duration of ischemia. Correspondingly, NAD* decreased as ischemia continued in glucose hearts. After an ischemic interval of 30 and $45 \mathrm{~min}$, the ratio $\mathrm{NADH} / \mathrm{NAD}^{*}$ was significantly higher in glucose hearts than in lactate or pyruwate hearts. 
Table 3.5. The content of NADH, NAD and the ratio NADH/NAD in isolated working rat hearts subjected to 15,30 or 45 min of ischemia, followed by $35 \mathrm{~min}$ af reperfusion, in the absence or presence of lactate or pyruvate.

$\begin{array}{lll}\text { NADH } & \text { NAD } & \text { NADH } \\ & \text { NAD }\end{array}$

\begin{tabular}{|c|c|c|c|}
\hline \multicolumn{4}{|l|}{ Pre-1 } \\
\hline$G$ & $0.41(0.26-0.71)$ & $3.60(2.75-3.90)$ & $0.11(0.08 \div 0.26)$ \\
\hline L. & $0.49(0.37-0.80)$ & $3.13(2.63-3.60)$ & $0.18(0.12 \times 0.28)$ \\
\hline $\mathrm{P}$ & $0.69(0.19-1.12)$ & $3.69(3.09-4.15)^{\circ}$ & $0.17(0.05=0.32)$ \\
\hline \multicolumn{4}{|l|}{151} \\
\hline $\mathrm{G}$ & $1.17(0.74-1.35)^{a}$ & $3.07(2.66-3.48)^{\mathrm{a}}$ & $0.39(0.28-0.41)^{\mathrm{a}}$ \\
\hline $\mathrm{L}$ & $1.03(0.89-1.11)^{\mathrm{a}}$ & $2.99(2.11-4.17)$ & $0.34(0.27=0.50)^{a}$ \\
\hline P & $1.14(0.28-1.46)$ & $3.04(2.99-3.20)^{a}$ & $0.38(0.09-0.47)$ \\
\hline \multicolumn{4}{|l|}{301} \\
\hline$G$ & $1.66(1.14-2.15)^{a, b}$ & $2.34(2.02-2.79)^{a, b}$ & $0.65(0.47-0.94)^{a, b}$ \\
\hline$E$ & $0.88(0.43-1.14)^{a, 0}$ & $2.82(2.65-3.11)^{d}$ & $0.33(0.15 \cdot 0.40)^{\mathrm{a}, \mathrm{d}}$ \\
\hline P & $1.01(0.65-1.63)^{d}$ & $2.95(2.76-3.40)^{d}$ & $0.35(0.24-0.57)^{\mathrm{a}, \mathrm{d}}$ \\
\hline \multicolumn{4}{|l|}{451} \\
\hline$G$ & $2.16(1.59-3.15)^{\mathrm{a}, \mathrm{b}}$ & $1.73(1.47-2.17)^{a . b}$ & ${ }_{1.28}(0.82-1.79)^{a} b$ \\
\hline $\mathrm{L}$ & $1.09(0.52-1.51)^{\mathrm{and}}$ & $2.33(2.11-2.66)^{a, b, d}$ & $0.50(0.20-0.63)^{\mathrm{a} . d}$ \\
\hline $\mathrm{p}$ & $0.79(0.71-1.62)^{d}$ & $2.61(2.08-2.99)^{a}$ & $0.38(0.27-0.71)^{a, d}$ \\
\hline \multicolumn{4}{|c|}{$15^{\prime} / / A$} \\
\hline $\mathrm{G}$ & $0.43(0.20-0.82)^{\mathrm{C}}$ & $3.85(3.44-5.33)^{c}$ & $0.11(0.04-0.23)^{c}$ \\
\hline $\mathrm{L}$ & $0.55(0.36-0.84)^{\mathrm{C}}$ & $4.12(2.85-4.71)^{a}$ & $0.13(0.08 \cdot 0.24)^{c}$ \\
\hline $\mathrm{P}$ & $0.49(0.40-0.70)$ & $3.96(3.38-4.27)^{c}$ & $0.14(0.09-0.18)$ \\
\hline \multicolumn{4}{|c|}{$30 \| / R$} \\
\hline G & $0.37(0.12-1.15)^{\mathrm{C}}$ & $3.24(3.01-4.14)^{c}$ & $0.11(0.04-0.34)^{c}$ \\
\hline $\mathrm{L}$ & $0.37(0.28-0.63)^{c}$ & $3.54(2.78-3.66)^{\mathrm{C}}$ & $0.11(0.08-0.21)^{c}$ \\
\hline$P$ & $0.44(0.34-0.47)^{\mathrm{e}}$ & $3.63(3.04-4.00)^{0}$ & $0.12(0.10-0.12)^{\mathrm{C}}$ \\
\hline \multicolumn{4}{|c|}{$45^{\prime} / \mathrm{A}$} \\
\hline $\mathrm{G}$ & $0.60(0.05-0.77)^{\mathrm{C}}$ & $3.35(2.93-3.74)^{\mathrm{c}}$ & $0.19(0.01 \cdot 0.20)^{\mathrm{c}}$ \\
\hline $\mathrm{L}$ & $0.50(0.20-1.21)^{\mathrm{C}}$ & $2.06(1.93-4.14)^{\mathrm{a} . d}$ & $0.13(0.10=0.54)$ \\
\hline $\mathrm{P}$ & $0.25(0.03-0.74)^{\mathrm{c}}$ & $3.49(2.88-3.82)^{c e}$ & $0.07(0.01-0.21)^{c, 0}$ \\
\hline
\end{tabular}

For abbreviations and legends see lable 3.4.

By reperfusion following 15,30 or 45 min of ischemia, NADH and NAD levels returned towards baseline values in all hearts, except in lactate hearts subjected to 45 min of ischemia. These lactate hearts kept lowered $\mathrm{NAD}^{*}$ values during reperfusion. The ratios $\mathrm{NADH} / \mathrm{NAD}^{*}$ reached basal values as measured under normoxic conditions. 


\subsection{DISCUSSION}

The present study focusses on susceptibility of the reperfused ischemic heart to lactate $(5 \mathrm{mM})$ and evaluates the role of glycogenolysis/glycolysis herein. The working rat heart model, which provides valid parameters to monitor hemodynamic performance was used. Cardiac output turned out to be a more sensitive indicator than left ventricular developed pressure, showing sooner a significant decline after restoration of flow. At this point "the working heart model may be preferable above the Langendorff model as the last model only measures pressure indices.

\section{Hemodynamic function}

Earlier findings in our laboratory demonstrated that extracellular lactate is a suitable substrate for the isolated heart and is not detrimental to cardiac function under normoxic conditions (Chapter 2; De Groot et $\mathrm{al}_{s}$ 1989). However, the present study shows that addition of extracellular lactate to a glucose containing buffer impairs cardiac function of reperfused ischemic hearts. Hearts were exposed to three different time intervals of ischemia, i.e. 15,30 or $45 \mathrm{~min}$, followed by reflow. After a short interval of ischemia ( $15 \mathrm{~min}$ ), no marked effect of exogenous lactate was evident as cardiac output was only slightly decreased. After longer intervals of ischemia impairment by exogenous lactate became manifest. In general "lactate reperfused hearts were not able to eject any more following 30 min of ischemia. After 45 min of ischemia, mechanical activity was entirely absent in 4 of 7 hearts. Total coronary flow was lowered after $45 \mathrm{~min}$ of ischemia indicating overall decrease of perfusion or severe underperfusion of certain areas. Moreover, lactate increased the incidence of rhythm disturbances after 30 min of ischemia. Studies on the hemodynamic effect of extracellular lactate on myocardium are limited. In accordance with our data, Bünger and colleagues (1989) demonstrated a detrimental effect of lactate by increasing lactate supply from 5 to $15 \mathrm{mM}$ in hearts exposed to $45 \mathrm{~min}$ of low flow ischemia. Opie and associates (1979) pointed to increased incidence of arrhythmias by lactate. Pyruvate, the oxidized form of lactate, has been more frequently studied. Both beneficial and adverse effects on cardiac function are reported. Bünger et al (1989) found improved hemodynamic recovery after $45 \mathrm{~min}$ of low flow ischemia when pyruvate was supplied to lactate perfused hearts. Mochizuki and Neely (1980) reported improvement by pyruvate on mechanical function after 30 min of global ischemia. In contrast, Gutterman et al (1986) failed to limit infarct size in dogs after three hours of circumflex coronary acclusion by intracoronary administration of pyruvate. Moreover, Bricknell and Opie (1978) found that pyruvate stimulated the occurrence of arrhythmias during reflow following $30 \mathrm{~min}$ of ischemia. Obviously, our data show improvement of cardiac function by pyruvate after a short ischemic interval (up to 30 min) as well as decline of performance and increased incidence of thythm disturbances after a longer period ( $45 \mathrm{~min}$ ) of ischemia compared to glucose perfused hearts. Thus, under these conditions transition to impaired function in pyruvate hearts takes place between 30 and $45 \mathrm{~min}$ of ischemia. In lactate hearts a detrimental decline occurs sooner, i. $\theta$. between 15 and 30 min of ischemia. Interestingly, severe loss of function was retarded in glucose hearts as after 45 min of ischemia some glucose repertused hearts were still able to eject fluid through the aortic valve. It should be noted that differences in 
response as unction of the preceding duration of ischemia may in part explain the variations in effect of pyruvate published in literature.

\section{Enzyme release}

The release of intracellular enzymes is a commonly applied index of cell damage (Hermens et al, 1982). In accordance with hemodynamic dysfunction, lactate induced greater leakage of $\mathrm{LDH}$ after a $30 \mathrm{~min}$ ischemic interval when compared to glucose and pyruvate hearts. After 15 and $45 \mathrm{~min}$ of ischemia, no such obvious differences between the substrate groups were observed. Total LDH activity in rat hearts is about 355 U per gram wet weight (Snoeckx et al, 1986). This implies that by 30 min of ischemia at least $4.3 \%$ of the cells in laciate hearts have lost their LDH content versus 1.7 and $0.7 \%$ in glucose and pyruvate hearts, respectively.

The pattern of LDH release was found persisting in lactate hearts after 30 min of ischemia and also in glucose and pyruvate hearts after 45 min of ischemia. This might indicate that washout of the enzyme is delayed (ischemic damage; Humphrey et al, 1984 ) or that cells are continuously broken down after reinstallation of flow (reperfusion damage; Mohanlal et al, 1988).

\section{Gilycogenolysis/glycolysis}

In the present study, glycogen content was manipulated by use of three different substrates (glucose, glucose plus lactate, glucose plus pyruvate) in the perfusion medium. During the preischemic phase, glycogen stores were better preserved in lactate and pyruvate perfused hearts than in glucose hearts. Introducing ischemia, glycogen consumption was considerable in all three groups. Degradation of tissue glycogen started with an average rate of about 5 to $6 \mu$ mol glucose equivalents $/ g$ dry weight.min during the first 15 min of ischemia in all three groups (fig 3.3). During the next 30 min of ischemia, glucose and pyruvate hearts continued to use glycogen at a slow rate (less than $1.5 \mu \mathrm{mol}$ glucose equivalents/g dry weight. min). In lactate hearts the decrease of the glycogenolysis rate was more gradual, i.e. $3.1 \mathrm{\mu mol}$ glucose equivalents/g dry weight. min between 15 and $30 \mathrm{~min}$ of ischemia and 0.5 umol glucose equivalents/g dry weight. min between 30 and $45 \mathrm{~min}$ of ischemia. Thus the delivery of glucose moleties for glycolysis during ischemia was less compromised in lactate hearts compared to glucose hearts or pyruvate hearts.

The progress of glycolysis was dissimilar in glucose, lactate and pyruvate hearts as measured by $\mathrm{NADH}$, lactate and glycerol-3-P, parameters related to glycolysis in the oxygen-deprived heart. Cytoplasmic NADH is formed by conversion of glyceraldehyde-3-P and $\mathrm{NAD}^{+}$to 3-phosphoglycerate and NADH. NADH will accumulate when NADH formation is faster than its oxidation. Oxidation of NADH during ischemia (no oxygen is available) may be accomplished by conversion of pyruvate to lactate or dihydroxy-acetone-P to glycerol-3-P. Limited availability of reducable substrates will restrict removal of NADH resulting in inhibition of glyceraldehyde-3-P-dehydrogenase by a feed back mechanism (Rovetto et al, 1975). In this context, glucose hearts showed elevated NADH levels compared to lactate or pyruvate hearts. Obviously, lactate and pyruvate hearts were able to oxidize a significant amount of NADH as lower contents of NADH concomitant with higher tissue contents of lactate and glycerol-3-P were found compared to glucose hearts. In the 


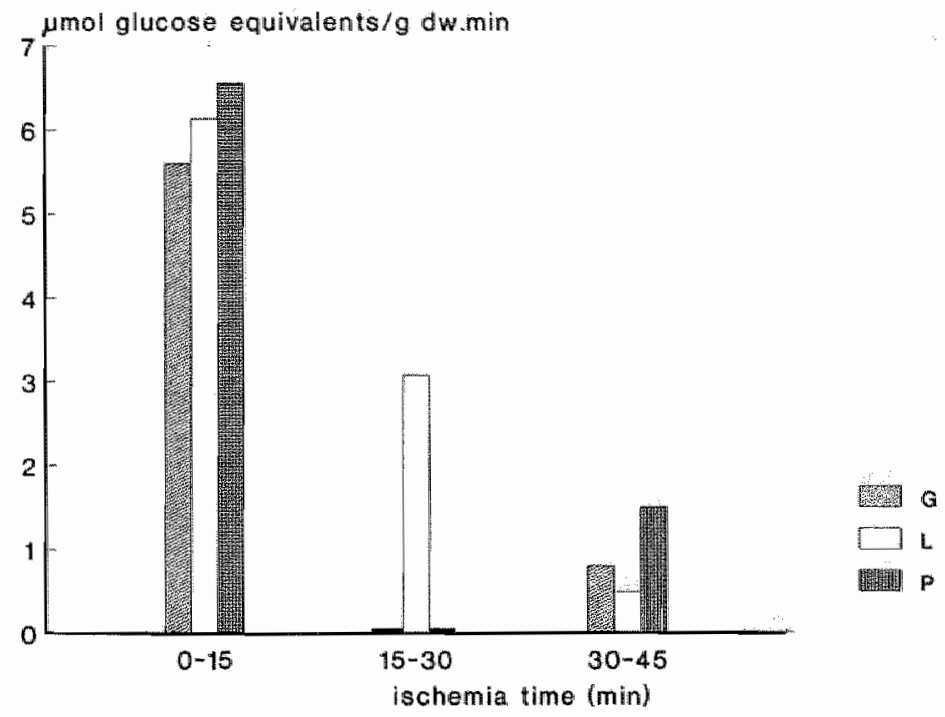

Fig 3.3 Glycogenolysis rate during ischemia in hearts perfused with glucose, glucose plus lactate or glucose plus pyruvate. Data are calculated by median values of the several groups. Glycogenolysis rate is expressed as $\mu \mathrm{mol}$ giucose equivalents/g dry weight.min. $G=$ glucose $(11 \mathrm{mM}), L \approx$ glucose $(11 \mathrm{mM})$ plus lactate $(5 \mathrm{mM}), P=$ glucose $(11 \mathrm{mM})$ plus pyruvate $(5 \mathrm{mM})$

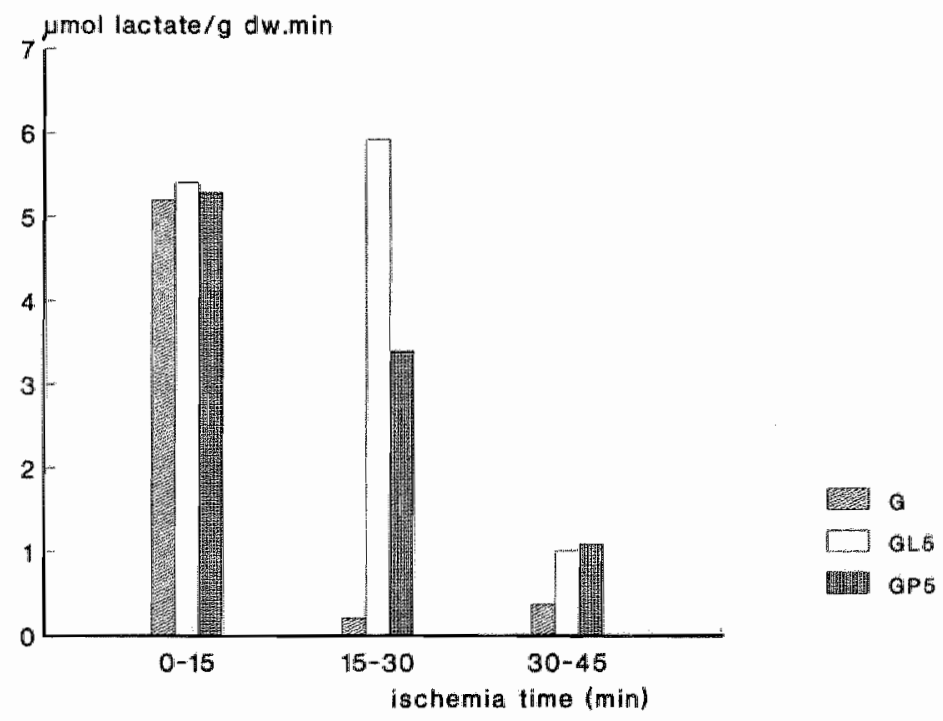

Fig 3.4 Lactate production rate during ischemia in hearts perfused with glucose, glucose plus lactate or glucose plus pyruvate. Data are calculated by median values of the several groups. Lactale production rate is expressed as $\mu$ mol/g dry weight min. $G=$ glucose (11 $\mathrm{mM}$ ), $L=$ glucose $(11 \mathrm{mM}$ ) plus lactate $(5 \mathrm{mM}), P=$ glucose $(11 \mathrm{mM})$ plus pyruvate $(5 \mathrm{mM})$ 
present paper, though, total NADH (i.e. in cytoplasm and mitochondria) was considered and hence. NADH data need to be interpreted with some caution.

The tissue content of lactate was about 20 times the content of glycerol-3-P in lactate and pyruvale hearts, indicating that inhibition at an earlier step in the glycolytic pathway is limited. This is substantiated by the fact that lactate production, which accounts for 40 to $70 \%$ of glycogen utilised, followed a nearly similar pattern as glycogenolysis rate, i.e. considerable rates of formation fabout $5 \mu \mathrm{mol} / \mathrm{g}$ dry weight.min) during the first 15 min of ischemia and low rates at longer intervals of ischemia (30-45 min; 0 to $1 \mu \mathrm{mol} / \mathrm{g}$ dry weight.min; see fig 3.4). However, between 15 and 30 min of ischemia when glycogenolysis rate was halved in lactate hearts and more severely reduced in pyruvate hearts, lactate production was still considerable in lactate $(5.9 \mu \mathrm{mol} / \mathrm{g}$ dry weight.min) and pyruvate $(3.4 \mu \mathrm{mol} / \mathrm{g} \mathrm{dry}$ weight.min) hearts. Intermediate products are likely to be responsible for continuing lactate formation.

\section{The role of glycogenolysis/glycolysis in reperfusion dysfunction}

The mechanism underlying impairment of cardiac function of the postischemic heart is incompletely understood. In the present study the importance of glycogen preservation and accumulation of glycolytic products is chalienged as supported by the following findings: 1. Preischemic glycogen levels were comparable in lactate and pyruvate hearts while recovery after $30 \mathrm{~min}$ of ischemia was diverse. 2 . The preischemic glycogen content was lower in glucose hearts than in lactate or pyruvate hearts while recovery after $45 \mathrm{~min}$ of ischemia was better in glucose hearts. 3 . The end-ischemic (total) NADH content was markedly lower in lactate than in glucose hearts while hemodynamic recovery was worse after 30 and 45 min of ischemia. 4 . The contents of $\mathrm{NADH}$ lactate and glycerol-3-P were not significantly different in lactate and pyruvate hearts at the end of 30 min of ischemia, but functional recovery was markedly better in pyruvate hearts.

These findings are not in agreement with those of Neely and Grotyohann (1984), who demonstrated a detrimental role of glycolytic products (lactate, hydrogen ion, NADH) in ischemic damage. In addition, the results of Lagerstrom and associates (1988) showing that preservation of glycogen stores prior to ischemia is important in sustaining myocardial viability, could not be confirmed. Both Neely and Grotyohann (1984) and Lagerstrom and coworkers (1988) based theif findings on depletion of glycogen pools by hypoxic intervention. In addition, the latter authors reduced glycogen stores by substrate free perfusion. In contrast, the present findings were obtained by use of different substrates, while no hypoxic intervention was performed.

Studies by Mickle et al (1986) and Renstrom et al (1990) demonstrated that ischemic stress disturbs lactate metabolism when flow is reintroduced. Kobayashi and Neely (1983) suggested an important function of the pyruvate dehydrogenase flux during reperfusion, which might be inhibited by high NADH levels. Thus end-ischemic products might affect the metabolism of the heart during reperfusion. However, our findings do not indicate that metabolic processes are disturbed during reperfusion. Firstly, the accumulation of lactate, glycero-3-P and NADH in tissue during 15 and 30 min of ischemia was removed by reperfusion of glucose, lactate and pyruvate hearts. While lactate seems to be released via coronary effluent (see fig 3.2), NADH and glycerol-3-P are likely to be oxidized by mitochondrial activity indicating a still functional oxidative phosphorylation capacity of the mitochondria. Secondly, after initial 
net release of lactate produced during ischemia, the presented data revealed net lactate extraction (calculated from arterial-venous differences and coronary flow) in lactate hearts during reperfusion. As the total amount of lactate uptake by far exceeds the tissue content of lactate at the end of reperfusion, lactate oxidation seems reasonable. Lactate oxidation implies that the pyruvate dehydrogenase flux is operational. Kobayashi and Neely (1983) have suggested that pyruvate accelerates recovery of the pyruvate dehydrogenase flux at the onset of reperfusion. In the present study possible stimulating effects of exogenous pyruvate on the pyruvate dehydrogenase flux result in improved recovery after mild ischemia only (i.e 30 min or less). By longer intervals of ischemia beneficial effects of pyruvate on hemodynamic function completely disappeared.

\section{Alternative factors involved in reperfusion dysfunction}

It is of interest that lactate uptake was considerable while lactate dehydrogenase was leaking from the cell. As lactate dehydrogenase is necessary to convert lactate to pyruvate, lactate will be utilized in other cells than in those that lost their lactate dehydrogenase content. These findings imply heterogeneity in the lactate reperfused hearts. This suggestion is substantiated by the observation that in lactate hearts the endogenous tissue content of lactate was raised after long-term ischemia and subsequent repertusion whereas after a short period of flow cessation the tissue content of lactate decreased during reperfusion. Similarly, glycerol-3-P remained elevated following $45 \mathrm{~min}$ of ischemia. Moreover, the characteristic pattern of persisting LDH release in lactate reperfused hearts subjected to 30 or $45 \mathrm{~min}$ of ischemia may result from local areas of ischemia during reperfusion. Hence it seems reasonable to us to speculate that lactate induces underperfusion in the myocardium. Likely, disturbance of homogenous flow may have contributed to loss of hemodynamic function in the lactate hearts.

In summary, exogenous lactate impairs hemodynamic function of the reperfused ischemic heart. No protective role of high or low glycogen levels can be observed. The overall redox state and the accumulation of lactate or glycerol-3-P in tissue seem to be responsible for this decay neither. Alternatively, we suggest that lactate-induced impairment of flow may play a role in loss of cardiac function during reperfusion.

\subsection{REFERENCES}

1. Apstein CS, Puchner SE, Brachfeld N (1970) Improved automated lactate determination. Anal Biochem 38: 20-34.

2. Bergmeyer HU, Bernt E (1974) UV assay for lactate dehydragenase with pyruvate and NADH. In: Bergmeyer HU (ed) Methods of enzymatic analysis. Weinheim: Verlag Chemie GmbH, Vol 2: 574 579 .

3. Bricknell OL, Opie LH (1978) Effects of substrates on tissue metabolic changes in the isolated rat heart during underpertusion and on release of lactale dehydrogenase and arrhylhmias during repertusion. Circ Ries 43: 102-115

4. Bünger R, Mallet RT, Hartman DA (1989) Pyruvate-enhanced phosphorylation potentiall and inotropism in normoxic and postischemic isolated working hear. Eur $J$ Biachem 180: 221-233

5. Cighetti $C$, Del Puppo $M$, Andreetla $F$, Galli Kienle M (1989) Xanthine oxidase activily: simullaneous 
HPLC evaluation of the " $\mathrm{O}$ " and "O" forms. Biochem Int 18:1211-1220

6. De Groot MUM, Willemsen PHM, Coumans WA, Van Bilsen $M_{n}$ Van der Vusse GJ (1989) Lactate induced stimulation of myocardial triacylglycerol tumover. Biochim Biophys Acta 1006: 111-115

7. Drake AJ, Haines JR, Noble MIM (1980) Preferential uptake of lactate by the normal myocardium in dogs. Cardiovase Res 14:65-72

8. Gutterman DD, Chilian WM, Easthem CL, Tetsu I, White CW, Marcus ML (1986) Failure of pyruvate to salvage myociardium after prolonged ischemia. Am J Physiol 250: $\mathrm{H} 114-\mathrm{H} 120$

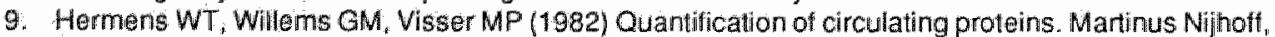
The Hague/Baston /London.

10. Humphrey SM. Thomson AW, Gawin JB (1984) The influence of the no-reflow phenomenon on reperfusion and reoxygenation damage and enzyme release from anoxic and ischaemic isolated rat hearts. J Mol Cell Cardiol 16: $915-930$

11. Kobayashi $K$, Neely JR (1983) Effects of ischemia and reperfusion on pynuate dehydrogenase activily in isolated rat hearts. $\mathrm{J}$ Mol Cell Cardiol $15: 359 \cdot 367$

12. Lagerstrom $\mathrm{CF}$. Walker WE. Taegtmeyer $\mathrm{H}$ (1988) Fallure of glycogen depletion to improve left ventricular function of the rabbit heant after hypothermic ischemic arrest. Circ Res 63: 81-86

13. Laurell $S$, Tibbling $G$ (1966) An enzymatic fluorometric micromethod for the determination of glycerol. Clin Chirn Acta 13: 317.322

14. Liedtke AJ, Nellis SH (1978) Effects of buffered pyruvate on regional cardiac function in moderate, short-term ischemia in swine heart. Circ Res 43: 189-199

15. Mallet RT, Hartman DA, Bünger If (1990) Gilucose requirement for pastischemic recovery of perfused working heart. Eur $\rfloor$ Biochem 188: 481-493

16. Mickle DAG, Del Nido PJ. Wilson GJ, Harding RD, Romaschin $A D$ (198.6) Exogenous substrate preterence of the post- ischaemic myocardium. Cardiowasc Res 20: 256-263

17. Mochizuki S, Neely JR (1980) Energy metabolism during reperfusion following ischemia. J Physiol 76: $805-812$

18. Mohanlal RW, Mauve I, Zoet ACM, Van der Laarse A (1988) Reperfusion induced enzyme release: washout effect or manifestation of reperlusion damage? Cardiovasc Res 22: 603-610

19. Moret PFi (1980) Opening remarks. In: Morel PR, Weber J, Haissly J $\mathrm{Cl}$, Denolin $\mathrm{H}$ (ed) Lactatephysiologic, methodologic and pathologic approach. Springer Verlag Berlin/Heidelberg/New York, pp 195-196

20. Neely JR, Morgan HE (1974) Relalionship between carbohydrate and lipid metabolism and the energy balance of heart muscle. Ann Rev Physiol 36: 413-459

21. Neely JR, Grotyohamn LW (1984) Fole of glycolytic products in damage to ischemic myocardium. Dissociation of adenosine triphosphate levels and recovery of function of reperfused ischemic hearts. Circ Res 55:816-824

22. Opie LH, Nathan D, Lubbe WF (1979) Biochemical aspects of arrhythmogenesis and ventricular filbrillation. Am J Cardiol 43: 131-148

23. Pissonneau J (1974) Fluorometric method for the determination of lactate with $L D H$. In: Bergmeyer HU (ed) Methods of enzymatlc analysis. Weinheim: Verlag Chemie GmbH, Vol 3: 1468-1472

24. Renstrom B, Neilis SH, Lledike AJ (1990) Metabolic oxydation of pyruvate and lactate during early myocardial repertusion. Circ Res 66: 282-288

25. Rovetto MJ, Lamberton WF" Neely JR (1975) Mechanisms of glycolytic inhibition in ischemic rat hearts. Circ Res 37: 742-754

26. Snoeckx LHEH, Van der Vusse G, Coumans WA, Willemsen PHM Van der Nagel T, Reneman RS (1986) Myocardial lunction in normal and spontaneously hypertensive rals during reperfusion after a period of global ischemia. Cardiovasc Res 20:67-75

27. Van Bilsen $M$, Van der Vusse Gi, Snoeckx LHEH, Arts $T$, Coumans WA, Willemsen PHM, Peneman RS (1988) Ellects of pyruvate on postischemic myocardial recovery at various workloads. Pllogers Archiv-Eur J Physiol 413: 167-173

28. Van Bilsen M, Snoeckx LHEH, Arts T, Van der Vusse GJ, Rememan RS (1991) Performance of the isolated, ejecting heart: effects of aortic impedance and exogenous substrates. Pflügers Archiv-Eur $J$ Physiol 419:7-12

29. Van der Vusse GJ, Coumans WA, Van der Veen FH, Drake A, Flameng W, Suy R (1984) ATP, creatine phosphate, and glycogen content in human myocardial biopsies: markers for the efficacy of cardioprotechion during aorta-coronary bypass surgery. Vasc Surg 18: 127-134 
30. Wasserman $K(1986)$ Anaerobiosis "lactate; and gas exchange during exercise: the issues. Fed Proc 45: 2904-2909

31. Wijnants J, Van Belle $H$ (1985) Single-run high performance liquid chromatography of nucleotides, nucleosides and major purine bases and its application to different issue extracts. Anal Biochem 144: $258-266$ 

CHAPTER 4

LACTATE-INDUCED CHANGES IN THE LIPID CONTENT OF THE ISCHEMIC AND REPERFUSED MYOCARDIUM

\#The results of this chapter are in preparation for publication by De Groot MJM, Coumans WA, Willemsen PHM, Van der Vusse GJ 


\begin{abstract}
The effect of exogenous lactate on endogenous lipid levels in the normoxic, ischemic and reperfused myocardium was examined. Isolated working rat hearts were exposed to various grades of ischemic insult $(15,30$ or $45 \mathrm{~min})$. Glucose $(11 \mathrm{mM})$ was present as basal substrate in the pertusion medium while lactate $(5 \mathrm{mM})$ or pyruvate $(5 \mathrm{mM})$ was added as cosubstrate. Lipid metabolism was evaluated by fatty acid accumulation, phospholipid content and triacylglycerol turnover. Lactate significantly increased fatty acid content above preischemic levels after 45 min of ischemia. In glucose hearts, fatty acid accumulation was more pronouriced than in lactate hearts, whereas in pyruvate hearts accumulation of fatty acids was less compared to lactate hearts. By reperfusion, tatty acid levels returned to control values in glucose hearts. In lactate and pyruvate hearts, fatty acid accumulation was further enhanced after reinstallation of flow. Changes in fatty acid content during reperfusion were associated with impairment of function. Accumulation of arachidonic acid revealed disturbances in phospholipid turnover. The total phospholipid and triacylglycerol content did not change during ischemila and reperfusion. Postischemic release of glycerol was appreciably augmented in lactate hearts after $30 \mathrm{~min}$ of ischemia, suggesting that triacylglycerol turnover is greatly enhanced under these conditions. Following $45 \mathrm{~min}$ of ischemia, all groups of hearts showed release of glyceral.

These findings imply that lactate-induced ischemia/reperfusion damage is associated with changes in lipid homeostasis, although a causal relationship remains to be established.
\end{abstract}




\subsection{INTRODUCTION}

Myocardial ischemia and reperfusion are associated with specific pathological changes which may lead to decline in function and acceleration of cell death. Disturbances of lipid metabolism have been recognized as an important contributor to myocardial damage (Katz and Messineo, 1981; Corr et al, 1984; Van Bilsen et al, 1989). Accumulation of fatty acids has been detected in flow-deprived tissue by several studies (Van der Vusse et al, 1982, Prinzen et al, 1984; Chien et al, 1984: Otani et al, 1989). Additional fatty acid accumulation has been found in reperfused hearts (Van Bilsen et al, 1989, Otani et al, 1989). High levels of fatty acids and acyl derivatives may exert detrimental effects on cardiac function (Katz and Messineo, 1981; Katz and Messineo, 1982; Liedtke and Shrago, 1990). Moreover, the relatively high increase of arachidonic acid, a fatty acid almost exclusively incorporated in the phospholipid pool, indicates that membrane phospholipids are degraded and thus that the integrity of the cell might be compromised (Weglicki et al, 1973; Chien et al, 1984; Van der Vusse et al, 1989; Miyazakil et al, 1990). Recently, Prasad and coworkers (1991) have strengthened the important role of hydrolysis of phospholipids in membrane damage.

In addition, release of glycerol from ischemic tissue (Vik-mo et al, 1979; Van Bilsen et al, 1989) might imply hydrolysis of the triacylglycerol pool. So far, glycerol release has been generally accepted as a valid index of hydrolysis of triacylglycerols since other sources of glycerol are reported to be of minor importance (i.e. glycerol-3-P, phospholipids; see discussion). Trach and colleagues (1986) referred to 'futile cycling' of triacylglycerols. Reesterification of fatty acids into the triacylglycerol pool with glycerol-3-phosphate produced by glycolysis may stimulate the turnover process. This process gives rise to enhanced ATP consumption, and may further aggravate ischemic or reperfusion damage (see fig 4.1 ).

The extent of cardiac injury and the recovery of hemodynamic function after ischemia have been shown to be influenced by substrates exogenously present. In this context, pyruvate in addition to glucose was found to improve cardiac recovery after mild ischemia (Mochizuki and Neely, 1980; Van Bilsen et al, 1988; Bünger et al, 1989). We have recently demonstrated that exogenous lactate $(5 \mathrm{mM})$ impairs cardiac function after ischemia (Chapter 3; De Groot and Van der Vusse, 1990). Bünger and his coworkers (1989) also reported functional impairment by lactate (15 mM). Attention has been focused on involvement of lactate in the glycolytic process. (Rovetto et all, 1975; Neely and Feuvray, 1981; Neely and Grotyohann, 1984). However, little information is available as to whether lactate alters lipid homeostasis in ischemic and reperfused hearts. As lactate reduces oxidation of fatty acids under normoxic conditions (Rose and Goresky, 1977; Drake el al "1980; Bielefeld et al. 1985), it may interfere with removal of fatty acids during reperfusion. Hence, raised fatty acid levels will be maintained which might further increase the insult inflicted upon the ischemic and reperfused heart.

It was the aim of the present study to investigate the effect of lactate on changes in the cardiac lipid pool under ischemic and reperfused conditions and to delineate the relationship between fatty acid accumulation and hemodynamic recovery during reperfusion. To this end isolated working rat hearts were exposed to various intervals of no-flow ischemia $(15,30$ or $45 \mathrm{~min})$ with or without reperfusion. In all experiments, glucose $(11 \mathrm{mM})$ was present as basal substrate. Either lactate $(5 \mathrm{mM})$ or pyruwate 


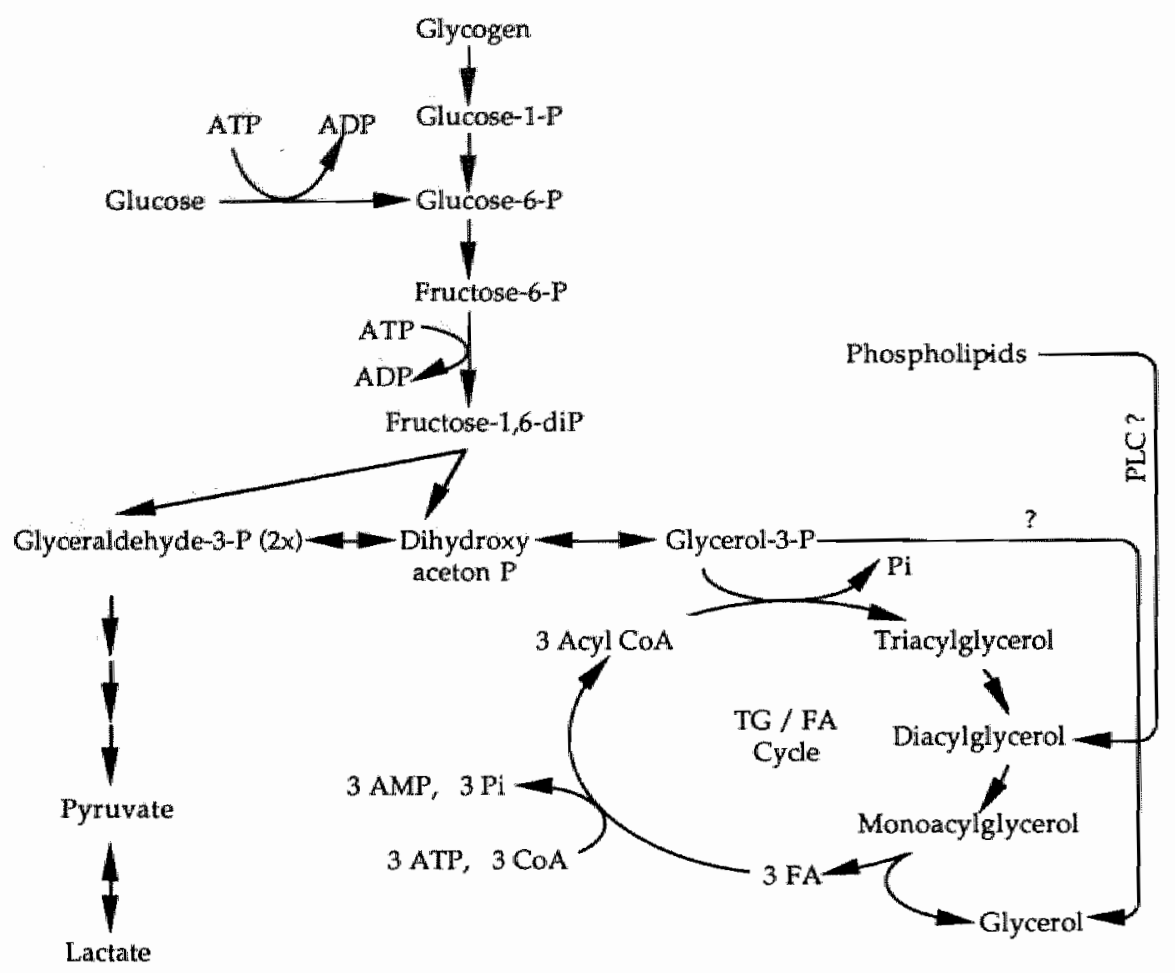

Fig 4.1 Retationship between glycolysis and triacylgycerol turnover. TG, triacylgycerol; $F A_{\text {s }}$ fatty acids; COA, coenzyme A; PLC, phospholipase $C$

(5 mM) was added as cosubstrate. Hearts perfused with gllucose as sole substrate were taken as controls. Total fatty acid accumulation in cardiac tissue was determined at the end of the preischemic, ischemic (15,30 or 45 min) and reperfusion phase (35 min). Changes in cardiac phospholipid homeostasis were assessed by the total content of phospholipids and the liberation of arachidonic acid. Triacylglycerol homeostasis was assessed by the cardiac content of triacylglycerols, glycerol-3phosphate and glycerol as well as the release of glycerol in coronary effluents. Hemodynamic function was monitored by the recovery of stroke volume. 


\subsection{METHODS}

\section{Animals}

Hearts were obtained from male Lewis rats ( 10 weeks old, body weight ranging from 250-350 g). The animals were fed ad libitum (Diet SRM-A, Hope Farms), had free access to water and were kept under an artificial light cycle of 12 hours.

\section{Experimental set up}

Under light ether anaesthesia, hearts were rapidly excised and immediately immersed in an ice-chilled perfusion medium (see below). Lung and fat tissue were removed. Subsequently hearts were ligated to the aortic cannula of the perfusion system and retrograde perfusion was started at a perfusion pressure of $8 \mathrm{kPa}$. A second cannula was connected to the left atrium to allow antegrade perfusion of the hearts. The perfusion system thas been described previously (Snoeckx et al, 1986; Van Bilsen et al, 1991). The composition of the perfusion medium was as follows (in mmol/l): $\mathrm{NaCl}(130.0), \mathrm{KCl}(5.6), \mathrm{CaCl}_{2}(2.2), \mathrm{MgCl}_{2}$ (1.2), $\mathrm{NaH}_{2} \mathrm{PO}_{4}$ (1.2), $\mathrm{NaHCO}_{3}$ $(25.0)$. $\mathrm{D}(+)$ Glucose $(11 \mathrm{mM})$ was added as substrate. Where indicated $L(+)$ lactate $(5.0 \mathrm{mM})$ or pyruvate $(5.0 \mathrm{mM}$, sodium salt) was added as cosubstrate. The $\mathrm{pH}$ of the lactate buffer was adjusted by $\mathrm{NaOH}$. The buffer was continuously gassed with a mixture of $95 \% \mathrm{O}_{2} / 5 \% \mathrm{CO}_{2}\left(\mathrm{pO}_{2}>75 \mathrm{kPa}\right)$ and filtered (Millipore filter; $1.2 \mu \mathrm{m}$ pore size) during perfusion. The final $\mathrm{pH}$ range varied from 7.35 to 7.45 . Temperature was kept at $37^{\circ} \mathrm{C}$ throughout the experiment.

\section{Protocol}

After a stabilization period of $10 \mathrm{~min}$ in retrograde mode, hearts were subjected to antegrade perfusion for $30 \mathrm{~min}$. Left atrial filling pressure was $1 \mathrm{kPa}$ and diastolic aortic pressure was $8 \mathrm{kPa}$. Then, hearts were subjected to 15,30 or $45 \mathrm{~min}$ of normothermic no-flow ischemia and subsequently reperfused during $35 \mathrm{~min}$ (retrogradely during the first 5 min and antegradely, thereafter). Since hearts were perfused in the assisted mode (Van Bilsen et al, 1991) coronary perfusion pressure $(8 \mathrm{kPa})$ was maintained even when reperfused hearts were unable to provide their own coronary flow. Aortic pressure was continuously monitored at the entrance of the aortic cannula, with a catheter connected to an external pressure transducer (CTC). Mean aortic flow was measured with an electromagnetic flow probe (Skalar) connected to a "sine wave" electromagnetic flowmeter (Transfllow 601). Coronary flow was measured by timed collection of the coronary perfusate, dripping from the heart. Cardiac output was calculated by adding aortic flow and coronary flow. Platinum electrodes were attached to the surface of right atrium and ventricle to record the electrogram. Heart rate was calculated by using the electrogram registrations. Stroke volume was defined as cardiac output divided by heart rate.

\section{Collection of tissue and effluent samples}

At the end of the preischemic, ischemic $(15,30$ or $45 \mathrm{~min})$ or reperfusion phase, ventricular tissue was rapidly dissected from atrial tissue with a surgical blade and 
immediately treeze clamped with the use of aluminum tongues, cooled in liquid nitrogen. Coronary effluents were sampled during preischemic perfusion and during reperfusion. Samples were stored at $-80^{\circ} \mathrm{C}$ until analysis.

\section{Blochemical analysis}

\section{Tissue}

Fatty acids, triacylglycerols and phospholipids: Part of the frozen tissue was powdered at the temperature of liquid nitrogen and subsequently extracted with chloroform/methanol (2:1, by vol; Van der Vusse et al, 1982; Roemen and Van der Vusse, 1985). Neutral and polar lipids were separated by silicagel column chromatography (Roemen and Van der Vusse, 1985). The neutral lipid fraction was further separated using thin-layer chromatography. The lipid spots, corresponding to fatty acids and triacylglycerols, were scraped from the plates. After elution from the silica-gel powder and methylation, the fatty acid methyl esters were quantified by gas chromatography (Van der Vusse et al, 1982; Roemen and Van der Vusse, 1985).

Glycerol-3-phosphate and glycerol: Analyses of glyceral-3-phosphate (glycerol-3P) and glycerol were performed in small parts of the frozen ventricles freeze dried at $-30^{\circ} \mathrm{C}$. The compounds were extracted by use of a mixture of perchloric acid $(3 \mathrm{M})$ and dithiothreitol (5 mM) as described previously (Snoeckx et al, 1986). Glycerol-3-P and glycerol were determined fluorometrically according to Laurell and Tibbling (1966).

\section{Coronary effluent}

Glycerol was determined fluorometrically in deproteinized (perchloric acid) and neutralized ( $\mathrm{KHCO}_{3}$ ) effluent samples according to the method of Laurell and Tibbling (1966).

\section{Normalization of data}

Measurements in tissue samples are expressed in moles per gram dry weight. The dry weight of cardiac tissue was determined by freeze drying overnight. Data concerning release of glycerol in the coronary effluent are converted to moles per gram dry weight. Therefore it is accepted that release per heart corresponds to release per gram wet weight, as earlier findings demonstrated that hearts of rats of this age weigh approx. $1 \mathrm{~g}(0.97 \pm 0.07$; mean $\pm \mathrm{sd})$. For conversion of wel weight to dry weight an average factor 6.25 is used as empirically determined.

\section{Statistical analysis}

Data are presented as median values and $95 \%$ confidence limits throughout. The number of experiments per group varied from 6 to 8 . Differences within groups were evaluated for significance using Wilcoxon's matched-pairs signed ranks test. Differences between groups were tested by Mann Whitney $U$ test. $P$ values less than 0.05 were considered to be statistically significant. 


\subsection{RESULTS}

\section{Hemodynamic recovery}

Hemodynamic recovery after various intervals of ischemia was dependent on substrates available in the perfusion buffer (fig 4.2). Lactate or pyruvate addition did not influence recovery of stroke volume after a short interval of ischemia $(15 \mathrm{~min})$. However, the effects of lactate and pyruvate became manifest after mild to severe ischemia (30 and $45 \mathrm{~min}$ ). When lactate was present in the perfusion medium, recovery of stroke volume was impaired after $30 \mathrm{~min}$ of ischemia. In contrast, by pyruvate addition cardiac function of postischemic hearts was slightly improved compared to glucose as sole substrate. After $45 \mathrm{~min}$ of ischemia, both lactate and pyruvate were detrimental for hemodynamic performance during reperfusion. Only in glucose repenfused hearts stroke volume returned to $19 \%$ of its preischemic value (i.e. median recovery when each heart serves as its own control).

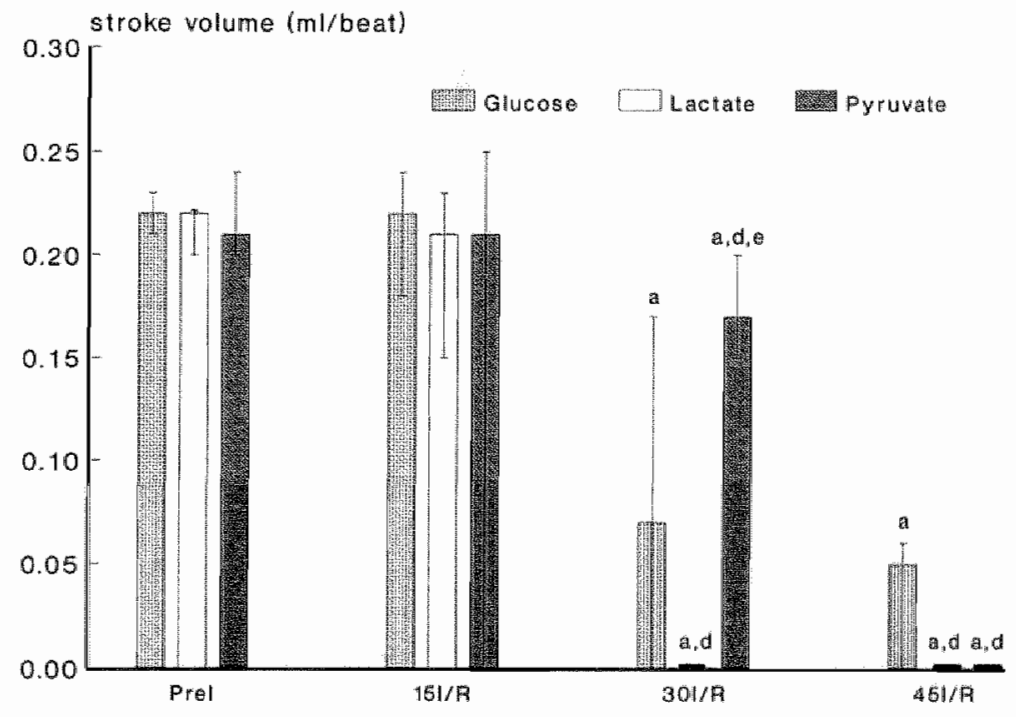

Fig 4.2 The recovery of stroke wolume during repurfusion following 15,30 or 45 min of ischemia, in absence or presence of either lactate or pyruvate. Dala represent median values and $95 \%$ confidence limits. Stroke volume is expressed as milbeat. The number of experiments per group varies from 6 to 8. Pre-l refers to preischemic value; $15 \mathrm{~W} / \mathrm{R}, 30^{\prime} / \mathrm{h}$ and $45^{\prime} / / 9$ refer to wallues measured at the end of repertusion preceded by 15,30 and $45 \mathrm{~min}$ of ischemia, respectively.

andicates significantly different from preischemic value;

oindicates significiantly different from corresponding glucose hearts:

- indicates significantly different from corresponding lactale hearts; $(p<0.05)$. 
Tisue Hatry acid content nothellat dor weigh
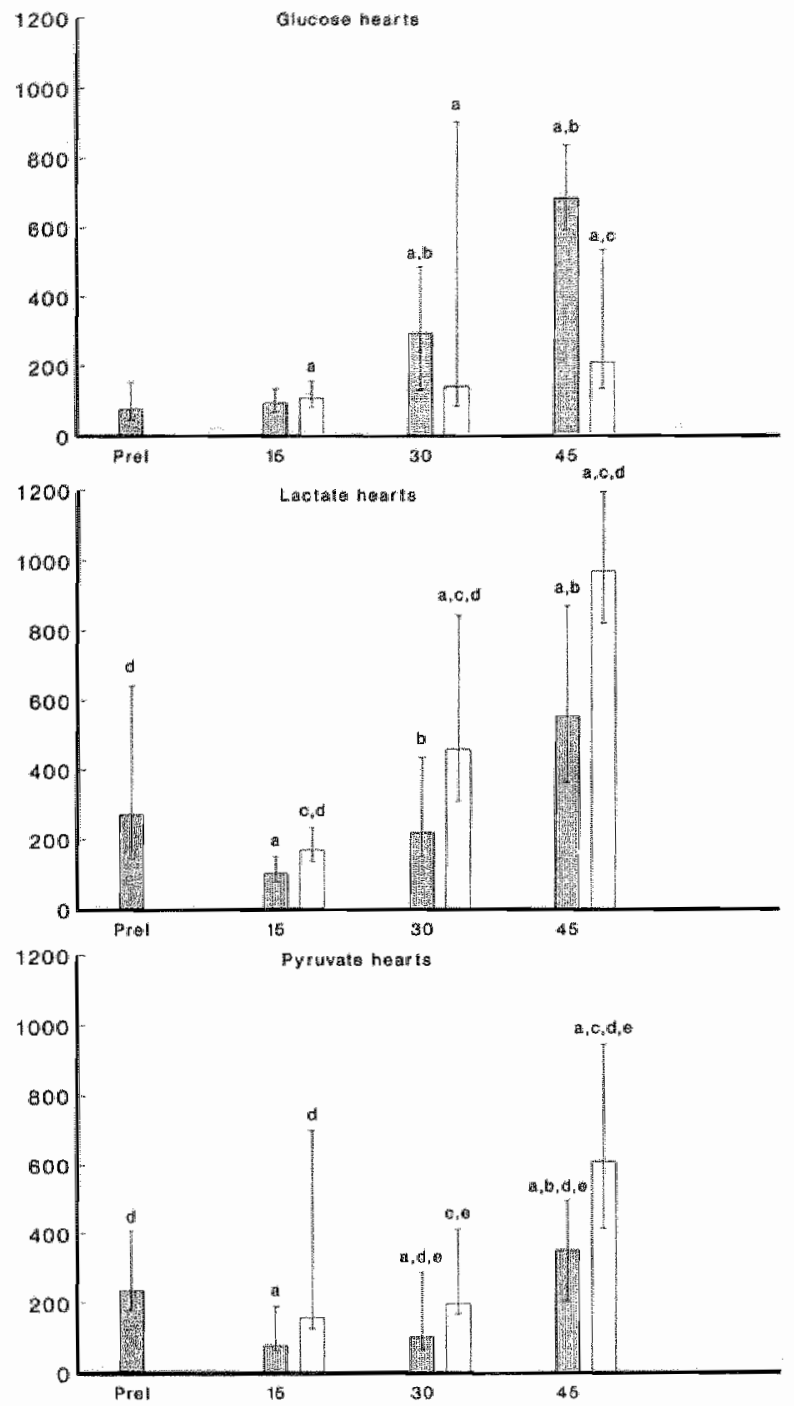

time $(\min )$

Fig 4.3 The content of fatly acids in myocardial tissue of givcose $(11 \mathrm{~mm}$. glucose $(11 \mathrm{~mm})$ plus lactate $(5 \mathrm{mM})$ and glucose $(11 \mathrm{mM})$ plus pyruwate $(5 \mathrm{mM})$ perfused hearts betore ischemia (Pre-l), after 15 , 30 or 45 min of ischemia ( 1 ) or after subsequent reperfusion (F). Data represent median values and $95 \%$ confidence timits. The amount of latty acids is expressed as nmolg dry weight. WWe Pre-l;

[in] $1 ; \square R$;

andicates significantly different from preischemic value;

b indicates significantly different from preceding ischemic interval:

c indicates a significant difference between ischemic and repertusion value:

' indicates significantly different from corresponding glucose hearts:

- indicates significantly different from corresponding lactate hearts; $(0<0.05)$. 


\section{Fatty acids}

The preischemic fatty acid content was significantly higher in lactate and pyruvate hearts than in glucose hearts (fig 4.3). During early ischemia, these contents were reduced to about $35 \%$ of the preischemic level. In contrast, the content of fatty acids in glucose perfused hearts remained unchanged. When the duration of ischemia was extended to $30 \mathrm{~min}$, fatty acids started to accumulate in hearts of the lactate and glucose group. In pyruvate hearts fatty acid levels were maintained at the $15 \mathrm{~min}$ ischemia level. After 45 min of ischemia, fatty acid levels were also increased in the pyruvate group. At this time point, the fatty acid content tended to be lower in lactate hearts than in glucose hearts $(0.05<p<0.10)$ after $45 \mathrm{~min}$ of ischemia, whereas fatty acid levels in pyruvate hearts were appreciably lower than in glucose or lactate hearts $(p<0.05)$.

During reperfusion, fatty acids produced by ischemia were partly consumed in glucose hearts. In contrast. lactate and pyruvate hearts showed additional fatty acid accumulation by reperfusion. In lactate reperfused hearts fatty acid levels were significantly increased above preischemic values when previous ischemia time was 30 or $45 \mathrm{~min}$. Pyruvate reperfused hearts reached values above the preischemic content when previous ischemia time was $45 \mathrm{~min}$. At the end of reperfusion, fatty acid values were markedly higher in lactate and pyruvate hearts than in glucose hearts. Lactate hearts showed significantly higher values than pyruvate hearts when previous ischemia time was 30 or $45 \mathrm{~min}$.

\section{Phosphollipids}

The total content of phospholipids in glucose, lactate and pyruvate perfused hearts did not change during ischemia and reperfusion (table 4.1). However, changes in the content of arachidonic acid, a fatty acid predominantly incorporated in the phospholipid pool, followed a pattern qualitatively comparable to alterations in the total amount of fatty acids (table 4.1 and fig 4.3). In glucose perfused hearts, arachidonic acid significantly accumulated after $30 \mathrm{~min}$ of ischemia and reached levels 35 times the preischemic content after 45 min of flow cessation. In contrast, arachidonic acid levels initially decreased at $15 \mathrm{~min}$ of ischemia in lactate and pyruvate hearts. Prolongation of ischemia to $30 \mathrm{~min}$ resulted in significant increase of the arachidonic acid content in lactate hearts and further raise at 45 min of ischemia. In pyruvate hearts, ischemia-induced accumulation of arachidonic acid was somewhat retarded. Onlly after $45 \mathrm{~min}$ of ischemia the arachidonic acid content reached a significant elevation above preischemic values in lactate and pyruvate hearts.

Reperfusion dramatically reduced tissue arachidonic acid levels in glucose perfused hearts when the preceding ischemic time lasted 30 and 45 min. On the other hand, reperfusion enhanced tissue arachidonic acid content under all circumstances in lactate and pyruvate perfused hearts (table 4.1).

\section{Triacylglycerol, glycerol and glycerol-3-P}

Preischemic triacylglycerol values were lower in glucose hearts than in lactate $(0.05<p<0.10)$ or pyruvate hearts $(p<0.05$, table 4.1$)$.

During ischemia no pronounced changes were found in the total triacylglycerol content of lactate and pyruvate hearts. In general, the same also held true for glucose hearts 
Table 4. The content of arachidonic acid phospholipids and triacylghyerols in tissue of ghcose, lactate and pyruvate hearts tefore ischemia, after 15,30 or 45 min of ischemia or after subsequent 35 min of repertusion.

Arachidonic acid

Phospholipids

$254.4(228.7-275.5)$

$250.1(234.7-271.0)$

$243.2(226.1-295.0)$

$263.4(243.6-292.1)$

$13.1(0.0-15.3)$

$10.2(0.0 .12 .0)^{2}$

$7.9(0.0-15.4)^{2}$

301

G $\quad 35.7(12.0-51.0)^{\mathrm{a}_{b} \mathrm{~b}}$

$22.8(17.5 .50 .8)^{b}$

$9.7(6.3-16.6)^{a}, d_{0}$

$45^{\prime \prime}$

$\begin{array}{lr}G & 100.3(47.3-145.4)^{\mathrm{ab} b} \\ L & 81.6(32.0-103.4)^{\mathrm{ab}} \mathrm{b} \\ \mathrm{P} & 53.0(22.1 .82 .0)^{\mathrm{a}, \mathrm{b}, \mathrm{d}}\end{array}$

$151 / R$

$\begin{array}{ll}G & 10.4(8.8-15.8)^{\mathrm{a}} \\ \mathrm{L} & 21.1(6.9-27.4)^{\mathrm{c}} \\ \mathrm{P} & 17.2(11.3 \mathrm{mb} .3)^{\mathrm{a}, \mathrm{c}, \mathrm{d}}\end{array}$

$30^{\prime} \mid / \mathrm{R}$

$\begin{array}{lc}G & 7.4(1.8-140.6) \\ L & 53.0(20.5 \cdot 115.3)^{c, d} \\ P & 26.3(9.1-66.3)^{c} \\ 45 \text { "l/R } & \\ \text { G } & 29.7(14.3-69.7)^{a, c} \\ L & 118.2(105.9-147.7)^{a, c, d} \\ P & 96.9(44.8-100.8)^{a, c, d, \theta}\end{array}$

$264.9(206.2-282.8)$

$263.3(256.8-285.1)$

$237.0(187.0-268.4)$

$228.2(223.3-251.5)$

$231.9(228.3-237.0)$

$251.1(233.9-272.4)$

$245.8(199.0-277.4)$

$233.8(214.0-298.0)$

$252.2(242.9-278.2)$

$258.9(244.1 .288 .1)$

$268.0(243.3-276.9)$

$269.9(236.6-287.8)$

$244.4(210.8-279.1)$

$241.7(235.9-285.0)$

$237.4(231.0-264.2)$

$260.6(238.0-290.1)$

$246.3(211.4-266.0)$
Triacylglycerols

$11.1(5.7-20.5)$

$18.7(12.6-26.4)$

$20.6(13.6-34.2)^{d}$

$7.3(6.6-16.4)$

$25.6(16.1-28.9)^{d}$

$27.8(17.4-41.2)^{d}$

$42.0(5.7-54.8)^{\mathrm{a} .6}$

$16.3(12.2-24.7)^{\mathrm{d}}$

$22.5(16.8-24.3)$

$9.1(4.7-11.7)^{b}$

$17.8(1.4 .0-28.8)^{\mathrm{d}}$

$23.4(18.1-28.1)^{\mathrm{d}}$

$15.0(3.9-24.3)$

$20.8(16.3-22.2)$

$23.2(17.4-30.4)$

$9.0(6.9-29.1)^{\mathrm{C}}$

$17.7(15.1-24.1)$

$22.2(18.6-29.8)^{d, s}$

$11.6(4.8-27.3)$

$20.3(16.9-30.0)^{d}$

$24.3(20.6-29.4)^{\mathrm{d}}$

Data represent median values and $95 \%$ contidence limits. The amounis of arachidonic acid, phospholipids and triacylgiycerois are expressed as mmolig dry weight, $\mu$ mol fatty acid equivalentsig dry weight and umol tatty acid equivalents'g dry weight, respectively. Pre-t refers to preischemic value: $15 \%, 30 \%$ and $45 \%$ reter to values measured at the end of 15,30 and 45 min of ischemia, respectively; $15 \mathrm{~W}, 30 \% / \mathrm{a}$ and $45 \mathrm{~W} / \mathrm{h}$ reter to values measured at the end of reperfusion preceded by 15, 30 and $45 \mathrm{~min}$ of ischemia, respectively. $G, L$ and $P$ refor to glucose $(11 \mathrm{mM})$, glucose (11 $\mathrm{mM}$ ) plus lactate (5 $\mathrm{mM}$ ) and glucose (11 $\mathrm{mM}$ ) plus pyruvate $(5 \mathrm{mM})$ perfused hearts, respectively.

*indicates significantly different from the preischemic value:

bindicates significantly different from the preceding ischemic interval;

cindicates a significant difference between ischemic and reperfusian value;

"indicates significantly different from glucose hearts;

indicates significantly different from lactate hearts; $0<0.05$.

except in those hearts exposed to $30 \mathrm{~min}$ of ischemia. The reason for the marked increase in tissue triacylglycerols after $30 \mathrm{~min}$ of ischemia is unknown. Probably, some outlliers in this group have caused this unexpected finding as illustrated by wide $95 \%$ confidence limits in this subgroup of hearts. 
Table 4.2 The amount of arachidonic acyl moieties in triacylolycerols of glvcose, lactate and pyruvate hearts before ischemia, after 15, 30 or 45 min of ischemia or after subsequent 35 min of repertusion.

$\mathrm{G}$

$\begin{array}{ll}\text { Pre.l } & 0.25(0.13-0.42) \\ 15^{\prime \prime} & 0.25(0.20-0.38) \\ 30^{\prime \prime} & 0.53(0.22-0.65)^{a} \\ 45^{\prime} 1 & 0.30(0.28-0.39)^{a} \\ 15^{\prime \prime} / / R & 0.26(0.18-0.52) \\ 30^{\prime \prime} / / R & 0.25(0.19-0.52)^{\circ} \\ 45^{\prime \prime} / / \mathrm{R} & 0.36(0.21-0.48)\end{array}$

L

$0.53(0.44-0.62)^{d}$

$0.62(0.49 \cdot 0.78)^{\circ}$

$0.63(0.56 \cdot 0.76)^{\mathrm{a}} \mathrm{d}$

$0.61(0.48-0.79)^{\mathrm{d}}$

$0.55(0.51-0.68)^{d}$

$0.62(0.55-0.95)^{a, d}$

$0.77(0.61-0.87)^{a, 0.01}$
$P$

$0.46(0.32-0.60)^{d}$

$0.72(0.49-1.00)^{a, d}$

$0.64(0.57-0.78)^{a . d}$

$0.86(0.64-1.03)^{a, b, d, e}$

$0.59(0.54-0.68)^{\mathrm{a}_{\mathrm{d}} \mathrm{d}}$

$0.70(0.61-0.81)^{\mathrm{a} . d}$

$0.88(0.73 \cdot 1.04)^{a_{1} d}$

Data represent median walues and $95 \%$ confidence limits. The amount of arachidonic acid is expressed as $\mu$ molkg dry weight. For abbreviations and legends see table 4.7 .

Upon reperfusion tissue triacylglycerol levels remained at their end-ischemic values in all groups of hearts studied, except for the glucose group reperfused after $30 \mathrm{~min}$ of ischemia. The high end-ischemic levels returned to preischemic values (table 4.1).

An appreciable change in the fatty acyl composition of triacylglycerols was found for the arachidonic acid moiety (table 4.2). In pyruvate hearts the content of arachidonic acyl chains increased during early ischemia. The increase was about 0.3 $\mu \mathrm{mol} / \mathrm{g}$ dry weight. During $45 \mathrm{~min}$ of ischemia, arachidonic acid incorporation amounted up to $0.4 \mu \mathrm{mol} / \mathrm{g}$ dry weight. In lactate hearts there was also a slight increase during ischemia (about $0.1 \mu \mathrm{mol} / \mathrm{g}$ dry weight), reaching a significant level after $30 \mathrm{~min}$ of ischemia. In glucose hearts, the content of arachidonic acyl chains increased only $0.05 \mu \mathrm{mol} / \mathrm{g}$ dry weight after $45 \mathrm{~min}$ of ischemia (excluding the $30 \mathrm{~min}$ ischemic group). By reperfusion, the arachidonic acid content of triacylglycerols continued to raise in lactate hearts subjected to $45 \mathrm{~min}$ of ischemia $(0.24 \mu \mathrm{mol} / \mathrm{g}$ dry weight above preischemic value). In glucose and pyruvate hearts the amount of arachidonic acid incorporation in triacylglycerols did not further increase.

The cardiac content of glycerol-3-P was found markedly elevated during ischemia in all hearts (table 4.3). In glucose perfused hearts glycerol-3-P levels increased to 4.6 $\mu \mathrm{mol} / \mathrm{g}$ dry weight during the first $15 \mathrm{~min}$ of ischemia and no further significant change was observed thereafter. In lactate hearts glycerol-3-P reached a comparable level after 15 min of ischemia as observed in glucose perfused hearts, but the increase continued till 30 min of ischemia. At this time point the glycerol-3-P amount was significantly higher in lactate hearts than in glucose hearts. Continuing the ischemic phase till $45 \mathrm{~min}$, glycerol-3-P levels were maintained at about $10 \mu \mathrm{mol} / \mathrm{g}$ dry weight. 
Table 43 The convent of glycerof-3.P and glycerol in tissue of glucose, lactate and pyruvate hearts before ischemia, after 15,30 or 45 min of ischemia or affer subsequent 35 min of repertusion.

\begin{tabular}{|c|c|c|}
\hline & Glycerol-3-P & Glycerol \\
\hline \multicolumn{3}{|c|}{ Pre-1 } \\
\hline G & $0.00(0.00-0.47)$ & $1.21(0.00-1.43)$ \\
\hline L & $0.41(0.00=0.97)^{\mathrm{d}}$ & $0.22(0.00-0.92)^{\mathrm{d}}$ \\
\hline $\mathrm{P}$ & $0.00(0.00-0.95)$ & $0.06(0.00-1.42)$ \\
\hline \multicolumn{3}{|l|}{$15 !$} \\
\hline$G$ & $4.58(2.75-5.62)^{\mathrm{a}}$ & $4.72(4.02-6.75)^{7}$ \\
\hline $\mathrm{L}$ & $6.23(3.98-7.04)^{\mathrm{a}}$ & $2.87(0.41-14.02)^{a}$ \\
\hline $\mathrm{P}$ & $3.62(2.28-6.85)^{\mathrm{a}_{i} / 8}$ & $3.01(0.97-4.24)^{a} .0$ \\
\hline \multicolumn{3}{|l|}{$30 \%$} \\
\hline $\mathrm{G}$ & $6.29(3.60-8.22)^{\mathrm{a}}$ & $5.44(1.24 \times 17.28)^{a}$ \\
\hline L & $9.77(6.84-13.30)^{a, b, d}$ & $4.00(0.34-6.56)^{\mathrm{a}}$ \\
\hline $\mathrm{P}$ & $6.82(4.69-9.79)^{a . b}$ & $3.30(1.87-5.91)^{\mathrm{a}}$ \\
\hline \multicolumn{3}{|l|}{$45 \prime$} \\
\hline$G$ & $5.34(3.13-6.35)^{\mathrm{a}}$ & $4.55(2.14-8.28)^{\mathrm{a}}$ \\
\hline L & $10.02(6.18 \cdot 10.79)^{a, d b}$ & $4.52(2.25-9.72)^{\mathrm{a}}$ \\
\hline p & $8.86(6.10-12.12)^{a_{1} d}$ & $3.88(2.32-4.18)^{a}$ \\
\hline \multicolumn{3}{|c|}{$15 \mathrm{l} / \mathrm{R}$} \\
\hline$G$ & $0.00(0.00-0.39)^{c}$ & $1.06(0.00-4.84)^{\mathrm{c}}$ \\
\hline$L$ & $0.03(0.00-0.52)^{a, c}$ & $0.30(0.00-1.23)$ \\
\hline $\mathrm{P}$ & $0.00(0.00-0.32)^{\mathrm{c}}$ & $0.00(0.00-0.70)^{c}$ \\
\hline \multicolumn{3}{|c|}{$30 \% / / 8$} \\
\hline $\mathrm{G}$ & $0.00(0.00-1.64)^{c}$ & $2.87(0.00-5.99)$ \\
\hline L & $1.38(0.00-3.11)^{c}$ & $0.18(0.00-1.30)^{6.0}$ \\
\hline P & $0.02(0.00-0.74)^{0.0}$ & $0.06(0.00-0.73)^{c, 0}$ \\
\hline \multicolumn{3}{|c|}{$45^{\circ / / R}$} \\
\hline $\mathrm{G}$ & $0.00(0.00-0.86)^{c}$ & $1.40(0.00-4.14)^{0}$ \\
\hline L & $7.00(1.00-9.18)^{\mathrm{a} d \mathrm{~d}}$ & $2.16(0.21-5.50)^{a}$ \\
\hline$P$ & $1.04(0.01-3.03)^{a, c, d, e}$ & $0.56(0.00-2.28)^{c .0}$ \\
\hline
\end{tabular}

Dota represent median values and $95 \%$ confidence limits. The amounts of glycerol-3-P and glyceroi are expressed as $\mu$ molig dry weight. For abbreviations and legends see table 4.1.

In pyruvate hearts the rise in glycerol-3-P was more gradual during 45 min of ischemia. After 45 min of ischemia the content of glycerol-3-P was significantly higher in pyruvate hearts than in glucose hearts and was comparable to lactate hearts.

During reperfusion, glycerol-3-P levels were lowered to preischemic values in all hearts, except in lactate and pyruvate reperfused hearts exposed to $45 \mathrm{~min}$ of ischemia. In these hearts, glycerol-3-P levels were still significantly raised above preischemic values. This elevation was more pronounced in lactate than in pyruvate hearts $(p<0.05)$.

Like glycerol-3-P, glycerol accumulated during ischemia in all hearts (table 4.3). The three substrate groups showed the highest rate of increase during the first fifteen min of ischemia and levels were nearly constant thereafter. At the end of 45 min of ischemia, the total giycerol content was not significantly different in the three groups. By reperfusion, glycerol content decreased towards preischemic values in all hearts. Only in lactate hearts previously exposed to $45 \mathrm{~min}$ of ischemia, the end-reperfusion 
Table 4.4 The amount of glycerol released in coronary effluents versus the expected amount of glycerol release during reperfusion, in absence or presence of lactate or pyruvate.

$\begin{array}{llll}\text { Duration of } & \text { Measured glycerol } & \text { Expected glycerol } & \Delta \text { Glycerol } \\ \text { ischemia (min) } & \begin{array}{l}\text { release during } \\ \text { reperfusion }\end{array} & \text { release } & \end{array}$

$\begin{array}{clll}15 & & \\ G & 3.2(0.8-7.8) & 3.5 & -0.3 \\ L & 2.5(1.3-11.5) & 2.6 & -0.1 \\ P & 5.7(2.6-6.3) & 3.0 & 2.7 \\ 30 & & & \\ G & 3.0(1.3-11.5) & 2.5 & 0.5 \\ \text { L } & 7.3(5.8-16.1)^{\natural} & 3.8 & 3.5^{9} \\ P & 4.2(0.0-15.2) & 3.2 & 1.0 \\ 45 & & & \\ G & 5.6(5.3-6.0) & 3.1 & 2.5^{9} \\ \text { L } & 8.9(4.5-15.2) & 2.4 & 6.5^{9} \\ P & 8.2(1.6-11.7) & 3.3 & 4.9^{9}\end{array}$

The release of glycerol in coronary effluent and expected glycerol release are expressed as $\mu$ mollg dry weight. Coronary release values are carrected for basal values measured during the preischemic phase. Expected glycerol release is the amount of glycerol accumulation in tissue during ischemia minus amount remained in cardiac tissue at the end of 35 min of reperfusion. $\Delta$ glycerol is the actual amount of glycerol released minus the expected amount. Data of glycerol release represent median values and $95 \%$ confidence limits. Data of expected glycerol release and $\Delta$ glycerol represent calculated values (by median). For abbreviations see table 4.1.

${ }^{i}$ indicates significantly different from glycerol release after 15 min of ischemia in corresponding hearts;

$g^{g}$ indicates a significant difference between glycerol release during repertusion and expected glycerol release; $p<0.05$.

level was still slightly elevaled above the preischemic value.

Release of glycerol in coronary effluent during $35 \mathrm{~min}$ of repertusion was comparable in the three substrate groups when preceding ischemia time was 15 min (table 4.4). Prolonging the time of ischemia to $45 \mathrm{~min}$, cumulative glycerol release was maintained in the same order as measured after $15 \mathrm{~min}$ of ischemia in glucose and pyruvate hearts. In lactate hearts, glycerol release increased when ischemia time was extended from 15 to 30 min of ischemia $(p<0.05)$. After 30 min of ischemia, the total amount of glycerol release tended to be higher $(0.05<\mathrm{p}<0.10)$ in lactate than in glucose or pyruvate hearts. After $45 \mathrm{~min}$ of ischemia, glucose, lactate and pyruvate hearts reached to similar levels of glycerol release.

When previous time of ischemia was $15 \mathrm{~min}$, the amount of glycerol released in the coronary effluent of glucose and lactate hearts fairly matched the quantity of glycerol decreased in tissue by reperfusion (i.e glycerol content at the end of ischemia minus glycerol content at the end of reperfusion; table 4.4). In pyruvate hearts, cumulative glycerol release was slightly above the amount expected on basis of glycerol decrease in tissue $(0.05<p<0.10)$. After $30 \mathrm{~min}$ of ischemia, glucose and pyruvate hearts showed comparable release of glycerol in effluent and decrease of 
tissue glycerol. In contrast, in lactate reperfused hearts the amount released in effuents significantly exceeded the amount of glycerol decrease in tissue. After $45 \mathrm{~min}$ of ischemia all three substrate groups showed more release of glycerol than was expected on basis of the difference between end-ischemic and end-reperfusion tissue contents of glycerol. This discrepancy was most pronounced in lactate perfused hearts (lable 4.4$)$

\subsection{DISCUSSION}

The present study illustrates the effect of lactate on cardiac lipid metabolism and delineates its relation to hemodynamic recovery. The effect of exogenous lactate was astablished by comparing lactate perfused hearts to hearts provided with no lactate or provided with pyruvate instead of lactate. In all groups, glucose was present as basal substrate in the perfusion medium.

\section{Hemodynamic function}

In addition to the time of ischemia, the choice of exogenous substrates markedly influenced recovery of stroke volume. In this respect, lactate compromised hemodynamic function after $30 \mathrm{~min}$ of ischemia compared to glucose and pyruvate perfused hearts. After 45 min of ischemia, pyruvate also impaired recovery, while glucose as sole substrate delayed severe cardiac depression. Correspondingly, Bünger and his colleagues (1989) reported a decrease of hemadynamic function after 45 min of low-flow ischemia by increasing the exogenous lactate concentration from 5 to $15 \mathrm{mM}$. Pyruvate has been found to exert a beneficial effect (Van Bilsen et al, 1988; Bünger et al, 1989). The present findings demonstrated the importance of ischemia time herein.

\section{Fatty acids}

The responsible mechanism of cardiac impaiment by lactate has not yet been clarified. Lactate has frequently been studied as a regulator of the glycolysis process (Rovetto et al, 1975; Neely and Feuvray, 1981; Neely and Grotyohann, 1984). Despite the fact that disturbances in cardiac lipid homeostasis have been identified to play a role in ischemia and/or reperfusion induced damage of the heart (Van der Vusse et al, 1982, Prinzen et al, 1984; Chien et al, 1984; Van Bilsen et al, 1989; Otani et al, 1989 , potential deleterious effects of exogenous lactate on lipid metabolism under ischemic and reperfusion conditions have not been investigated before.

Under normoxic conditions, lactate may compete with fatty acids for oxidation when the concentration is sufficiently increased (above $4.5 \mathrm{mM}$; Drake el al, 1980). In the present study, increased fatty acid levels in normoxic lactate hearts compared to glucose hearts most likely reflect the preference of lactate over endogenous fatty acids during preischemic periusion. In the same line, an earlier study in our laboratory demonstrated that lactate preserves the endogenous triacylglycerol pool during normoxic perfusion, whereas by perfusion with glucose as sole substrate this lipid pool becomes depleted (Chapter 2; De Groot et al, 1989). Bielefeld and coworkers (1985) 
reported that lactate may reduce fatty acid oxidation by inhibiting the enzyme camitine acyl transferase 1. which takes part in the transport of fatty acids from cytoplasm into mitochondria. Like lactate, pyruvate caused elevated fatty acid levels in the present study. Pyruvate is found a suitable substrate for the isolated heart as well (Van Bilsen et all, 1988).

During the ischemic phase, the tissue content of fatty acids changed differently in the three substrate groups. In glucose hearts the tissue content of fatty acids remained constant during the first 15 min of ischemia and markedly increased thereafter. In contrast, lactate and pyruvate hearts showed a decrease of fatty acids at the onset of ischemia. Lactate perfused hearts started to accumulate fatty acids after 15 min of ischemia, whereas pyruvate hearts delayed significant fatty acid accumulation till 30 min of ischemia. Burton and colleagues (1986) reported that during the initial phase of ischemia fatty acids are reesterified into the triacylglycerol pool. In the present study, increased incorporation of arachidonic acid moieties in the triacylglycerol pool of pyruvate or lactate perfused hearts during early ischemia may support the findings of Burton and coworkers (1986). However "these results can not be contirmed by hearts perfused with glucose, the substrate used in Burton's study.

During reperfusion, the fatty acid content was profoundly reduced in glucose perfused hearts. In contrast, in lactate and pyruvate hearts fatty acid levels were railsed above ischemic levels. Fatty acid accumulation was more pronounced in lactate than in pyruvate hearts at the end of reperfusion preceded by 30 and $45 \mathrm{~min}$ of ischemia. The decrease of accumulated fatty acids in glucose hearts may be due to oxidation or reincorporation into lipid pools. Release of fatty acids via coronary effluents is excluded in the present experimental set-up due to lack of circulating albumin. In case oxidation of fatty acids was responsible for the decrease in glucose hearts, the availability of alternative sources may explain limited fatty acid consumption in lactate or pyruvate perfused hearts. Interestingly, fatty acid accumulation did even continue in these hearts after restoration of flow. Fatty acids must be derived from endogenous pools as exogenous pools were not present in our study. Both phospholipids and triacylglycerols are possible candidates to deliver fatty acids. Theoretically, the measured fatty acid increase in glucose, lactate and pyruvate hearts reflect less than $0.4 \%$ phospholipid breakdown when the fatty acids totally come from the phospholipid pool and less than $5 \%$ triacylglycerol breakdown when the triacylglycerol poot is the only source. Indeed, changes in the tissue content of arachidonic acid and the release of glycerol in coronary effluent most likely indicate that both pools are involved (see below).

\section{Hemodynamics versus fatty acid accumulation}

The present study shows no clear correlation between fatty acid accumulation at the end of ischemia and subsequent recovery of stroke volume during reperfusion. Glucose perfused hearts showed the highest levels of fatty acids by ischemia while recovery of stroke volume was better than in lactate hearts after $30 \mathrm{~min}$ of ischemia and prevailed over both lactate and pyruvate hearts after $45 \mathrm{~min}$ of ischemia. However, an inverse relationship between tissue fatty acid content at the end of reperfusion and recovery of stroke volume is found. Considering the three substrate groups, the relation was not linear (itg $4.4 ; r_{\mathrm{s}}=-0.76$ ). When fatty acids were increased above $400 \mathrm{nmol} / \mathrm{g}$ dry weight, the recovery was zero. Correspondingly, Van 


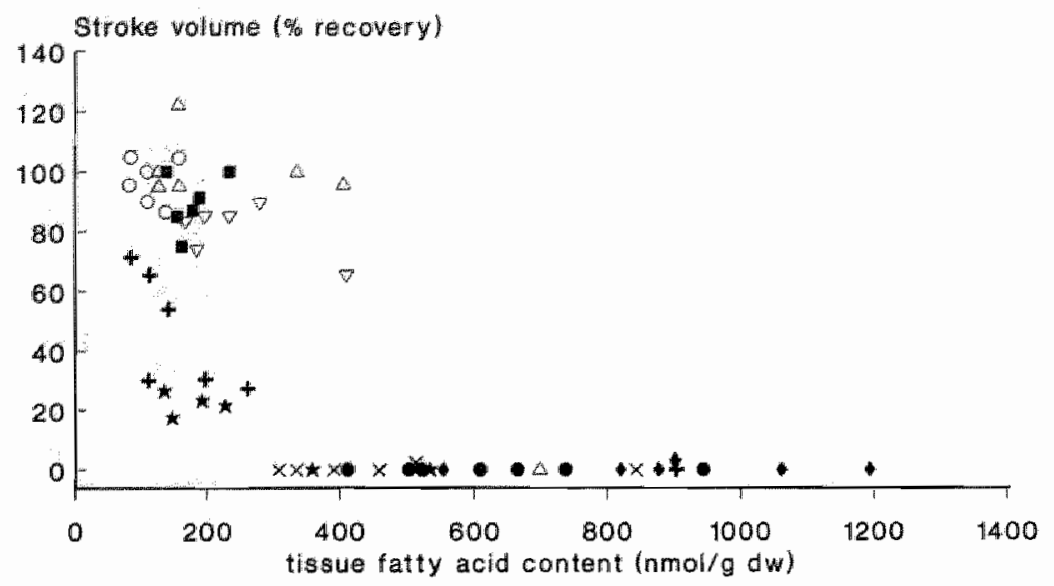

Fig 4.4 Relationship between the percentage recovery of stroke volume (expressed as percentage of the preischemic value) and the tissue content of fatty acids at the end of $35 \mathrm{~min}$ of repertusion. Data represent individual dala. Falty acids are expressed in nmol/g dry weight. $O G 15^{\prime} / / R_{;}+G 30 \% / \%$; $\star G$

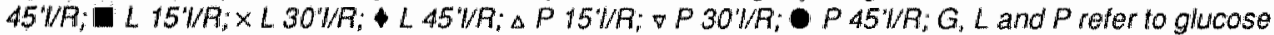
(11 $\mathrm{mM})$, glucose (11 $\mathrm{mM})$ plus lactate $(5 \mathrm{mM})$ and glucose $(11 \mathrm{mM})$ plus pyruvate $(5 \mathrm{mM})$ pertused hearts, respectively. $15 \% / \mathrm{A}, 30 \mathrm{~W} / \mathrm{R}$ and $45 \%$ refer to reperfused hearts subjected to 15,30 and $45 \mathrm{~min}$ of ischernia, respectively.

Bilsen and coworkers (1989) demonstrated an inverse relationship between tissue fatty acid content at the end of reperfusion and percentage recovery of stroke volume, but the relation was more linear. In their study, only hearts supplied with pyruvate plus glucose were considered.

A variety of metabolic mechanisms have been offered to explain detrimental effects of increased fatty acid levels or their derivatives on cardiac function. In this respect, it has been shown by in vitro studies that fatty acids might inhibit (Na,K)ATPase, adenine nucleotide translocase and various enzymes in the glycolytic pathway, uncouple mitochondrial oxidative phosphorylation, disturb calcium homeostasis, contribute to arrhythmogenesis and change biophysical properties of lipid membranes as a result of insertion in the lipid bilayer (for reviews see Katz and Messineo, 1981; Corr et al, 1984; Liedtke and Shrago, 1990).

\section{Involvement of phospholipid pool}

Several investigators (Van der Vusse et al, 1982; Chien ef al, 1984; Gunn et al, 1985) demonstrated that accumulation of arachidonic acid during ischemia and reperfusion most likely indicates disturbed phospholipid homeostasis as this fatty acid is mainly incorporated in the cellular phospholipid pool (over $99 \%$ ). Like the total amount of fatty acids, accumulation of arachidonic acid became manifest after 30 and 45 min of ischemia in glucose hearts. In lactate and pyruvate hearts, arachidonic acid content was elevated above preischemic levels after $45 \mathrm{~min}$ of ischemia. Arachidonic acid accumulation was more pronounced in glucose than in pyruvate hearts, whereas there was no significant difference between glucose and lactate hearts. It is of interest 
that in lactate and pyruvate hearts arachiconic acid was found to be reincorporated into triacylglycerols during early ischemia. By reperfusion, arachidonic acid was further set free in lactate and pyruvate hearts. Under these circumstances there was no incorporation of arachidonic acid in triacylglycerols of pyruvate hearts. When preceded by 45 min of ischemia, lactate hearts showed enhanced arachidonic acid moieties in triacylglycerols at the end of reperfusion. Reincorporation of arachidonic acid into triacylglycerols next to accumulation of free arachidonic acid implies even more phospholipid breakdown than would be suggested by free arachidonic acid only. When arachidonic acid release is confined to damaged cells (Van Bilsen et all 1989) or more selectively reflects sarcolemma breakdown (Miyazaki et al, 1990), the integrity of the cell may well be compromised. However, it is interesting to note that there was no relationship between arachidonic acid accumulation during ischemia and postischemic recovery. Moreover, in glucose hearts arachidonic accumulation during ischemia amounted to levels measured in lactate hearts after reperfusion, whille hemodynamic recovery was better in glucose hearts than in lactate hearts after ischemia. Hence, phospholipid breakdown may nat be a major determinant of overall postischemic function.

\section{Involvement of triacylglycerol pool}

Release of glycerol most likely indicated that endogenous triacylglycerols were degraded and hence, possibly contributed to total fatty acid accumulation. During ischemia, accumulation of glycerol was noticeable in all groups during the first $15 \mathrm{~min}$ (about $200 \mathrm{nmol}$ glycerol/g dry weight min as calculated by ischemic values corrected for preischemic values) and levelled of thereatter. During reperfusion, there was some additional glycerol release (compared to ischemic values) in lactate hearts after $30 \mathrm{~min}$ of ischemia and in all groups of hearts after 45 min of ischemia.

The rate of glycerol accumulation during ischemia (up to $200 \mathrm{nmol} / \mathrm{g}$ dry weight.min) exceeded the rate of fatty acid accumulation during ischemia (up to $26 \mathrm{nmol} / \mathrm{g}$ dry weight.min which is equivalent to $9 \mathrm{nmol}$ glycerol accumulation/g dry weight.min by complete hydrolysis). Similarly, the release of glycerol during reperfusion (up to 190 $\mathrm{nmol} / \mathrm{g}$ dry weight.min) far exceeded the rate of accumulation of fatty acids during reperfusion (up to $12 \mathrm{nmol} / \mathrm{g}$ dry weight.min corresponding to $4 \mathrm{nmol}$ glycerol/g diry weight.min by complete hydrolysis). Moreover, the total amount of glycerol accumulated during 45 min of ischemia or released during subsequent reperfusion by e.g. lactate hearts would implicate triacylglycerol breakdown of 13 and 19 umol fatty acid equivalents/g dry weight, respectively. Since no net degradation was found, these observations suggest cycling of triacyllycerols by which fatty acids are removed by reesterification. Correspondingly, Trach and coworkers (1986) observed triacylglycerol cycling in Langendorff perfused rat hearts during low-fllow ischemia. In the present study, the rate of triacylglycerol cycling, as estimated by rates of glycerol accumulation during ischemia over 15 min intervals (table 4.5), did not markedly differ between the three substrate groups. During reperfusion, cycling rates were more obvious in lactate hearts than in glucose or pyruvate hearts when previous ischemia time was 30 min, while glucose and pyruvate hearts also showed considerable cycling after 45 min of ischemia. Cycling of triacylglycerols is an energy consuming process. Hence, energy waste due to futile cycle might be more pronounced in lactate than in glucose or pyruvate hearts during reperfusion. 
Table 4.5 Calculated rate of Wacylglycerol cycling during ischemia and during reperfusion, in absence or presence of lactate or pyruvate.

\begin{tabular}{|c|c|c|c|}
\hline & $G$ & $L$ & $P$ \\
\hline 0||$-15 \mid$ & 0.23 & 0.18 & 0.20 \\
\hline $151-301$ & 0.05 & 0.08 & 0.02 \\
\hline $30^{\prime} / 45^{\prime}$ & 0.00 & 0.03 & 0.04 \\
\hline $15 \mathrm{UA}$ & 0.00 & 0.00 & 0.08 \\
\hline $30^{\circ} / / R$ & 0.01 & 0.10 & 0.03 \\
\hline $45 \% / / F$ & 0.07 & 0.19 & 0.14 \\
\hline
\end{tabular}

The rate of triacylglycerol cycling is calculatad by glycerol accumulation over 15 min ischemic intervals or by additional glycerol release over 35 min of reperfusion (i.e. measured glycerol release during repertusion minus expected glycerol release, see table 4.4). The rate of triacylglycerol cycling is expressed as $\mu$ molig dry weight.min. For abbreviations see rable 4.1.

\section{Factors involved in cycling of triacylglycerols}

Cycling of triacylglycerols might be explained by two mechanisms.

Firstly, removal of fatty acids via esterification may indirectly stimulate the rate of lipolysis by attenuation of product inhibition (Stam and Hülsmann, 1985). Secondly, the tight coupling between glycolysis and lipolysis (Hülsmann and Stam, 1979; Trach et al, 1986) might indicate to a role of glycerol-3-P in fatty acid-triacylglycerol cycling by stimulating esterification due to mass action (see fig 4.1).

The present data do no support the notion of a negative feed back of fatty acids on triacylglycerol cycling since increased cycling rates were found under circumstances that fatty acid levels were markedly elevated above preischemic values (e.g lactate hearts after $45 \mathrm{~min}$ of ischemia followed by reperfusion). Hence, increased rates of lipolysis of triacylglycerols are not likely explained by inhibition of triacylglycerol lipase by fatty acids, although it can not be excluded that accumulation of fatty acids and triacylglycerol cycling is compartmentalized in the affected cells.

Instead of removal of inhibiting fatty acids, esterification itself might offer a means to regulate triacylglycerol turnover. Fatty acid esterification is strongly dependent on the availability of the precursor, glycerol-3-P (Wood et al, 1972). Under ischemic circumstances though, the amount of available glycerol-3-P is not directly related to the amount of glycerol released (fig 4.5). This indicates that a higher concentration of glycerol-3-P does not simply induce higher rates of triacylglycerol cycling, although its presence is necessary to make reesterification of fatty acids possible.

\section{Other potential sources of glycerol}

Cycling of triacylglycerols was estimated by glycerol release. Other potential sources of glycerol release might be glycerol-3-P or phospholipid. The absence of any relation between glycerol-3-P and glycerol during ischemia (fig 4.5) suggests that direct dephosphorylation of glycerol-3-P is not likely responsible for the observed 


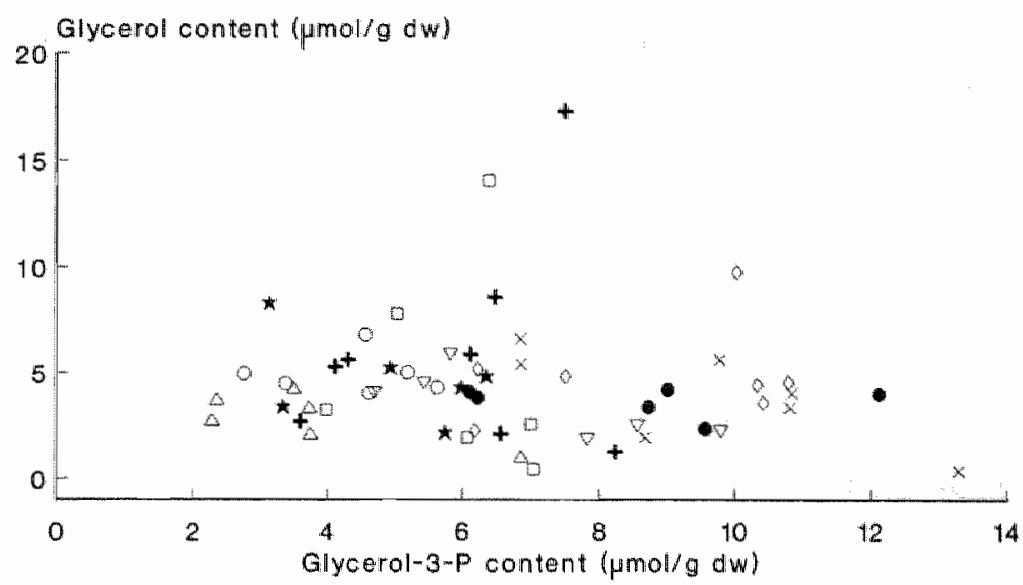

Fig 4.5 Relationship between glycerol-3-P and glycerol in tissue at the end of ischemia. Data represent individual data. The amount of glycerol-3-P and glycerol are expressed in $\mu$ mollg dry weight. $O G 15 \%$ $+G 30 \% ; G 45 \%, \square L 15 \% \times 130 \% \circ L 45 \% ; P 15 \% ; \nabla 30 \% \cup P 45 \%, G, L$ and $P$ refer to glucose $(11 \mathrm{mM})$. glucose $(11 \mathrm{mM})$ plus lactate $(5 \mathrm{mM})$ and glucose $(11 \mathrm{mM})$ plus pyruvate $(5 \mathrm{mM})$ perfused hearts, respectively. $15^{\prime} \mathrm{l}, 30^{\prime} \mathrm{r}$ and $45^{\prime} \mathrm{l}$ refer to 15,30 and $45 \mathrm{~min}$ of ischemia, respectively.

glycerol output. Similarly, Denton and Randle (1967) reported that the contribution of dephosphorylation of glycerol-3-P to total glycerol output is less than $10 \%$, although these observations relate to normoxic hearts. The contribution of phospholipid breakdown to glycerol release is yet unclear. Membrane attack by phospholipase $\mathrm{C}$ results in diacylglycerol production which is further hydrolysed to fatty acids and glycerol by intracellular lipases. Myrmel and coworkers (1989) found that energy depleted cells are very sensitive to exogenous phospholipase $C$, resulting in increased release of glycerol. However, contribution of endogenous phospholipase $C$ to glycerol release has not been quantified. Wolff and Gross (1985) identified phospholipase C activity on phosphatidylethanolamine and phosphatidylcholine upon purification of cytosol, but activity was inhibited by crude cytosol. This implies that cytoplasm contains potent inhibitors of phospholipase C. Schwertz and colleagues (1987) demonstrated phosphatidylinositol-specific phospholipase $\mathrm{C}$ activity in cytosol but the enzyme was not found active towards phosphatidylinositol incorporated into membranes. Whether catabolic circumstances turn out more favourable during ischemia or reperfusion (e.g. by loss of cytoplasmic inhibitors or by better contact between phosphatidylinositol and phospholipase $C$ ) remains to be elucidated. However, in case glycerol is derived from phospholipids instead of triacylglycerols interpretation will be the same, i.e. energy waste by futtle cycling of a lipid pool.

In summary, the present study illustrates that impairment of cardiac function by lactate is associated with changes in lipid metabolism including fatty acid accumulation, phospholipid breakdown and 'energy-wasting' cycing of triacylglycerols. No direct correlation between ischemic lipid changes and postischemic function is found, whereas lipid disturbances during reperfusion occur simultaneously with functional impairment. After 30 and 45 min of ischemia and subsequent reperfusion, lipid disturbances were more pronounced in lactate hearts than in glucose or pyruvate 
hearts. It remains to be elucidated whether these changes are causally related to ischemia/reperfusion induced irreversible damage of cardiac cells.

\subsection{REFERENCES}

1. Bielefeld DR, Vary TC. Neely JF (1985) Inthibition of carnitine palmitoyl-CoA transferase activity and fatty acid oxidation by lactate and oxfenicine in cardiac muscle. J Mol Cell Cardial 17:619-625

2. Bünger R, Mallet RT, Hartman DA (1989) Pyruvate-enhanced phosphorylation potential and inotropism in normoxic and postischemic isolated working heart. Eur $\mathrm{J}$ Biochem 180: 221-233

3. Burton KP, Buja LM, Sen A, Willerson JT, Chien KR (1986) Accumulation of arachidonate in triacylglycerols and unesteritied fatty acid during ischemia and retlow in the isolated rat heart. Am J Pathol 124: 238-245

4. Chien KR, Han A, Sen A, Buja LM, Willerson JT (1984) Accumulation of unesterified arachidonic acid in ischemic canine myocardium. Relationship to a phosphatidylcholine deacylation-reacylation cycle and the depletion of membrane phospholipids. Circ Res 54: $313-322$

5. Corr PB, Gross $\mathrm{RW}$, Sobel BE (1984) Amphipathic melabolites and membrane dysfunction in ischemic myacardium. Circ Res 55: 135-154

6. De Groat MJM, Willemsen PHM, Coumans WA, Van Bllsen M, Van der Vusse GJ (1989) Lactateinduced stimulation of myocardial triacylglycerol tumover. Biochim Biophys Acta 1006: 111-115

7. De Groot MJM, Van der Vuisse GJ (1990) The effect of laclate on ischemic and reperlused hearts. Pllugers Archiv-Eur J Physiol 416: s5.

8. Denton FM, Randle PJ (1967) Measurement of tlow of carbon atoms from glucose and glycogen glucose to glyceride glycerol and glycerol in rat heart and epididymal adipose tissue. Biochem $\mathrm{J}$ 104: $423-434$

9. Drake AJ, Haines JR, Noble MIM (1980) Preferential uptake of lactate by the normal myocardium in dogs. Cardiovasc Res 14:65-72

10. Gunn MD, Sen $A$, Chang $A_{0}$ Willerson JT, Buja LM, Chien KR (1985) Mechanisms of accumulation of arachidonic acid in cultured myocardial cells during ATP depletion. Am J Physial 249: H1188H1194

11. Hülsmann WC Stam $H$ (1979) Lipolysis in heart and adipose tissue; effecls of inhibition of glycogenolysis and uncoupling of oxidative phosphorylation. Biochem Biophys Res Commun 88: $867-872$

12. Katz AM, Messineo FC (1981) Lipid-membrane interactions and the pathogenesis of ischemic damage in the myocardium. Circ Res 48: 1-16

13. Katz AM, Messineo FC (1982) Fatty acid effects on membranes: possible role in the pathogenesis of ischemic myocardial damage. J Mol Cell Cardiol i4 (suppl 3) 119-122

14. Laurell $S$, Tibbling $G$ (1966) An enzymatic fluorometric micromelhod for the determination of glycerol. Clin Chim Acta 13: $317-322$

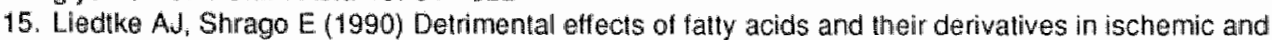
repertused myocardium. In: Piper HM (ed) Pathophysiology of severe ischemic myccardial injury. Kluwer Acad Publish, Dordrecht, pp 149-166

16. Miyazaki $Y$, Gross RW, Sobel BE, Satfitz JE (1990) Selective turnover of sarcolemmal phospholipids with lethal cardiac myocyte injury. Am J Physiol 259: C325-C331

17. Mochizuki S, Neely JR (1980) Energy metabolism during reperfusion tollowing ischemia. J Physiol $76: 805-812$

18. Myrmel T, Larsen T, Skulberg A, Forsdahl K, Lillle C (1989) Phospholipase C-evoked glycerol release in energy depleted rat myocardial cells. Mol Cell Biochem 88: 107-111

19. Neely JR, Feuvray D (1981) Metabolic products and myocardial ischemia. Am J Pathol 102: 282291

20. Neely JR, Grotyohann LW (1984) Role of glycolytic products in damage to ischemic myocardium. Circ Res 55: 816-824

21. Otani $\mathrm{H}$, Prasad RM, Jones JM, Das DP (1989) Mechanism of membrane phospholipid degradation in ischemic-repertused rat hearts. Am J Physiol 257: H252-H258 
22. Prasad RM, Popescu LM, Moraru II, Liu X, Maity S, Engeiman RM, Das DP (1991) Role of phospholipases A2 and C myocardial ischemic repertusion injury. Am J Physiol $260: 41877-4883$

23. Prinzen FW, Van der Vusse GJ, Arts T. Roemen THM, Coumans WA Reneman RS (1964) Accumulation of nonesterified falty acids in ischemic canine myocardium. Alm J Physio $247:$ H264272

24. Roemen THM, Van der Wusse GJ (1985) Application of silicage column chromatography in the assessment of non-esterited fatty acids and phosphoglycerides in myocardial tissue. J Chromatogr 344: $304-308$.

25. Rose CP, Goresky CA (1977) Constraints on the uptake of labeled palmitate by the heart. Circ Fes 41: $534-545$

26. Rowetto MJ, Lamberton WF. Neely JA (1975) Mechanisms of glycolytic inhibition in ischemic rat hearts. Circ Res 37: 742-75\%

27. Schwertz DW, Halverson JB, Palmer JW, Feinberg H (1987) Characterization of phospholipase C. mediated phosphatidylinositol degradation in rat heart ventricle. Archiv Biochem Biophys $253: 388$ 398

28. Snoeckx LHEH, Van der Vusse GJ, Coumans WA, Willemsen PHM, Van der Wagel T, Reneman RS (1986) Myocardial function in normal and spontaneously hypertensive rats during repertusion alter a period of global ischemia. Cardiovasc Res 20:67-75

29. Stam H, Hüsmann WC (1985) Regulation of lipases involved in the supply of substrate latty acids for the heart. Eur Heart $J$ 6:158-167

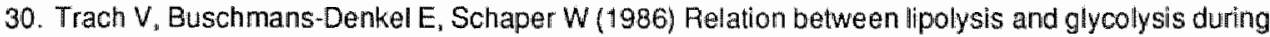
ischemia in the isolated rat heart. Basic Res Cardiol 81: 454-464

31. Vain Bilsen M, Van der Vusse GJ Snoeckx LHEH. Arts T, Coumans WA, Willemsen PHIM, Reneman RS (1988) Effects of pyruvate on post-ischemic myocardial recovery al various workloads. Plügers Archïv-Eur ل Physiol 413: $167-173$

32. Van Bilsen $M$, Van der Vusse $G$ J, Willemsen PHM, Coumans WA, Roemen THM, Reneman RS (1989) Lipid alterations in isolated, working rat hearts during ischemia and reperfusion: its relation to myocardial damage. Circ Res 64: 304-314

33. Van Bilsen M, Snoeckx LHEH, Arts T, Van der Wusse GJ, Reneman RS (1991) Pertormance of the isolated, ejecting heart: ellects of aortic impedance and exogenous substrates. Pflügers Archiv-Eur J Physiol 419: 7-12

34. Van der Vusse GJ Roemen THM, Prinzen FW, Coumans WA, Reneman RS (1982) Uptake and tissue content of fatty acids in dog myocardium under normoxic and ischemic conditions. Circ Res 50: $538-546$

35. Van der Vusse GJ, Van Bilsen M, Reneman AS (1989) Is phospholipid degradation a critical event in ischemia- and repertusion-induced damage? NIPS 4:49.53

36. Vik-mo H, Riemersma RA, Mos OD, Oliver MF (1979) Effect ol myocardial issthemia and antilipolytic agents on lipolysis and latty acid metabolism in the in-situ dog heart. Scand J Clin Lab Invest 39: $559-568$

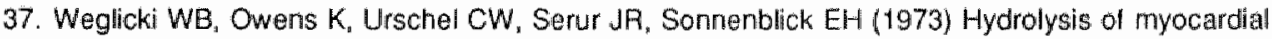
lipids during acidosis and ischemia. Recent Adv Studies Cardiac Struct Metab 3: $78: 793$

38. Wolf RA, Gross RW (1985) Identiffication of neulral active phospholipase $\mathrm{C}$ which hydrolyzes choline glycerophospholipids and plasmalogen selective phospholpase $A_{2}$ in canine myocarditm. $\checkmark$ Biol Chem 260:7295-7303

39. Wood JM, Hutchings AE, Brachteld N (1972) Lipid melabolism in myocardial cetl-free homogenales. $\checkmark$ Mal Cell Cardiol 4: 97-111 


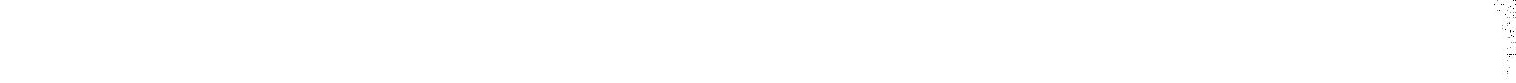

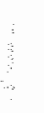

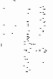

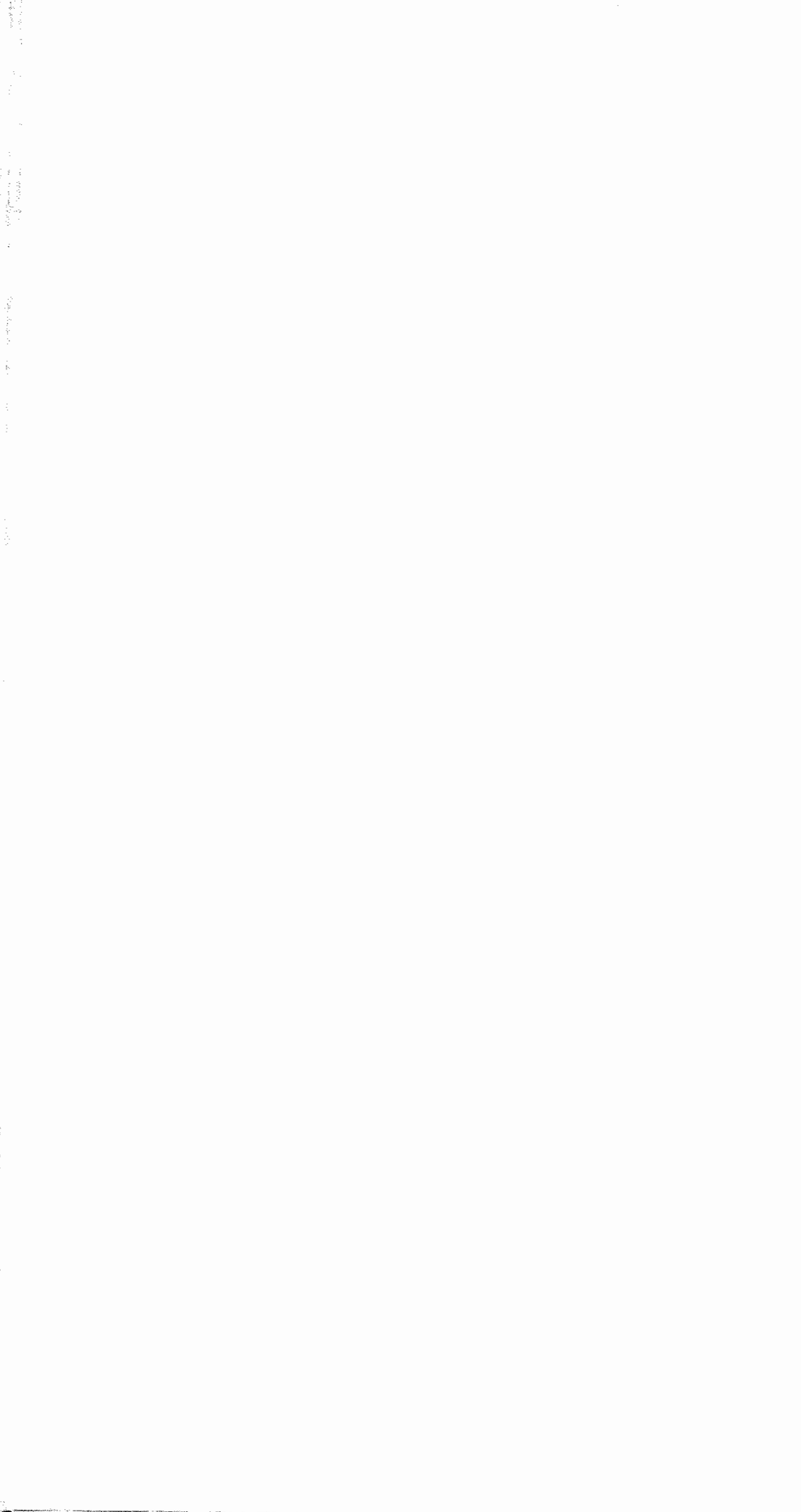


CHAPTER 5

\section{LACTATE-INDUCED CHANGES IN THE NUCLEOTIDE} METABOLISM OF THE POSTISCHEMIC HEART

\#The results of this chapter are in preparation for publication by De Groot MJM, Coumans WA, Van der Vusse GJ 


\begin{abstract}
It was examined whether lactate unfavourably influences cardiac high-energy phosphate metabolism under ischemic and reperfused conditions. To this end, isolated working rat hearts were perfused with glucose $(11 \mathrm{mM})$, glucose $(11 \mathrm{mM})$ plus lactate ( $5 \mathrm{mM}$ ) or glucose (11 mM) plus pyruvate $(5 \mathrm{mM})$. The extent of ischemic injury was varied by changing the intervals of ischemia, ie. 15,30 and $45 \mathrm{~min}$. Addition of lactate to a glucose buffer resulted in impaired cardiac function as measured by the product of heart rate and left ventricular developed pressure after $30 \mathrm{~min}$ of ischemia, whereas pyruvate hearts showed depressed cardiac function after $45 \mathrm{~min}$ of ischemia. Glucose hearts were still able to recover hemodynamic performance to some extent after 45 min of ischemia. In comparison to glucose or pyruvate, lactate did not further enhance degradation of high-energy phosphates during ischemia. However, after $35 \mathrm{~min}$ of reperfusion following 30 min of ischemia lower levels of high-energy phosphates and higher amounts of purine release were found in lactate hearts compared to pyruvate hearts. Glucose hearts did not significantly differ from lactate hearts at this time point. After 45 min of ischemia and reperfusion, ATP and GTP levels remained depressed in lactate hearts. In glucose and pyruvate reperfused hearts, high-energy phosphate levels were partly restored. Coronary release of purines was elevated above basal levels at the end of reperfusion in lactate and pyruvate hearts. In addition, the content of purines in tissue was raised in lactate and pyruvate hearts. This accumulation of purines was more pronounced in lactate than in pyruvate hearts. The present findings indicate that degradation of high-energy phosphates and loss of purines is not likely responsible for hemodynamic impairment by lactate. Alternatively, our data suggest that underperfusion may have contributed to lactate-induced dysfunction during the reperfusion phase.
\end{abstract}




\subsection{INTRODUCTION}

The extent of ischemic and reperfusion damage may be influenced by the nature of exogenous substrates. In this regard, pyruvate has been found beneficial on cardiac recovery of the postischemic heart (Van Bilsen et al, 1988; Bünger et al, 1989). Recent experiments in our laboratory demonstrated that exogenous lactate has detrimental effects on functional recovery of the postischemic heart. After $30 \mathrm{~min}$ of ischemia, hemodynamic function was severely impaired compared to glucose plus pyruvate perfused hearts (Chapter 3; De Groot and Van der Vusse, 1990). The precise nature of the harmful effect of exogenous lactate on postischemic cardiac function is incompletely understood. Since earlier studies revealed that loss of cardiac function after an ischemic insult is associated with severe impairment of cardiac energy metabolism (Reibel and Rovetto, 1978; Reimer and Jennings, 1981; Zimmer, 1983), it is tempting to state that exogenous lactate may unfavourably influence cardiac high-energy phosphate stores under ischemic and reperfused conditions.

For the normal heart, ATP is an essential energy-donor for contractile processes and ion pumping. Under oxygen restricted conditions, ATP generation is insufficient to meet ATP requirement and high-energy phosphate stores are depleted (Zimmer et al, 1973; Reimer and Jennings, 1981). Catabolites of the nucleotides (i.e. adenosine, inosine, hypoxanthine, xanthine and uric acid) are released into coronary effluents during reperfusion, which may impair salvage of ATP during the postischemic state (Van Belle et al, 1987; De Jong and Achterberg, 1988; Van Bilsen et al, 1989). Cardiac nucleotide metabolism shows a high degree of complexity. In the cardiomyocyt about $90 \%$ of total ATP is present in cytoplasm (Bünger and Soboll, 1986). Hydrolysis of ATP results in the production of ADP and AMP. However, cytoplasmic changes of ADP and AMP are difficult to detect as the majority of ADP and AMP is bound to actomyosin or compartmentalized in mitochondria (Bünger and Soboll, 1986; Bünger et al, 1988), Zucchi and colleagues (1990) suggested that detection of the degradation products of ATP (purine nucleosides and oxypurines) in the coronary effluents may be a more simple and sensitive method to evaluate changes in cardiac energy metabolism. The amount of purine release should be related to the cytoplasmic AMP concentration, which in turn is derived from cytoplasmic ATP (Bünger and Soboll, 1986; Bünger et al, 1988). In addition, purine release reflects breakdown of myocardial guanine nucleotides. These compounds may be relevant for energy delivery as well (Achterberg et al, 1985).

The aim of the present study was to elucidate whether depletion of cardiac highenergy phosphate stores can be responsible for lactate induced failure of the postischemic heart. To this end, isolated working rat hearts were perfused with either glucose $(11 \mathrm{mM})$ plus lactate $(5 \mathrm{mM})$, glucose $(11 \mathrm{mM})$ plus pyruvate $(5 \mathrm{mM})$ or glucose as sole substrate $(11 \mathrm{mM})$. The hearts were subjected to 15,30 or $45 \mathrm{~min}$ of global no-flow ischemia in order to vary the severity of the ischemic insult. In a subset of experiments, ischemic hearts were reperfused for $35 \mathrm{~min}$. Cardiac function was monitored by the product of heart rate and left ventricular developed pressure. Overall tissue contents of high-energy phosphates including creatine phosphate, ATP and GTP were determined before ischemia, after ischemia and after reperfusion. Breakdown of high-energy phosphates was evaluated by tissue accumulation and/or coronary release of nucleosides and oxypurines. 


\subsection{METHODS}

\section{Isolated working heart preparation}

Hearts were obtained from male Lewis rats $(10$ weeks old, range body weight 250-350 g). Isolation and cannulation were performed as previously described (De Groot et al, 1989). Working hearts were perfused with a modified Krebs-Henseleit bicarbonate buffer $\left(37^{\circ} \mathrm{C}\right.$, pH range 7.35-7.45) equilibrated with $95 \% \mathrm{O}_{2} / 5 \% \mathrm{CO}_{2}$ $\left(\mathrm{PO}_{2}>75 \mathrm{kPa}\right)$. The perfusion buffer contained (in mM): $\mathrm{NaCl}(130.0), \mathrm{KCl}(5.6), \mathrm{CaCl}_{2}$ (2.2), $\mathrm{MgCl}_{2}(1.2), \mathrm{NaH}_{2} \mathrm{PO}_{4}(1.2), \mathrm{NaHCO}_{3}(25.0)$. D(t)-glucose (11 mM) was added as a basal substrate. Where indicated, $L(+)$-Lactate $(5 \mathrm{mM})$ or pyruvate $(5 \mathrm{mM}$, sodium salt) was added as cosubstrate. The lactate buffer was neutralized by $\mathrm{NaOH}$.

\section{Experimental protocol}

During a stabilization period of $10 \mathrm{~min}$, the hearts were retrogradely perfused according to the Langendorff technique. Subsequently, the hearts were subjected to antegrade perfusion for $30 \mathrm{~min}$. Left atrial tilling pressure was set at $1 \mathrm{kPa}$ and diastolic aortic pressure at $8 \mathrm{kPa}$. After $30 \mathrm{~min}$ of normoxic perfusion, the hearts were subjected to either 15,30 or 45 min of ischemia and reperfused for additional $35 \mathrm{~min}$ (retrogradely during the first 5 min and antegradely thereafter). Since the hearts were perfused in the assisted mode (Van Bilsen et al, 1991), coronary perfusion pressure was maintained even when reperfused hearts were unable to provide their own coronary flow. Hemodynamic characteristics [aortic pressure, left ventricular pressure (systolic and end-diastolic), and electrogram] were continuously monitored on a sixchannel recorder (Schwarz) as has been described earlier (De Groot et al, 1989; Van Bilsen et al, 1991). The pressure-rate product was defined as the product of heart rate and left ventricular developed pressure (difference between systolic and end-diastolic pressure).

\section{Biochemical analysis}

At the end of either the preischemic, ischemic or postischemic phase, ventricular tissue was rapidly dissected from atrial tissue with a surgical blade and immediately freeze clamped with the use of aluminum tongues, cooled in liquid nitrogen. Throughout the preischemic and postischemic phase of the experimental protocol. coronary effluents were collected and sampled. Tissue and effluent samples were stored at $-80^{\circ} \mathrm{C}$ until analysis.

\section{Tissue}

Creatine phosphate, ATP, GTP, nucleosides and oxypurines: small aliquots of deeply frozen ventricle tissue were freeze dried. Metabolites were extracted by an icecold mixture of perchloric acid ( $3 \mathrm{M})$ and dithiothreitol $(5 \mathrm{mM})$ and subsequently neutralised by $\mathrm{KHCO}_{3}$ (Snoeckx et al, 1986). Creatine phosphate was determined fluorometrically (Van der Vusse et al, 1984). Tissue contents of ATP, GTP, IMP, purine nucleosides (adenosine, inosine) and oxypurines (hypoxanthine, xanthine, uric acid) were assayed by high performance liquid chromatography (Wijnants and Van Belle, 1985: Van Bilsen et al, 1989). 


\section{Coronary effuent}

The release of nucleosides and oxypurines in coronary effluents was monitored by an isocratic HPLC procedure (Harmsen et al, 1981; Van Bilsen et al, 1989).

\section{Normalization of data}

Measurements in tissue samples are expressed in moles per gram dry weight. The dry weight of cardiac tissue was determined by freeze drying overnight. Data concerning release of substances in the coronary effluent are expressed in moles per gram wet weight (release per heart corresponds to release per gram wet tissue). For conversion of moles per gram dry weight to moles per gram wet weight an average, empirically determined, factor of 6.25 was used.

\section{Statistical analysils}

Results are expressed as median values and $95 \%$ confidence limits throughout. The number of experiments per group varied from 6 to 8 . Differences within groups were evaluated for significance using Wilcoxon's matched-pairs signed rank test. Differences between groups were evaluated for significance by Mann Whitney U test. $P$ values less than 0.05 were considered statistically significant.

\subsection{RESULTS}

\section{Hemodynamics}

Under preischemic, normoxic conditions, addition of lactate or pyruvate to the glucose buffer did not influence the pressure-rate product (table 5.1). However, addition of lactate turned out detrimental under ischemic/reperfused conditions. Whereas after 15 min of ischemia the recovery of the pressure-rate product was still $94 \%$ of the preischemic value (recovery when each heart serves as its own control), a marked decrease was observed after 30 min of ischemia (recovery $4 \%$ ) in lactate hearts. In pyruvate hearts the decline of pressure-rate product was obvious after 45 min of ischemia (recovery $0 \%$ ). In contrast, in glucose hearts the pressure rate product was less severely reduced after $45 \mathrm{~min}$ of ischemia and reperfusion (recovery $60 \%)$.

\section{Creatine phosphate, ATP and GTP}

The level of high-energy phosphates was not increased by addition of lactate to the glucose buffer during the preischemic period (table 5.2). Supply of pyruvate instead of lactate slightly improved the myocardial content of creatine phosphate (CP) and ATP compared to glucose only. During ischemia, a decline in the tissue content of high-energy phosphates could be observed in all substrate groups. CP levels rapidly decreased by about $50 \%$ during the first fifteen min of ischemia in the glucose, lactate and pyruvate group. Thereafter the CP content was maintained at nearly the same level in glucose hearts, but continued to decrease in lactate and pyruvate hearts. After an ischemic interval of $45 \mathrm{~min}, 25 \%$ of the baseline content of CP was left in the lactate 
Table 5. 1 Recovery of pressurevrate product during reperfusion following 15,30 or 45 min of ischemia, of hearts perfused with glucose, glucose plus lactate or glucose plus pyruvate.

G

$\begin{array}{ll}\text { Pre-1 } & 3583(3334-3714) \\ 15^{\prime} / / R & 3194(3028-3382) \\ 30^{\prime} \text { V/R } & 2779(0-3462)^{\mathrm{a}} \\ 45^{\prime} / / R & 2099(0-2297)^{\mathrm{a}}\end{array}$

$\mathrm{L}$

3546 (3325-3808)

$3399(2984-3739)^{\mathrm{a}}$

176. $(0-1961)^{a, d}$

$0(0-1053)^{\text {a,d }}$
$P$

3417 (3322-3683)

$3514(0-4000)$

$3353(2900-3998)^{\mathrm{d}, \mathrm{e}}$

$0(0-2000)^{\mathrm{a}, \mathrm{d}}$

Data represent median values and $95 \%$ confidence limits. Pressure-rate product (HA $\times$ LVDP) is expressed as $\mathrm{kPa}$ (min. The number of experiments per group varies from 6 to 8 . Pre-l refers to preischemic value, $15 \mathrm{~K} / \mathrm{R}, 30 \mathrm{NR}$ and $45 \mathrm{~V} / \mathrm{h}$ refer to values measured at the end of $35 \mathrm{~min}$ of reperfusion preceded by 15,30 and 45 min of ischemia, respectively. $G, L$ and $P$ refer to glucose (11 $\mathrm{mM}$ ), glucose (11 $\mathrm{mM})$ plus lactate $(5 \mathrm{mM})$ and glucose plus pyruvate $(5 \mathrm{mM})$ perfused hearts, respectively.

andicates significantly different from preischemic value:

"indicates significantly different from corresponding glucose hearts;

indicates significantly different from corresponding lactate hearts; $0<0.05$.

and pyruvate group, which was slightly lower $(p<0.05$ and $0.05<p<0.10$, respectively) than in glucose hearts. Like CP. ATP levels were reduced to 50 to $70 \%$ of preischemic values at the end of $15 \mathrm{~min}$ of ischemia in all groups of hearts. After 30 min of ischemia, the ATP conient was decreased to 12,18 and $23 \%$ of preischemic values in glucose, lactate and pyruvate hearts, respectively. Prolonging the ischemic phase from 30 to $45 \mathrm{~min}$. ATP pools were not further depleted in glucose and lactate hearts, but in pyruvate hearts ATP contents decreased to about $5 \%$ of preischemic values. Despite these changes, no mutual significant differences of ATP content could be observed between substrate groups at the end of a given ischemic interval. After 15 min of ischemia, the GTP pool was depleted by about $65 \%$ in glucose and lactate hearts and by $53 \%$ in pyruvate hearts. After 45 min of ischemia, GTP depletion reached to 12,22 , and $14 \%$ of preischemic values in glucose, lactate and pyruvate hearts, respectively. There were no significant differences for GTP tissue levels between the substrate groups at the end of either 15,30 or 45 min of ischemia.

By reflow following 15 or 30 min of ischemia, the pools of high-energy phosphates were (partly) replenished in the three substrate groups. The CP pool was better restored than the ATP or GTP pools. CP levels reached above preischemic values in glucose and lactate reperfused hearts when preceded by 15 or $30 \mathrm{~min}$ of ischemia and in pyruvate reperfused hearts subjected to 30 min of ischemia. The ATP and GTP levels did return to about $90 \%$ of the preischemic value in glucose and lactate hearts and to about $72 \%$ in pyruvate hearts after $15 \mathrm{~min}$ of ischemia and subsequent reperfusion. Following $30 \mathrm{~min}$ of ischemia, both ATP and GTP contents were replenished for 50 to $60 \%$ of preischemic values in the three substrate groups. After 45 min of ischemia, only glucose hearts did recover $\mathrm{CP}$ above preischemic levels, while ATP and GTP levels stabilized on about $55 \%$ of baseline values. In lactate 
Table 5.2 The content of creatine phosphate (CP). ATP and GTP in tissue of glucose, lactate and pyruvate hearts, subjected to 15,30 or $45 \mathrm{~min}$ of ischemia, followed by $35 \mathrm{~min}$ of reperfusion.

\begin{tabular}{|c|c|c|c|}
\hline & $\mathrm{CP}$ & ATP & GTP \\
\hline \multicolumn{4}{|c|}{ Pre-1 } \\
\hline $\mathbf{G}$ & $20.2(9.7-25.4)$ & $16.6(14.7-18.2)$ & $0.93(0.78-1.02)$ \\
\hline $\mathrm{L}$ & $22.2(9.6-32.4)$ & $16.9(14.2-20.7)$ & $0.94(0.86-1.07)$ \\
\hline$P$ & $29.2(11.4-56.7)^{d}$ & $20.1(13.6-22.8)^{d}$ & $1.01(0.30-1.15)$ \\
\hline \multicolumn{4}{|l|}{$15^{\prime}$} \\
\hline $\mathrm{G}$ & $10.9(8.2-17.9)^{\mathrm{a}}$ & $8.7(5.2-14.0)^{\mathrm{a}}$ & $0.31(0.12-0.63)^{\mathrm{a}}$ \\
\hline L & $10.0(6.4-16.1)^{\mathrm{a}}$ & $12.1(10.4-14.7)^{a}$ & $0.33(0.28-0.57)^{\mathrm{a}}$ \\
\hline$P$ & $15.5(6.1-19.2)^{\mathrm{a}}$ & $11.3(6.7-14.5)^{\mathrm{a}}$ & $0.47(0.30-0.75)^{\mathrm{a}}$ \\
\hline \multicolumn{4}{|l|}{$30 \%$} \\
\hline$G$ & $7.8(5.3-13.4)^{\mathrm{a}}$ & $2.0(0.8-6.5)^{\mathrm{a}, \mathrm{b}}$ & $0.17(0.08-0.35)^{\mathrm{a}}$ \\
\hline $\mathrm{L}$ & $6.8(3.1-22.2)^{\mathrm{a}}$ & $3.0(1.4-6.4)^{\mathrm{a}, \mathrm{b}}$ & $0.19(0.11-0.25)^{\mathrm{a}, b}$ \\
\hline$p$ & $10.2(3.2-14.6)^{\mathrm{a}}$ & $4.6(1.2-9.1)^{a, b}$ & $0.21(0.09-0.42)^{a, b}$ \\
\hline \multicolumn{4}{|l|}{$45^{\prime}$} \\
\hline $\mathrm{G}$ & $9.9(7.7-17.0)^{\mathrm{a}}$ & $2.0(1.0-2.9)^{\mathrm{a}}$ & $0.11(0.07-0.20)^{\mathrm{a}}$ \\
\hline $\mathrm{L}$ & $5.8(4.0-6.6)^{a}, d$ & $2.8(0.2-5.2)^{a}$ & $0.21(0.10-0.27)^{\mathrm{a}}$ \\
\hline$P$ & $7.4(3.8-9.8)^{\mathrm{a}}$ & $0.9(0.6-2.5)^{a, b}$ & $0.14(0.06-0.19)^{\mathrm{a}}$ \\
\hline \multicolumn{4}{|c|}{$15^{\prime} / / \mathrm{R}$} \\
\hline $\mathbf{G}$ & $35.7(15.9-46.9)^{\mathrm{a}, \mathrm{c}}$ & $15.5(11.1-18.0)^{\mathrm{C}}$ & $0.84(0.63-0.93)^{\mathrm{c}}$ \\
\hline $\mathrm{L}$ & $47.7(28.7-51.7)^{\mathrm{a}, \oplus, \mathrm{d}}$ & $15.9(12.2-19.7)^{\mathrm{C}}$ & $0.79(0.04-0.97)^{a, 0}$ \\
\hline $\mathrm{p}$ & $27.7(12.9-49.7)^{c_{1} \theta}$ & $14.2(5.5-19.7)$ & $0.74(0.44-0.93)^{\mathrm{a}}$ \\
\hline \multicolumn{4}{|c|}{$30^{\prime} / / R$} \\
\hline $\mathbf{G}$ & $28.5(23.7-41.6)^{\mathrm{a}, \mathrm{c}}$ & $9.1(7.1-11.1)^{\mathrm{a}, \mathrm{c}}$ & $0.54(0.49-0.67)^{\mathrm{a}, \mathrm{c}}$ \\
\hline $\mathrm{L}$ & $29.6(20.2-36.2)^{a, c}$ & $8.5(7.2-10.9)^{\mathrm{A}_{\mathrm{C}} \mathrm{C}}$ & $0.53(0.43-0.66)^{\mathrm{a}, \mathrm{c}}$ \\
\hline$P$ & $35.5(17.6-40.9)^{\mathrm{c}}$ & $11.3(10.1-12.6)^{a_{n} c_{10} \theta}$ & $0.61(0.56-0.75)^{a, c, 0}$ \\
\hline \multicolumn{4}{|c|}{$45^{\prime} / / \mathrm{R}$} \\
\hline G & $33.6(28.4-37.6)^{a, c}$ & $9.0(5.8-11.1)^{\mathrm{a}, \mathrm{c}}$ & $0.55(0.41-0.68)^{\mathrm{a}, \mathrm{c}}$ \\
\hline $\mathrm{L}$ & $10.8(4.1-38.0)^{c, d}$ & $2.3(0.9-11.7)^{\mathrm{a}, \mathrm{d}}$ & $0.24(0.13-0.55)^{\mathrm{a}, \mathrm{d}}$ \\
\hline$P$ & $14.5(9.8-23.3)^{\mathrm{a}, c_{2} \mathrm{~d}}$ & $5.0(1.9-9.1)^{a, G, d}$ & $0.37(0.21-0.62)^{a, c, d}$ \\
\hline
\end{tabular}

Data are presented as median values and $95 \%$ confidence limits. Tissue contents of CP. ATP and GTP are expressed as umol per $g$ dry weight; Pre.l refors to preischemia; $15 \%, 30 \%$ and $45 \%$ to 15,30

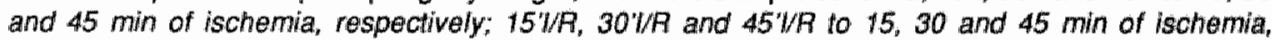
respectively followed by $35 \mathrm{~min}$ of repertusion. G refers to glucose $(11 \mathrm{mM}) ; \mathrm{L}$ to glucose $(11 \mathrm{mM})$ plus lactate $(5 \mathrm{mM})$; P to glucose $(11 \mathrm{mM})$ plus pyruvate $(5 \mathrm{mM})$.

a indicates significantly different from preischemic values;

$b$ indicates significantly different from the preceding ischemic value (30 versus 15 min of ischemia and 45 versus 30 min of ischemia.

indicates significantly different from its ischemic walue;

of indicates significantly different from glucose perfused hearts at corresponding times;

${ }^{2}$ indicates significantly different from lactate hearts at corresponding times; $(P<0.05)$

hearts CP content slightly increased following the ischemic phase, but ATP and GTP stores did not recover after 45 min of ischemia. Pyruvate hearts demonstrated a small replenishment of the CP. ATP and GTP content. Comparing the three substrate groups, there was a higher content of CP in the lactate group than in the glucose or pyruvate group after $15 \mathrm{~min}$ of ischemia and reperfusion. A lower content of ATP and GTP was observed in the lactate group than in the pyruvate group following 30 min 
Table 5.3

The content of IMP, adenosine $(A)$, inosine $(I)$, hypoxanthine $(H X)$, xanthine $(X)$ and the sum of these compounds in tissue of glucose, lactate and pyruvate hearts, subjected to 15,30 or 45 min of ischemia. tollowed by reperfusion.

\begin{tabular}{|c|c|c|c|}
\hline & IMP & A & 1 \\
\hline \multicolumn{4}{|l|}{ Pre-ll } \\
\hline $\mathrm{G}$ & $0.00(0.00-0.15)$ & $0.22(0.14-0.64)$ & $0.05(0.00-0.09)$ \\
\hline $\mathrm{L}$ & $0.00(0.00-0.11)$ & $0.25(0.06-0.50)$ & $0.04(0.00-0.62)$ \\
\hline$P$ & $0.00(0.00-0.12)$ & $0.20(0.00-0.32)$ & $0.07(0.00-0.37)$ \\
\hline \multicolumn{4}{|l|}{154} \\
\hline$G$ & $0.42(0.00-0.59)^{\boxplus}$ & $2.56(1.76-3.99)^{\mathrm{a}}$ & $1.87(1.50-2.07)^{\mathrm{ad}}$ \\
\hline L & $0.31(0.02-0.39)^{\mathrm{a}}$ & $1.96(1.37-2.57)^{\mathrm{a}}$ & $2.12(1.60-2.49)^{\mathrm{a}}$ \\
\hline $\mathrm{P}$ & $0.49(0.40-0.91)^{a, a}$ & $1.55(0.16-2.82)^{\mathrm{a} d \mathrm{~d}}$ & $3.05(2.32-4.51)^{\mathrm{a}_{1} \mathrm{~d}_{n} \mathrm{e}}$ \\
\hline \multicolumn{4}{|l|}{$30 \%$} \\
\hline$G$ & $1.02(0.00-1.57)^{\mathrm{a}, \mathrm{b}}$ & $4.32(3.43-6.73)^{a, b}$ & $3.18(2.44-4.26)^{a, b}$ \\
\hline L & $0.49(0.34-0.94)^{a, b, d}$ & $4.33(3.18-5.81)^{a, b}$ & $3.28(2.95-4.00)^{\mathrm{a}, \mathrm{b}}$ \\
\hline $\mathrm{P}$ & $0.52(0.26-0.87)^{\mathrm{a}, \mathrm{d}}$ & $3.79(2.40-5.03)^{a / b}$ & $4.87(3.36-5.30)^{a, b, d_{1} \theta}$ \\
\hline \multicolumn{4}{|l|}{$45^{\prime}$} \\
\hline a & $1.93(1.22-2.31)^{a, b}$ & $3.45(3.01-3.90)^{\mathrm{a}, \mathrm{b}}$ & $3.97(3.28-5.00)^{a, b}$ \\
\hline L & $0.77(0.44-1.77)^{a, d}$ & $3.32(2.97-3.81)^{\mathrm{a}, b}$ & $4.85(3.59-6.28)^{a, b}$ \\
\hline$P$ & $0.64(0.44-0.75)^{\mathrm{a}, d}$ & $3.20(2.05-4.29)^{a}$ & $6.14(5.31-6.88)^{a, b, d, e}$ \\
\hline \multicolumn{4}{|c|}{$15^{\prime} / / R$} \\
\hline G & $0.07(0.00-0.93)$ & $0.21(0.00-0.57)^{\mathrm{C}}$ & $0.09(0.00-1.16)^{\mathrm{C}}$ \\
\hline L & $0.00(0.00 \cdot 0.11)^{\circ}$ & $0.11(0.00-0.17)^{\mathrm{a}_{2} \mathrm{c}}$ & $0.00(0.00-0.14)^{c}$ \\
\hline $\mathbb{P}$ & $0.00(0.00-0.76)^{c}$ & $0.07(0.00-0.28)^{\mathrm{C}}$ & $0.00(0.00-0.06)^{a_{1} c}$ \\
\hline \multicolumn{4}{|c|}{$30^{\prime} / / \mathrm{R}$} \\
\hline $\mathrm{G}$ & $0.13(0.00-1.39)^{a}$ & $0.60(0.00-11.53)^{\mathrm{C}}$ & $0.09(0.00-1.75)^{c}$ \\
\hline L & $0.46(0.06-0.96)^{\mathrm{a}}$ & $0.26(0.00-0.48)^{c}$ & $0.10(0.04-0.39)^{\mathrm{c}}$ \\
\hline $\mathrm{P}$ & $0.03(0.00-0.09)^{C_{n} \theta}$ & $0.22(0.00-0.56)^{\mathrm{C}}$ & $0.03(0.00-0.47)^{\mathrm{c}}$ \\
\hline \multicolumn{4}{|c|}{$45^{\prime} \mathrm{t} / \mathrm{R}$} \\
\hline G & $0.23(0.02-0.54)^{a_{4} c}$ & $0.23(0.00-0.66)^{\mathrm{c}}$ & $0.05(0.00-0.64)^{\mathrm{c}}$ \\
\hline $\mathrm{L}$ & $1.08(0.58-1.43)^{\mathrm{a}, \mathrm{d}}$ & $1.12(0.38-1.79)^{a, c, d}$ & $2.48(0.85-6.94)^{\mathbf{a}, d}$ \\
\hline P & $0.94(0.39-1.87)^{\mathrm{a}, \mathrm{d}}$ & $0.52(0.00-0.80)^{0, \theta}$ & $1.17(0.05-2.91)^{\mathrm{a}_{\mathrm{a}} \mathrm{cod}}$ \\
\hline
\end{tabular}

Date are presented as median values and $95 \%$ confidence limits. Tissue contents of IMP, $A, I_{*}, H X$, $X$ and the sum of purines are expressed as $\mu$ mol per $g$ dry weight: The sum of purines is based on individual data. For abbreviations and legends see table 5.2

of ischemia and reperfusion. At this time point there was no significant difference between the lactate and glucose group. Lactate and pyruvate reperfused hearts showed lower levels of CP. ATP and GTP than glucose repertused hearts when previous ischemia time was $45 \mathrm{~min}$.

\section{Accumulation of degradation products of nucleotides in tissue}

The preischemic content of IMP and purine components was small (table 5.3). During ischemia, purine nucleosides and oxypurines accumulated in all groups. Total purine accumulation increased from 0 to $30 \mathrm{~min}$ of ischemia to comparable contents in the glucose, lactate and pyruvate group, i.e. 9 to $12 \mu \mathrm{mol} / \mathrm{g}$ dry weight. Thereafter, 
continuation table 5.3

$H X$

$0.00(0.00-0.00)$

$0.20(0.00-0.80)^{d}$

$0.00(0.00-0.00)^{e}$

$0.38(0.00-0.58)^{\mathrm{a}}$

$0.45(0.40-0.49)$

$0.54(0.40-1.94)^{\mathrm{a}, \mathrm{d}}$

$0.62(0.52 \times 3.51)^{a, b}$

$0.60(0.39-1.94)$

$1.26(0.61-2.25)^{\mathrm{a}}$

$0.98(0.78-1.10)^{a, b}$

$2.18(0.55-2.46)^{\mathrm{a}}$

$2.97(2.59-3.27)^{a, b, d, \theta}$

$0.00(0.00-0.00)^{\mathrm{c}}$

$0.00(0.00-0.00)^{a, c}$

$0.00(0.00-0.87)^{\mathrm{a}}$

$0.00(0.00-0.00)^{\mathrm{C}}$

$0.00(0.00-0.00)$

$0.03(0.00-1.03)^{\mathrm{a}, \mathrm{c}}$

$0.00(0.00-0.00)^{\mathrm{c}}$

$1.66 \cdot(0.00-3.05)^{\mathrm{a}, \mathrm{d}}$

$0.61(0.00-1.85)^{a, c, d}$ $x$

$0.00(0.00-0.00)$
$0.00(0.00-0.18)$
$0.00(0.00-0.00)$
$0.30(0.00-2.89)^{\mathrm{a}}$
$0.14(0.00-0.34)$
$0.41(0.00-0.52)^{\mathrm{a}, \mathrm{e}}$
$0.82(0.44-3.41)^{\mathrm{a}, \mathrm{b}}$
$0.98(0.51-1.31)^{\mathrm{a}, \mathrm{b}}$
$1.08(0.82-1.42)^{\mathrm{a} b}$

$0.71(0.58-0.99)^{\mathrm{a}}$

$0.67(0.56-0.97)^{\mathrm{a}}$

$1.51(1.29-2.13)^{a, b, d, e}$

$0.00(0.00-0.00)^{c}$

$0.00(0.00-0.00)$

$0.00(0.00-0.00)^{\circ}$

$0.00(0.00-0.00)^{\mathrm{c}}$

$0.07(0.00-0.117)^{\mathrm{cd}}$

$0.00(0.00-0.16)^{c}$

$0.00(0.00-0.00)^{\mathrm{c}}$

$0.35(0.00-0.86)^{a, c, d}$

$0.08(0.00-0.88)^{a, c, d}$
Sum

$0.37(0.19-0.64)$

$0.77(0.06-1.77)$

$0.30(0.00-0.55)$

$5.37(3.63-9.34)^{\mathrm{a}}$

$4.89(3.96-5.87)^{\mathrm{a}}$

$6.78(4.54-9.24)^{\mathrm{a}_{i} \mathrm{a}}$

$10.09(7.98-17.27)^{a, b}$

$9.41(8.50-13.54)^{a b}$

$11.83(8.70-13.90)^{\mathrm{a} b \mathrm{~b}}$

$11.18(9.36-12.78)^{\mathrm{a}}$

$11.60(8.41 \cdot 14.27)^{\mathrm{a}}$

$14.74(12.24-16.05)^{a_{0}, b, d, \theta}$

$0.48(0.14-2.31)^{\circ}$

$0.12(0.00-0.31)^{\mathrm{a}, \mathrm{c}, \mathrm{d}}$

$0.17(0.00-1.82)^{\mathrm{c}}$

$0.94(0.00-4.67)^{\circ}$

$0.87(0.47-2.54)^{\mathrm{C}}$

$0.47(0.04-2.31)^{\mathrm{c}}$

$0.62(0.02-1.50)^{\mathrm{c}}$

$7.49(1.81-13.87)^{\mathrm{a}, \mathrm{d}}$

$3.56(0.57-9.19)^{a_{i}, c_{i} d}$

purine accumulation was nihil in the glucose and lactate group, but continued during 45 min of ischemia in the pyruvate group. At this time point, total purine accumulation was significantly higher in pyruvate than in glucose or lactate hearts.

Major compounds of breakdown products were adenosine and inosine (each varying between 22 and $48 \%$ of total degradation products). IMP, hypoxanthine and xanthine were present in minor amounts (3-20\%). The amount of uric acid in ischemic tissue was negligible. Changes of individual purines differed between the three substrate groups. In this respect, IMP pronouncedly increased during $45 \mathrm{~min}$ of ischemia in glucose hearts whereas the raise of IMP was considerably less in lactate and pyruvate hearts. Inosine accumulation was obvious in pyruvate hearts during 45 min of ischemia. The content of hypoxanthine was also higher in pyruvate hearts com- 
Table 5.4

Cumulawwe release of adenosine (A), inosine (1), hypoxanthine $(H X)$, xanthine $(X)$, uric acid (U) and the sum of these purimes in coronary effluents of givcose, lactate and pyruvate hearts subjected to 15, 30 or $45 \mathrm{~min}$ of ischemia, followed by 35 min of reperfusion.

\begin{tabular}{|c|c|c|c|}
\hline & A & 1 & $H X$ \\
\hline \multicolumn{4}{|c|}{$151 / 9$} \\
\hline G & $0.25(0.12-0.44)$ & $0.63(0.52-0.69)$ & $0.16(0.10-0.26)$ \\
\hline$L$ & $0.15(0.11-0.28)$ & $0.54(0.53-0.77)$ & $0.14(0.12-0.17)$ \\
\hline P & $0.16(0.04-0.18)$ & $0.77(0.63-0.83)$ & $0.18(0.11-0.20)$ \\
\hline \multicolumn{4}{|c|}{$30 * / / R$} \\
\hline $\mathrm{a}$ & $0.36(0.20-0.63)$ & $1.03(0.98-1.55)^{b}$ & $0.27(0.17-0.44)^{b}$ \\
\hline L & $0.36(0.28-0.47)^{b}$ & $1.14(0.84-1.28)^{b}$ & $0.29(0.18-0.42)^{b}$ \\
\hline $\mathbf{P}$ & $0.21(0.10-0.27)^{d, 10}$ & $0.87(0.29-1.05)^{d, e}$ & $0.25(0.14-0.47)$ \\
\hline \multicolumn{4}{|c|}{$45^{\prime} \mathrm{l} / \mathrm{R}$} \\
\hline 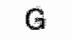 & $0.34(0.23-0.74)$ & $1.28(0.86-2.56)^{c}$ & $0.45(0.28-0.84)^{b, c}$ \\
\hline L & $0.17(0.04-0.36)^{b, d}$ & $1.15(0.78-1.82)^{\mathrm{c}}$ & $0.29(0.15-0.40)^{c}$ \\
\hline $\mathrm{P}$ & $0.26(0.18-0.51)^{c}$ & $1.23(0.92-1.34)^{b, c}$ & $0.30(0.22-0.38)^{c}$ \\
\hline
\end{tabular}

Data are presented as median values and $95 \%$ confidence limits. Release values are expressed as utmol per $g$ wel weight per $35 \mathrm{~min}$ and are corrected for basal values measured before ischemia; The sum of purine release is based on individual data. For abbreviations and legends see table 5.2 .

pared to glucose or lactate hearts after $45 \mathrm{~min}$ of ischemia. Xanthine continuously accumulated during the first $30 \mathrm{~min}$ of ischemia, but levelled off thereatter in glucose and lactate hearts. In pyruvate hearts, xanthine accumulation proceeded till 45 min of ischemia, resulting in elevated levels of xanthine compared to glucose and lactate hearts. The pattern of adenosine changes was similar in glucose, lactate and pyruvate hearts, i.e. an increase of the content of adenosine during 30 min of ischemia and a decrease trom 30 to $45 \mathrm{~min}$ of ischemia. After $15 \mathrm{~min}$ of ischemia, there was a markedly lower content of adenosine in pyruvate hearts than in glucose hearts. No significant differences of adenosine content between the three substrate groups were further observed.

By reperfusion following 15 and 30 min of ischemia, only small amounts of IMP and purines remained in cardiac tissue of glucose, lactate and pyruvate hearts (table 5.3), since degradation products were washed out (see below). However, following 45 min of ischemia and reperfusion, the content of degradation products of nucleotides was still significantly elevated in lactate and pyruvate hearts. All degradation compounds (i.e IMP, adenosine, inosine, hypoxanthine and xanthine) contributed to this elevation.

\section{Coronary release of purine compounds}

During the preischemic phase, only uric acid was released into coronary effluents. Significantly higher amounts of uric acid were released in pyruvate hearts $(5.6 \mathrm{nmol} / \mathrm{g}$ wet weight.min) than in glucose or lactate hearts $(4.1$ and $3.9 \mathrm{nmol} / \mathrm{g}$ wet weight.min, respectively). Appreciable amounts of purines were released in all hearts following the ischemic phase (table 5.4). Equal amounts of purines were released by 
$x$

$0.18(0.14-0.26)$

$0.15(0.12-0.17)^{\mathrm{d}}$

$0.15(0.14-0.18)$

$0.35(0.21-0.51)^{b}$

$0.27(0.18-0.29)^{b}$

$0.20(0.12-0.25)^{\mathrm{d}}$

$0.41(0.27-1.29)^{\mathrm{c}}$

$0.27(0.11-0.45)^{\mathrm{c}}$

$0.25(0.17-0.39)^{b, c, d}$
U

$0.18(0.11-0.23)$

$0.16(0.13-0.24)$

$0.11(0.05-0.24)$

$0.30(0.10-0.40)$

$0.31(0.18-0.70)^{b}$

$0.27(0.15-0.40)^{\mathrm{b}}$

$0.26(0.09-0.75)$

$0.15(0.00-0.35)^{\mathrm{B}}$

$0.40(0.31-0.59)^{b, c, e}$
Sum

$1.33(1.20-1.89)$

$1.14(1.06-1.36)$

$1.29(1.16-1.61)$

$2.26(1.98-3.24)^{\mathrm{b}}$

$2.45(1.95-2.90)^{6}$

$1.88(0.94-2.09)^{\mathrm{d}, e(e}$

$2.75(1.89-6.10)^{\circ}$

$2.01(1.45-3.15)^{\mathrm{C}}$

$2.58(1.81-3.00)^{6, c}$

the three groups after 15 min of ischemia. Extending the ischemic period from 15 to $30 \mathrm{~min}$, a marked increase of total purines rellease (corrected for basal values) was observed in glucose and lactate reperfused hearts, whereas in pyruvate hearts release of purines was significantly lower. Extending the time of ischemia from 30 to $45 \mathrm{~min}$, no further increase of cumulative purine release was detected in glucose and lactate hearts. In pyruvate hearts, though, purine washout was elevated up to levels measured in glucose and lactate hearts.

Off individual purines released, inosine was the major component, i.e. $4.4 \%$ to $57 \%$ of total purines, while adenosine, hypoxanthine, xanthine and uric acid were in the order of 8 to $19 \%$ in the three groups. Release of the individual purines (corrected for basal values) was nearly similar after 15 min of ischemia comparing the glucose, lactate and pyruvate group. Following $30 \mathrm{~min}$ of ischemia, adenosine and inosine were markedly reduced in pyruvate hearts compared to glucose and lactate hearts while there was also less xanthine release in the pyruvate group versus the glucose group. Following 45 min of ischemia, there was still significantly less xanthine release in pyruvate hearts compared to glucose hearts. In lactate hearts there was reduced adenosine release compared to glucose hearts and lowered uric acid release compared to pyruvate hearts.

The pattern of total purines release during repertusion is illustrated in fig 5.1 . After 15 min of ischemia, the majority of purine products was released duning the first 5 min of reperfusion and preischemic values were regained within 15 min in each group. When preceded by 30 min of ischemia, total purine release was also maximal during the initial 5 min of reperfusion in the three substrate groups. Peak values were 


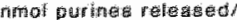

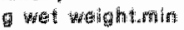
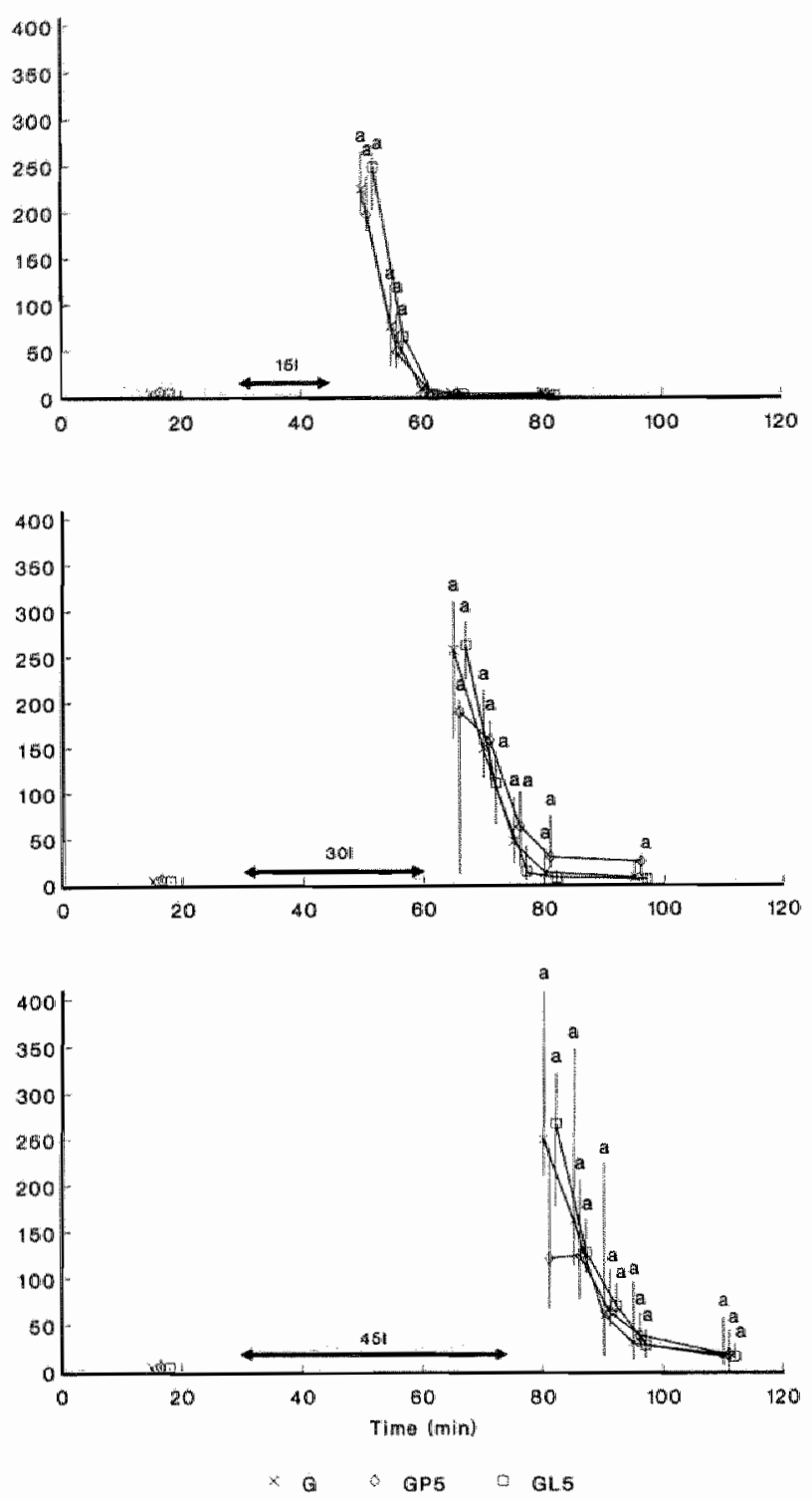

Fig 5.1 The release of purines (the sum of adenosine, inosine, hypoxanthine, xanthine and uric acid) during the preischemic phase and during reperfusion following 15,30 or 45 min of ischemia. Ischemia stanted after $30 \mathrm{~min}$ of antegrade perfusion, as indicated by dauble headed arrow. $\times$ glucose $(11 \mathrm{mM})$ perfused hearts, G; $\bigcirc$ glucose $(11 \mathrm{mM})$ plus lactate $(5 \mathrm{mM})$ perfused hearts, $L ; \square$ glucose (11 $\mathrm{mM})$ plu's pyruvate $(5 \mathrm{mM})$ perfused hearts, $P$. Data are presented as median values and $95 \%$ confidence limits. ${ }^{a}$ indicates significantly different from its preischemic values. 
comparable to those maximal values measured after 15 min of ischemia. However, after 35 min of reperfusion purine release was still elevated above basal values in lactate hearts. Following 45 min of ischemia, only glucose and pyruvate hearts showed maximal release at the onset of reperfusion, which is comparable to peak values measured after 15 and 30 min of ischemia. In lactate hearts, maximal release was spread out over $10 \mathrm{~min}$ and was severely depressed. During reperfusion, purine release gradually decreased but was still significantly elevated above preischemic values after $35 \mathrm{~min}$ in each substrate group.

\section{Purine balance: ischemic versus reperfusilon values}

Fig 5.2 depicts the balance of purine accumulation during ischemia and the amount of purines released during reperfusion plus the amount remained in tissue at the end of reperfusion. Totall cumulative amount of purines at the end of reperfusion significantly exceeded the amount accumulated at the end of ischemia in all cases except in pyruvate hearts exposed to $30 \mathrm{~min}$ of ischemia. It should be noted that the cumulative amount of adenosine at the end of reperfusion (in tissue and effluent) was less than expected on basis of the ischemic tissue content. In contrast, inosine, hypoxanthine and xanthine were higher than expected in the three substrate groups. Uric acid did not accumulate during ischemia, but was produced after restoration of flow.

\subsection{DISCUSSION}

The present study evaluates the effect of lactate on certain aspects of cardiac energy metabolism as a function of ischemia time. Despite marked differences in postischemic functional recovery evoked by lactate in the perfusion medium, this substance did not lead to more severe depletion of high-energy phosphates (CP, ATP and GTP) during ischemia compared to glucose or pyruvate. Concomitantly, the accumulation of nucleosides or oxypurines was not found more increased in lactate hearts than in glucose hearts. Pyruvate, though, the oxidized form of lactate, stimulated formation of purines during prollonged (i.e. $45 \mathrm{~min}$ ) ischemia. After $30 \mathrm{~min}$ of ischemia and reperfusion, lower levels of ATP and GTP and higher amounts of purine release were observed in lactate hearts compared to pyruvate hearts. Under these circumstances, glucose hearts showed similar results as lactate reperfused hearts. After severe ischemia (45 min), no replenishment of ATP and GTP was observed in lactate hearts whereas glucose and pyruvate hearts were still able to partly restore high-energy phosphate pools. Release of purines was found to be incomplete in lactate and pyruvate hearts subjected to $45 \mathrm{~min}$ of ischemia. The amount of purines accumulated in tissue was more pronounced in lactate hearts than in pyruvate hearts at the end of reperfusion.

\section{Hemodynamic function}

The present detrimental effects of exogenous lactate on postischemic recovery extend previous work of Bünger and coworkers (1989). These investigators demon- 
umal putines/

g) wet weight
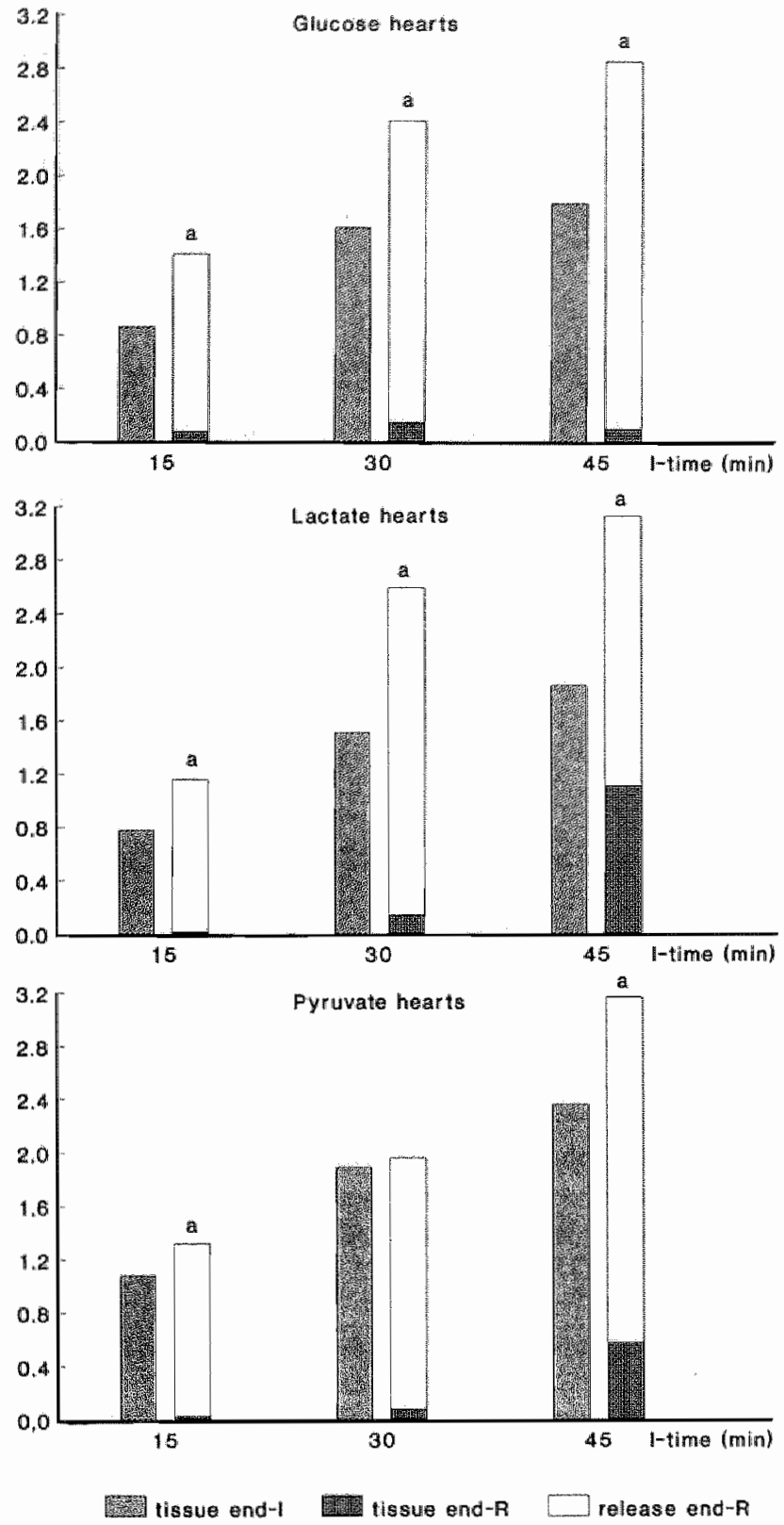

Fig 5.2. The dissue accumulation of purines (the sum of adenosine, inosine, hypoxanthine and $x$ anthine) during ischemia ( 1 -time $=15,30$ or $45 \mathrm{~min}$ ) compared to the residual tissue content of purines (the sum of adenosine, inosine, hypoxanthine and xanthine) plus the cumulative release into coronary effluent (the sum of adenosine, inosine, hypoxanthine, xanthine and uric acid; corrected for basal values) at the end of $35 \mathrm{~min}$ of reperfusion. ${ }^{a}$ indicates significantly different from the corresponding ischemic value. 
strated a concentration-dependent ( $5 \mathrm{mM}$ versus $15 \mathrm{mM}$ ) decrease of cardiac recovery by lactate after $45 \mathrm{~min}$ of low-flow ischemia. The present study shows that hemodynamic impairment by lactate is dependent on the ischemic time interval, $1 . \theta$. after $15 \mathrm{~min}$ of ischemia no marked influence of lactate on hemodynamic recovery was found, while after 30 min of ischemia cardiac function was severely depressed by lactate. In contrast, when pyruvate was added to the buffer instead of lactate, carcliac function was improved after 30 min of ischemia compared to either glucose plus lactate or glucose as sole substrate in the perfusion buffer. However, beneficial effects of pyruvate were limited to the 30 min interval of ischemia since hemodynamic function markedly decreased by extending ischemia time to $45 \mathrm{~min}$. After this time interval glucose perfused hearts were still recovering pressure-rate product. Hence, pyruvate improvements mentioned by several reports (Mochizuki and Neely, 1980; Van Bilsen et al, 1988; Bünger et al, 1989) can not be generalized but are confined to mild circumstances of ischemia.

\section{Nucleotides and their degradation products}

Myocardial energy metabolism was studied by the level of high-energy phosphates (CP, ATP and GTP) in relation to production of purines, the degradation products of ATP and GTP. The phosphorylation state of ATP in cytoplasm has been reported to present a correct expression of myocardial energy (Olsson and Bünger, 1987; Kammermeier et al, 1982). By degradation of cytoplasmic ATP, ADP and AMP are produced. Cytoplasmic changes of ADP and AMP are technically difficult to detect as the concentrations in cytoplasm are rather small compared to the overall content of ADP and AMP (mainly protein bound or compartmentalized in mitochondria (Bünger and Soboll, 1986; Bünger et al, 1988)). Bünger and Soboll (1986) estimated cytoplasmic alterations of ADP and AMP by various equations under restriction of assumptions about cytoplasmic solvent space and intracellular $\mathrm{pH}$. Alternatively, Zucchi and colleagues (1990) suggested that detection of degradation products of AMP might a more simple method to evaluate changes of cytoplasmic AMP and hence cytoplasmic ATP. Enzymatic degradation of AMP results in the production of adenosine, inosine, hypoxanthine, xanthine and uric acid which are released in the coronary effluents (Van Bilsen et al, 1989). By measuring the total amount of purines released, breakdown of AMP both via the adenosine-inosine pathway as via IMPinosine pathway is reflected. In addition, degradation of GTP is taken in account by total purine release as guanine nucleotide degradation may contribute to production of xanthine and subsequently uric acid (Achterberg et $\mathrm{al}_{\mathrm{l}}$ 1985). The capacity of the heart to convert purines into nucleotides is limited. Hence efflux of purines after restoration of flow is more rapid than reincorporation in the cellular nucleotide pool (Harmsen et al, 1984; Van der Meer and de Jong. 1988).

\section{Changes of nucleotide metabolism during Ischemia}

Our data show that the extent of depletion of high-energy phosphates and formation of nucleosides and purines during $30 \mathrm{~min}$ of ischemia was not affected by lactate. By extending the time of ischemia, further breakdown of high-energy phosphates and formation of nucleosides and purines was diminished in lactate hearts whereas in pyruvate hearts the degradation process continued. In the same line, 
Bunger and coworkers (1989) demonstrated no marked differences of cytoplasmic phosphorylation potential between glucose $(5 \mathrm{mM})$ plus lactate $(5 \mathrm{mM})$ and glucose $(5 \mathrm{mM})$ plus lactate $(5 \mathrm{mM})$ plus pyruvate $(5 \mathrm{mM})$ perfused hearts after $45 \mathrm{~min}$ of low flow ischemia. These authors did not investigate the energy state after more severe ischemia. In contrast to our results, in an earlier publication they reported higher production of purines during $45 \mathrm{~min}$ of low-flow ischemia by glucose plus lactate perfused hearts than by glucose plus lactate plus pyruvate perfused hearts (Bünger et al, 1988). Different experimental circumstances (no-flow ischemia versus low-flow ischemia, use of noradrenaline during ischemia and use of different combinations of substrates) might be responsible for this discrepancy.

Major components of the degradation products produced during ischemia were adenosine and inosine, while IMP, hypoxanthine and xanthine were present in minor amounts. This might imply that nucleoside metabolism is more active than purine metabolism during ischemia. Glucose hearts showed significantly higher contents of IMP than lactate or pyruvate hearts after 30 and 45 min of ischemia. Concomitantly, inosine levels were lower in glucose hearts than in pyruvate hearts, though they did not significantly differ from lactate hearts. Possibly, the activity of the enzyme 5"nucleotidase is limited in glucose hearts as this enzyme is responsible for the conversion of IMP to inosine. Elevated IMP levels also suggest deamination of AMP to IMP rather than dephosphorylation to adenosine. Moreover, inosine levels were lower in lactate than in pyruvate hearts after the various intervals of ischemia. Correspondingly, metabolites of inosine, i.e. hypoxanthine and xanthine were less accumulated in lactate hearts compared to pyruvate hearts reaching a significant level after severe ischemia. However, despite these interesting differences in purine formation during the ischemic period, no translation to better hemodynamic recovery of lactate hearts upon reperfusion was found.

\section{Changes of nucleotide metabolism during reperfusion}

The present findings show substantial washout of nucleosides and purines during reperfusion. No significant differences of total purine release were found between glucose, lactate or pyruvate hearts after a short period of ischemia, i.e. $15 \mathrm{~min}$. After 30 min of ischemia, release of purines was attenuated in pyruvate hearts compared to glucose or lactate hearts. Correspondingly, ATP and GTP pools were better recovered in pyruvate hearts than in glucose $(0.05<p<0.10)$ and lactate $(p<0.05)$ hearts. Bünger and coworkers (1989) similarly found better preservation of cytosolic phosphorylation after 45 min of low-flow ischemia followed by reperfusion when pyruvate was present. However, our data show that after 45 min of no-flow ischemia, pyruvate lost its protective effect. The content of high-energy phosphates and the amount of purines release reached the same level as in lactate hearts. Interestingly, in glucose hearts purine release was of the same order as in lactate and pyruvate hearts after 45 min of ischemia, but the recovery of high-energy phosphates was better in the glucose reperfused hearts. In this case, there is a discrepancy between purine release and the amount of ATP and GTP replenished.

The contribution of individual purines released during reperfusion differed from the relative composition of purines produced during ischemia. The relative amount of adenosine was decreased, the contribution of inosine was slightly increased while the release of uric acid was remarkable during reperfusion. Thus, the metabolic flux 
towards uric acid, inhibited in ischemic tissue, is relieved duming reperfusion. Reduced purine release by pyruvate after $30 \mathrm{~min}$ of ischemia can be mainly ascribed to decreased release of adenosine and inosine. This implies lowered AMP supply and, hence, better preservation of the cytoplasmic energy state in myocardium rather than inhibition of the degradative pathway. Further, after $45 \mathrm{~min}$ of ischemia a striking difference of uric acid release was demonstrated between lactate and pyruvate perfused hearts i.e uric acid release was less in lactate hearts. In glucose hearts, uric acid release was also smaller compared to pyruvate hearts $(0.05<p<0.10)$. Uric acid is produced from xanthine by the enzymes xanthine dehydrogenase or xanthine oxidase (Bindoli et al, 1988). The activity of xanthine oxidase is increased upon reperfusion following ischemia (Bindoli ef al, 1988). By enzymatic conversion of xanthine to uric acid via xanthine oxidase free radicals are produced. Free radicals have been proposed to damage the heart during reoxygenation (Bolli, 1988; Kloner et $a l, 1989)$. Hence, in case the increased levels of uric acid release in pyruvate hearts are due to increased formation via the xanthine oxidase pathway, production of free radicals might have contributed to functional impairment in these hearts. In lactate and glucose hearts, the contribution of free radicals from this source is likely less important.

Our results illustrate that purines were well washed out by coronary effluents when the preceding time of ischemia was 15 min (fig 5.2). When the ischemic interval was prolonged to $30 \mathrm{~min}$, purine release was still elevated above preischemic levels at the end of reperfusion in lactate hearts. After $45 \mathrm{~min}$ of ischemia, all hearts demonstrated raised levels of purine release after $35 \mathrm{~min}$ of reperfusion. Moreover, in lactate and pyruvate hearts accumulation of purines in cardiac tissue was detected at the end of reperfusion. Accumulation of degradation products was more profound in lactate hearts tham in pyruvate hearts $(0.05<\mathrm{p}<0.10)$. Tissue accumulation of purines might be explained by inhomogeneous perfusion causing regional ischemia. Regional ischemia may further stimulate breakdown of adenine and guanine nucleotides. Under these circumstances, purines released in coronary effluent are partly derived from purines produced during global ischemia and partly from purines formed during the reperfusion phase in areas with persistent ischemia.

Further, the amount of purines released in coronary effluents plus the amount remained in tissue at the end of reperfusion exceeded the amount of purines produced during ischemia (fig 5.2). As suggested above, additional purine formation during repertusion may explain this discrepancy. However, as purine imbalance was also found after short intervals of ischemia, i.e. after $15 \mathrm{~min}$, it can not be excluded that in coronary effluents purines were detected from alternative sources such as degradation products of RNA and pyridine nucleotides or purines which were not recognized in tissue by the currently applied extraction procedure (Mowbray et al, 1984).

Relating changes in energy metabolism to hemodynamic recovery during reperfusion, the present results indicate that small differences in purine loss after 15 min of ischemia are associated with small differences in hemodynamic recovery. After 30 min of ischemia, the decreased loss of purines and the better preservation of highenergy phosphates in pyruvate hearts are related to improved function. In contrast, small differences in the content of high-energy phosphates and the amount of purine loss in lactate and glucose hearts are associated with pronounced differences in hemodynamic recovery. Hence, impairment of hemodynamic function by exogenous lactate does not seem to be explained by influence on the high-energy phosphate 
levels. The accumulation of purines in tissue after $45 \mathrm{~min}$ of ischemia and reperfusion suggest underperfusion in certain areas of the myocardium. As the accumulation of purines was most profound in lactate hearts, underperfusion may have contributed to lactate-induced impairment of cardiac function during reperfusion preceded by longer periods of ischemia.

\subsection{REFERENCES}

1. Achterberg PW, Harmsen E, De Jong JW (1985) Adenosine deaminase inhibition and myocardial purine release during normoxia and ischaemia. Cardiovasc Res 19: 593-598

2. Bindoli $A$, Cavallini $L$, Rigobello MP, Coassin M, Di Lisa F (1988) Modification of the xanthineconverting enzyme of perfused rat heart durning ischemia and oxidative stress. Free Radical Biol Med 4: 163-167

3. Bolli $\mathrm{A}$ (1988) Oxygen-derived free radicals and postischemic myocardial dysfunction ("stunned myocardium"). J Am Coll Cardiol 12: 239-249

4. Bünger $\mathrm{R}$, Soboll $S(1986)$ Cylosolic adenylates and adenosine release in perfused working heart. Eur J Biochem 159: 203-213

5. Bünger R, Mallet RT, Hartman DA (1988) Redox manipulation of free cardiac adenylates and purine nucleoside release. Feciprocily between cytosolic phosphorylation potential and reduction-oxidation state or free AMP in perfused working heart. In: De Jong JW (ed) Myocardial Energy Metabolism. Martinus Nijhoff Publ Dordrecht, pp 67-81

6. Bünger $R$, Mallet RT; Hartman DA (1989) Pyruwate-enhanced phosphorylation potential and inotropism in normoxic and postischemic isolated working heart. Eur J Biochem 180: 221-233

7. De Groot MJM, Willemsen PHM, Coumans WA, Van Bilsen $M$, Van der Vusse GJ (1989) Lactateinduced stimulation of myocardial triacylglycerol tumover. Biochim Biophys Acta 1006: 111-115

8. De Groot MJM, Van der Vusse GJ (1990) The effect of lactate on ischemic and reperfused hearts. Pflügers Archiv-Eur J Physiol 416: S5

9. De Jong JW, Achterberg PW (1988) ATP-metabolism in normoxic and ischemic heart. In: De Jong JW (ed) Myocardial Energy Metabolism. Martinus Nijhoff Publ Dordrecht, pp 3-7

10. Harmsen $E$, De Jong JW, Serruys PW (1981) Hypoxanthine production by ischemic heart demonstrated by high pressure liquid chromatography of blood purine nucleosides and oxypurines. Clin Chim Acta 115: 73-84

11. Harmsen E, De Tombe PP, De Jong JW, Achterberg PW (1984) Enhanced ATP and GTP synthesis from hypoxanthine or inosine after myocardial ischemia. Am J Physiol 246: $\mathrm{H37}+\mathrm{H} 43$

12. Kammermeler $H$, Schmidt $P$, Jungling $E$ (1982) Free energy change of ATP-hydrolysis: A causal factor of early hypoxic lailure of the myocardium? J Mol Cell Cardiol 14: 267-277

13. Kloner RA, Przyklenk $K$, Whittaker $P$ (1989) Deleterious effects of oxygen radicals in ischemia/repertusion. Circ $80: 1115-1127$

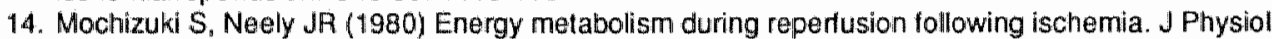
$76: 805-812$

15. Mowbray d, Hutchinson WL, Tibbs GR, Morris PG (1984) The discovery of a rapidly metabolized polymeric tetraphosphate derivative of adenosine in perfused rat heart. Biochem $\mathrm{J} 223: 627-632$

16. Olsson RAA, Bünger R (1987) Metabolic control of coronary blood flow. Progr Cardiovasc Dis 29: 369-387

17. Reibel DK, Rovelto MJ (1978) Myocardial ATP synthesis and mechanical function following oxygen deficiency. Am J Physiol 234: H620-H624

18. Reimer KA, Jennings RB (1981) Energy metabolism in the reversible and irreversible phases of severe myocardial ischemia. Acta Med Scand 651: 19-27

19. Snoeckx LHEH, Van der Vusse GJ, Coumans WA, Willemsen PHM, Van der Nagel T, Reneman RS (1986) Myocardial function in normal and spontaneously hypentensive rats during reperfusion after a period of global ischemia. Cardiovasc Res 20:67-75

20. Van Belle $H$, Goossens $F$, Wynants $J(1987)$ Formation and release of purine catabolites during hypopertusion, anoxia, and ischemia. Am J Physiol 252: $\mathrm{H} 886-\mathrm{H} 893$ 
21. Van Bilsen M, Van der Vusse G.J, Snoeckx LHEH, Arts T, Coumans WA, Willemsen PHM, Reneman RS (1988) Effects of pynuate on postischemic myocardial racovery al various workloads. Plügers Archiv-Eur J Physiol 413:167-173

22. Van Bilsen $M$, Van der Vusse GJ, Coumans WA, De Groot MJM, Willemsen PHM, Reneman RS (1989) Degradation of adenine nucleotides in ischemic and reperfused rat heart. Am J Physiol 257: $\mathrm{H} 47 \cdot \mathrm{H} 54$

23. Van Bilsen M. Snoeckx LHEH, Arts T, Van der Vusse GJ, Reneman RS (1991) Performance of the isolated, ejecting heart: effects of aortic impedance and exogenous substrates. Pilugers Archiv-Eur $\checkmark$ Physiol 419: 7-12

24. Van der Meer P, De Jong JW (1988) Regeneration of adenine nucleotides in the heart. In: De Jong JW (ed) Myocardial Energy Metabolism. Martinus Nihoff Publ Dordrecht, pp 283-289

25. Van der Vusse GJ, Coumans WA, Van der Veen FH, Drake A, Flameng W, Suy R (1984) ATP, creatine phosphate and glycogen content in human myocarial biopsies: markers for the efticacy of cardioprotection during aorta-coronary bypass surgery. Vasc Surg 18: 127-134

26. Wijnants $\sqrt{ }$, Van Belle $H$ (1985) Single-run high performance liqulid chromatography of nucleasides and major purime bases and its application to different tissue extracts. Anal Blochem 144: $258-266$

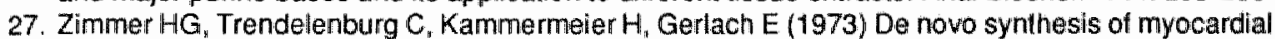
adenine nucleotides in the rat. Acceleration during recovery from oxygen deficiency. Circ Res 32 : $635-642$

28. Zimmer HG (1983) Normalization of depressed heart function in rats by ribose. Science 220:81:82

29. Zucchi $R$, Limbruno $U$, Poddighe $R$, Mariani M, Ronca $G$ (1990) Purine release from isolaled rat heart: a new approach to the study of energy metabolism. J Mol Cell Cardiol 22: 815-826 

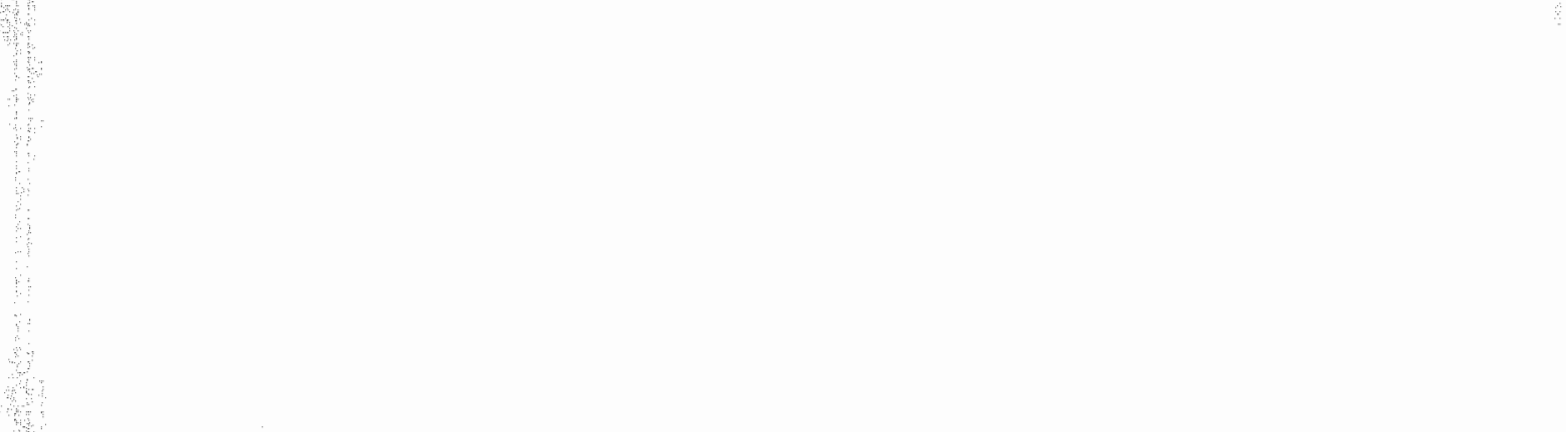
CHAPTER 6

\section{LACTATE-INDUCED UNDERPERFUSION OF THE LEFT}

VENTRICULAR INNER LAYERS OF THE POSTISCHEMIC HEART 


\begin{abstract}
The effect of lactate on myocardial blood flow (total, regional) of the reperfused ischemic myocardium was evaluated. Isolated, working rat hearts were subjected to various grades of ischemic insult $(15,30$ or 45 min interval). Glucose $(11 \mathrm{mM})$ was present as a basal substrate in the perfusion medium while lactate $(5 \mathrm{mM})$ or pyruvate $(5 \mathrm{mM})$ was added as cosubstrate. Total flow was determined by sampling over timed intervals and regional flow was measured by a microsphere technique. Following $15 \mathrm{~min}$ of ischemia, glucose, lactate and pyruvate hearts showed reactive hyperemia at the onset of reperfusion. Increased flow values were detected in both the inner and outer layers of the myocardium. After $30 \mathrm{~min}$ of ischemia and $5 \mathrm{~min}$ of reperfusion, no increase of coronary flow through the inner layers was found in lactate and glucose hearts. Moreover, in lactate hearts flow in inner layers was transiently depressed. In contrast, pyruvate hearts were still able to raise flow above preischemic levels. After $45 \mathrm{~min}$ of ischemia, all substrate groups demonstrated lowered coronary flow in inner layers of myocardium at the early stages of reperfusion, but more severely in lactate than in glucose and pyruvate hearts. Continuing reperfusion for $40 \mathrm{~min}$, flow through inner layers remained depressed in lactate and pyruvate hearts, but returned to preischemic levels in glucose hearts. In lactate hearts flow through inner layers remained more severely impaired than in pyruvate hearts. These findings indicate that lactate may aggravate ischemic insult by causing (transient) underperfusion of inner layers of the ischemic myocardium after reinstallation of flow.
\end{abstract}




\subsection{INTRODUCTION}

Blood flow through the coronary vessels is essential to supply the heart with substrates and oxygen and to remove metabolic products. The major arteries receive blood from the aorta and distribute it via smaller arteries, arterioles and capillaries over the inner and outer layers of the cardiac muscle wall. Several studies reported that under normal circumstances the distribution of flow over the inner and outer layers of the left ventricle is approximately uniform. Others, though, indicated a slightly higher flow in the inner than outer layers (for review see Van der Vusse et al, 1990). Functionally significant variations in flow distribution occur with certain physiologic or pathologic disturbances. For instance, ischemia may impair coronary flow regulation resulting in suppressed coronary circulation during the postischemic phase which is called 'no reflow phenomenon'(Kloner et al, 1974; Gavin et al, 1983). In this situation neither sufficient amount of oxygen will be delivered nor metabolites will be effectively removed. Hence, a disturbance between metabolic supply and demand may arise and the ischemic insult will actually proceed. It has been reported that the inner layers are exceptionally vulnerable to ischemia and that a flow deficit during reperfusion is more likely to occur in the inner layers than in the outer layers of the left ventricle (Feigl, 1983; Hofman, 1987).

Earlier findings in our laboratory indicated that extracellular lactate prevents adequate mechanical recovery of the postischemic heart (Chapter 3; De Groot and Van der Vusse, 1990) and concomitantly impairs washout of endogenously produced lactate and purines (Chapter 3 and 5). When exogenous pyruvate was added instead of lactate, these compounds also remained in tissue after reperfusion, but the accumulation was less pronounced. In contrast, glucose perfused hearts showed a more complete washout of endogenously produced lactate and purines during reperfusion. These findings may indicate that exogenous lactate induces underperfusion in part of the postischemic myocardium, resulting in aggravation of the ischemic insult. To test this hypothesis the present study evaluated the effect of glucose $(11 \mathrm{mM})$ plus lactate $(5 \mathrm{mM})$ in the perfusion medium on coronary flow (total and regional) in comparison to glucose $(11 \mathrm{mM})$ only or glucose $(11 \mathrm{mM})$ plus pyruvate $(5 \mathrm{mM})$. Isolated working rat hearts were subjected to 15,30 or $45 \mathrm{~min}$ of ischemia in order to vary the severity of the ischemic insult. After ischemia, hearts were reperfused for 35 to $40 \mathrm{~min}$. During preischemic and postischemic intervals, hemodynamic parameters (stroke volume, positive $\mathrm{dP} / \mathrm{dt}$ max and end-diastollo left ventricular pressure) were assessed. Total coronary flow rate was monitored by collecting coronary effluents over timed intervals. In a subset of experiments, hearts were injected with microspheres to determine flow distribution over various regions of the myocardium (i.e. right ventricle, inner and outer layers of left ventricle).

\subsection{METHODS}

\section{Animal preparation and perfusion setup}

Hearts of male Lewis rats $(250-350 \mathrm{~g})$ were isolated and cannulated as has been described elsewhere (Snoeckx et al, 1986). Hearts were retrogradely perfused as Langendorff preparations (aortic pressure is $8 \mathrm{kPa}$ ) or antegradely as 'ejecting' 
preparations (left atrial filling pressure is $1 \mathrm{kPa}$, diastolic aortic pressure is $8 \mathrm{KPa}$ Van Bilsen et al, 1991). Since hearts were perfused in the assisted mode, coronary perfusion pressure was maintained even when hearts were not able to eject and hence to provide their own coronary flow during reperfusion (Van Bilsen et al, 1991). The perfusion medium (a modified Krebs Henseleit bicarbonate buffer) consisted of (in mM): $\mathrm{NaCl}(130.0), \mathrm{KCl}(5.6), \mathrm{CaCl}_{2}(2.2), \mathrm{MgCl}_{2}(1.2), \mathrm{NaH}_{2} \mathrm{PO}_{4}(1.2), \mathrm{NaHCO}_{3}$ (25.0). Glucose (11 $\mathrm{mM}$ ) was added as a basal substrate. Where indicated, $4(+)$ lactate ( $5 \mathrm{mM})$ or pyruvate $(5 \mathrm{mM}$, sodium salt) was added as cosubstrate. The lactate buffer was neutralized by $\mathrm{NaOH}$. The perfusion medium was continuously gassed with $95 \% \mathrm{O}_{2}-5 \% \mathrm{CO}_{2}$. Temperature was kept at $37{ }^{\circ} \mathrm{C}$. The final $\mathrm{pH}$ varied from 7.35 to 7.45 .

Following cannulation, the hearts were allowed to stabilize for $10 \mathrm{~min}$ by retrograde perfusion (Langendorft). Subsequently, the hearts were perfused in antegrade mode (preischemic phase). After $30 \mathrm{~min}_{3}$ an ischemic period was introduced. The hearts were subjected to either 15,30 or 45 min of no-flow ischemia. In general, the ischemic phase was followed by a reperfusion period of 35 minutes, unless otherwise indicated. The first $5 \mathrm{~min}$ of reperfusion was a retrograde perfusion followed by 30 min of antegrade perfusion by opening the left atrial line.

\section{Hemodynamics and total coronary flow}

A constant perfusion pressure of $8 \mathrm{kPa}$ (diastolic aortic pressure) was maintained. The aortic pressure was measured at the entrance of the aortic cannula by a catheter connected to an external pressure transducer (CTC). The left ventricular pressure (systolic, end-diastolic) was measured via a catheter inserted into the left ventricle via the apex of the heart and connected to a CTC pressure transducer. The maximal first derivative of the left ventricular pressure (positive) was assessed with an analog differentiator (Janssen Scientific Instruments). The mean aortic flow was measured with an electromagnetic flow probe in the aortic outflow tract (Skalar) connected to a "sine wave" electromagnetic flowmeter (Transflow 601). Total coronary flow was measured by timed collection of the coronary perfusate dripping from the heart during the preischemic (a 10 min interval) and postischemic phase (0 to $5 \mathrm{~min}, 5$ to $10 \mathrm{~min}, 10$ to $15 \mathrm{~min}, 15$ to 20 and 20 to $35 \mathrm{~min}$ of reperfusion). Platinum electrodes were attached to the surface of the right atrium and ventricle to record the electrogram. The heart rate was estimated from electrogram registrations. Stroke volume was defined as the sum of aortic flow and coronary flow divided by heart rate. The number of experiments in each group varied from 6 to 8 .

\section{Regional flow measurements}

The regional How in the myocardium was estimated in a subset of experiments by radioactive microspheres as described by Snoeckx and colleagues (1989). A nearly identical protocol was employed as described above. A 10 min stabilization phase in retrograde mode was followed by a $30 \mathrm{~min}$ preischemic phase in antegrade mode. The antegrade phase was interrupted for $5 \mathrm{~min}$ by a retrograde interval during which microspheres were injected. Subsequently, the hearts were made ischemic for 15,30 or $45 \mathrm{~min}$ followed by a reperfusion phase. The reperfusion interval was prolonged by $5 \mathrm{~min}$ ( $40 \mathrm{~min}$ total). During the first five min of retrograde 
perfusion a second injection of microspheres was performed. Then, heart pertusion was turned to the antegrade mode for $30 \mathrm{~min}$. After $35 \mathrm{~min}$ of reperfusion, the hearts were perfused for additional $5 \mathrm{~min}$ in retrograde mode and the third bolus of microspheres was administered. Before injection, radioactive microspheres [about $5 \times 10^{4}$ in haemacel (Behring Pharma); NEN, Boston, MA, USA, $15 \mu \mathrm{m}$ in diamater] were kept in suspension by sonication. Subsequently, a syringe was filled with about $5 \times 10^{3}$ microspheres $(0.1 \mathrm{ml})$ labelled with either ${ }^{95} \mathrm{Nb},{ }^{103} \mathrm{Ru}$, ${ }^{113} \mathrm{Sn}$ or ${ }^{14} \mathrm{Ce}$. The microspheres were injected as a bolus into the aorta via a small catheter over 10 to 15 seconds, after which the catheter was flushed with a small volume of Krebs Henseleit bicarbonate buffer. During injection, coronary effluent was sampled to monitor loss of microspheres from the coronary system. Regional flow was measured at three different time points (during the preischemic phase, at the beginning and at the end of the reperfusion phase as indicated above), using three batches of differently labelled microspheres. At the end of the experiment, hearts were weighed and stored overnight in a glutaraldehyde solution $(2.5 \%$ in phosphate buffer). The fixed hearts were cut into 5 slices (atria and 4 ventricular slices). The ventricular slices were further split into right ventricle and left ventricle. The left ventricle was divided into inner and outer layers. The radioactivity of the individual tissue samples was counted in a Packard Multichannel Analyzer, as described by Prinzen and colleagues (1981). Radioactivity measurements were corrected for background radiation and the spill-over produced by scattering. The various tissue samples were welighed and flow was calculated as $\mathrm{ml} / \mathrm{g}$ wet weight.min (Snoeckx et al, 1989). As proper cutting of the inner and outer layers is technically difficult in the apex region and the tissue near atria, only the two middle slices were considered for flow values. No systematic differences were found between flow values in the inner layers of these two slices or un the outer layers of the two slices. Hence, data of the respective layers were pooled. For the pooled set of data the ratio of flow over inner and outer layers was calculated. The number of experiments in each group varied from 4 to 6 .

\section{Osmotic active substances}

The content of osmotic active substances was determined by the sum of glycolytically derived compounds (lactate, glycerol-3-phosphate and glycerol). These metabolites were measured in the first set of experiments. At the end of preischemic and ischemic periods ventricular tissue was rapidly dissected from atrial tissue and immediately frozen between aluminum clamps, cooled in liquid nitrogen. Tissue samples were stored at $-80^{\circ} \mathrm{C}$ until analysis. Small aliquots of deeply frozen tissue were freeze dried and extracted with perchloric acid (Snoeckx et al, 1986). In neutralized extracts, lactate, glycerol-3-phosphate and glycerol were determined fluorometrically (Laurell and Tibbling, 1966; Passonneau 1974).

\section{Statistical analysis}

Data are presented as median values and $95 \%$ confidence limits throughout. Differences within groups were evaluated for significance using Wilcoxon's matchedpairs signed rank test. Differences between groups were analyzed by Mann Whitney $U$ test. $P$ values less than 0.05 indicated statistically significance. In case the 
number of experiments (n) was less than 5, a $P$ value between 0.05 and 0.10 was considered.

\subsection{RESULTS}

\section{Cardlac function}

During the normoxic control period neither lactate nor pyruvate addition influenced stroke volume, positive $\mathrm{dp} / \mathrm{dt} \max$ or ventricular end-diastolic pressure (table 6.1).

After a short interval of ischemia (15 min) no profound effect of the substrates on hemodynamic variables was noticeable either. By extending the time of ischemia

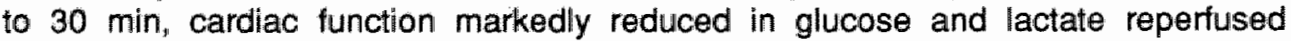
hearts. Stroke volume was decreased to $30 \%$ in glucose hearts and to $0 \%$ in lactate hearts (recovery of preischemic value when each heart serves as its own control). Likewise, positive dp/dt max was lowered to $76 \%$ and $7 \%$ of preischemic

Table 6.1 Cardiac function affer 15,30 or $45 \mathrm{~min}$ of ischemia, followed by $35 \mathrm{~min}$ of reperfusion, in absence or presence of either lactate or pyruvate.

\begin{tabular}{|c|c|c|c|c|}
\hline & Pre-1 & SV & $+\mathrm{dP} / \mathrm{dt} \max$ & Plv dias \\
\hline G & 19 & $0.22(0.21 \cdot 0.23)$ & $640(587-693)$ & $0.8(0.5-0.9)$ \\
\hline $\mathrm{L}$ & 21 & $0.22(0.20-0.22)$ & $647(600-720)$ & $0.9(0.8-1.1)$ \\
\hline$P$ & 20 & $0.21(0.20 .0 .24)$ & $633(587-720)$ & $0.8(0.8 \times 1.1)$ \\
\hline \multicolumn{5}{|c|}{$15^{\prime} \mathrm{l} / \mathrm{R}$} \\
\hline G & 6 & $0.22(0.18-0.24)$ & $573(533-587)$ & $0.7(0.5-1.1)$ \\
\hline $\mathrm{L}$ & 6 & $0.21(0.15-0.23)$ & $793(453-907)$ & $0.8(0.5-1.1)$ \\
\hline$P$ & 7 & $0.21(0.00-0.25)$ & $720(0-800)$ & $1.1(0.5-2.1)$ \\
\hline \multicolumn{5}{|c|}{30 啫/月 } \\
\hline $\mathrm{G}$ & 7 & $0.07(0.00-0.17)^{\mathrm{a}}$ & $533(0-620)^{2}$ & $1.2(0.8-1.6)^{\mathrm{a}}$ \\
\hline $\mathrm{L}$ & 8 & $0.00(0.00-0.00)^{a d}$ & $107(0-293)^{a_{1} d}$ & $1.9(1.3-7.5)^{\mathrm{a}, \mathrm{d}}$ \\
\hline $\mathrm{P}$ & 6 & $0.17(0.15-0.20)^{\mathrm{a}, d, \theta}$ & $667(587-800)^{\mathrm{d}, \theta}$ & $1.1(0.5-1.1)^{d, e}$ \\
\hline \multicolumn{5}{|c|}{$45^{\prime} / / R$} \\
\hline $\mathrm{G}$ & 6 & $0.05(0.00-0.06)^{\mathrm{a}}$ & $427(0.533)^{2}$ & $1.6(1.1-5.9)^{\mathrm{a}}$ \\
\hline $\mathrm{L}$ & 7 & $0.00(0.00-0.00)^{a, d}$ & $0(0-267)^{a, d}$ & $0.0(0.0-5.3)$ \\
\hline$\ddot{\mathrm{P}}$ & 7 & $0.00(0.00-0.00)^{a, d}$ & $0(0-293)^{a, d}$ & $4.5(0.0-5.3)^{a, 0}$ \\
\hline
\end{tabular}

Hemodynamic parameters were measured at the end of the preischemic phase (Pre-1) and at the

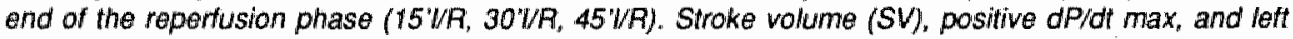
ventricular end-diastolic pressure (PIV dias) are expressed in mUbeat, $k P a / s$, and $k P a$, respectively. $G=$ glucose $(11 \mathrm{mM}): L=$ glucose $(11 \mathrm{mM})$ plus lactate $(5 \mathrm{mM}) ; P=$ glucose $(11 \mathrm{mM})$ plus pyruvate $(5$ $\mathrm{mM}$ ). n refers to the number of experiments. Data are presented as median values and $9.5 \%$ confidence limits.

indicates significantly different from preischemic values;

indicates significantly different from glucose perfused hearts at corresponding times;

indicates significantly different from lactale hearts at corresponding times; $(\rho<0.05)$ 
levels in glucose and lactate hearts, respectively. In contrast, in pyruvate reperfused hearts an ischemic interval of $45 \mathrm{~min}$ was necessary to significantly decrease mechanical function. After this ischemic time interval, stroke volume and positive $\mathrm{dP} / \mathrm{dt}$ max were severely depressed in pyruvate hearts, like in lactate hearts. Glucose perfused hearts were still recovering stroke volume and $+\mathrm{dP} / \mathrm{dt}$ max for $23 \%$ and $67 \%$ of preischemic values, respectively. Cardiac dysfunction was associated with an increase in left ventricular end-diastolic pressure. A significant elevation of the end-diastolic pressure at the end of reperfusion was found in glucose hearts after 30 and 45 min of ischemia, in lactate hearts after 30 min of ischemia and in pyruvate hearts after $45 \mathrm{~min}$ of ischemia. Although the median value of the enddiastolic pressure was zero in lactate hearts following $45 \mathrm{~min}$ of ischemia and reperfusion, high levels of this parameter could be detected in those hearts which regained mechanical activity (i.e. $4.5 \mathrm{kPa}$, three out of seven hearts). The heart rate did not significantly alter when hearts in regular sinus thythm were considered. Irregular beating hearts demonstrated trains up to 5500 electrical signals per min.

\section{Total coronary flow}

Fig 6.1 illustrates total coronary flow during the preischemic period and during reperfusion. Under preischemic conditions exogenous lactate did not influence total coronary flow compared to glucose. In pyruvate hearts flow was significantly higher than in lactate hearts.

Following $15 \mathrm{~min}$ of ischemia (upper panel), all substrate groups demonstrated an increase in flow during the early stages of reperfusion (between 5 and 10 min of reperfusion). Coronary flow returned to preischemic values thereafter. After 30 min of ischemia (middle panel), both in glucose and lactate hearts flow was impaired during the first $5 \mathrm{~min}$ of reperfusion and returned to normal levels during the remaining time. In contrast to glucose and lactate hearts, pyruvate perfused hearts were still able to show reactive hyperemia during the first $10 \mathrm{~min}$ of reperfusion following $30 \mathrm{~min}$ of ischemia. After $45 \mathrm{~min}$ of ischemia (lower panel), all substrate groups demonstrated lowered coronary flow at the early stages of reperfusion and hearts were still underperfused at the end of reperfusion. In lactate hearts coronary flow was more severely reduced than in glucose or pyruvate hearts.

\section{Regilonal flow}

Tables 6.2 and 6.3 illustrate regional flow values as assessed by the microsphere technique. The coronary flow expressed as $\mathrm{ml} / \mathrm{g}$ wet weight.min was of the same order in the right and left ventricular wall under preischemic conditions $(6.1$ to $9.8 \mathrm{ml} / \mathrm{g}$ wet weight.min). In the left ventricle, flow was higher in the inner than in the outer layers. The ratio of the flow through the inner layers and the flow through the outer layers (inner/outer ratio) was on the average about 1.5 . The addition of lactate did not change flow over the inner or outer layers of the myocardium whereas pyruvate slightly increased coronary flow in the inner (not significant) and outer (significant) layers.

Remarkable effects of substrates on flow distribution occurred when hearts were exposed to ischemia and reperfusion. After $15 \mathrm{~min}$ of ischemia, all groups showed a hyperemic response in the inner and outer layers of the left ventricle during 

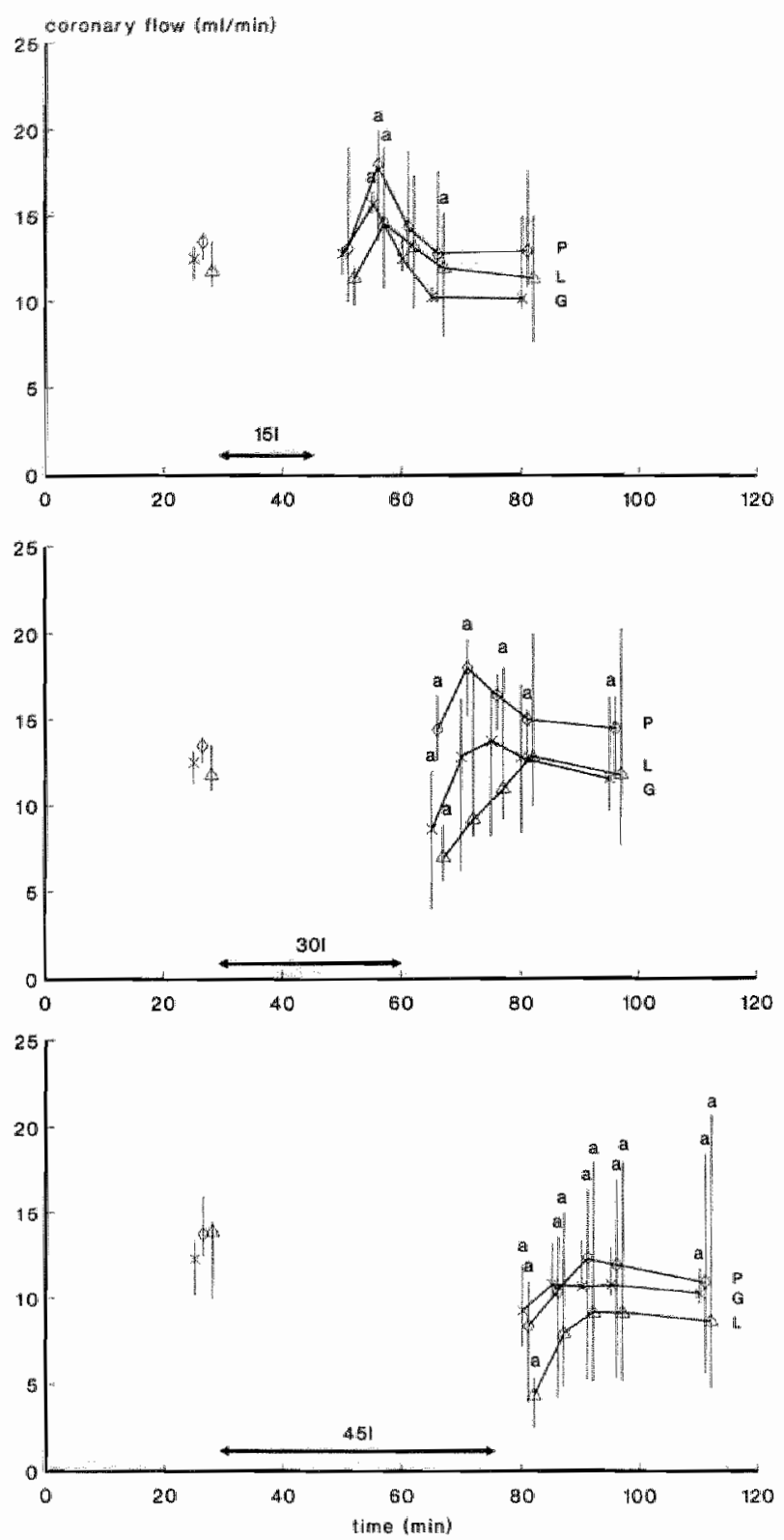

Fig 6.1 Total coronary flow prior to and after 15,30 ar 45 min of ischemia, in hearts perfused with gincose, lactate or pyruvate.

Flow was measured by sampling over timed intervals and is expressed in mimin. Data are presented as median values and $95 \%$ confidence limits. The number of experiments per group varies from 5 to 8. $x=$ ghucose hearts $(11 \mathrm{mM}), G_{;} \Delta=$ glucose $(11 \mathrm{mM})$ plus lactate $(5 \mathrm{mM}), L ; 0=$ glucose $(11 \mathrm{mM})$ plus pyruvate $(5 \mathrm{mM})$. P. Ischemia started atter 30 min of normoxic antegrade pertusion.

a indicates significantly different from preischemic values $(p<0.05)$. 
Table 6.2 Coronary flow in the inner and outer layers of the left ventricle prior to and after 15.30 or 45 min of ischemia, of hearts perfused with glucose, laclate or pyruvale.

\begin{tabular}{|c|c|c|c|c|c|}
\hline $15 !$ & layer & $\mathrm{n}$ & Pre-1 & $5 \mathbb{P}$ & $40 \mathrm{~A}$ \\
\hline $\mathrm{G}$ & 0 & 4 & $6.2(5.7-7.0)$ & $16.4(14.0-18.1)^{2 *}$ & $5.0(4.4-5.5)$ \\
\hline & i & 4 & $9.0(7.9-9.5)$ & $17.5(16.7-18.5)^{\mathrm{a}}$ & $7.0(6.3-7.1)^{3}$ \\
\hline$L$ & 0 & 6 & $6.1(5.4-6.7)$ & $17.6(14.7-23.7)^{\mathrm{a}}$ & $5.7(4.9-5.7)^{d}$ \\
\hline & $i$ & 6 & $9.2(8.5-10.4)$ & $15.9(14.6-20.4)^{a}$ & $8.3(7.4 .8 .9)^{d}$ \\
\hline$P$ & $\begin{array}{l}0 \\
i\end{array}$ & $\begin{array}{l}4 \\
4\end{array}$ & $\begin{array}{l}7.3(5.9-8.8)^{0} \\
9.8(8.4-11.1)\end{array}$ & $\begin{array}{l}16.9(15.1-17.5)^{a^{*}} \\
18.9(18.3-20.6)^{a^{4}}\end{array}$ & $\begin{array}{l}6.5(5.4-6.9)^{d} \\
7.9(7.7-9.0)^{d}\end{array}$ \\
\hline $30 \%$ & & & & & \\
\hline $\mathrm{G}$ & i & $\begin{array}{l}6 \\
6\end{array}$ & $\begin{array}{l}6.2(5.7-7.0) \\
9.0(7.9-9.5)\end{array}$ & $\begin{array}{c}10.2(8.7-16.1)^{\mathrm{a}} \\
8.0(6.2-13.5)\end{array}$ & $\begin{array}{c}7.8(4.9-10.9) \\
12.0(9.1-13.9)^{\mathrm{a}}\end{array}$ \\
\hline$L$ & 0 & $\begin{array}{l}6 \\
6\end{array}$ & $\begin{array}{l}6.1(5.4-6.7) \\
9.2(8.5-10.4)\end{array}$ & $\begin{array}{c}11.2(10.7-15.3)^{\mathrm{a}} \\
2.1(1.2-5.6)^{\mathrm{a} . \mathrm{d}}\end{array}$ & $\begin{array}{c}11.7(10.0-15.1)^{\mathrm{a} . \mathrm{d}} \\
9.3(6.9 \cdot 12.3)\end{array}$ \\
\hline$P$ & i & $\begin{array}{l}6 \\
6\end{array}$ & $\begin{array}{l}7.3(5.9-8.8)^{6} \\
9.8(8.4-11.1)\end{array}$ & $\begin{array}{l}17.3(15.1-18.6)^{a, d, \theta} \\
19.8(17.7-23.3)^{a, d, 0}\end{array}$ & $\begin{array}{c}7.6(6.5 \cdot 9.1)^{0} \\
11.3(10.4-12.3)\end{array}$ \\
\hline $45^{\prime}$ & & & & & \\
\hline $\mathrm{G}$ & 0 & 4 & $6.2(5.7-7.0)$ & $13.2(9.5-16.6)^{a^{\circ}}$ & $8.8(4.7-13.8)$ \\
\hline & $i$ & 4 & $9.0(7.9-9.5)$ & $4.8(1.0-13.5)$ & $9.2(2.7-11.4)$ \\
\hline$L$ & 0 & 6 & $6.1(5.4-6.7)$ & $7.2(5.8-9.2)^{a}, d$ & $9.5(6.6 \times 12.0)^{2}$ \\
\hline & i & 6 & $9.2(8.5-10.4)$ & $0.3(0.1-0.6)^{\mathrm{a}, \mathrm{d}}$ & $0.8(0.1-1.4)^{\mathrm{a}, \mathrm{d}}$ \\
\hline $\mathrm{P}$ & 0 & $\begin{array}{l}4 \\
4\end{array}$ & $\begin{array}{l}7.3(5.9-8.8)^{\theta} \\
9.8(8.4-11.1)\end{array}$ & $\begin{array}{c}15.7(14.3-17.6)^{\mathrm{a}^{*}, \mathrm{e}} \\
4.9(3.1-6.4)^{\mathrm{a}}{ }^{*}{ }^{0}\end{array}$ & $\begin{array}{c}14.1(12.0-16.3)^{\mathrm{a} .0} \\
4.1(2.6-12.8)^{\mathrm{e}}\end{array}$ \\
\hline
\end{tabular}

Flow was measured by microspheres during the preischemic phase (Pre-1), during the first 5 minutes of reperfusion ( $\left.5^{\prime} \mathrm{A}\right)$ and during 35 to $40 \mathrm{~min}$ of reperfusion (40'R). Ischemic lime was 15,30 or 45 min (15\%, 30\% and 45\%, respectively). G means hearts pertised with glucose (11 mM); $L$ means perfused with glucose (11 mM) plus lactate (5 mM); P means perfused with glucose (11 $\mathrm{mM}$ ) plus pyruvate $(5 \mathrm{mM})$. o=outer layer, $j=i n n e r$ layer; Values are expressed in $\mathrm{m} / \mathrm{g}$ wet weight.min; $n$ presents number of experiments. Data are presented as median values and $95 \%$ confidence limits. $a^{*}$ indicates significantly different from preischemic values $(0.05<p<0.10)$. For other symbols see table $6 . \%$

the initial 5 min of reperfusion (table 6.2). In the glucose and pyruvate group the inner/outer ratio did not significantly change, but in the lactate group the inner/outer ratio fell to 0.9 , indicating a relative underperfusion of the inner layers of the left ventricle. After $40 \mathrm{~min}$ of reperfusion flow through the left ventricle returned towards preischemic values. Following a 30 min ischemic interval, glucose and lactate hearts demonstrated elevated coronary flow rates in the outer layers, but failed to increase coronary flow above preischemic levels in the inner layers of the left ventricle at the onset of reperfusion. In lactate perfused hearts coronary flow was even significantly depressed in the inner layers. The inner/outer ratio decreased to 0.7 in the glucose group and to 0.2 in the lactate group. Continuing reperfusion for $40 \mathrm{~min}$, glucose and lactate hearts restored flow equal to or above preischemic values, but in lactate hearts the inner/outer ratio remained depressed. In contrast to glucose and lactate hearts, pyruvate hearts demonstrated raised flow values in both inner and outer layers after $30 \mathrm{~min}$ of ischemia followed by $5 \mathrm{~min}$ of reperfusion. At the end af reperfusion flow values were returned to normal preischemic levels. 
Table 6.3 Coronary flow in right ventricle prior to and after 15,30 or 45 min of ischemia, of hearts perfised with glucose, lactate or pyruwate.

\begin{tabular}{|c|c|c|c|c|}
\hline & $n$ & Pre-l & $5 R$ & $40^{\circ} \mathrm{R}$ \\
\hline \multicolumn{5}{|l|}{154} \\
\hline$G$ & 4 & $8.1(5.3-6.8)$ & $9.9(5.1-13.7)^{a^{*}}$ & $4.8(4.1-5.7)$ \\
\hline $\mathrm{L}$ & 6 & $7.6(6.7-9.3)$ & $16.9(14.9-22.8)^{\mathrm{a}_{1} d}$ & $7.5(3.9-9.1)$ \\
\hline $\mathrm{P}$ & 4 & $8.8(7.5-10.1)^{d}$ & $19.9(15.8-26.5)^{a^{*}, d}$ & $7.8(7.5-12.4)^{d}$ \\
\hline \multicolumn{5}{|l|}{$30 \|$} \\
\hline$G$ & 6 & $8.1(5.3-8.8)$ & $16.1(12.5 \cdot 26.4)^{\mathrm{a}}$ & $8.6(5.9-12.3)$ \\
\hline L & 6 & $7.6(6.7-9.3)$ & $15.6(10.9-24.8)^{2}$ & $10.1(6.4-19.5)$ \\
\hline P & 6 & $8.8(7.5-10.1)$ & $15.9(13.7-28.3)^{\mathrm{a}}$ & $7.6(5.9-17.0)$ \\
\hline \multicolumn{5}{|c|}{$45^{\prime} 1$} \\
\hline Gi & 4 & $8.1(5.3-8.8)$ & $13.4(3.8-18.2)^{a^{*}}$ & $9.4(2.5-12.7)$ \\
\hline $\mathrm{L}$ & 6 & $7.6(6.7-9.3)$ & $12.9(8.9-14.9)^{\mathrm{a}}$ & $12.0(9.6-14.0)^{\mathrm{a}}$ \\
\hline $\mathrm{P}$ & 4 & $8.8(7.5-10.1)$ & $14.5(9.1-18.2)$ & $13.0(8.8-14.8)$ \\
\hline
\end{tabular}

Flow was measured by microspheres during the preischemic phase (Pre-l), during the first 5 minutes of reperfusion ( $5^{\prime} R$ ) and during 35 to 40 min of reperfusion (40'R). Ischemic time was 15, 30 or 45 $\min (15 \%, 30 \%$ and $45 \%$, respectively). $G$ means glucose (11 $\mathrm{mM})$ perfused hearts; $L$ means glucose (11 $\mathrm{mM}$ ) plus lactate (5 mM) perfused hearts; $P$ means glucose (11 $\mathrm{mM}$ ) plus pyruvate $(5 \mathrm{mM}$ ) perfused hearts. Values are expressed in $\mathrm{mW} / \mathrm{g}$ wet weigh. min. $n$ presents number of experiments. Data are presented as median values and $95 \%$ confidence limits.

$a^{*}$ indicates significanlly different from preischemic values $(0.05<0<0.10)$. For other symbols see table 6.1.

When preceded by $45 \mathrm{~min}$ of ischemia, each substrate group demonstrated underperfusion of the inner layers of the left ventricle at the beginning of reperfusion (although not significant in glucose hearts). Flow through the inner layers was more decreased in lactate hearts than in glucose or pyruvate hearts. The inner/outer ratio decreased to $0.5,0.05$ and 0.3 in glucose, lactate and pyruvate hearts, respectively. Continuing repertusion, flow values were restored in the inner layers of glucose hearts, whereas in lactate and pyruvate hearts flow through the inner layers remained depressed. The inner/outer ratio was $1.3,0.08$ and 0.3 in glucose, lactate and pyruvate hearts, respectively, after $40 \mathrm{~min}$ of reperfusion following $45 \mathrm{~min}$ of ischemia.

In contrast to impairment of flow in the lleft ventricle, no indication for reduced perfusion in the right ventricle was found in the three substrate groups (table 6.3). The right ventricle showed hyperemic flow responses by initiating reperfusion after various intervals of ischemia. Continuing reperfusion for $40 \mathrm{~min}$, flow values returned to preischemic levels except in lactate hearts subjected to $45 \mathrm{~min}$ of ischemia. In these hearts, flow in the right ventricle remained significantly increased.

Radioactive microspheres were absent in coronary effluents collected after injection, indicating that injected microspheres were entirely captured in the coronary (microvascular) system. In fig 6.2 a microsphere trapped in a microvessel is shown. 

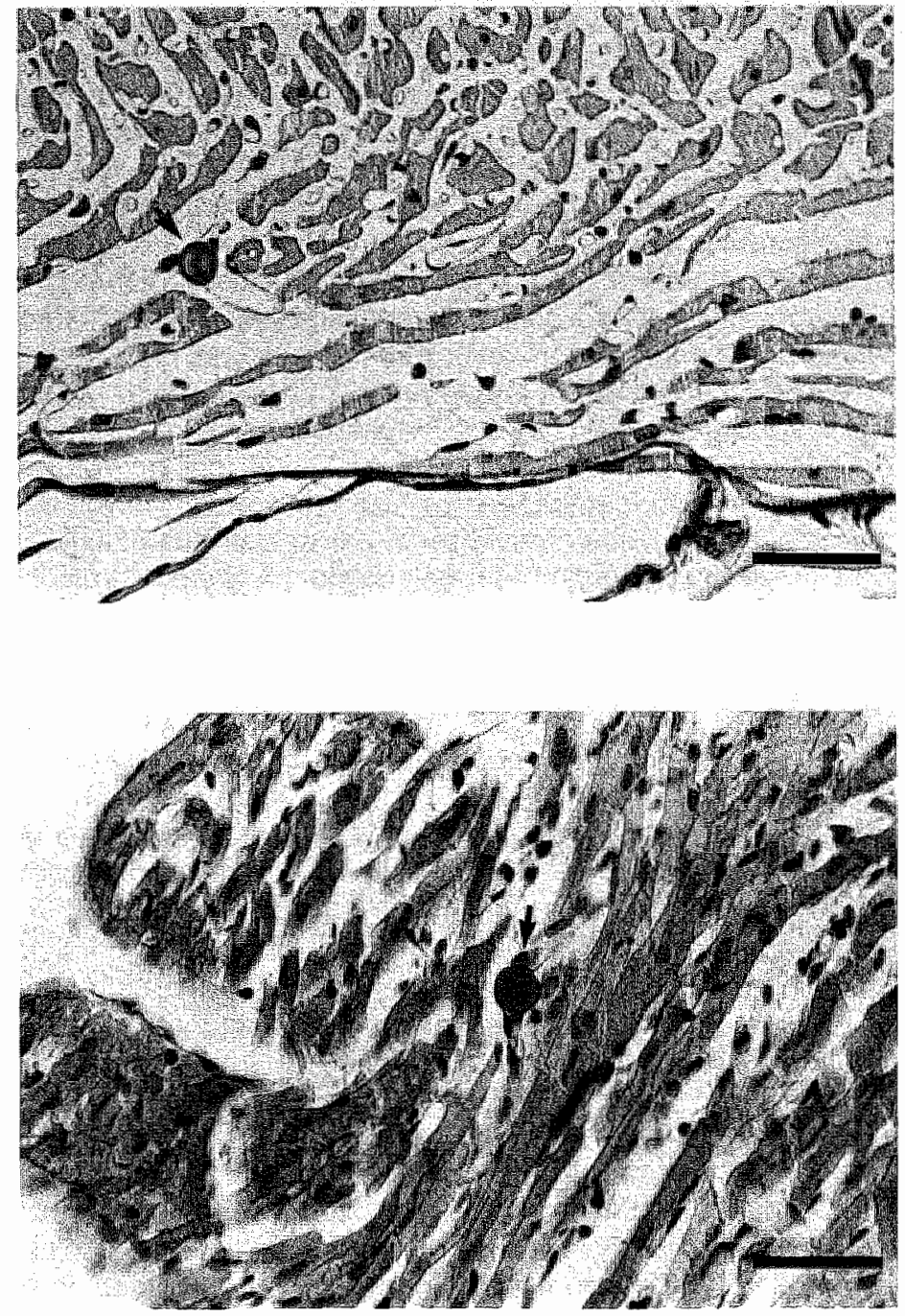

Fig 6.2 Trapping of a microsphere in a microvessel (arrow). A cross sectional (A) and a longitudinal sectional $(B)$ detail. The heart was perfused with a normoxic Krebs Henseleit bicarbonate buffer containing glucose $(11 \mathrm{mM})$ plus lactate $(5 \mathrm{mM})$ for $30 \mathrm{~min}$. Subsequently, the heart was injected with a bolus of microspheres $\left(0.1 \mathrm{ml}, 5 \times 10^{4}\right.$ microspheres/ml). Then, the heart was pertused with $2.5 \%$ glutaraldehyde in phosphate buffer, disconnected from the perfision apparatus and postfixed in $2.5 \%$ glutaraldehyde phosphate buffer ovemight. The ventricular part of the heart was cut into small slices. These slices were dehydrated by ethanol in increasing concentrations and dehydrated tissue slices were embedded in paraffine blocks at $60^{\circ} \mathrm{C}$. The blocks were routinely cut for light microscopy. Bar represents $50 \mu \mathrm{m}$. 


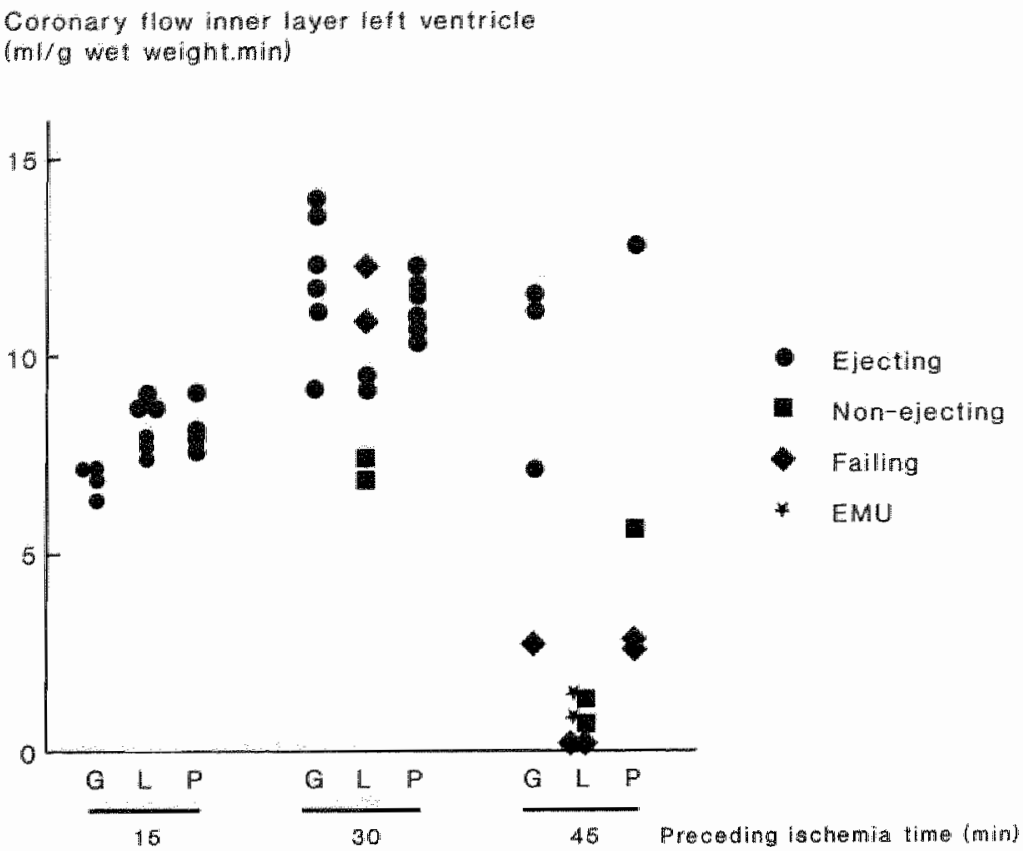

Fig 6.3 Intraindividual relationship between hemodynamic behaviour at $35 \mathrm{~min}$ of reperfusion and coronary thow in the inner layers of the left ventricle at 40 min of reperfusion of hearts subjected to 15,30 or 45 min of ischemia.

Cardiac behaviout was classified into ejecting (restoring stroke volume to same extent), non-ejecting (regular mechanical activity without stroke volume), failing (sinus rhythm disturbed) and electromechanically uncoupled hearts (regular sinus thythm, no mechanical activity, no stroke volume). Coronary llow in the inner layers is expressed as $\mathrm{m} / \mathrm{g}$ wet weight. min; $\mathrm{G}=$ glucose (11 $\mathrm{mM}$ ); $L=$ glucase $(11 \mathrm{mM})$ plus lactate $(5 \mathrm{mM}) ; \cdot P=$ glucose $(11 \mathrm{mM})$ plus pyruvate $(5 \mathrm{mM})$.

\section{Hemodynamic behavlour versus coronary flow through the inner layers}

The intraindividual relationship between hemodynamic performance and coronary flow through the inner layers is illustrated in fig 6.3. A classification of behaviour of reperfused hearts was made. Four types of classes could be identified: first, ejecting hearts (restoring stroke volume to some extent); second, non-ejecting hearts (regular mechanical activity without stroke volume); third, failing hearts (sinus rhythm disturbed, i.e. tachycardia, fibrillation, no stroke volume) and fourth, electromechanically uncoupled hearts (regular sinus rhythm, no mechanical activity. no stroke volume). Fig 6.3 depicts functional behaviour and flow through the inner layers of the left ventricle measured at the end of reperfusion (i.e. at $35 \mathrm{~min}$ and 40 min of reperfusion, respectively).

When subjected to $15 \mathrm{~min}$ of ischemia, all hearts regained the ejecting mode during antegrade reperfusion. In these ejecting hearts flow through the inner layers at the end of reperfusion was comparable to preischemic flow.

When the preceding ischemic interval was $30 \mathrm{~min}$, glucose and pyruvate hearts were able to resume stroke volume. Flow in the inner layers of glucose and pynuvate 
hearts was adequately restored. Lactate hearts were either ejecting, non-ejecting or failing. Flow values were higher in ejecting hearts than in those lactate hearts that were non-ejecting, but flow levels in the inner layers of failing hearts were comparable to those in ejecting hearts at 40 min of reperfusion.

After 45 min of ischemia, 3 of 4 glucose perfused hearts were in the ejecting mode, while 1 heart was failing. The ejecting hearts showed higher flow values than the failing heart in the glucose group. Lactate hearts were either non-ejecting, fibrillating or electromechanically uncoupled. In all cases flow was extremely low. Of pyruvate hearts, just 1 heart was able to eject, 1 heart was in non-ejecting mode and 2 hearts were out of rhythm. The ejecting heart reached better perfusion of the inner layers than the non-ejecting or failing hearts. The non-ejecting heart showed more flow through the inner layers than the failing hearts in the pyruvate group.

Over all (i.e. all ischemic intervals and substrate groups included), ejecting hearts varied flow in the inner layers from 6.3 to $13.9 \mathrm{ml} / \mathrm{min}$. Non-ejecting hearts demonstrated lower values, i.e. 0.7 to $7.4 \mathrm{ml} / \mathrm{min}$ compared to ejecting hearts. Failing hearts fluctuated flow in the inner layers over a wide interval, 1.e. 0.1 to 12.3 $\mathrm{ml} / \mathrm{min}$. In electromechanically uncoupled hearts flow was severely depressed $(0.8$ to $1.4 \mathrm{ml} / \mathrm{min}$ ) at the end of reperfusion.

\section{Osmotic active substances}

The content of osmotic active substances is presented by the sum of glycolytically derived compounds including lactate, glycerol-3-phosphate and glycerol. Accumulation of these intermediates during ischemia was corrected for the preischemic content.

After 15 min of ischemia, similar amounts of low molecular weight substances were accumulated in the three substrate groups (fig 6.4). During $30 \mathrm{~min}$ of ischemia, accumulation of the glycolytic compounds continued in the lactate and pyruvate group. The total content was markedly higher in the lactate and pyruvate group than in the glucose group, but the lactate group did not significantly differ from the pyruvate group. After $45 \mathrm{~min}$ of ischemia, the accumulation of glycolytic compounds was not further increased. Values were significantly elevated in lactate and pyruvate hearts compared to glucose hearts. The levels in lactate and pyruvate hearts were not significantly different.

\subsection{DISCUSSION}

The present study illustrates the effect of exogenous lactate on coronary flow distribution of the postischemic heart. After $30 \mathrm{~min}$ of ischemia, addition of lactate to a glucose containing buffer transiently impaired coronary flow in the inner layers of the myocardium during reperfusion. After $45 \mathrm{~min}$ of ischemia, flow in the inner layers remained severely depressed throughout reperfusion. In pyruvate perfused hearts an increase of coronary flow at the onset of reperfusion was still observed after moderate ischemila (15 and $30 \mathrm{~min}$ ). However, like in lactate hearts, flow in inner layers was compromised after $45 \mathrm{~min}$ of ischemia and $5 \mathrm{~min}$ of reperfusion and did not recover thereafter. In contrast to lactate and pyruvate hearts, glucase hearts did 
Tiscue content of glyoolytic compounds (umol/g dry weight)

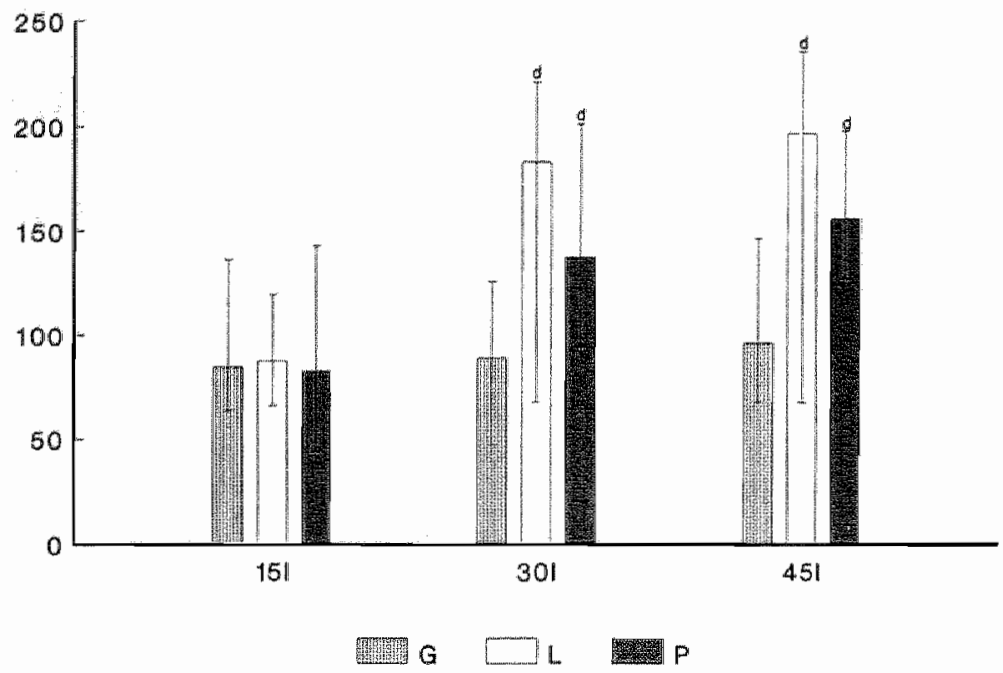

Fig 6.4 Accumulation of glycolytic compounds during 15,30 or 45 min of ischemia in glucose, lactate and pyruvate hearts.

Glycolytic compounds reter to the sum of lactate, glycerol-3-phosphate and glycerol. Values are corrected for the preischemic content. Tissue contents are expressed in $\mu$ malvg dry weight. Data are presented as median values and $95 \%$ confidence limits. $G=$ glucose $(11 \mathrm{mM}) ;$ plus lactate $(5 \mathrm{mM}) ; P_{=}$glucose $(11 \mathrm{mM})$ plus pyruvate $(5 \mathrm{mM})$.

${ }^{d}$ indicates significantly different from glucose hearts $(p<0.05)$

not show severe underperfusion of the inner layers following 45 min of ischemia and 40 min of reperfusion.

\section{Hemodynamic recovery}

The recovery of cardiac pertormance after ischemia was determined by the presence of exogenous substrates. In this respect, lactate pertused hearts demonstrated remarkable impairment of hemodynamic recovery after $30 \mathrm{~min}$ of ischemia compared to glucose hearts. In contrast, pyruvate perfused hearts improved resumption of stroke volume and positive $\mathrm{dP} / \mathrm{dt}$ max after $30 \mathrm{~min}$ of ischemia in comparison to glucose hearts. However, after $45 \mathrm{~min}$ of ischemia its effect was detrimental whereas hearts perfused with glucose only were still able to resume stroke volume and positive $\mathrm{dP} / \mathrm{dt}$ max. Bünger and coworkers (1989) showed a similar detrimental effect of exogenous lactate on functional periormance after $45 \mathrm{~min}$ of low-flow ischemia by increasing its concentration from $5 \mathrm{mM}$ to 15 
$\mathrm{mM}$. The beneficial effect of pyruvate confirms the findings of Liedtke and Nellis (1978), Mochizuki and Neely (1980), Van Bilsen et al (1988) and Bünger al (1989). These authors, though, did not mention limitation of a protective effect of pyruvate as relatively compared to glucose perfused hearts by longer intervals of ischemia.

\section{Regional flow}

Under preischemic normoxic conditions, no profound effect on the flow distribution was present by addition of lactate or pyruvate to the glucose buffer. Flow through the inner layers of the left ventricle was higher than flow through the outer layers. The ratio of flow over the inner and outer layers was about 1.5. Snoeckx et al (1989) mentioned a lower inner/outer ratio, i.e. 1.2 in rat hearts. In dog hearts, blood flow ratio's vary from unity to slightly higher than one, depending on the experimental conditions and techniques used (Van der Vusse et al, 1990). The high inner/outer ratio in the present study might be related to the experimental model used (isolated heart, blood free perfusion medium).

The exogenous substrates influenced transmural flow of the postischemic heart. In this respect pronounced impairment of flow in the inner layers was observed in lactate hearts after 30 min of ischemia but this reduction was transient. After 45 min of ischemia, flow in the inner layers remained severely depressed in lactate hearts. Glucose and pyruvate hearts also showed decreased flow through the inner layers at the onset of reperfusion following 45 min of ischemia albeit to a lesser extent than in lactate hearts. Like in lactate hearts, the perfusion defect was sustained in pyruvate hearts. In contrast to lactate and pyruvate hearts, glucose perfused hearts showed no continuation of flow impairment in the inner layers of left ventricle. Hence, glucose may be a protective substrate against no-reflow after longterm ischemia (45 min) whereas lactate stimulates perfusion defects after a short interval of ischemia (30 min). Flow in the outer layers was not lowered by the preceding period of ischemia. Accordingly, several authors reported higher vulnerability of the inner layers than the outer layers of the left ventricle for ischemia (Feigl, 1983; Hofman, 1987; Bolli, 1988).

Like the outer layers of the left ventricle, the right ventricle did not become underperfused due to ischemic processes. In all cases, a hyperemic response was found in the right ventricle during the first minutes of reperfusion and normal (i.e. near base line value) flow at the end of reperfusion. Lactate hearts showed slightly but significantly increased values above the preischemic level after 45 min of ischemia and $35 \mathrm{~min}$ of reperfusion. This indicates that flow is redistributed from the inner layers of the left ventricle to the right ventricle. Correspondingly, Guth and coworkers (1991) described possible interventricular redistribution of flow under ischemic conditions which favours flow through the right ventricle at the expense of flow through the inner layers of the left ventricle. Such an interventricular redistribution may further enhance damage to the inner layers.

\section{Relationship between hemodynamic recovery and flow in the inner layers}

Our data indicate that a relationship may exist between postischemic recovery of hemodynamic function and flow through the inner layers of left ventricle. In this 
respect, lactate hearts demonstrated transient flow impairment in the inner layers after 30 min of ischemia, while after the same ischemic interval hemodynamic recovery was severely reduced. In pyruvate hearts hyperemic response was still observable after 30 min of ischemia, while restoration of hemodynamic performance was pronounced. In glucose hearts no hyperemic response was detected, but flow through the inner layers was still considerable and functional recovery was moderate. After 45 min of ischemia, severely reduced flow values in the inner layers of the left ventricle of lactate and pyruwate hearts coincided with poor performance. In glucose hearts, perfusion defects were less extreme and hemodynamic recovery was better than in lactate and pyruvate hearts. Moreover, a relationship between hemodynamic function and flow restoration is supported by individual comparison of hemodynamic behaviour and flow through the inner layers during reperfusion in the same set of experiments (fig 6.3). Although there were no strict flow ranges for the different modes of action, the ejecting hearts recovered at least $75 \%$ of the preischemic low value. In hearts with no mechanical activity (and regular sinus thythm, i.e. electromechanically uncoupled hearts) flow decreased to less than $15 \%$ of preischemic value. Hence, a severe reduction of flow in the inner layers of the left ventricle is related to loss of mechanical activity, while only a slight decrease of flow may be related to impaired stroke volume. Correspondingly, Vatner (1980) and Gallaghan and colleagues (1982) reported a close coupling between blood flow in the inner layers and functioning. In the present study, failing hearts displayed a wide range of flow values in the inner layers of the left ventricle, but the inner/outer ratio was lowered in all failing hearts. Deleterious effects of ventricular fibrillation on flow through the inner layers compared to the outer layers are in agreement with findings of others (Salerno et al, 1979; Sink et al; 1983).

Our results indicate that in lactate hearts flow impairment after 30 and $45 \mathrm{~min}$ of ischemia coincided with a marked increase of the end-diastolic pressure during reperfusion (except in those hearts lacking mechanical activity). Pyruvate hearts also demonstrated disturbed flow in the inner layers when end-diastolic pressure reached to $4.5 \mathrm{kPa}$. Likewise, Kjekshus (1984) mentioned a relationship between vascular shutdown in deeper layers of myocardium and raise of the end diastolic pressure.

\section{Possible factors involved in flow defect}

The mechanism causing severe flow restriction in the inner layers is not completely understood. As coronary perfusion pressure is maintained in the model used (assisted heart model), flow impairment should be related to an increase of coronary resistance. However, coronary resistance seems to be affected only in the inner layers of the left ventricle, whereas coronary resistance in the outer layers of the left ventricle is probably less changed. There are several factors which may influence vascular resistance.

1. Obstruction. Obstruction by blood particles (e.g. red blood cell packing and neutrophil plugging) as suggested by Ambrosio and coworkers (1989) can not be the causative factor of flow reduction in our study as we used an isolated rat heart model and perfused the hearts by a blood free buffer.

2. Edema. Tranum-Jensen and associates (1981) recognized celli swelling as an important factor in the compression of the capillary lumen. During ischemia, tissue osmolarity raises due to accumulation of low molecular weight substances such as 
lactate. By restoration of flow fluid may be retained while intercellular and interstitial edema might develop. In the present study, the overall content of various glycolytically derived compounds was assessed to explore the possibility of osmotic cell swelling. Our data showed that exogenous lactate stimulated production of low molecular weight substances compared to glucose hearts. However, in pyruvate hearts considerable accumulation of glycolytically derived compounds was found as well. It is important to note that Humphrey and coworkers (1988) failed to observe differences in the extent of accumulation of low molecular weight substances (lactate and purines) between the inner and outer layers of the left ventricle. Hence, the contribution of osmotic active compounds cloes not seem to be a feasible explanation for flow differences in the inner and outer layers, induced by the three substrates during the postischemic phase.

3. Contracture of myocytes. Humphrey and colleagues (1984) suggested that hypercontraction of myocytes may be a significant event in the development of vascular defects. Increased contraction tension may elevate tissue pressure on the coronary vasculature and hence increase resistance. Moreover, hypercontraction is associated with decreased relaxation and hence increased diastolic pressure. By elevation of diastolic pressure flow to the inner layers is more severely inhibited than flow to the outer layers (Kjekshus; 1984). Experimental findings of Armiger and coworkers (1974) indicated that ultrastructural damage of cardiac myocytes may be aggravated by exogenous lactate ( $\mathrm{pH} 7.2-7.4)$. In contrast, Geisbuhler and Rovetto (1990) reported that exogenous lactate $(10 \mathrm{mM}$ and $50 \mathrm{mM}$; $\mathrm{pH}$ value 6.9 or 7.3 ) does not enhance damage of isolated myocytes during anoxia. These last findings might indicate to derangements of the vasculature itself as outlined below.

4. Contracture of vascular smooth muscles. Reactivity of smooth muscles of the vasculature is regulated by noradrenaline. Abrahamson and associates (1983) demonstrated that exogenous lactate $(\mathrm{pH} 7.4)$ enhances ischemia-induced noradrenaline release. Hence, exogenous lactate may stimulate hypercontraction of the smooth muscles. Crarlsson and colleagues (1987), though, reported that the increase of ischemia-induced noradrenaline release by exogenous lactate $(\mathrm{pH} 7.4)$ can be markedly attenuated by the presence of glucose. Besides, if lactate would influence vascular tone, the question remains why effects are manifest in the inner layers and not in the outer layers.

5. Damage of endothelial cells. Carter and Gavin (1989) showed that exagenous lactate ( $\mathrm{pH} 6.4$ or 7.4 ) induced severe and progressive endothelial cell damage which includes separation and exfoliation. Subsequently, progressive damage may result by exposure of underlying connective tissue and myocardial cells.

The extent to which oxygen radicals contribute to ischemia or reperfusion induced cell damage is still a matter of debate (Reimer et al, 1989). Although extracellular sources (lleucocytes and granulocytes) have not contributed to radical formation in the present case, generation of oxygen reactive molecules is possible by intracellular sources (Bolli, 1988). Further research is needed to elucidate whether lactate-induced impairment of postischemic coronary flow is mediated by enhanced production of oxygen free radicals. It should be noted that the possibility exists that the effect of exogenous lactate on flow through the inner layers of the postischemic left ventricle as observed in the present study is causally related to processes not listed above. 
In summary, the present study illustrates for the first time that exogenous lactate may aggravate an ischemic insult by causing underperfusion of the inner layers of the previously ischemic myocardium after reinstallation of flow. It is worth mentioning that in man blood lactate readily increases under several conditions (i.e. exercise, hypoxemia during shock, perfusion by lactate-Ringer solution during open heart surgery; Moret; 1980). Therefore, adverse effects of lactate mediated by pertusion defects in the inner layers of the left ventricle of transient ischemic hearts in man has also to be considered.

\section{Acknowledgments}

We greatly acknowledge the expert contribution of Dr F.W. Prinzen and Dr L.H.E.H. Snoeckx to this investigation.

\subsection{REFERENCES}

1. Ambrahamson T, Almgren $O$, Carlsson L (1983) Ischemia- induced noradrenaline release in the isolated rat heart: influence of perfusion substrate and duration of ischemia. J Mol Cell Cardiol $15: 821 \div 830$

2. Ambrosio G, Weisman HF, Mannisi JA, Becker LC (1989) Progressive impairment of reglonal myocardial perfusion after initial restoration of postischemic blood flow. Circulation 80:1846-1861

3. Armiger LC, Gavin JB, Herdson PB (1974) Mitochondrial changes in dog myocardium induced by neutral lactate in vitro. Lab Invest 31:29-33

4. Bolli IR (198B) Oxygen-derived free radicals and postischemic myocardial dysfunction ("stunned myocardium"). J Am Coll Cardiol 12: 239-249

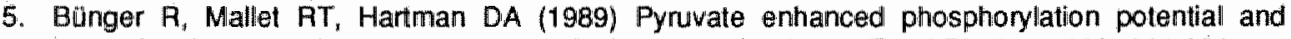
inotropism in normoxic and postischemic isolated working heart. Eur $\mathrm{J}$ Biochem 180: 221-233

6. Carisson L, Abrahamsson T, Almgren $O$, Svensson LS (1987) Ischaemia-induced release of noradrenalline and creatine kinase in the isolated, working rat heart. Acta Physiol Scand 130:8393

7. Carter G, Gavin JB (1989) Endocardial damage induced by lactate, lowered pH and lactic acid in non-ischemic beating hearts. Pathology 21: 125-130

8. De Groot MJM, Van der Vusse GJ (1990) The effect of lactate on ischemic and repertused hearts. Pflugers Archiv-Eur J Physiol 416: S5 (abstract)

9. Feigl (1983) Coronary physiology. Physiol Rev 63: 1-205

10. Gallagher KP, Osakada G, Matsuzaki M, Kemper WS, Fioss J (1982) Myocardial blood flow and function with critical coronary stenosis in exercising dogs. Am J Physiol 243: $\mathrm{H} 698-\mathrm{H} 707$

11. Gavin JB, Humphrey $S M$, Herdson $P B$ (1983) The no-reflow phenomenon in ischemic myocardium. Int Rev Exp Pathol 25: 361-383

12. Geisbuhler TP, Rovetto MJ (1990) Lactate does not enhance anoxia/reoxygenation damage in adult rat cardiac myocytes. J Mol Cell Cardiol 22: 1325-1335

13. Guth BD. Schulz R, Thaulow E (1991) Interventricular redistribution of myocardial blood flow during imetabolic vasodilation. Pflügers Archiv-Eur J Physiol 417: 485-492

14. Hoftman JIE (1987) Transmural myocardial perfusion. Progr Cardiovasc Dis 29:429-464

15. Humphrey SM, Thomson AW, Gavin JB (1984) The influence of the na-reflow phenomenon on repertusion and reoxygenation damage and enzyme release from anoxic and ischaemic isolated rat hearts. J Mol Cell Cardiol 16: 915-930

16. Humphrey SM, Vanderwee MA, Gavin JB (1988) Transmural differences in the postischemic recovery of cardiac energy metabolism. Am J Pathol 131:5-11

17. Kjekshus JK (1984) The coronary circulation in normal and ischemic hearts. Scand J Clin Lab Invest 44 (suppl 173): 9-18 
18. Kloner RA, Ganote $C E_{\text {, Jennings }} \mathrm{RB}$ (1974) The no-reflow phenomenon after temporary occlusion in the dog. J Clin Invest 54: 1494-1508

19. Laurell S, Tibbling $G$ (1966) An enzymatic fluorometric micromethod for the determination of glycerol. Clin Chim Acta 13: 317-322

20. Liedtke AJ, Nellis SH (1978) Effects of buffered pyruvate on regional cardiac function in moderate, short-term ischemia in swine heart. Circ Res 43: 189-199

21. Mochizuki S, Neely JR (1980) Energy metabolism during reperfusion following ischemia. J Physiol 76: 805-812

22. Moret PR (1980) Opening remarks. In: Moret $\mathrm{PR}_{n}$ Weber J $\mathrm{J}_{4}$ Haissly J CL, Denolin $\mathrm{H}$ (ed) Lactatephysiologic methodologic and pathologic approach. Springer Verlag Berlin/Heidelberg/New York, pp 195-196

23. Neely JR, Grotyohann LW (1984) Role of glycolytic products in damage to ischemic myocardium. Dissociation of adenosine triphosphate levels and recovery of function of reperfused ischemic hearts. Circ Res 55:816-8:24

24. Passonneau J (1974) Fluorometric method for the determination of lactate with LDH. In: Bergmeyer HU (ed) Methods of enzymatic analysis. Weinheim: Verlag Chemle $\mathrm{GmbH}_{*}$ Vol. 3 : $1468-1472$

25. Prinzen FW, Van der Vusse GJ, Reneman RS (1981) Blood flow distribution in the left ventricular free wall in open- chest dogs. Basic Res Cardiol 76; $431-437$

26. Reimer KA, Murry CE, Richard, VJ (1989) The role of neutrophils and free radicals in the ischemic, repertused heart: Why the confusion and controversy? J Mol Cell Cardiol 21: 12251239

27. Salerno TA, Shizgal HM, Dobell ARC (1979) Pulsatile perfusion: its effects on blood flow distribution in hypertrophied hearts. Ann Thorac Surg 27: 559-563

28. Sink JD, Hill RC, Attarian DE, Wechsler AS (1983) Myocardial blood flow and oxygen consumption in the empty- beating, fibrillating, and potassium-arrested hypertrophied canine heart. Ann Thorac Surg 35: 372-379

29. Snoeckx LHEH, Van der Vusse GJ, Coumans WA, Willemsen PHM, Van der Nagel T, Reneman RS (1986) Myocardial function in normal and spontaneously hypertensive rats during reperfusion after a period of global ischemia. Cardiovasc Res 20: 67-75

30. Snoeckx LHEH, Van der Vusse, GJ, Van der Veen FH, Coumans WA, Reneman RS (1989) Recovery of hypentrophied rat hearts after global ischemia and reperfusion at different perfusion pressures. Pflügers Archiv-Eur J Physiol 413: 303-312

31. Tranum-Jensen J, Janse MJ, Fiolet JWT, Krieger WJG, D'Alnoncourt CN, Durrer D (1981) Tissue osmolarity, cell swelling, and repentusion in acute regional myocardial ischemia in the lisolated porcine heart. Circ Res 49: 364-381

32. Van Bilsen $M$, Van der Vusse $G J$, Snoeckx LHEH, Arts $T$, Coumans WA, Willemsen PHM, Reneman RS (1988) Effects ofpyruvate on postischemic myocardial recovery at various workloadls. Pflügers Archiv-Eur J Physiol 413: 167-173

33. Van Bilsen $M_{n}$ Snoeckx LHEH, Arts T, Van der Vusse GJ, Reneman FS (1991) Performance of the isclated, ejecting heart: effects of aortic impedance and exogenous substrates. Pllugers Archiv-Eur J Physioll 419: 7-12

34. Van der Vusse GJ, Arts T, Glatz JFC, Reneman RS (1990) Transmural differences in energy metabolism of the left ventricular myocardium: fact or fiction. J Mol Coll Cardiol 22: 23-37

35. Vatner $S(1980)$ Correlation between acute reductions in myocardial blood flow and function in conscious dogs. Circ Res 47:201-207 
CHAPTER 7

\section{GLYCEROL-3-PHOSPHATE HYDROLYSING ACTIVITY AND ITS}

SUBCELLULAR LOCALIZATION IN RAT CARDIAC MUSCLE

\#The results of this chapter are in preparation for publication by De Grool MJM, De Jong YF, Van der Vusse GJ 


\begin{abstract}
Direct hydrolysis of glycerol-3-phosphate (glycerol-3-P) into glycerol was evaluated in cardiac homogenates and its subcellular fractions. In addition, glycerol-3-P hydrolysing activity in some skeletal muscles was determined. In cardiac tissue, the glycerol-3-P hydrolysing activity appeared to be dependent on $\mathrm{pH}$. A higher activity was observed when pH decreased from 7.2 to 5.0. At pH 7.2, apparent $V_{\text {max }}$ and $K_{m}$ values were 0.25 $\pm 0.03 \mu \mathrm{mol} / \mathrm{g}$ wet weight.min and $2.86 \pm 0.96 \mathrm{mM}$, respectively. At pH 5.0, apparent $V_{\max }$ and $K_{m}$ values were $0.94 \pm 0.11 \mu$ mol/g wet weight.min and $4.24 \pm 1.12 \mathrm{mM}$, respectively. The relative specific activity was highest in the lysosomal fraction. There was no barrier for the contact between the substrate glycerol-3-P and its hydrolysing enzyme in lysosomes. Skeletal muscles also demonstrated glycerol-3-P hydrolysing activity. In this regard, white muscles showed higher activity than red muscles.
\end{abstract}




\subsection{INTRODUCTION}

Glycerol serves as the backbone of triacylglycerols. By complete hydrolysis of these lipids glycerol is set free. So far, glycerol is generally accepted as a valid index of lipolysis in cardiac tissue. Firstly, this is based on the observation that the heart contains very low glycerol kinase activity (Robinson et al, 1967) resulting in limited conversion of glycerol to glycerol-3-phosphate (glycerol-3-P). Secondly, both perfused tissue and myocytes lack the ability to oxidize glycerol (Scheuer and Olson, 1967; Tamboli et al, 1983).

It has been suggested that lipolysis and, hence, glycerol release is tightly coupled to glycolysis via production of glycerol-3-P. Glycerol-3-P is required for esterification of acyl moieties into triacylglycerols (Hülsmann and Stam, 1979; Trach et al, 1986). In this context, the glycerol part of glycerol-3-P is incorporated into the triacylglycerol pool and released as glycerol by lipolysis, i.e. tumover of the triacylglycerol pool. The possibility that glycerol stems directly from glycerol-3-P instead of passing the triacylglycerol pool has been found of minor importance under normoxic conditions (Denton and Randle, 1967). However, direct dephosphorylation of glycerol-3-P under ischemic conditions has not been adequately explored. Under these circumstances, the cardiac content of glycerol-3-P and, hence, substrate supply is increased (Rovetto et al, 1975). Recently, Myrmel and coworkers (1991) have demonstrated a linear relationship between cellular glycerol-3-P and glycerol output during hypoxic incubation of isolated myocardial cells. These findings can be explained by hydrolysis of glycerol-3-P yielding glycerol.

It was the aim of the present study to identify the presence of glycerol-3-P hydrolysing activity in rat heart. $\mathrm{pH}$ dependency of glycerol-3-P hydrolysis was determined over the $\mathrm{pH}$ range 5.0 to 7.2 , which reflects the range of acidosis in ischemic hearts (Cobbe and Poole-Wilson, 1979; Bailey et all, 1982). Kinetic properties of the glycerol-3-P hydrolysing enzyme were determined at the ultimate values of this range, i.e. $\mathrm{pH} 7.2$ and $\mathrm{pH} 5.0$. Special attention has been paid to subcellular localization of glycerol-3-P hydrolysing activity.

In addition, glycerol-3-P hydrolysing activity in cardiac tissue was compared to glycerol-3-P hydrolysing activity in a limited number of rat skeletal muscles.

\subsection{METHODS}

\section{Animals}

Hearts were obtained from male Lewis rats (10 weeks old, range body weight 250-350 g). The animals were kept under an artificial light cycle of 12 hours and had free access to laboratory chow (SRM-A, Hope Farms) and water.

\section{Preparation}

Under light ether anaesthesia, hearts were removed from the rats and immediately immersed in ice-cold saline $(0.9 \% \mathrm{NaCl})$. The hearts were trimmed free of lung and fat tissue. Subsequently, the hearts were ligated to the aortic cannula of 
a perfusion system. Retrograde perfusion was stanted at a perfusion pressure of $8 \mathrm{kPa}$ to rinse the vascular bed. Thereatter, the hearts were removed from the perfusion system and placed in ice-cold SET buffer (sucrose $250 \mathrm{mM}$, EDTA $2 \mathrm{mM}_{1}$. Tris.HCl 10 $\mathrm{mM}, \mathrm{pH} 7.4)$. All further operations were carried out at $4{ }^{\circ} \mathrm{C}$. The ventricular tissue was cut into small pieces, quickly dried and transferred into centrifugation tubes with SET buffer. The final content of SET buffer was adjusted to obtain a $15 \%$ homogenate (w/w). The tissue was homogenized in a glass Potter-Elvehjem homogenizer, using pestle clearances of $0.1,0.05$ and $0.025 \mathrm{~mm}$. These homogenates were sonicated (MSE, 150 W Ultrasonic disintegrator, amplitude $77 \mu \mathrm{m}$, frequency $20 \mathrm{kHz}, 4$ times 15 sec) and centrifuged (1 mim at 10,000 g) in order to get a homogenous suspension for enzyme assay.

\section{Subcellular fractionation}

The procedure of preparation of subcellular fractions is illustrated in fig 7.1 . The obtained pellets of the subcellular fractions (nuclei, mitochondria, lysosomes and microsomes) and cytosol were suspended in SET buffer. The purity of the different fractions was determined by marker enzymes: cytochrome $\mathrm{C}$ oxidase (EC 1.9.3.1, recovery $98 \%$ ), a mitochondrial marker; n-acetyl- $\beta$-glucosaminidase (EC 3.2.1.30, recovery $118 \%$, a lysosomal marker; rotenone-insensitive NADPH-cytochrome $\mathrm{C}$ reductase (EC 1.6.2.5, recovery $100 \%$ ), a microsomal marker; lactate dehydrogenase (EC 1.1.1.27, recovery $123 \%$ ), a cytosolic marker.

\section{Skeletal muscle preparation}

From the hind legs of rats, the soleus, quadriceps and gastrocnemius muscles were removed, weighed and transferred to tubes containing ice-cold SET buffer. The amount of SET buffer was further adjusted to obtain a $5 \%, 10 \%$ and $10 \%$ homogenate of the soleus, gastrocnemius and quadriceps muscle, respectively. The homogenate was prepared in a glass Potter-Elvehjem homogenizer, subsequently using pestle clearances of $0.1,0.05$ and $0.025 \mathrm{~mm}$. These homogenates were sonicated (see above) and centrifuged (1 min at 10,000 g) in order to get a homogenous suspension for enzyme assay.

\section{Enzyme assays}

Glycerol-3-P hydrolysing activity: $50 \mu$ of fresinly prepared tissue fraction was combined with $350 \mu$ l Na-acetate buffer $(160 \mathrm{mM}$, pH 5.0$)$ or Tris. $\mathrm{HCl}$ buffer $(160 \mathrm{mM}$, $\mathrm{pH}$ 7.2). Glycerol-3-P was added as substrate $(100 \mu$ of $50 \mathrm{mM}$ unless otherwise stated). Final assay volume was $500 \mu \mathrm{l}$. After $60 \mathrm{~min}$ of incubation at $37^{\circ} \mathrm{C}$, the reaction was terminated by addition of TCA $(500 \mu \mathrm{l} ; 10 \%)$. Precipitated protein was removed by centrifugation $\left(5 \min 3000 \mathrm{~g}, 5{ }^{\circ} \mathrm{C}\right.$ ) and the amount of phosphate was measured as described by Van Belle (1970). A zero-time control (to correct for phosphate in the tissue preparation) and no-tissue control (to correct for any nonenzymatic hydrolysis) were subtracted from the values found.

Marker enzymes: Cytochrome $C$ oxidase was determined by the method of Gohil

et al (1981). N-acetylglucosaminidase was assayed according to Koldovsky and Palmieri (1971). Rotenone-insensitive NADPH-cytochrome $C$ reductase was 


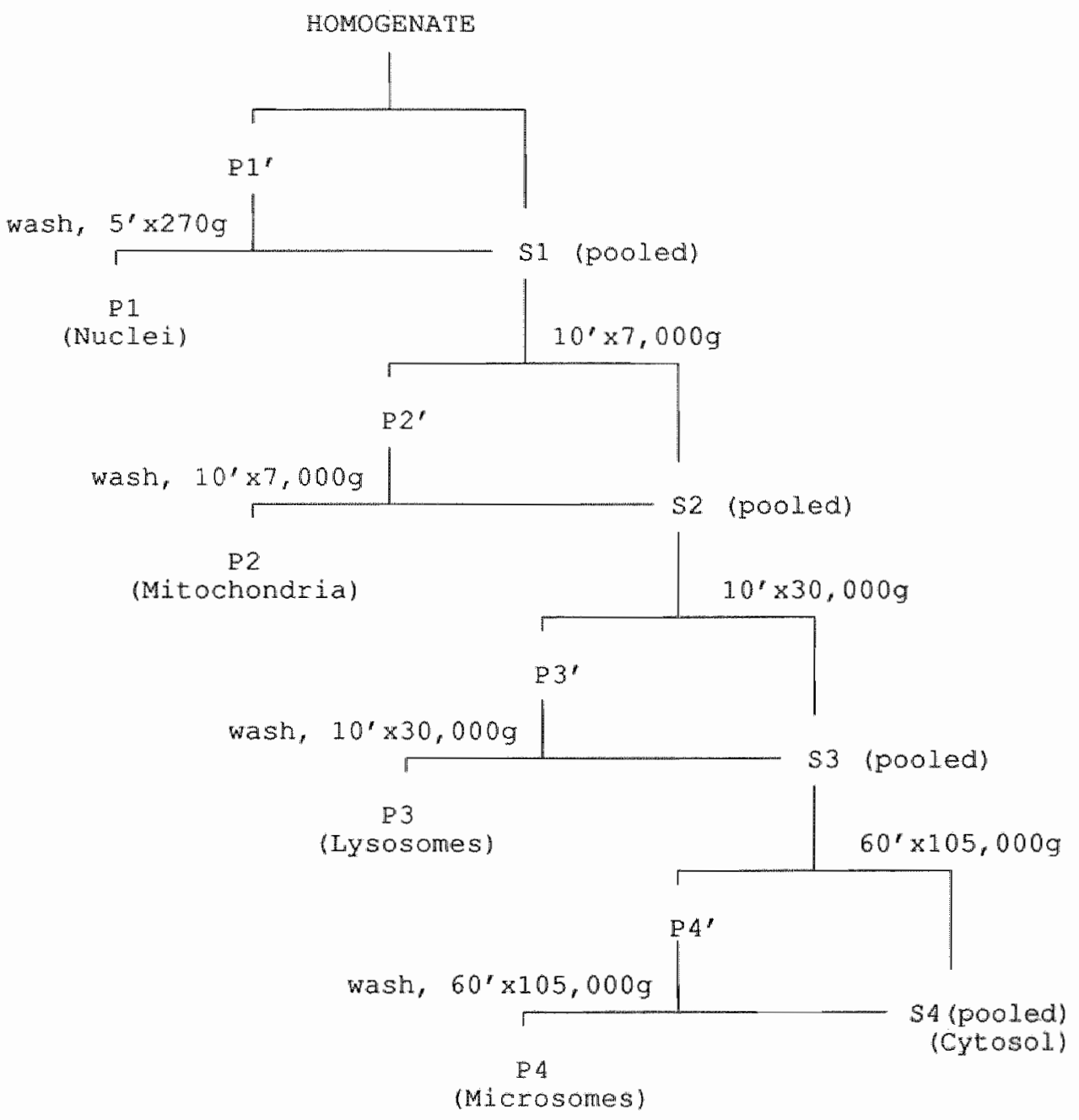

Fig 7.1 Preparation of subcellular fractions from homogenates ( $15 \%$ ). P refers to pellet; $S$ refors to supernatant.

determined according to Sottocosa et al (1967). Lactate dehydrogenase was assayed according to Bergmeyer and Bernt (1974).

\section{Protein determination}

Protein was determined according to Lowry and colleagues (1951). Bovine serum albumin was used as a standard. 
Table 7.1 The glycerol-3-P hydrolysing activity in cardiac and skeletal muscle under standard assay conditions

$\begin{array}{lrll}\text { Muscle } & \text { n } & \text { Activity } & \text { pH } \\ \text { Heart } & & & \\ \text { Heart } & 14 & 0.76 \pm 0.15 & 5.0 \\ \text { Soleus } & 11 & 0.22 \pm 0.07 & 7.2 \\ \text { Gastrocnemius } & 3 & 0.81 \pm 0.21 & 5.0 \\ \text { Quadriceps } & 3 & 1.10 \pm 0.21^{\mathrm{a}} & 5.0 \\ & 1 & 1.59 & 5.0\end{array}$

Data are presented as means $\pm S D$ and expressed in $u$ mol $P / g$ wet weight min. $n$ refers to number of experiments. Under standard assay conditions the concentration of glycerol-3-P was $10 \mathrm{mM}$. andicates significantly different from cardiac tissue at pH 5.0 (Mann Whitney U-test, $p<0.05$ )

\section{Expression of enzymatic activity}

The enzymatic activity is expressed as $\mu \mathrm{mol} P_{i}$ produced/g wet weight.min or $\mu \mathrm{mol} \mathrm{P}_{\mathrm{i}}$ produced/mg protein.min. The relative specific activity is calculated by the percentage of total activity divided by the percentage of total protein in the respective fraction. The number of experiments varied from 3 to 4 , unless otherwise indicated.

\subsection{RESULTS}

\section{Cardiac glycerol-3-P hydrolysing activity and its $\mathrm{pH}$ dependency}

Table 7.1 shows that rat cardiac tissue contains appreciable glycerol-3-P hydrolysing activity under standard assay conditions (substrate concentration $10 \mathrm{mM}$ ). The hydrolysis of glycerol-3-P was linear with time for at least $60 \mathrm{~min}$ and the reaction velocity was proportional to the amount of enzyme. At normal intracellular $\mathrm{pH}(\mathrm{pH} 7.2)$, the activity was found to be of the order of $0.2 \mu \mathrm{mol}$ glycerol-3-P hydrolysed per gram wet weight of tissue per min (table 7.1). Fig 7.2 illustrates glycerol-3-P hydrolysing activity as a function of the $\mathrm{pH}$. Decreasing $\mathrm{pH}$ from 7.2 to 5.0 , a 3- fold increase of glycerol-3-P hydrolysing activity was observed (fig 7.2).

\section{Kinetic properties of glycerol-3-P hydrolysing activity in rat heart homogenate}

Fig 7.3 shows the substrate dependency of glycerol-3-P hydrolysing activity in homogenates at $\mathrm{pH} 5.0$ and $\mathrm{pH} 7.2$. The glycerol-3-P hydrolysing activity exhibited classical Michaelis Menten kinetics. A non-linear least squares fit of the rate equation $v=\left(V_{\max } \times S\right) /\left(K_{m}+S\right)$ to these data yielded apparent $K_{m}$ and $V_{\max }$ values. Although these $K_{r m}$ and $V_{\max }$ values were determined in homogenates instead of in purified enzyme samples, they may serve as an indication of the affinity for glycerol-3-P and the hydrolysing activity in the heart. At $\mathrm{pH} 7.2$, the apparent $K_{\mathrm{m}}$ and $\mathrm{V}_{\max }$ values were $2.86 \pm 0.96 \mathrm{mM}$ and $0.25 \pm 0.03 \mu \mathrm{mol} / \mathrm{g}$ wet weight. min, respectively. At pH 5.0, 


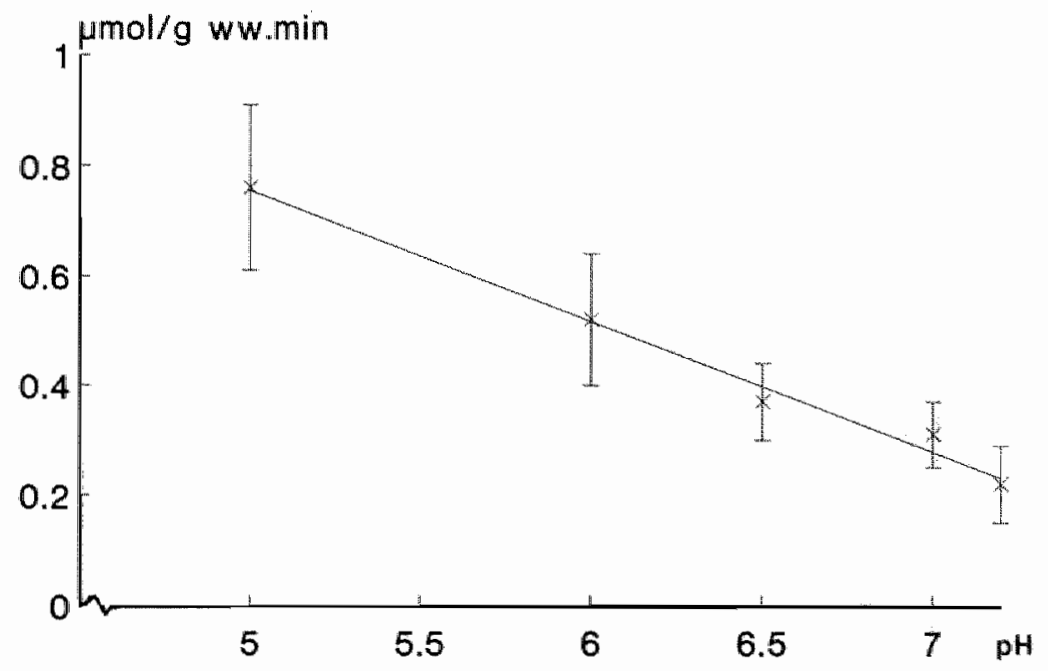

Fig 7.2 pH dependency of the glycerol-3-P hydrolysing activity in rat hearts.

Glycerol-3-P hydrolysing activity is expressed as $\mu \mathrm{mol} P / g$ wet woight.min. Data are presented as means $\pm s d_{,} n=3$

apparent $K_{m}$ and $V_{\max }$ values were $4.24 \pm 1.12 \mathrm{mM}$ and $0.94 \pm 0.11 \mu \mathrm{mol} / \mathrm{g}$ wet weight.min, respectively.

\section{Subcellular distribution}

The various subcellular fractions were checked on purity. All subcellular fractions were enriched in their proper marker enzyme (fig 7.4). Moderate cross-contamination was found for the mitochondrial, lysosomal and microsomal fraction.

Glycerol-3-P hydrolysing activity was enriched in the lysosomal and microsomal fraction at $\mathrm{pH} 7.2$, while at $\mathrm{pH} 5.0$ glycerol-3-P hydrolysing activity became also manifest in cytosol (fig 7.5). Similarly, the lysosomal marker enzyme $\mathrm{N}$-acetyl glucosaminidase showed activity in cytosol.

\section{Latency of lysosomal enzymes}

The latency of the lysosomal glycerol-3-P hydrolysing activity $(\mathrm{pH} 5.0)$ was determined by sonic treatment of lysosomes (Ultrasonic disintegrator; amplitude 77 $\mu \mathrm{m}$, frequency $20 \mathrm{kHz}, 4$ times $15 \mathrm{sec}$ ). The glycerol-3-P hydrolysing activity in the lysosomal fraction did not change by sonication ( $28.7 \mathrm{nmol} / \mathrm{mg}$ protein.min before sonication versus $27.3 \mathrm{nmol} / \mathrm{mg}$ protein.min after sonication). In contrast, the activity of the lysosomal marker enzyme $\mathrm{N}$-acetylglucosaminidase was increased by sonication (from $0.19 \mathrm{nmol} / \mathrm{mg}$ protein.min before sonication to $0.34 \mathrm{nmol} / \mathrm{mg}$ protein.min after sonication). 

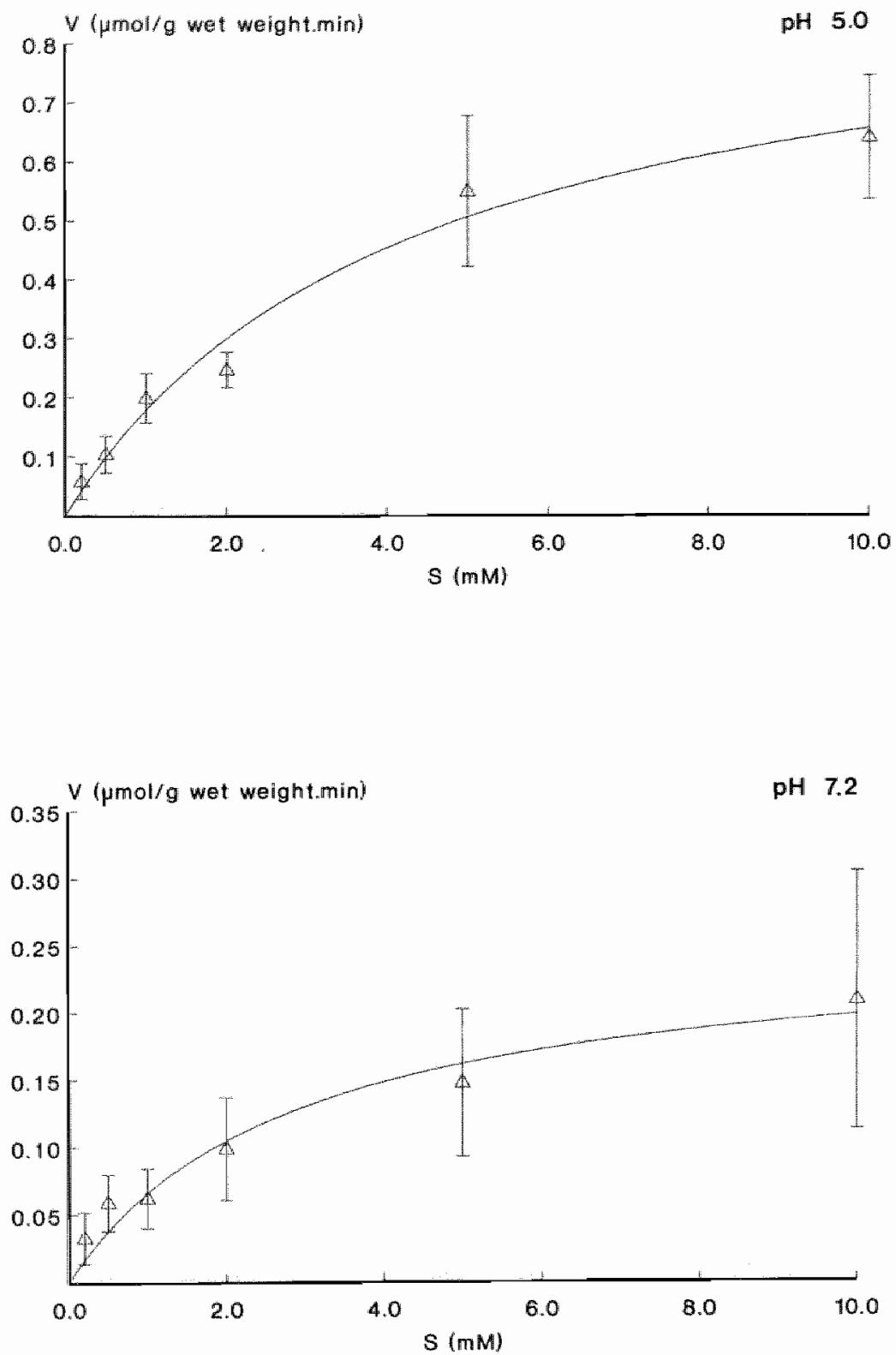

Fig 7.3 The glycerol-3-P hydrolysing activity in rat heart at $\mathrm{pH} 5.0$ or at $\mathrm{pH} 7.2$ as a function of the substrate concentration. Data are presented as means $\pm s d_{x} n=4$ 

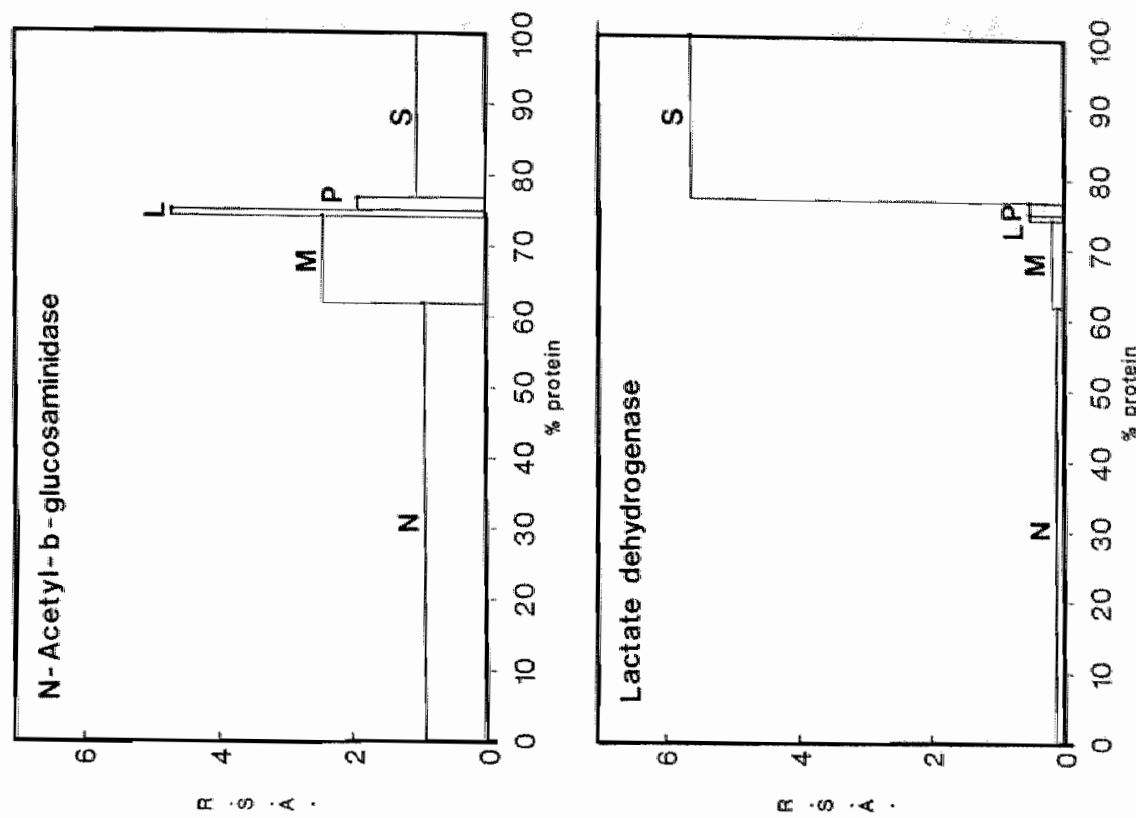

농

온?

9

क्षे है

(2)

2 용

वे

要要 8

w.

次要

ำ

ह5

드웡

8 \$

战的

ज的

동

क人

응

놀
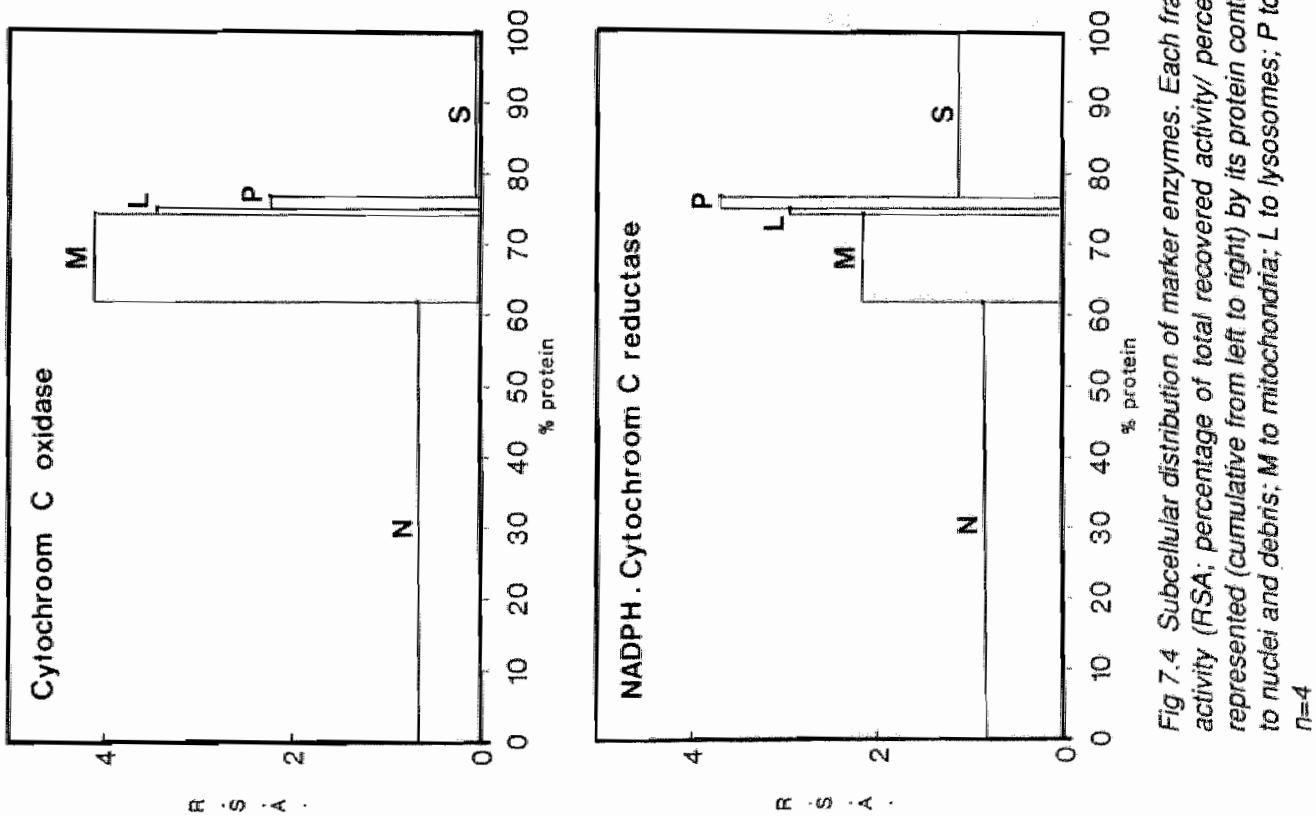

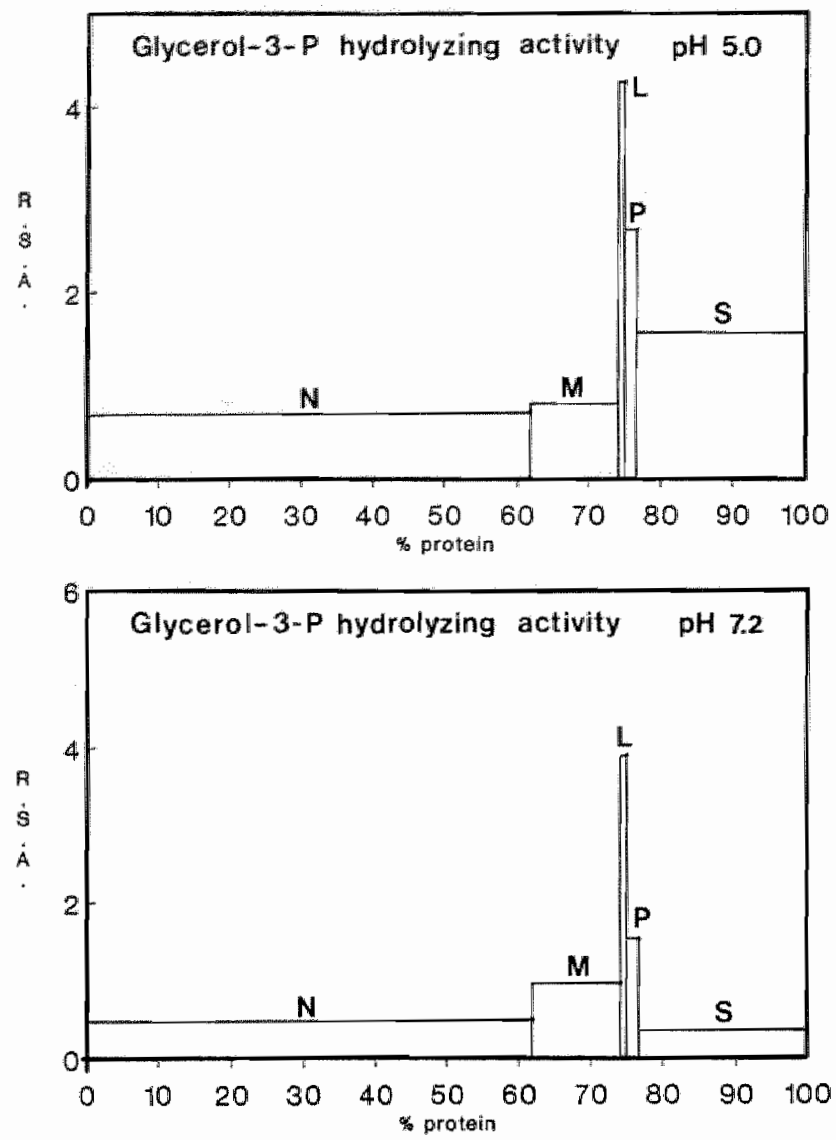

Fig 7.5 Subcellular distribution of glycerol-3-P hydrolysing activity $(\rho \mathrm{H}=5.0$ or $\mathrm{pH}=7.2)$. Each fraction is represented on the ordinary scale by its relative specific activity (RSA; percentage of total recovered activity/ percentage of total protein). On the abscissa scale each fraction is represented (cumulative from left to right) by its protein content expressed as percentage of total recovered protein. $N$ refers to nuclei and debris; $M$ to mitochondria; $L$ to lysosomes; $P$ to microsomes; $S$ to cytosol Data are presented as mean values, $n=3$.

\section{Glycerol-3-P hydrolysing activity in cardiac tissue compared to activity in sikeletal muscle tissue}

Table 7.1 shows glycerol-3-P hydrolysing activity in heart tissue versus rat soleus, gastrocnemius and quadriceps muscle. The activity in the heart (at $\mathrm{pH} 5.0$ ) is of the same order as the activity in the soleus muscle, whereas the gastrocnemius and quadriceps muscles show somewhat higher activities. 


\subsection{DISCUSSION}

The present study evaluates the possibility that glycerol-3-P is directly hydrolysed to glycerol instead of passing the triacylglycerol pool in cardiac tissue. Therefore, glycerol-3-P hydrolysing activity in cardiac tissue should be present. This study shows that, indeed, rat myocardium was able to release inorganic phosphate from glycerol-3$P$. The glycerol-3-P hydrolysing activity was increased in acid environment. The $\mathrm{pH}$ range studied reflects the range of acidosis in ischemic hearts.

At pH 7.2, the apparent $K_{m}$ and $V_{\max }$ values were $2.86 \pm 0.96 \mathrm{mM}$ and $0.25 \pm 0.03$ $\mu \mathrm{mol} / \mathrm{g}$ wet weight.min, respectively. At $\mathrm{pH} 5.0$, apparent $\mathrm{K}_{\mathrm{m}}$ and $\mathrm{V}_{\max }$ values were 4.24 $\pm 1.12 \mathrm{mM}$ and $0.94 \pm 0.11 \mu \mathrm{mol} / \mathrm{g}$ wet weight.min, respectively. The relative specific activity of the enzyme was highest in the lysosomal fraction.

\section{The possible role of glycerol-3-P hydrolysing activity in cardiac tissue under normoxic conditions.}

It has been reported that the intracellular $\mathrm{pH}$ in the normoxic heart is about 7.2 (Bailey et al, 1982; Bünger et al, 1989). At this $\mathrm{pH}$, the rate of glycerol-3-P hydrolysis was found to be small compared to $\mathrm{pH} 5.0$ (table 7.1 and fig 7.2). The glycerol-3-P content in the isolated, normoxic perfused rat heart varies between 0 and $1 \mu \mathrm{mol} / \mathrm{g} \mathrm{dry}$ (Chapter 2; De Groot et al, 1989). The latter value may correspond to an intracellular concentration of $0.3 \mathrm{mM}$ (assuming an intracellular volume of $60 \%$ of total volume and a dry to wet weight ratio of 0.16 ). This is markedly below the $K_{m}$ value of the enzyme hydrolysing glycerol-3-P at $\mathrm{pH} 7.2$ calculated in the present study $(2.86 \pm 0.96 \mathrm{mM})$. Our data show that the lysosomal fraction was predominantly enriched with glycerol-3$\mathrm{P}$ hydrolysing activity ( $\mathrm{pH}$ 7.2). It should be noted that in the cardiomyocyt glycerol-3-P is formed in cytoplasm via glycolysis. This may imply compartmentalization of enzyme and substrate under normal circumstances. However, compartmentalization does not seem be a limitation (see below).

Thus, under normal normoxic circumstances the conditions in cardiac tissue are not optimal for resulting in high glycerol-3-P hydrolysing activity ( $\mathrm{pH}$ too high, substrate availability limited). Correspondingly, Denton and Randle (1967) found that in the normoxic heart glycerol produced by direct dephosphorylation of glycerol-3-P was less than $10 \%$ of that formed from triacylglycerol hydrolysis.

\section{The possible role of glycerol-3-P hydrolysing activity in cardiac tissue under ischemic conditions.}

Neely and coworkers (1975) reported that the intracellular pH may decrease from 7.2 to 6.8 when low-flow ischemia is introduced. Garlick and coworkers (1979) as well as Bailey and associates (1982) even demonstrated a higher extent of acidification under conditions of no-flow ischemia ( $\mathrm{pH}$ varying from 5.6 to 6.0). Reducing $\mathrm{pH}$ in vitro over the $\mathrm{pH}$ range 7.2 to 5.0 resulted in increased glycerol-3-P hydrolysing activity in the present study (fig 7.2). Further, preliminary experiments in our laboratory demonstrated that glycerol-3-P accumulation amounted to $10 \mu \mathrm{mol} / \mathrm{g}$ dry weight of tissue under ischemic conditions (Chapter 4). This amount of glycerol-3-P may correspond to $3 \mathrm{mM}$ which reaches near the $K_{\mathrm{m}}$ value at $\mathrm{pH} 5.0$ (i.e. $4.24 \pm 1.12 \mathrm{mM}$ ). At pH 5.0, glycerol-3-P hydrolysing activity became manifest in cytosol in addition to 
activity in Iysosomal and microsomal fractions. This may give the impression of hydrolysing activity in cytosol when $\mathrm{pH}$ is lowered. However, it seems more likely that cytosol is contaminated with some lysosomal particles and/or lysosomal enzymes since the lysosomal marker enzyme $\mathrm{N}$-acetyl glucosaminidase similarly showed activity in cytosol. It is of interest that glycerol-3-P hydrolysing activity in lysosomes $(\mathrm{pH} 5.0)$ was not enhanced by sonication of the lysosomal preparation in contrast to increased activity of the lysosomal marker enzyme $\mathrm{N}$-acetyl glucosaminidase. As sonication is known to disrupt lysosomal membranes, resulting in loss of latency of most lysosomal enzymes, the present findings imply that glyceroll-3-P is freely accessible to the lysosomal proteins responsible for hydrolysis of glycerol-3-P. Either the lysosomal membrane is easily passed by the substrate or proteins are located at the outside of the membrane.

Thus, the presented data show that under ischemic conditions hydrolysis of glycerol-3-P to glycerol may become important as catabolic circumstances turn out more favourable, i.e. $\mathrm{pH}$ decreases and substrate supply increases. Although lysosomes may be damaged by ischemia (Wildenthal, 1978) and release their enzymes in cytoplasm, the compartmentalization of glycerol-3-P and the enzyme does not seem to be a limiting factor when lysosomes are intact.

\section{Gilycerol-3-P hydrolysing activity in cardiac tissue versus other muscles}

The glycerol-3-P hydrolysing activity was found higher in the gastrocnemius and quadriceps muscles than in the soleus muscle and cardiac muscle. Cardiac muscle is generally considered to be a red muscle. Likewise, the soleus is a red muscle (Koerker et al, 1990) whereas the gastrocnemius and quadriceps are white muscles (Baldwin et al, 1972; Ariano et al, 1973). In white muscles glucose is a major fuel and glycolysis is an important source of energy delivery (Baldwin et all, 1972). In contrast, red muscles prefer oxidation of fatty acids (Baldwin et al, 1972). As result of the role of glycolysis, the content of glycerol-3-P is likely to be more increased in white muscles than in red muscles. It is of interest that in this type of muscles the activity to hydrolyse glycerol-3-P is also enhanced.

In summary, the present study demonstrates that the heart is able to hydrolyse glycerol-3-P into glycerol. Under normoxic conditions, the glycerol-3-P hydrolysing activity may be less pronounced since the $\mathrm{pH}$ and substrate concentration are not optimal. When the heart is exposed to ischemia, catabolic conditions turn out more favourable and glycerol-3-P hydrolysing activity may become significant. There seems to be no barrier for the contact between glycerol-3-P and its hydrolysing enzyme.

In addition to glycerol-3-P hydrolysing activity in heart muscle, there is glycerol-3-P hydrolysing activity in skeletal muscles. In this regard, white muscles show higher activity than red muscles.

\subsection{REFERENCES}

1. Ariano MA, Armstrong RB, Edgerton VA (1973) Hind-limb muscle fiber populations of five mammals. J Histochem Cytochem 21: 51-55

2. Bailey JA, Radda GK, Seymour AL, Willams SR (1982) The effects of insulin on myocardial metabolism and acidosis in normoxia and ischaemia. Biochim Biophys Acta 720: 17-27 
3. Baldwin KM, Klinkerluss GH, Terjung RL, Molé PA, Holloszy JO (1972) Respiratory capacity of white, red, and intermediate muscle: adaptive response to exercise. Am J Physiol 222:373-378

4. Bergmeyer $\mathrm{HU}_{2}$ Bernt $\mathrm{E}$ (1974) UV assay for lactate dehydrogenase with pyruvate and NADH. In Bergmeyer HU (ed) Methods of enzymatic analysis. Weinheim: Verlag Chemie GmbH Vol 2: 574 579 .

5. Bunger $R_{t}$ Mallet RT, Hartman DA (1989) Pyruvate-enhanced phosphorylation potential and inotropism in normoxic and postischemic isolated working rat heart. Eur $\mathrm{J}$ Biochem 180: 221-233

6. Cobbe SM, Poole-Wilson PA (1980) The time of onset and severity of acidosis in myociardial ischaemia. J Mol Cell Cardioll 12: 745-760

7. De Groot MJM, Willemsen PHM, Coumans WA, Van Bisen M, Van der Vusse GJ (1989) Lactate induced stimulation of myocardial triacylglycerol turnover. Biochim Biophys Acta 1006:111.115

8. Denton $\mathrm{RM}_{\mathrm{u}}$ Randle $\mathrm{PJ}$ (1967) Measurement of flow of carbon atoms from glucose and glycogen glucose to glyceride glycerol and glycerol in rat heart and epididymal adipose tissue. Biochem $J$ 104: 423-434

9. Garlick PB, Radda GK, Seeley PJ (1979) Studies of acidosis in the ischaemic heart by phosphorus nuclear magnetic response. Biochem J 184: 547-554

10. Gohil K, Jones DA, Edwards RHT (1981) Analysis of muscle mitochondrial function with techniques applicable to needly biopsy samples. Clin Physiol 1: 195-207

11. Hülsmann WC, Stam (1979) Lipolysis in heart and adipose tissue, effects of inhibition of glycogenolysis and uncoupling of oxidative phosphorylation. Biochem Biophys Res Commun 88: 867-872

12. Koerker DJ, Sweet IR, Baskin DG (1990) Insulin binding to individual rat skeletal muscles. Am J Physiol 259: E517-E523

13. Koldowsky $O$, Palmieri $M$ (1971) Cortisone-ewoked decrease of acid $\beta$-galactosidase, $\beta$ glucuronidase, $\mathrm{N}$-acetyl-3-glucosaminidase and arylsulphatase in the ileum of suckling rats. Biochem J 125: 697-701

14. Lowry OH, Rosebrough NJ, Farr AL, Randall RJ (1951) Protein measurement with the folin phenol reagent. J Bial Chem 193: 265-275

15. Myrmel T, Forsdahl K, Sager G, Larsen T (1991) Regulation of lipolysis in normoxic and hypoxic rat myocyles. J Mol Cell Cardiol 23: 207-215

16. Neely RiN, Whitmer JT, Rovetto MU (1975) Effect of coronary blood flow on glycolytic flux and intracellular $\mathrm{pH}$ in isolated rat hearts. Circ Res $37: 733-7.41$

17. Robinson J, Newsholme EA (1967) Glycerol kinase activities in rat heart and adipose tissue. Biochem J 104: 2-4

18. Rovetto MJ, Lamberton WF, Neely JR (1975) Mechanisms of glycolytic inhibition in ischemic rat hearts. Circ Res 37: 742-751

119. Scheuer J, Olson RE (1967) Metabolism of exogenous triglyceride by the isolated pertused rat heart. Am I Physiol 212: $301 \cdot 307$

20. Sottocosa GL, Kuylenstierna B. Ernster L. Bergstrand A (1967) An electron-transpont system associalted with the outer membrane of liver milochondria. I Cell Biol 32: 415-438

21. Tamboli A, O'Looney $P$, Vander Maten M, Vahouny G (1983) Comparative metabolism of tree and esteritied fatty acids by the perfused rat heart and rat cardiac myocyles. Biochim Bioptiys Acta 750 : 404-410

22. Trach V. Buschmans--Denkel E, Schaper W (1986) Relation between lipolysis and glycolysis during ischemia in the isolated rat heart. Basic Res Cardiol 81:454-464

23. Van Belle $\mathrm{H}(1970)$ New and sensitive reaction for automatic determination of inorganic phosphate and its application to serum. Anal Biochem 33: $132-1.42$

24. Wildenthal $K$ (1978) Lysosomal alterations in ischemic myocardium: resull or cause of cellular damage? J Mol Cell Cardiol 10: 595-603 


\section{CHAPTER 8}

\section{GENERAL DISCUSSION}

The present thesis describes the effect of exogenous lactate on the isolated working rat heart under long-term normoxic perfusion and under ischemic and reperfused conditions. Both hemodynamic and metabolic function were considered. Lactate perfused hearts were compared to glucose and glucose plus pyruvate perfused hearts in an attempt to elucidate the mechanisms involved.

\subsection{FUNCTION}

The effect of exogenous lactate on hemodynamic stability under normoxic and ischemic/reperfused circumstances was two-sided. During long-term normoxic perfusion exogenous lactate improved cardiac stability compared to glucose as sole substrate, but exogenous lactate was detrimental after ischemia. Severe loss of function was observed after $30 \mathrm{~min}$ of ischemia, a time interval at which both the glucose and pyruvate pertused hearts were still able to recover hemodynamic function to a considerable extent. However, a two-sided influence was also observed for pyruvate, the oxidized form of lactate. After $45 \mathrm{~min}$ of ischemia, pyruvate impaired cardiac function compared to glucose, whereas pyruvate protected the hearts during prolonged normoxic perfusion and after 15 and $30 \mathrm{~min}$ of ischemia. Hence, exogenous lactate and pyruvate seem to exert similar effects on cardiac stability except that lactate accelerates the transition to severe loss of cardiac function during the postischemic phase. 


\subsection{FUNCTION IN RELATION TO METABOLIC FACTORS}

\section{The role of glycogenolysis/glycolysils}

It has been suggested that glycolysis plays a role in maintaining cell viability during ischemia (Opie, 1990a; Opie, 1990b). In line with this suggestion, several authors reported that preservation of glycogen prior to ischemia is beneficial to the affected heart (Lagerstrom et al, 1988, Schneider and Taegtmeyer, 1991). The glycogen pool delivers glucose moieties for glycolysis during ischemia. However, in the present thesis it could not be confirmed that the preischemic content of glycogen is a major determinant of hemodynamic recovery after no-flow ischemia. Lactate hearts showed higher levels of endoglenous glycogen than glucose hearts and comparable levels to pyruvate hearts prior to ischemia, whereas hemodynamic recovery was worse in the lactate hearts following $30 \mathrm{~min}$ of ischemia. The rate of glycolysis during ischemia as evaluated by glycogen utilization and endogenous lactate production was neither beneficial to hemodynamic recovery as evidenced by comparing glucose, lactate and pyruvate hearts after 30 min of ischemia. On the other hand, detrimental effects of glycolytic products could not be obsenved either as suggested by Neely et al (1984). Therefore, it seems that glycolytic flux during no-fllow ischemia is not a major determinant of postischemic recovery. However, it can not be excluded that glycolysis benefits the ischemic heart under low-flow conditions as under these circumstances glucose uptake is enhanced and end-products of glycolysis are released (Rovetto et al, 1973, Neely et al, 1976).

Interestingly, in the present studies, a protecting effect of exogenous glucose on postischemic hearts was obvious when the preceding time of ischemia was 45 min. in contrast to depletion of endogenous substrate pools under normoxic conditions, endogenous glycogen and triacylglycerols were not utilized under reperfused conditions in glucose hearts. The fatty acids, accumulated during ischemia, could not have been sufficient to provide fuel during $35 \mathrm{~min}$ of reperfusion (the observed decrease of $475 \mathrm{nmol}$ fatty acids/g dry weight during $35 \mathrm{~min}$ of reperfusion following $45 \mathrm{~min}$ of ischemia would be reached in about one minute as oxidation rate of fatty acids in reperfused hearts is approximately $4.00 \mathrm{nmol} / \mathrm{g}$ dry weight.min; Lopaschuk et al, 1990). Moreover, considerable glycogen synthesis in the glucose reperfused hearts was observed. Hence, it seems reasonable to assume that the uptake of exogenous glucose is increased in these hearts. It can be speculated that enhanced glucose utilization during reperfusion may have protected the heart against detrimental damage. Supporting evidence for the necessity of glucose for postischemic recovery can be derived from the observation that with pyruvate or lactate as sole substrate severe contractile failure developed and leakage of cytoplasmic enzymes increased (Bricknell and Opie, 1978; Mallet et al, 1990). Lactate and pyruvate oxidation differ from glucose axidation by the glycolysis pathway. Hence, maintenance of glycolysis during reperfusion may be important for postischemic recovery. Lactate and pyruvate perfused hearts might have limited glycolysis by substrate competition which turns out detrimental under unfavourable conditions. 


\section{The role of lipids}

Fatty acids were found to accumulate in myocardial tissue of lactate and glucose hearts after 15 min of ischemia. In pyruvate hearts accumulation started after 30 min of ischemia. During reperfusion fatty acid increase continued in lactate and pyruvate hearts. No clear relationship between fatty acid accumulation during ischemia and postischemic hemodynamic recovery was found. In contrast, a negative relationship was observed between fatty acid accumulation during reperfusion and hemodynamic recovery. In this regard, a worse recovery of lactate reperfused hearts was related to high levels of fatty acids. High concentrations of fatty acids during reperfusion may disturb several metabolic processes. From in vitro studies it has become cllear that elevated fatty acid levels may inhibit the activity of several glycolytic enzymes, uncouple mitochondrial oxidative phosphorylation, disturb callium homeostasis and reduce the activity of ( $\mathrm{Na}, \mathrm{K})$-ATPase. In addition, fatty acids may be involved in altering physico-chemical properties of the membrane and electrophysiological derangements (For reviews see Katz and Messineo, 1981; Corr et al, 1984; Liedtke and Shrago, 1990).

Delivery of fatty acids by breakdown of membrane phospholipids may result in loss of membrane integrity. Accumulation of arachidonic acid indicated that the phospholipid pool was involved. Total fatty acid accumulation in lactate reperfused hearts after $45 \mathrm{~min}$ of ischemia (i.e. $1 \mu \mathrm{mol} / \mathrm{g}$ dry weight) may theoretically correspond to a breakdown of only $0.4 \%$ of the total phospholipid pool (on fatty acid basis). It is hard to imagine that this low percentage of phospholipid breakdown, in general, impairs cardiac function and integrity. However, if the breakdown of phospholipids is confined to certain layers of the left ventricle (inner or outer, see below) and even more selectively reflects breakdown of sarcolemma (Miyazaki et al, 1990), it may seriously compromise cell's integrity. A conflicting result of the significance of phospholipid breakdown is the observation that there is no relationship between fatty acid accumulation during ischemia and postischemic recovery. The critical levell of about $400 \mathrm{nmol}$ fatty acids/g dry weight above which there was no recovery for reperfused hearts, is not applicable to ischemic hearts (for instance, in hearts with glucose as sole substrate fatty acid accumulation amounted to about $700 \mathrm{mmol} / \mathrm{g}$ dry weight after $45 \mathrm{~min}$ of ischemia, while hemodynamic recovery was still appreciable during reperfusion).

In addition to phospholipids, fatty acids may be derived from endogenous triacylglycerols. If glycerol is a reliable marker of lipolysis (see below), the tissue accumulation or coronary release of glycerol may indicate that triacylglycerols were broken down. However, as no changes in triacylglycerol levels were observed, cycling of triacylglycerols was suggested. In lactate hearts, cycling of triacylglycerols was found under normoxic, ischemic and reperfused conditions. Under normoxic circumstances, the cycling rate of triacylglycerols as determined by glycerol release was $17.2 \mathrm{nmol} / \mathrm{g}$ wet weight.min, corresponding to cycling of about $1.5 \%$ of the total triacylglycerol pool per min. In contrast, no such high cycling rates of triacylglycerols were observed in normoxic pyruvate hearts. In normoxic glucose hearts cycling of triacylglycerols was absent. When ischemia was introduced, cycling rate was initially raised to about $32 \mathrm{nmol} / \mathrm{g}$ wet weight.min (on glycerol basis) in all groups of hearts but levelled off thereafter. Cycling is an energy consuming process and may add to energy depletion under oxygen-restricted conditions. Glycolytic ATP production as indicated by endogenous lactate production was comparable during the first 15 min of ischemia 
in the three substrate groups. Hence, the burden on the energy stores due to cycling of triacylglycerols seems to be of similar extent in glucose, lactate and pyruvate hearts. By reperfusion, cycling did continue more noticeably in lactate hearts than in glucose and pyruvate hearts subjected to 30 min of ischemia $(16.0,1.6$ and $4.8 \mathrm{nmol} / \mathrm{g}$ wet weight, min, respectively; corrected values i.e. additional cycling above preischemic cycling). Similarly, after 45 min of ischemia cycling rates were most pronounced in lactate hearts (30.4 nmol/g dry weight.min versus 11.2 and $22.4 \mathrm{nmol} / \mathrm{g}$ wet weight. $\mathrm{min}$ in glucose and pyruvate hearts, respectively). Possibly, "energy wasting" cycling of triacylglycerols may have contributed to impairment of cardiac function in lactate hearts during reperfusion. However, higher rates of cycling did not unanimously result in lower contents of high-energy phosphates at the end of reperfusion (e.g. compare glucose and lactate hearts after 30 min of ischemia). As ATP production in reperfused hearts is not known, the relative ATP utilization can not be calculated and can even vary for the three substrate groups.

Determination of turnover rate of triacylglycerols by glycerol release has to be considered with some caution. Glycerol can also be derived from phospholipids via phospholipase $\mathrm{C}$ activity and hence glycerol release may imply cycling of phospholipids. More important is the possibility that glycerol-3-phosphate is directly hydrolysed into glycerol (see Chapter 7). Although under normal normoxic circumstances enzymatic conditions are not optimal, the hydrolysing conditions turn out more favourable under ischemic circumstances. The measured glycerol-3phosphate hydrolysing activity in homogenates at $\mathrm{pH} 5.0$ was found very high (1.e. 760 $\mathrm{nmol} / \mathrm{g}$ wet weight.min under standard assay conditions) compared to the amount of glycerol produced during ischemia (up to $32 \mathrm{nmol} / \mathrm{g}$ wet weight.min) in the isolated 'intact' heart. However, the absence of any relationship between the content of glycerol-3-phosphate and glycerol in ischemic tissue (Chapter 4) does not favour the idea that glycerol is directly derived from glycerol-3-phosphate.

\section{The role of energy deficiency}

Since energy depletion may lead to severe disturbances in contractile function of the heart, to electrolyte shifts and to changes in metabolism, a relationship between energy deficiency and resuscitation of the ischemic heart may be present.

Lactate did not affect depletion of high-energy phosphates and formation of purines during ischemia, while recovery was worse compared to glucose and pyruvate hearts following $30 \mathrm{~min}$ of ischemia and compared to glucose hearts following $45 \mathrm{~min}$ of ischemia. Hence, no relationship between energy depletion during ischemia and postischemic recovery could be established. At the end of reperfusion following $30 \mathrm{~min}$ of ischemia, lower levels of high-energy phosphates and higher amounts of breakdown products were found in lactate hearts compared to pyruvate hearts, while concomitantly hemodynamic recovery was worse in the lactate hearts. However, the amount of high-energy phosphates and degradation products did not significantly differ between glucose and lactate hearts at this time point while hemodynamic recovery was better in glucose hearts. Hence, there was also no relationship between the content of high-energy phosphates or the extent of purine formation at the end of reperfusion on one side and hemodynamic recovery on the other side. Opie (1990) suggested that the source of ATP may be more important than the total ATP level. ATP produced by glycolysis could play a specific role in protection of the sarcolemma 
as well as in stimulation of the relaxation of the heart muscle. In the presented studies, it is rather unlikely that ATP produced by glycolysis has benefitted the heart during ischemia. Glycogen consumption and endogenous lactate production (indices of glycolysis rate) were higher in lactate hearts than in glucose or pyruvate hearts during $30 \mathrm{~min}$ of ischemia, while recovery was worse in lactate hearts. ATP produced via glycolysis has possibly played a role during reperfusion considering the protecting effect of giucose after long-term ischemia (see above).

\section{The role of alternative chemical factors}

Other factors which were not investigated in our studies, but that may have contributed to the detrimental effect of exogenous lactate on cardiac function, are calcium accumulation and formation of free radicals.

Wallukat and coworkers (1991) have recently suggested that lactate induces $\beta$ adrenergic supersensitivity in cardiac myocytes. $\beta$-Adrenergic stimulation may increase cytoplasmic calcium concentrations (Opie, 1986). Moreover, irreversibly injured myocardial cells lose their ability to maintain the transsarcolemmal gradient of calcium and consequently "cytoplasmic calcium concentrations may rise. High cytoplasmic calcium concentrations may cause hypercontracture of the myofibrils. The raised enddiastolic pressure in lactate hearts during reperfusion following $30 \mathrm{~min}$ of ischemia may support the involvement of hypercontracture. Hypercontracture leads to massive disruption of cytoskeletal structures. In addition, high cytoplasmic calcium levels may cause damage to mitochondria as mitochondria tend to buffer cytoplasmic calcium. In this context, the lactate-induced damage of mitochondria as found by Armiger and coworkers (1974) can be ascribed to callum overload. However, in the present studies, the oxidative capacity of the mitochondria of lactate hearts did not seem to be disturbed since there was still marked lactate oxidation during reperfusion (the amount of exogenous lactate uptake far exceeded the amount of endogenous accumulation). Further, increased cytoplasmic calcium concentrations may increase the activity of phospholipases which, in turn, may degrade cell membrane phospholipids. The increased fatty acid levels in lactate hearts during reperfusion may be ascribed to calcium-stimulated phospholipase activity.

The pole of oxygen free radicals in myocardial injury has been extensively discussed (Bolli, 1988; Reimer et al, 1989; Downey, 1990). The normal heart is able to handle and survive oxygen free radicals due to several endogenous defense mechanisms. During reperfusion following ischemia these defense mechanisms might be impaired, while radical production may be increased. There are several sources which can be responsible for the production of oxygen free radicals including leucocytes, cyclo-oxygenase, xanthine-oxidase, catecholamines and mitochondria. Ferrari and coworkers (1990) have recently described mitochondria as an important source of radical production. Vanderplassche and coworkers (1989) demonstrated that in ischemic tissue the enzyme NADH-oxidase becomes activated which is involved in mitochondrial hydrogen peroxide generation. By enhanced availability of NADH due to intracellular conversion of lactate into pyruvate, it may be possible that radical production is activated via this route in lactate perfused heart under injured conditions. 


\subsection{FUNCTION IN RELATION TO CORONARY FLOW THROUGH THE INNER AND OUTER LAYERS OF THE LEFT VENTRICLE}

Flow measurements indicated that exogenous lactate induced transient underperfusion of the inner layers of the reperfused left ventricle, when the preceding time of ischemia was $30 \mathrm{~min}$. Following $45 \mathrm{~min}$ of ischemia, flow in the inner layers remained severely depressed during reperfusion. Pyruvate hearts preserved coronary flow reserve after $30 \mathrm{~min}$ of ischemia. However, flow in the inner layers was compromised after 45 min of ischemia like in lactate hearts. In contrast to lactate and pyruvate hearts, glucose hearts showed no severe underperfusion of the inner layers. Heterogenous perfusion of the postischemic heart seemed to be related to malfunction of the postischemic heart.

\subsection{CORONARY FLOW AND METABOLIC FACTORS}

Underperfusion of the inner layers of the left ventricle may explain continued lactate dehydrogenase release in lactate hearts after $30 \mathrm{~min}$ of ischemia and in all hearts after $45 \mathrm{~min}$ of ischemia (Chapter 3). Underperfusion can also explain tissue accumulation of lactate and purines in reperfused hearts (Chapter 3 and 5). However, the presence of no-reflow areas hampers the interpretation of metabolic data measured in tissue at the end of reperfusion, since the measured values will be an average reflection of both reperfused and ischemic regions. In this context, the observed increase of fatty acids in lactate and pyruvate hearts during reperfusion may be the result of damage in either local areas of ischemia or in reperfused areas or both. Similarly, increased turnover of triacylglycerols during reperfusion can be ascribed to well-perfused areas or to border zones between reperfused and ischemic regions. Turnover of triacylglycerols in ischemic areas does not seem very likely as it is only pronounced at the onset of ischemia.

\subsection{CONCLUSION AND HYPOTHESIS}

In the present thesis it has been demonstrated that exogenous lactate is a suitable substrate for the heart under normoxic conditions. In contrast, it impairs hemodynamic function, induces underperfusion of inner layers of left ventricle and disturbs lipid homeostasis of the postischemic heart. Similar findings were observed for pyruvate when present as cosubstrate except that disturbances of cardiac processes were delayed. Hence, the effect of lactate can be described as compromising the period during which the heart can sustain an ischemic attack. Glucose perfused hearts differed in several aspects from lactate and pyruvate perfused hearts, such as glycolytic pathway, fatty acid accumulation and regional perfusion, relating to a better hemodynamic recovery.

Which mechanism is responsible for lactate-induced impairment of the postischemic heart is still an unresolved problem: Does dysfunction originate from underperfusion or does dysfunction cause underperfusion; Are metabolic changes a reflection of either 
ischemic or reperfusion damage or are they involved in causing damage.

An interesting observation in the present thesis was that glucose was not able to maintain cardiac stability under normoxic conditions, but it protected the heart after an ischemic interval when lactate and pyruvate failed to do so. The hypothesis that glycolysis is important for maintaining cell viability of the ischemic damaged heart needs further research. Since glycolysis is the basic pathway of energy delivery of endothelial cells (Spahr et al, 1989), it may be a challenging speculation that lactate interferes the glycolytic process in endothelial cells of the postischemic heart. This may result in impaired endothelial function, subsequently proper coronary perfusion may fail and, hence, resupply of the myocytes with oxygen and substrates will be prevented. Support for this hypothesis can be obtained from the study of Geisbuhler and Rovetto (1990), demonstrating that lactate itself does not enhance damage of rat cardiac myocytes exposed to anoxia and reoxygenation.

It is important to realize that in man the heart can be exposed to increased lactate concentrations under several physiological and pathophysiological conditions (Moret, 1980). Infusion of lactate containing buffers in the clinical setting (e.g. lactate-Ainger solutions during cardiopulmonary bypass) and moderate to severe physical exercise performed by cardiac patients (Messin, 1980) easily lead to ellevated blood lactate concentrations. In addition, circulatory shock hypoxemia, uncontrolled diabetes and glycogen storage disease are associated with hyperlactaemia (Waters et al, 1963). Hence, adverse effects of lactate on the human myocardium, especially when transient ischemia occurs, has to be considered as well.

\subsection{REFERENCES}

1. Armiger LC, Gavin JB, Herdson PB (1974) Mitochondrial changes in dog myocardium induced by neutral lactate in vitro. Lab Invest 31: 29-33

2. Bolli $R$ (1988) Oxygen-derived free radicals and postischemic myocardial dysfunction ('stunned myocardium'). J Am Coll Cardiol 12: 239-249

3. Bricknell OL, Opie LH (1978) Effects of substrates on tissue metabolic changes in the isolated rat heart during underperfusion and on release of laclate dehydrogenase and arrtiythmias during repertusion. Circ Res 43: 102-115

4. Downey $J M$ (1990) Free radicals and their involvement during long term myocardial ischemia and reperfusion. Annu Rev Physiol 52: 487-504

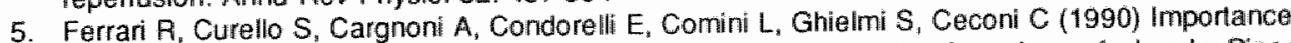
of free radicals generated by endothelial and myocardial cells in ischemia and repertusion. In: Piper HM (ed) Pathophysiology of severe ischemic myocardial injury. Kluwer Academic Publishers Dordrecht, pp 221-238

6. Geisbuhler TP. Rovetto MJ (1990) Lactate does not enhance anoxia/reoxygenation damage in adult rat cardiac myocytes. I Mol Cell Cardiol 22: 13.25-1335

7. Katz AM, Messineo FC (1981) Lipid-membrane interactions and the pathogenesis of ischemic damage in the myocardium. Circ Res $48: 1 \cdot 16$

8. Lagerstrom CF, Walker WE, Taegtmeyer $H$ (1988) Failure of glycogen depletion to improve lett ventricular function of the rabbit heart after hypothermic ischemic arrest. Circ Res 63: 81-86

9. Lopaschuk GD, Spafford MA, Davies NJ, Wall SR (1990) Glucose and palmitate oxidation in isolated working rat hearts reperiused after a period of transient global ischemia. Circ Res $66: 546$ 553

10. Mallet RT, Hartman DA, Bünger R (1990) Glucose requirement for postischemic recovery ol perfused workingl heart. Eur J Biochem 188: 481-493

11. Messin R (1980) Peripheral lactic acid production in heart disease. In: Moret PR, Weber J, Haissly 
JC, Denoln $\mathrm{H}$ (eds) Lactate physiologio, methodologic and pathologic approach. Springer Verlag Berlin, pp $160 \mathrm{~m} 173$

12. Myrzaki $Y$, Grose RW, Sobrel BE, Saffitz JE (1990) Selective tumover of sarcolemmal phospholipids with lethal cardiac myocyte injun. Am J Physiol 259: C325-C331

13. Moret PR (1980) Opening remarks. In: Moret PR, Weber J, Haissly $J$ Cl, Denolin H (eds) Lactatephysiologic, methodologic and pathologic approach. Springer Verlag. Berlin, pp 195-196

14. Neely JP, Whitmer JT, Rovetto $\mathrm{MJ}$ (1976) Umhibition of glycolysis in hearts during ischemic repertusion. In Harrs $P$, Bing $R$, Fleckenstein $A$ (ed) Recent advances in studies on cardiac structure and metabolism. University Park Press Baltimore, pp 243-248

15. Neely JA, Grotyohann LW (1904) Role of glycolytic products in damage to ischemic myocardium. Circ Pes $55: 816-824$

16. Ople $L H$. Nayler $W$, Gevers $W(1986)$ Calcium fluxes. In: Opie $L$ (ed) The heart - physiology, metabolsm, pharmacology, therapy. Grune and Stratton Orlando, pp 88-97

47. Opie LH (1990a) Myocardial Ischemia - Metabolic pathways and implication of increased glycolysis. Cardiovasc Drugs Ther 4: $777-790$

18. Opie LH (1990b) Importance of glycolytically produced ATP for the integrity of the threattened myocardial cell. In: Piper HM (ed) Pathophysiology of severe ischemic myocardial injury. Kluwer Aciademic Publishers Dordrecht, pp 221-238

19. Reimer KA, Mury CE, Richard $V J(1989)$ The role of neutrophils and free radicals in the ischemicreperfused hear: why the confusion and controversy? J Mol Cell Cardiol 21: 1225-1239

20. Rovetto MJ, Whitmer JT, Neely JA (1973) Comparison of the effecls of anoxia and whole heart ischemia on carbohydrate utilization in isolated working rat hearts. Circ Res 32: 699-711

21. Schneider CA. Taegtmeyer $H$ (1991) Fasting in vivo delays myocardial cell damage atter brief periods of ischemia in the isolated working rat heart. Circ Res 68: 1045-1050

22. Spahr $R$, Krützfeldt $A_{\mu}$ Mertens $S$, Siegmund $B$, Piper HM (1989) Fatty acids are not an important fuel for coronary microwascular endothelial cells. Mol Cell Biochem 88: 59-64

23. Vandeplassche G. Thoné F, Borgers M (1990) Cytochemical ewidence of NADH-oxidase activity in the isolated working rabbit heart subjected to normothermic global ischaemia. Histochem $\mathbf{J} 22$ : $11-17$

24. Wallukat G, Nemecz G, Farkas T, Kuehn $H_{4}$ Wollenberger A (1991) Modulation of the betaadrenergic response in cultured rat heart cells. Mol Cell Biochem 102: $35-47$

25. Waters WC. Hall JD "Schwartz, WB (1963) Spontaneouls lactic acidosis. The nature of the acidbase disturbance and considerations in diagnosis and management. Am J Med 35: 781-793 


\section{SUMMARY}

In this thesis the influence of exogenous lactate $(5 \mathrm{mM})$ on hemodynamic and metabolic properties of the heart under normoxic, ischemic and reperfused conditions was studied.

The isolated working rat heart was used as a standard model. To establish the effect of lactate and to elucidate mechanisms involved, hearts were perfused with either glucose $(11 \mathrm{mM})$, glucose $(11 \mathrm{mM})$ plus lactate $(5 \mathrm{mM})$ or glucose $(11 \mathrm{mM})$ plus pyruvate $(5 \mathrm{mM})$.

During 120 min of perfusion exogenous lactate was well tolerated by the normoxic heart (chapter 2). Exogenous lactate reduced the decline in functional performance compared to glucose perfused hearts. Likewise, pyruvate improved cardiac stability in normoxic hearts during prolonged perfusion. Endogenous glycogen and triacylglycerol pools were preserved in both lactate and pyruvate hearts. In glucose hearts these endogenous substrate pools became depleted. Unlike pyruvate and glucose, lactate stimulated the turnover of triacylglycerols throughout the perfusion period. Increased availability of glycerol-3-phosphate may be involved in control of triacylglycerol turnover.

The cardiac tolerance for extracellular lactate under ischemic and reperfused conditions was dependent on ischemia time (chapter 3-6). After 15 min of ischemia, lactate did not influence hemodynamic recovery. However, cardiac function was severely impaired after 30 and $45 \mathrm{~min}$ of ischemia in lactate hearts compared to glucose hearts. Pyruvate perfused hearts demonstrated improved functional recovery after $30 \mathrm{~min}$ of ischemia, but inferior function after $45 \mathrm{~min}$ of ischemia compared to glucose hearts. The release of lactate dehydrogenase (chapter 3 ) implied marked cell damage in lactate hearts after 30 min of ischemia and in all groups of hearts after 45 min of ischemia.

The glycolysis process was evaluated as a possible determinant of hemodynamic recovery (chapter 3). No protective role of either high or low glycogen stores prior to ischemia could be observed. Accumulation of lactate, glycerol-3-phosphate and total NADH (parameters related to glycolysis) during ischemia did not seem to be responsible for the diversity of cardiac function either.

Deprivation of coronary flow as well as subsequent reperfusion caused characteristic changes in lipid metabolism (chapter 4). During the first fifteen minutes of ischemia, the turnover of triacylglycerols was increased in all groups of hearts as suggested by glycerol accumulation and concomitantly maintained levels of triacylglycerols. After $15 \mathrm{~min}$ of ischemia glucose and lactate hearts started to accumulate fatty acids. Fatty acid levels were more elevated in glucose hearts than in lactate hearts. In pyruvate hearts fatty acid accumulation was retarded. By reperfusion, fatty acid levels were further increased in lactate and pyruvate hearts, whereas in glucose hearts the fatty acid content returned to control values. Although no net changes were found for the phospholipid content, arachidonic acid accumulation during ischemia and reperfusion suggested degradation of phospholipids. Further, during reperfusion the content of triacylglycerols was maintained at a constant level, but the activity of the triacylglycerol cycle was increased in lactate hearts when the preceding time of ischemia was $30 \mathrm{~min}$. The glucose and pyruvate reperfused hearts also demonstrated elevated rates of cycling of triacylglycerols after 45 min of 
ischemia. No direct correlation between ischemic lipid changes and postischemic recovery was found. However, lipid disturbances during reperfusion occurred simultaneously with functional impairment of the postischemic hearts. The causal relationship remains to be established.

The content of highenergy phosphates was decreased after ischemia whereas the content of breakdown products was increased (chapter 5). Lactate did not stimulate the degradation of high-energy phosphates compared to glucose or pyruvate. During reperfusion degradation products were washed out. When preceded by $30 \mathrm{~min}$ of ischemia, the lactate hearts showed higher amounts of purine release and lower levels of high-energy phosphates at the end of reperfusion compared to pyruvate hearts. At this time point there was no difference of high-energy phosphate content or purine release between lactate and glucose hearts. Following $45 \mathrm{~min}$ of ischemia, ATP and GTP levels remained severely depressed in lactate hearts, but were partly restored in glucose and pyruvate hearts. Degradation products were incompletely washed out both in lactate and pyruvate hearts. Accumulation of purines in tissue at the end of reperfusion was most pronounced in lactate hearts. A relationship between the changes in energy metabolism and hemodynamic recovery could not be established.

Myocardial metabolism depends on the supply of substrates and oxygen which is available by coronary flow through the capillaries. Lactate did not influence the distribution of coronary flow over the inner and outer layers of the left ventricular tissue during the preischemic normoxic phase (chapter 6). Following $15 \mathrm{~min}$ of ischemia, all groups of hearts increased coronary flow (hyperemic response) in both the inner and outer layers of the myocardium at the onset of reperfusion. After $30 \mathrm{~min}$ of ischemia, there was no increase of flow through the inner layers in lactate and glucose hearts. Flow in the inner layers of lactate hearts was even transiently depressed. In contrast, pyruvate hearts were still able to raise flow above preischemic levels. After $45 \mathrm{~min}$ of ischemia, all substrate groups demonstrated lowered coronary flow in the inner layers of the myocardium at the onset of reperfusion. In lactate hearts flow through the inner layers remained depressed during continued reperfusion. Likewise, flow did not recover in pyruvate hearts but the disturbance was less severe than in lactate hearts. In contrast in glucose hearts flow through the inner layers returned to preischemic levels. These findings indicate that lactate may aggravate an ischemic insult by causing (transient) underperfusion of the inner layers of the ischemic myocardium after reinstallation of flow.

Finally, special attention was paid to the validity of glycerol release as a measure of lipolysis. Chapter 7 shows that the heart contains glycerol-3-phosphate hydrolysing activity. In cardiac homogenates, the apparent $\mathrm{V}_{\max }$ value of the hydrolysis of glycerol$3-\mathrm{P}$ at $\mathrm{pH} 7.2$ was $0.25 \pm 0.03 \mu \mathrm{mol} P / g$ wet weight.min while the $K_{m}$ value was estimated to be $2.86 \pm 0.96 \mathrm{mM}$. The hydrolysing activity increased when the $\mathrm{pH}$ was decreased from 7.2 to 5.0 (this $\mathrm{pH}$ range covers the range of acidosis in ischemic hearts). At pH 5.0, the apparent $V_{\max }$ and $K_{\mathrm{m}}$ values were $0.94 \pm 0.11 \mu \mathrm{mol} P \mathrm{P} / \mathrm{g}$ wet weight. min and $4.24 \pm 1.12 \mathrm{mM}$, respectively. Under normal normoxic circumstances, the content of glycerol-3-phosphate in cardiac tissue is far below the $K_{m}$ value measured at $\mathrm{pH} 7.2$. However, under ischemic circumstances the content of glycerol3-P may amount to levels close to the $\mathrm{K}_{\mathrm{m}}$ value measured at $\mathrm{pH} 5.0$. Hence, glycerol3-phosphate hydrolysis may contribute to glycerol production under ischemic circumstances. 
In conclusion, lactate improves cardiac stability during prolonged normoxic pertusion, but impairs hemodynamic function after $30 \mathrm{~min}$ of ischemia. There is no correlation between postischemic hemodynamic recovery and glycolytic tux, lipid changes or degradation of high-energy phosphates during ischemia. During reperfusion, lipid disturbances occur simultaneously with functional impairment in the lactate hearts. In addition, lactate-induced underperfusion in the inner layers of the myocardium during reperfusion seems to be related to functional impairment. Future research should focus on the responsible mechanism for underperiusion of the left ventricular inner layers of the heart by lactate. 


\section{SAMENVATTING}

De hartspier heeft zuurstof en substraten nodig om in zijn energiebehoefte te voorzien. Onder normale omstandigheden zijn vetzuren, glucose, lactaat en pyruvaat geschikte voedingsstoften voor het hart. Lactaat blikt kwantitatief een belangrijke bijdrage als energiebron te leveren wanneer de concentratie lactaat in het bloed stijgt. Een verhoogde lactaatconcentratie treedt o.a. op bij fysieke inspanning tijdens sport. Voor de verbranding van lactaat is zuurstof nodig. Het gezonde hart krijgt voldoende zuurstof aangeboden vanuit het bloed om lactaat te oxycleren. Deze situatie verandert echter wanneer de doorbloeding van het hart gestoord is (ischemie). Hierdoor ontstaat een zuurstof tekort in het hart en gaat het hart zelf lactaat produceren. Tijdige opheffing van ischemie maakt herstel van de hartspierfunctie mogelijk. Er zijn aanwijzingen dat de aanwezigheid van de circulerende substraten hierbij van invloed is. Het doel van dit onderzoek was om het effect van een verhoogde exogene laciaat concentratie op het postischemisch herstel van het hart te bestuderen. Tevens werd aandacht geschonken aan de functionele en metabole veranderingen in het hart tijdens langdurige normoxische perfusie.

Het onderzoek werd uitgevoerd met behulp van geisoleerde ratteharten die volgens het werkende (-ejecterende) hartmodel geperfundeerd werden. Het perfusiemedium was een gemodificeerde Krebs-Henseleit buffer waarin standaard glucose (11 mM) als substraat aanwezig was. Lactaat of pyruvaat werd extra toegevoegd (concentratie $5 \mathrm{mM}$ ). Er werd een vergelijking gemaakt tussen glucose, glucose plus lactaat en glucose plus pyruvaat gepertundeerde harten om meer inzicht te verkrijgen in het werkingsmechanisme van lactaat. Glucose werd gekozen als controle t.0.v. lactaattoevoeging. Pyruvaat werd bestudeerd omdat lactaat en pyruvaat vrijwel identieke verbindingen zijn in de metabole route (pyruvaat is de geoxideerde vorm van lactaat).

Gedurende twee uren normoxische perfusie bleek de combinatie exogeen lactaat en glucose een beter behoud van de hemodynamische functie te waarborgen dan glucose alleen (hoofdstuk 2). Ook in pyruyaal harten bleef de stabiliteit beter gehandhaafd dan in glucose harten. Hiervoor werd geen aanspraak gemaakt op de endogene substraatbronnen in het hart. In de glucose harten daarentegen werd energle geput uit de endogene glycogeen en triacylglycerol voorraad. Opvallend was dat lactaat de omzetting van de triacylglycerol voorraad verhoogde. Dit betekent dat de synthese en afbraak van triacylglycerolen sneller verloopt. Een verhoogd glycerol-3fosfaat aanbod zou hiervoor de aamleiding kunnen vormen. Glycerol-3-fosfaat is betrokken bij de synthese van triacylglycerolen.

De tolerantie van de hartspier voor exogeen lactaat na blootstelling aan ischemie bleek athankelijk te zijn van de tijdsduur (hootdstuk 3-6). Na een ischemische periode van 15 minuten werd het hemodynamisch herstel nauwelijks beinvioed door exogeen lactaat. Echter na 30 minuten ischemie verslechterde de hemodynamische functie aanzienlijk in lactaat harten ten opzichte van glucose of pyruvaat harten. $\mathrm{Na} 45$ minuten ischemie ging ook het hemodynamisch herstel in pyruvaat harten verloren terwijl glucose harten nog een matig herstel van functie vertoonden. Het verhoogde verlies aan lactaatdehydrogenase, een enzym dat zich in het cytoplasma bevindt, wijst op het lek raken van cellen in lactaat harten die blootgesteld waren aan 30 minuten ischemie (hoofdstuk 3). In de glucose en pyruvaat groep werd een aanzienlijk verlies 
van lactaatdehydrogenase geconstateerd na 45 minuten ischemie.

De verminderde ischemie tolerantie van de hartspier in aanwezigheid van extracellulair lactaat bleek niet gerelateerd te zijn aan parameters uit de glycolyse (hoofdstuk 3). Noch een beschermende werking van glycogeen (de bron voor glycolyse) noch een schadelik effect van de eindprodukten van de glycolyse (melkzuur, glycerol-3-fosfaat of NADH) kon worden wastgesteld.

Tijdens ischemie en reperfusie traden veranderingen op in het vetmetabolisme (hoofdstuk 4). Reeds vroeg in de ischemische fase was de omzetting van de triacylglycerol voorraad verhoogd in de drie groepen maar deze verhoging bleef niet gehandhaafd. In de glucose en lactaat groep trad vervolgens vetzuur accumulatio op. Deze ophoping was iets hoger in de glucose harten dan in de lactaat harten. In de pyruvaat groep was de accumulatie van vetzuren enigzins vertraagd. Gedurende reperfusie zette de stapeling van vetzuren zich voort in lactaat en pyruvaat harten. Echter in glucose harten werd de endogene vetzuurinhoud hersteld tijdens reperfusie. De belangrijke bijdrage van arachidonzuur, een vetzuur dat voornamelijk is ingebouwd in fosfolipiden, impliceert dat membraantosfolipiden werden afgebroken. Omdat de totale vetzuurstapeling slechts een gering percentage van de totale fosfolipide voorraad reflecteert, werden er geen veranderingen in de totale fosfolipide inhoud waargenomen. Ook de totale triacylglycerol voorraad bleef behouden gedurende ischemie en reperfusie. Tijdens reperfusie bleek de omzetting van de triacylglycerolen gestimuleerd te worden in lactaat harten blootgesteld aan 30 minuten ischemie. Na 45 minuten ischemie werd de omzetting van de triacylglycerol voorraad ook in glucose en pyruvalat harten verhoogd.

Stapeling van vetzuren tijdens ischemie bleek niet gerelateerd te zijn aan het postischemisch hemodynamische herstel. Lipidstoornissen tijdens reperfusie leken wel enigzins geassocieerd te zijn met de mate van herstel.

Tijdens ischemie kon de beperkte energieleverantie niet voldoen aan de energiebehoefte van de hartspier (hoofdstuk 5). Energierijke fosfaten (creatine fosfaat, ATP en GTP) werden afgebroken en afbraakprodukten accumuleerden. De lactaat harten werden hierbij niet benadeeld ten opzichte van glucose of pyruvaat harten. Tijdens reperfusie werden afbraakprodukten uitgewassen. Hierdoor is geen volledig herstel van de ATP en GTP inhoud magelijk. In dit opzicht vertoonden de lactaat harten een hogere uitwas van afbraakprodukten en een lagere inhoud aan ATP en GTP na 30 minuten ischemie en 35 minuten reperfusie vergelleken met pyruvaat harten. Op dit tijdstip was er geen verschil tussen lactaat en glucose harten. $\mathrm{Na} 45$ ischemie waren de lactaat harten niet meer in staat het gehalte aan energierijke fosfaten te herstellen tijdens reperfusie. De glucose en pyruvaat harten daarentegen vertoonden een matig herstel van het gehalte aan energierijke fosfaten. De afbraakprodukten bleven sterk verhoogd aanwezig in het weefsel van de lactaat harten na 45 minuten ischemie en 35 minuten reperfusie. Ook in pyruvaat harten was de uitwas van purines niet volledig. Veranderingen in het energie metabolisme vertoonden geen direkte relatie met de mate van postischemisch herstel.

Voor aanwoer van zuurstof en substraat naar de hartcellen is coronaire doorbloeding noodzakelik. Hoofdstuk 6 beschrijft de invloed van lactaat op de doorbloeding door de binnenste en buitenste lagen van het linker ventrikel. Onder normoxische omstandigheden werden de binnenste lagen van een hogere doorbloeding voorzien dan de buitenste lagen. Lactaat bracht hierin geen verandering teweeg. Echter na blootstelling aan ischemie versnelde lactaat het optreden van 
onderperfusie in de binnenste lagen. Na 15 minuten ischemie waren de lactaat harten nog in staat de doorbloeding bij aanvang van reperfusie te verhogen in zowel de binnenste als buitenste lagen wan het linker ventrikel (reactieve hyperemie). Deze respons verdween voot de binnenste lagen na 30 minuten ischemie. De binnenste lagen werden zelfs tijdelijk ondergeperfundeerd. Na 45 minuten ischemie bleven de binnenste lagen verstoken van völdoende doorbloeding tijdens de gehele reperfusie fase. In glucose harten verdween ook na 30 minuten ischemie de verhoogde doorbloedingsrespons in de binnenste lagen bij aamvang van reperfusie. Echter hierbij trad geen onderperfusie op zoals in de lactaat harten. Na 45 minuten ischemie was de onderperfusie in de binnenste lagen slechts wan tijdelijke aard. In tegenstelling tot de lactaat en glucose harten, waren de pyruvaat harten na 30 minuten ischemie nog in staat hun doorbloeding door de binnenste lagen te verhogen bij aanvang van reperfusie. Daarentegen trad in deze harten een permanente onderperfusie van de binnenste lagen op na 45 minuten ischemie. De doorbloeding bleek in mindere mate verlaagd te zijn dan in de lactaat harten. Onderperfusie in de binnenste lagen van het linkerventrikel hangt mogelijk samen met een slechter hemodynamisch herstel. Lactaat verkort hierbij het tijdsinterval waarin de veranderingen optreden.

Ter aanvulling op hoofdstuk 2 en hoofdstuk 4 werd in hoofdstuk 7 de uitwas van glycerol als maat voor lipolyse nader in het licht gesteld. In harthomogenaten werd aangetoond dat het hart hydrolytische activiteit vertoont ten aanzien van glycerol-3fosfaat en dus dat een directe omzetting van glycerol-3-fosfaat naar glycerol mogelijk is. De hydrolytische activiteit bleek pH athankelijk d.w.z. een hogere activiteit bij pH 5.0 dan bij $\mathrm{pH} 7.2$. Het onderzochte $\mathrm{pH}$ gebied, $\mathrm{pH} 7.2$ tot $\mathrm{pH} 5.0$, reflecteent het interval waarover $\mathrm{pH}$ verlaging kan optreden tijdens ischemie. Onder ischemische omstandigheden stijgt de glycerol-3-fosfaat concentratie in thet hart tot nabij de $\mathrm{K}_{\mathrm{m}}$ waarde ( $\mathrm{pH}$ 5.0). Het is daarom niet uitgesloten dat directe defosforylatie van glycerol3-fosfaat bijdraagt aan glycerol produktie in het hart tijdens ischemie.

Samenvattend kan gesteld worden dat lactaat de hemodynamische stabiliteit van het hart verbetert tijdens normoxie, maar dat lactaat het hemodynamisch herstel verslechtert na een ischemisch tijdsinterval van 30 minuten. Er is geen eenduidige relatie gevonden tussen de mate van herstel en verscheidene metabole veranderingen (glycogenolyse, glycolyse, lipid verstoringen, afbraak energie rijke fosiaten) tijdens ischemie. Daarentegen traden lipid veranderingen tijdens reperfusie gelijktijdig op met de afname van de hemodynamische functie. Verder lijkt onderperfusie van de binnenste llagen van het linker ventrikel tijdens reperfusie samen te hangen met een slechter hemodynamisch herstel in de lactaat harten. Het mechanisme dat verantwoordelijk is voor onderperfusie verdient nadere aandacht in de toekomst. 


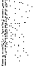

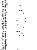

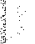

4

\&

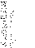




\section{PUBLICATIONS}

\section{Papers}

Mensink PP, De Groot MM, Van den Broeke LT, Severinen-Nobels AP, Demacker PNM, Katan MB (1989) Elfed of monounsaturated fatiy acids versus complex carbohydrates on serum lipoproteins and apolipoproteins in healthy men and women. Metabolism 38: 172-178

Van der Vusse GJ, De Groot MJM, Willemsen PHM, Van Bilsen M, Schrijvers AHGJ, Reneman RS (1989) Degradation of phospholipids and triacylglycerol, and accumulation of fatty acids in anoxic myocardial tissue, disrupted by freeze-twawing. Mol Cell Biochem 88: 83-90

Van Bilsen M, Van der Vusse G., Coumans WA, De Groot MJM, Willemsen PHM, Reneman RS (1989) Degradation of adenine nucleotides in ischemic and reperfused rat heart. Am J Physiol 257: H47H54

De Groot MUM, Willemsen PHM, Coumans WA, Van Bilsen M, Van der Vusse Gul (1989) Lactateinduced stimulation of myocardial triacylglycerol furnover. Biochim Biophys Acta 1006: 111-115.

Schrijvers AHG., De Groot MUM, Heijnen WVTh, Van der Vusse G.j, Frederik PM, Reneman RS (1990) Ischemia and repentusion induced multilamellar vesicles in isolated rabbit hearts: time correlation between morphometric data and metabolic alterations. J Mol Cell Cardiol 22:653-665

Engels W, Van Bilsen M, De Groot MJM, Lemmens P.JMA, Willemsen PHM, Reneman RS, Van der Vusse GJ (1990) Ischemia and reperfusion induced formation of elcosanoids in isolated rat hearts. Am J Physiol 258: H1865-H1871

Van der Vusse GJ, De Groot MJM (1991) The effect of exogenous lactate and pyruvate on Irlacylglycerol turnover in the normoxic heart. In: Sideman $S$, Beyar $\mathbb{R}$, Kléber $A G$ (ed) Cardiac electrophysiology, circulation and transport, Kluwer Academic Publishers, Boston/Dordrechthondon pp 351-358

Van der Vusse GJ, De Groot MMM (1992) Interrelationship between lactate and cardiac fatty acid metabolism. Mol Cell Biochem (accepted for publication)

\section{Abstracts}

De Groot MJM $M_{1}$ Van der Vusse GJ. (1989) Stimulation of myocardial triacylglycerol turnover by lactate. Pflügers Archiv-Eur J Physiol (Pflugers Arch) 414: $\$ 197$

De Groot MJM, Van der Vusse GJ (1989) Stimulation of myocardial triacylglycerol turnover by lactate. $J$ Mol Cell Cardiol 21 (suppl. IV): S.15

De Grool MJM, Van der Vusse GJ (1990) The effect of lactate on triacylglycerol metabolism in ischemic and reperfused hearts. J Mol Cell Cardiol 22 (suppl III): S.114

De Groot MJMn Van der Vusse GJ (1990) The effect of lactate on ischemic and reperfused hearts. Pflugers Archiv-Eur \& Physiol 416: S5

De Groot MMM, Van der Vusse GJ (1991) Susceptibility to lactate of reperfused ischemic myocardium. $\checkmark$ Mol Cell Cardiol 23 (suppl. V): P195

De Groot MMM, De Jong YF, Van der Vusse GJ (1992) Glycerol-3-phosphate hydrolysis and its subcellular localization in cardiac muscle. $J$ Mol Cell Cardiol (accepted for publication) 


\section{CURRICULUM VITAE}

De auteur werd geboren op 11 mei 1962 te Riel. In 1980 behaalde zij het gymnasium$\beta$ diploma aan het Theresia-lyceum te Tilburg. In datzelide jaar begon zij de studie Humane Voeding aan de Landbouwuniversiteit te Wageningen. Na de kandidaatsfase bracht zij enkele maanden door bij "The Rowett Reseach Institute" te Aberdeen, UK. De doctoraalfase vulde zij in met de hoofdvakken Voeding en Levensmiddelenchemie en een extra vak Zuivel. Het doctoraalexamen werd in januari 1987 afgelegd. April 1987 trad zij in dienst bij de Vakgroep Fysiologie, Rijksuniversiteit Limburg, alwaar het in dit proefschrift beschreven onderzoek werd verricht. Vanaf april 1991 is zij aangesteld via een Hartstichtingsproject voor een vervolg van het onderzoek bij de Vakgroep Fysiologie (Rijksuniversiteit Limburg). 


\section{NAWOORD}

Het onderzoek, beschreven in dit proefschrift, is uitgevoerd binnen de vakgroep Fysiologie aan de Rijksuniversiteit Limburg. Gaarne wil ik iedereen die op wat voor manier dan ook een bijdrage heeft geleverd aan het onderzoek en de tot standkoming van dit proefschrift bedanken.

In het bijzonder:

- Ger van der Vusse voor de stimulerende discussies alsook de inzichtelijke en inspirerende adviezen (zowel in de functie van begeleider als promotor).

- Will Coumans, Peter Willemsen en Theo Roemen voor hun geweldige ondersteuning op het gebied van biochemische analyses alsook computer problemen.

- Yvonne de Jong voor haar belangrijke bijdrage aan de enzymatische metingen.

- Viviane Heijnen voor haar vele geduld bij het microscopische werk.

- Marc van Bilsen voor de verfijnde inwijding in hartperfusies en de heldere suggesties bij aanvang van het onderzoek.

- Luc Snoeckx en Jan Glatz voor hun belangstelling en deskundige inbreng.

- de mensen van de spoelkeuken voor de vele liters water die zij hebben aangedragen voor de hartperfusies.

- de stagiares, Jürgen, Yvonne, Eusebio en Philippe voor het opmeten van tracings, het verrichten van chemische analyses en data invoer op de computer.

- alle overige medewerkers van de Fys Chem groep voor de prettige werksfeer.

- Trudy Sonderkamp en Marieke Linssen voor hun aangenaam gezelschap als kamergenoten.

- de leden van de becordelingscommissie, Prof. Dr. Arends, Prof. Dr. Borgers, Prof. Dr. Hülsmann, Prof. Dr. Penn en Prof. Dr Noble voor de kritische evaluatie van het manuscript.

- Frans waar ik immer op kan rekenen.

- Mijn ouders die mij de mogelijkheid en stimulans hebben gegeven om te studeren.

En verder:

- het secretariaat, overige medewerkers van de vakgroep Fysiologie alsook collega's van de vakgroep Biochemie, Pathologle, Anatomie en de Dienst Informatie Verwerking voor de door hen verrichte diensten.

- Mijn voormalige huisgenoten voor de gezellige en behulpzame tijd. 